Portland State University

PDXScholar

5-4-1994

\title{
Vocabulary Learning for Short-Term ESL Students: A Comparison of Three Methods
}

Michael William Bess

Portland State University

Follow this and additional works at: https://pdxscholar.library.pdx.edu/open_access_etds

Part of the Linguistics Commons

Let us know how access to this document benefits you.

\section{Recommended Citation}

Bess, Michael William, "Vocabulary Learning for Short-Term ESL Students: A Comparison of Three Methods" (1994). Dissertations and Theses. Paper 4713.

https://doi.org/10.15760/etd.6597

This Thesis is brought to you for free and open access. It has been accepted for inclusion in Dissertations and Theses by an authorized administrator of PDXScholar. Please contact us if we can make this document more accessible: pdxscholar@pdx.edu. 


\section{THESIS APPROVAL}

The abstract and thesis of Michael William Bess for the Master of Arts in TESOL were presented May 4, 1994, and accepted by the thesis committee and the department.

COMMITTEE APPROVALS:

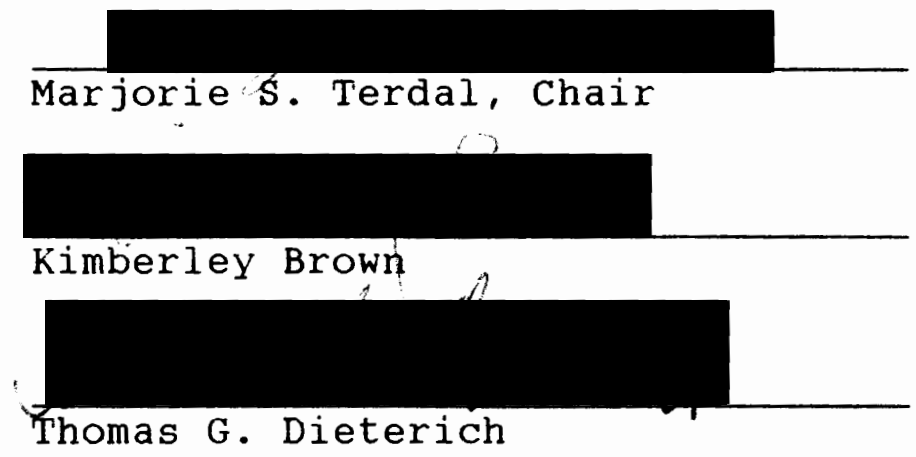

DEPARTMENT APPROVAL:

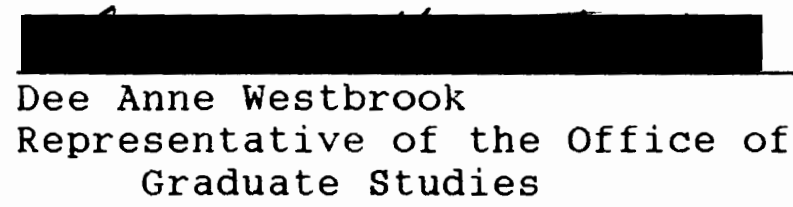

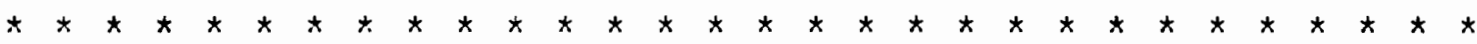

ACCEPTED FOR PORTLAND STATE UNIVERSITY BY THE LIBRARY

by

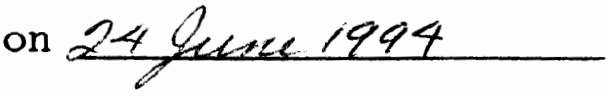




\section{ABSTRACT}

An abstract of the thesis of Michael William Bess for the Master of Arts in TESOL presented May 4, 1994.

Title: Vocabulary Learning for short-Term ESL students: A Comparison of Three Methods

Long-term studies with both native and non-native speakers of English have shown that vocabulary can be learned passively or "incidentally" simply through the act of reading, even through reading for pleasure. Generally, studies of incidental vocabulary learning have tested subjects' knowledge of words learned after reading novels or other longer works of prose fiction.

Eighty-four students from a short-term ESL program participated as subjects in this study. subjects were divided into three treatment groups and one control group. All subjects were given a 100-item word-recognition pretest, containing 45 test words and 55 distractors. The three treated groups were each given three treatments meant to increase their vocabulary knowledge: vocabulary exercises alone, short story reading alone, and a combination of vocabulary exercises and short story reading (using a short story which contained the words taught in the 
exercises). Fifteen of the 45 test words were taught under each treatment. All subjects were then given a 45-item multiple-choice post-test, testing the 45 vocabulary words taught in the three treatments.

It was hypothesized that story-reading alone would produce the highest gains between pre- and post-test scores, exercises and story together would produce median scores, and exercises alone would produce the lowest scores. Analysis of the data revealed a much different pattern: story-reading alone actually produced the lowest score gains, while the two treatments involving exercises produced gains that were similarly high.

Apparently, vocabulary exercises combined with a short story provided the extra context and practice the subjects needed to learn those words better than did story reading alone. Vocabulary exercises alone produced better scores than story reading alone perhaps because the subjects were accustomed to the task of learning vocabulary words through exercises, and because the task (learning words) was obvious. The subjects were probably not accustomed to learning words simply through reading stories, nor was the task of learning words obvious in that case. Thus, given the special parameters of this study and its subjects, score gains were lowest on the treatment that was expected to produce the highest gains. 
VOCABULARY LEARNING FOR SHORT-TERM ESL STUDENTS:

A COMPARISON OF THREE METHODS

\author{
by \\ MICHAEL WILLIAM BESS
}

A thesis submitted in partial fulfillment of the requirements for the degree of

\author{
MASTER OF ARTS \\ in \\ TESOL
}

Portland State University

1994 


\section{DEDICATION}

This thesis is about words, and it wouldn't exist without the constant sustenance of the Word, the Living Word. Thanks be to Him Who daily gives me strength! 


\section{ACKNOWLEDGEMENTS}

To the following people who sacrificed so that this project might see fulfillment, I would like to offer my deep appreciation and sincere thanks:

Mrs. Dee Anne Bess, long-suffering lifemate who shared the stings of every keystroke as if they were her own.

Dr. Marge Terdal, advisor, teacher, and mentor par excellence.

Dr. Kim Brown, Dr. Tom Dieterich, and Dr. Dee Anne Westbrook, patient, cooperative, instructive, and appreciated to the highest degree.

Xue-qing and Zhung-ren Peng for their help in translating the Informed consent Form into Chinese (sorry the Taiwan group didn't work out!).

Toyoko and steve Roberts for their help in translating the Informed Consent Form into Japanese.

Mrs. Patti Schlimpert for her support and cooperation in allowing the summer program students to participate in this experiment.

Char Kroemer and Judy Lorenz for donating their students and class time to "the cause".

Erik Terdal for his many hours of tedious number crunching, his cogent explanations of their meaning, and invaluable assistance in straightening out the messes of others.

Theresa Culbertson, text-files expert, for her advice in formatting data files.

Kristin Kautz and Ken wong for their trial-run graphs.

Uncle Denny Johnson and David Counterman for their help with graphs.

Wayne and Aunt wanda Haugen for their help with graphs, and for the use of their spreadsheet program (the only one that worked!).

Sharon Rose-Roth for her prayers for perseverance.

Family members, friends, and colleagues who provided emotional support, encouragement, and prayers along the way.

And to the chaperones and students of Concordia College Taiwan, shei-shei!, and to those of Aichi Gakuen, Bunka, Shoin, Fuji Phoenix, and Concordia College Japan, a sincere arigatou gozaimasu!

Thank you, one and all! I couldn't have done it without you! 
TABLE OF CONTENTS

PAGE

ACKNOWLEDGEMENTS . ...........................

LIST OF TABLES.............................

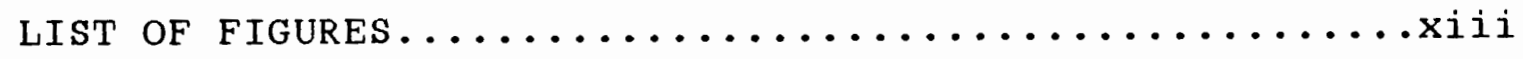

CHAPTER

I INTRODUCTION. $\ldots \ldots \ldots \ldots \ldots \ldots \ldots \ldots \ldots \ldots \ldots \ldots \ldots \ldots$

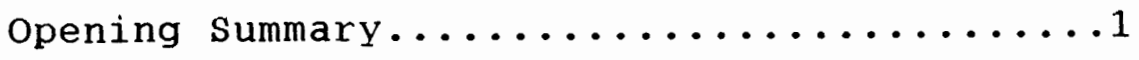

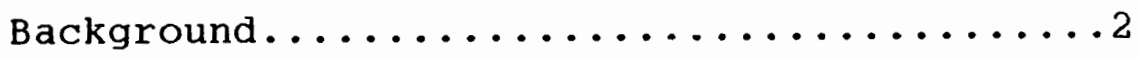

The Problem

other Solutions

The Reading Solution

This study

statement of Hypotheses..............11

Summary $\ldots \ldots \ldots \ldots \ldots \ldots \ldots \ldots \ldots \ldots \ldots \ldots \ldots \ldots \ldots$

I I REVIEW OF THE LITERATURE................ 44

Introduction..................

The Background of the Current study.......15

Similar studies

Definitions

The Problem of the Small Lexicon

Native Speakers and New words

An Historical Perspective

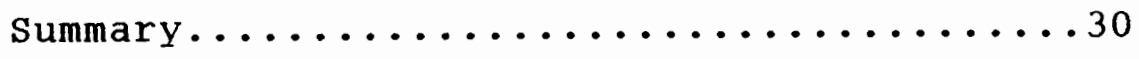

III METHODOLOGY $\ldots \ldots \ldots \ldots \ldots \ldots \ldots \ldots \ldots \ldots \ldots \ldots \ldots \ldots \ldots \ldots \ldots$

Introduction....................... 
A Brief Preview of the Experimental Design

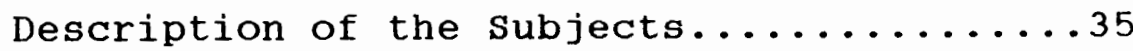

Developing Tests and Treatment Materials...37

Introduction

Choosing the stories

Choosing the Test words

Developing the pre-Test

Developing the Treatment Materials

Developing the Post-Test

Administering the Materials...........66

Administering the Tests

Administering the Treatments

The Problem of the short Time Lapse

Data Analyses Used.................... 73

summary .........................

IV RESULTS AND DISCUSSION...................

Introduction.......................

An Overview of the Data

Restatement of Hypotheses...........87

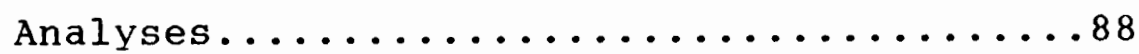

Introduction

Comparison of Groups

Comparison of stories

Comparison of Treatments

Summational Comparisons

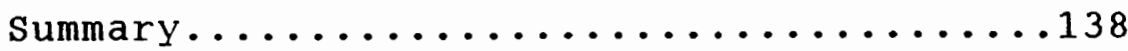

V SUMMARY AND CONCLUSIONS.................. 140

Introduction........................

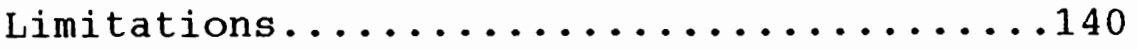

Design-Related Limitations

Subject-Related Limitations

Materials-Related Limitations

The value of this study 
Implications for Teaching ESL..........147 Avenues for Further Research..........153

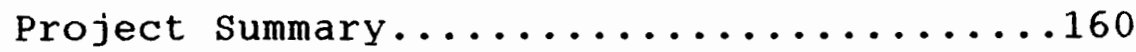

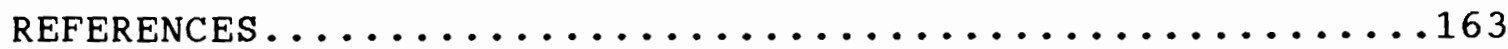
APPENDICES

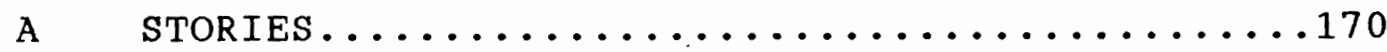

B DIRECTIONS FOR ADMINISTERING THE PRE-TEST.....187

C PRE-TEST............................. 191

D WORD FORM CHARTS/DEFINITIONS AND EXAMPLE

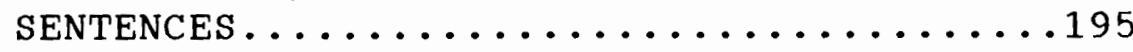

E EXERCISES................................

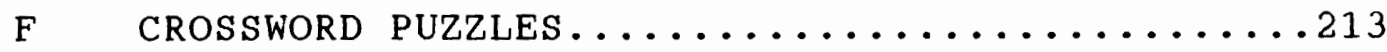

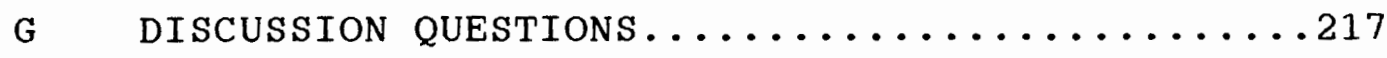

H DIRECTIONS FOR ADMINISTERING THE POST-TEST....224

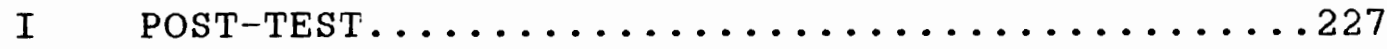

J WORD TABLES (TABLES XXXIX - XLVI) ............237 


\section{LIST OF TABLES}

TABLE

PAGE

I

II

III

IV

V

VI

VII
Order and Type of Treatment for Each

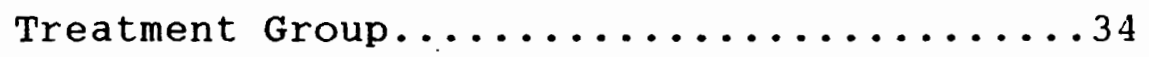

Test Words as a Percentage of the

Total Words in Each story...............43

Test Words with Double Meanings: A "Usual"

Meaning Known by students, and an

"Unusual" Meaning Not Known by students...57

Minimum, Maximum, Mean, and standard Deviation

for Points Correct on Entire Pre- and

Post-tests, by Group.................79

Mean Scores (and their Percentages)

by Group, for Entire Pre-test,

55 Distractors of Pre-test, and

45 Target Words of Pre-test; and

for Entire Post-test................81

Mean Scores on Pre- and Post-tests in order

by story (with Treatment Type), and

Improvement or Decline in Mean between

Pre- and Post-tests for Groups $1-4 \ldots \ldots .83$ Comparison of all 4 Groups, pre-tests only.....90 
VIII

IX

$\mathrm{X}$

$X I$

XII

XIII

XIV

Mean Scores on Pre- and Post-tests in Order by Group, CPE Only (with Treatment Type), and Improvement or Decline in Mean between Pre- and Post-tests for Groups $1-4$ 91

Mean Scores on Pre- and Post-tests in order by Group, LOT Only (with Treatment Type), and Improvement or Decline in Mean between Pre- and Post-tests for

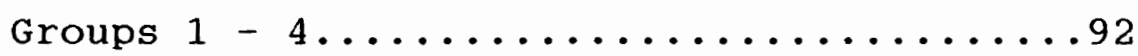

Mean Scores on Pre- and Post-tests in Order by Group, OCB Only (with Treatment Type), and Improvement or Decline in Mean between Pre- and Post-tests for Groups $1-4 \ldots \ldots \ldots \ldots \ldots \ldots \ldots \ldots \ldots \ldots \ldots \ldots \ldots$ Means across the Three Treatment Groups for Each Story, Lowest to Highest Gain....95 Means across all Four Groups for Each Story, Lowest to Highest, Pre-test only........100 Means Across Only the Three Treatment Groups for Each Story, Lowest to Highest, Pre-test only...................... Means across the Three Treatment Groups for Each Story, Lowest to Highest, Post-test Only.....................101 
Means across the Three Treatment Groups

for Each Treatment, Lowest to Highest,

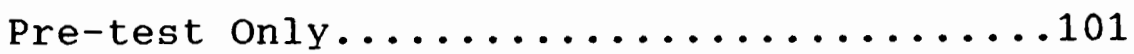

XVI Comparison of stories, Group 1 Only.........103

XVII Comparison of stories, Group 2 Only.........104

XVIII Comparison of Stories, Group 3 only.........105

XIX Comparison of stories, Group 4 only........106

XX Comparison of stories, Groups 1, 2, 3,

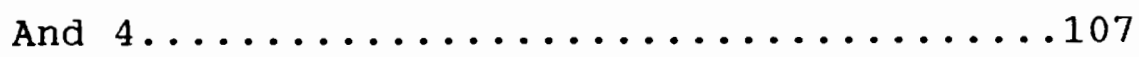

XXI Mean Scores on Pre- and Post-tests

in Order by Success of Treatment,

Least to Most Successful (with Story),

and Improvement or Decline in Mean

between Pre- and Post-tests for Groups

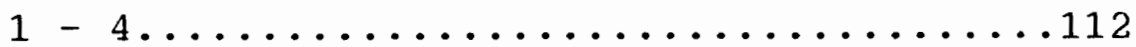

XXII Comparison of Treatments, Group 1 Only......117

XXIII Comparison of Treatments, Group 2 Only......118

XXIV Comparison of Treatments, Group 3 Only......119

XXV Comparison of Treatments, Groups

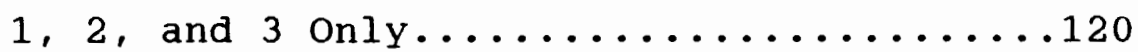

XXVI Expected and Actual Patterns of Success

for the Three Treatment Methods,

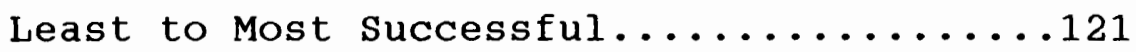


XXVII Expected and Actual Patterns of Success

for the Three Treatment Methods,

Least to Most Successful,

with Significant Differences Marked......122

XXVIII Mean Scores on Pre- and Post-tests

in Order by Group, so Treatment only

(with story), and Improvement or Decline

in Mean Between Pre- and Post-tests

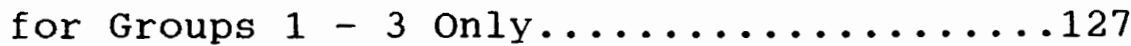

XXIX Mean Scores on Pre- and Post-tests

in Order by Group, EO Treatment Only

(with Story), and Improvement or Decline

in Mean between Pre- and Post-tests

for Groups $1-3$ only...................

XXX Mean Scores on Pre- and Post-tests

in order by Group, ES Treatment Only

(with Story), and Improvement or Decline

in Mean between Pre- and Post-tests

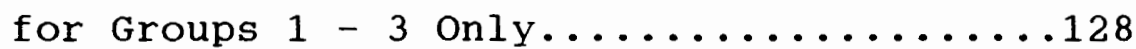

$\mathrm{XXXI}$

Means across the Three Treatment Groups

for Each Treatment, Least to Most

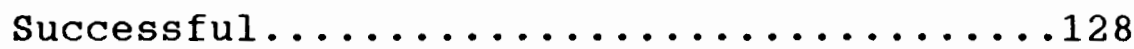

XXXII Hypothesized Order of Success of Treatments,

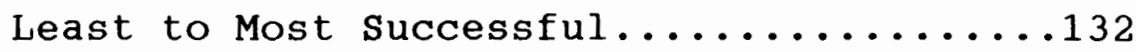

XXXIII Actual Order of success of Treatments,

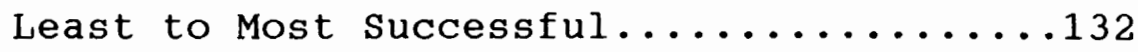


XXXIV Means (Out of 15) across the Three Treatments, for Each Group, Least to Most

Successful Group.................133

XXXV Mean Scores and their Percentages on

Pre- and Post-tests and Improvement

or Decline in Mean between Pre- and Post-

tests for Groups $1-4 \ldots \ldots \ldots \ldots \ldots \ldots 134$

XXXVI Overall Means for all 45 Test Words and any

15-Word Set, Three Treatment Groups

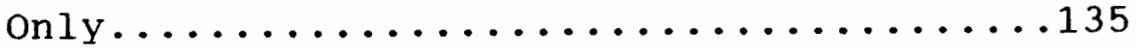

XXXVII Overall Mean for all 45 Test words and any

15-Word Set, Control Group (Group 4)

only.........................

XXXVIII Comparison of the Overall Loss in Mean for

Group 4 with the Overall Gain in Mean for

Groups 1, 2, and 3 Combined..........138

XXXIX Test Words in Base Form in order by Initial

Appearance in Each Story, by Appearance

in the Pre-test, and by Appearance in the

Post-test.....................238

XL Test Words in Base Form in order by Initial

Appearance in Each story with Frequency

of Occurrence.......................

XLI Test Words in Base Form in Alphabetical order with Frequency of Occurrence..........240 
XLII Test Words in Base Form in Order by

Frequency of Occurrence with

Frequency of Occurrence.............241

XLIII All Occurrences of all Forms of the

Test Words in Order as the Forms

Appeared throughout the stories.........242

XLIV

All Occurrences of all Forms of the

Test Words in Alphabetical Order........245

XLV

All Occurrences of all Forms of the

Test Words Grouped by Base Word

in Order by Initial Appearance

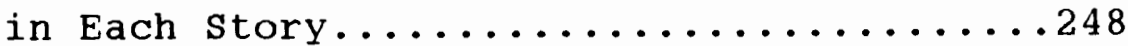

XLVI All Occurrences of all Forms of the

Test Words Grouped by Base Word

with Number of Occurrences of Forms

in Order by Initial Appearance

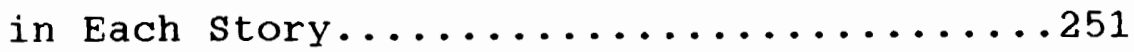




\section{LIST OF FIGURES}

FIGURE

PAGE

1. Group 1 Mean Scores on Pre- and Post-tests

by story (with Treatment Type).........85

2. Group 2 Mean Scores on Pre- and Post-tests

by story (with Treatment Type).........85

3. Group 3 Mean Scores on Pre- and Post-tests

by story (with Treatment Type)........86

4. Group 4 (Control Group) Mean Scores on Pre-

and Post-tests by story............86

5. Mean Scores on Pre- and Post-tests for

CPE Only, by Group (with Treatment Type)..93

6. Mean Scores on Pre- and Post-tests for

LOT Only, by Group (with Treatment Type) ..93

7. Mean Scores on Pre- and Post-tests for

OCB Only, by Group (with Treatment Type)...94

8. Mean Scores on Pre- and Post-tests,

Across Groups $1-3$, by story...........95

9. Group 1 Mean Scores by Treatment Type

from SO to ES - Overall Least to Most

Successful (with story)..............113

10. Group 2 Mean Scores by Treatment Type

from SO to ES - Overall Least to Most

Successful (with story).............113 
11. Group 3 Mean Scores by Treatment Type

from so to EO - Overall Least to Most

Successful (with Story)............114

12. Group 4 Mean Scores - Overall Least to Most

Successful (with story).............114

13. Mean Scores for Performance under the so

Treatment. Only, by Group (with Story)....129

14. Mean Scores for Performance under the EO

Treatment Only, by Group (with Story)....129

15. Mean Scores for Performance under the ES

Treatment Only, by Group (with Story)....130

16. Mean Scores Across all Three Treatment

Groups for each Treatment, Least to

Most Successful overall............130 
CHAPTER I

INTRODUCTION

\section{OPENING SUMMARY}

This project attempted to compare the success, relative to each other, of three methods of teaching vocabulary to English as a second Language (ESL) students. The three treatment methods were (1) vocabulary exercises alone (hereafter "EO" for "exercises only"), (2) story reading alone ("SO" for "story only"), and (3) pre-reading vocabulary exercises followed by story reading ("ES" for "exercises + story"). The experimental design involved a three-by-three matrix of three subject groups undergoing these three treatments. A fourth control group received no treatment. All four groups took a pre- and post-test. The relative success of each treatment method is based on the results of the post-test as well as the score gains between the pre- and post-tests.

This investigation begins with a discussion of the general context of vocabulary teaching and learning. This is followed with a review of the literature concerning vocabulary within the environment of ESL. Next, the discussion details the development and construction, informed by the literature, of materials and tests for the 
experiment, and records the procedures and execution of the experiment. The investigation continues with reports and analyses of the results of the experiment. Finally, this project concludes with a discussion of the limitations of the study, plus suggestions for teaching ESL based on the outcomes of the experiment, recommendations for further inquiry, and a summary of the entire project.

\section{BACKGROUND}

Now that the discipline of teaching ESL is officially in the "post-Krashen era" (Mendelsohn, 1992), and with Krashen's Communicative Approach being tempered by the realization that at some point form is important to meaning, vocabulary teaching is enjoying somewhat of a renaissance. Teachers and learners have found that it is not enough to try to merely "get the meaning across" (the communicative Approach), but that the meaning must be couched in an acceptable form. A "larger," better-organized vocabulary is important to the production of both a more acceptable form and a clearer meaning, as well as to a non-native speaker's comprehension of real-world written and spoken English. Much current research looks at how ESL students can best arrive at a larger and more usable vocabulary.

\section{The Problem}

At this point, perhaps the most obvious questions to ask are: 
"How important is vocabulary in second language (SL) learning?"

"How large a SL vocabulary is advantageous?"

"How small a SL vocabulary is disadvantageous?"

"How severe a problem is vocabulary learning for SL students?"

"How might SL students more successfully learn vocabulary?"

To answer the first question, Gass (1988, p. 93) cites Politzer, who believes that "not only is the lexicon central in communication, but there is evidence that students also believe that, of all the error types, vocabulary errors are the most serious."

According to other researchers, the acquisition of vocabulary is, furthermore, an integral part of learning a foreign language. Since words constitute the major carriers of meaning in language, a good command of vocabulary is a prerequisite of communicative competence (Paulston \& Bruder, 1976; Robinett, 1978; Wallace, 1982; Carter \& McCarthy, 1988; Julkunen, 1990). Vocabulary is definitely essential to SL learning.

Researchers point out the benefits of extensive SL lexicons, as well as the pitfalls of limited lexicons. Wilkins sums up the importance of a broader lexicon thus: "Without grammar very little can be conveyed; without vocabulary nothing can be conveyed" (1976, p. 111). 
Is the learning of words actually a great difficulty for SL students? Two Russian English as a Foreign Language (EFL) teachers/EFL teacher-trainers (Kerim-Zade \& Pavlov, 1989) had this to say about the matter:

Our experience as teachers of English shows that one of the most difficult aspects of TEFL is the teaching of vocabulary. This is also true of advanced foreign language students who are training to be teachers of English. (p. 382)

Finally, Krashen suggests a solution to this problem. He believes that there is "powerful evidence" to support the hypothesis that "reading, specifically pleasure reading, is by far the best way to acquire vocabulary" (1986, p. 51). Krashen points out that although many researchers see reading as beneficial to vocabulary growth, few "have claimed that reading is the major source of vocabulary" (p. 51). Furthermore, much of the research on reading as a source for new vocabulary comes from studies of native speakers. What is true for first languages is not always true for second languages, though Krashen strongly believes it to be so for vocabulary acquisition. Wallace (1982) comments on the general lack of research in the area of SL vocabulary learning:

It has often been remarked how strange it is that comparatively little has been written on the teaching and learning of foreign language vocabulary, because there is a sense in which learning a foreign language is basically a matter of learning the vocabulary of that language. (p. 9) 


\section{other solutions}

Decoding. The objective of vocabulary growth is by no means an end in itself. Rather, an ESL student might want a larger lexicon in order to read more, at a faster rate, and with greater comprehension. The means to a larger lexicon is through more reading. Thus, the tandem desires for more vocabulary and for better reading comprehension feed each other and feed off of each other. What other major approach to reading has ESL pedagogy seen?

For many years, the notion put forth by Goodman (1982) and others that unknown words in text (and, presumably, by extension, speech) can be understood from their context has guided many facets of ESL instruction, including vocabulary instruction. It was thought that if a student came to an unfamiliar word while reading, the student ought to be able to decode the meaning of that word through examining context clues and by looking at the word itself for familiar affixes and roots. These "guessing strategies" were supposed to help students read without having to resort to dictionaries too often, and without the students having large receptive vocabularies.

Why are decoding strategies too slow? They are nearly as slow as looking up the word in a dictionary, because the student must analyze the word into its constituent parts, if any, recall meanings of these constituent parts, reassemble the pieces of meaning, and finally check the meaning of the 
whole against the context to see if the guess makes sense. Of course, there is always the possibility that after this tortuous process, the guess is incorrect, and the student will have to try again, or worse, that the student may not recognize that it is incorrect. Those shortcomings aside, conscious decoding strategies are simply too time-consuming.

Although it may be too fine a distinction to make, this study distinguishes between consciously and actively using decoding or guessing skills to get the meaning of an unfamiliar word while reading, and unconsciously and passively meeting the unfamiliar word in a variety of meaningful contexts and gradually and naturally acquiring its meaning, in much the same way that vocabulary acquisition seems to take place in a native language (NL). (This may not be a luxury available in the sL due to restraints on time and students' language development.) If one assumption of the Goodman (1982) "decoding camp" is to enable students to comprehend a new word the first few times it is encountered, until it becomes an acquired part of the mental lexicon, then all the better. Generally, however, there seems to be no mention of this process approach. It is as if proponents of decoding would have students decode an unfamiliar word every time it is encountered and never allow it to become familiar.

Certainly the goal of learning roots and affixes as a decoding strategy should be recognition, not reproduction of 
words. Decoding is a receptive skill only, but at some point, that receptively recognized vocabulary should become part of the productive lexicon. Overdependence on decoding skills, Gidmark (1982) suggests, leads to confusion in the productive lexicon. Students begin to produce items like "miswise decision" or "nonwise decision" rather than ever having absorbed the target form "unwise decision".

If one of the goals of teaching ESL students more vocabulary is so that they can read faster with equal or greater levels of comprehension, then decoding strategies cannot solely be relied upon to help students with unfamiliar words. As Gidmark notes,

It would be foolhardy to encourage [SL] students to accelerate their reading rates if they are comprehending $50 \%$ or less of what they read, if the vocabulary is that frustratingly beyond them. (1982, p. 175)

Using decoding strategies to attempt to comprehend more would just slow students down that much more.

Granted, many studies show that native speaker (NS) and non-native speaker (NNS) readers can and do successfully use--conciously and unconsciously--guessing strategies while reading (Sachs, 1943; Cohen, 1968; Cohen, 1969; Saragi, et al., 1978; Na \& Nation, 1985; Nagy, et al., 1985; Krashen, 1989). However, for NNS readers, guessing strategies have not been nearly as successful (Swaffar, 1988; Haynes, 1993; stoller \& Grabe, 1993). In fact, there may be a consensus brewing among ESL professionals that large vocabularies are 
really the only true way to reading success for ESL students (Swaffar, 1988).

Exercises. The only other major approach to teaching SL vocabulary has been the traditional out-of-context vocabulary exercise (Gidmark, 1982), which seems to be too often characterized as ineffectual and boring. Every teaching technique and method has its utility, but frequently, it seems, within ESL pedagogy, methods are adopted and rejected wholesale, with equal degrees of enthusiasm and disgust, respectively (for example, note the eager embracing of the Audio-Lingual Method as the panacea to end all language-learning difficulties, and its equally eager abandonment for the Communicative Approach when it became obvious that ALM did not work [Kelly, 1969]).

Unfortunately, when a method or approach is seen as ineffective and is thereby rejected, whatever beneficial aspects of the method or approach there were are also usually rejected. Though Krashen (1986) and others have pronounced judgement, both subtly and explicitly, against the traditional vocabulary exercise, exercises do have a place in ESL teaching. However, they cannot be relied upon as the sole source of vocabulary input for ESL students (Nation, 1990). Again, as with decoding, students have trouble with context. However, in the case of vocabulary exercises, the problem is with a lack of context, especially a lack of extended (that is, discoursal) context (Nation, 
1990), in which complex webs of meaning build up around unfamiliar words as those words reappear naturally throughout the context.

Exercises such as true/false statements, matching words with definitions, pairing synonyms or antonyms, or leven worse, according to Gidmark, 1982) looking up word meanings in a dictionary and writing example sentences are clearly not the only solution to the ESL student's need for more vocabulary. There is, of course, no call for abandoning traditional exercises altogether, either.

\section{The Reading Solution}

The question then, is "How?" How can ESL students learn the vast amounts of vocabulary they need to learn in the all-short time in which they have to do it? To return to reading as a vocabulary source, Krashen (1986), offers this advice:

I have a radical suggestion for teaching vocabulary. I suggest that we neither teach vocabulary, nor test vocabulary. Instead, I suggest that we try to get our students "hooked on books," on all kinds of books written in the target language. If our students can become pleasure readers in their second language, I predict that we will see vocabulary development far superior to any we have ever had before.... (p. 51)

This study attempts to do something similar, but in a tightly controlled, highly time-constrained microcosm. It attempts to enlarge $\mathrm{SL}$ students' vocabularies through reading. It uses stories chosen for their likelihood of 
appealing to SL students, since as Krashen contends, students must become more or less addicted to reading in the SL to see vocabulary growth. Krashen also notes that the books we "get our students hooked on..." (p. 51) need not be authentic materials. Accordingly, this study was able to employ simplified adaptations of authentic stories.

\section{This Study}

The present study is an attempt to discover the relative effectiveness of a successful, passive vocabularyacquisition technique. Specifically, it attempts to determine if vocabulary can be better learned through reading simplified-for-ESL graded readers as compared with two other vocabulary learning/teaching methods.

The methodological problem remains: How can a teacher help students to learn the thousands of words they want and need to approach parity with NSs, in the short time of one to three terms that most students are in ESL classes? Many researchers and teachers are asking the same question. Parry (1991) puts it succinctly: "How can learners of a second language build up such a large and complicated structure in the few years, or even semesters, in which many of them have to do it?"

Nation (1991, p. 33) states that the teacher should first attempt to reduce the "learning burden" of the word in a variety of ways. One of those variables affecting the learning burden of a word is the way it is taught. To 
reduce the learning burden in this area, Nation suggests that teachers exploit naturally repeating words, highlight relationships with other words, and avoid presenting opposites. Nation seems to suggest, in agreement with Krashen (1986), that reading for pleasure can fulfill all of these needs. In stories, then, where words often repeat and are found in rich webs of relationship, the learning burden of words is naturally lower.

Taking into account the suggestions of Nation and Krashen, this study used three short stories from Draper's (1993a) Great American stories 1. These stories were simplified and graded specifically for ESL students. One of the purposes of this study was to test whether or not ESL students might increase their vocabularies by reading, even by reading smaller amounts of material. The success of reading as a source for ESL vocabulary was measured against the more traditional technique of vocabulary exercises, and against a combination of exercises and reading.

\section{STATEMENT OF HYPOTHESES}

The main questions posed by this study were whether reading simplified stories alone would help students learn any vocabulary at all, and whether reading alone would help students learn significantly more vocabulary than the other two methods. 
Based on these questions, the following hypotheses were proposed:

1. That mean pre-test scores will not vary significantly among the three sets of test words within the pre-test for any of the treatment or control groups.

2. That the so treatment will produce significantly higher vocabulary learning than the ES treatment, which will produce significantly higher vocabulary learning than the EO treatment, as measured by a post-test.

3. That there will be no significant improvement in vocabulary learning by the control group, as measured by the post-test.

The dependent variables were (a) the three subject groups, (b) the three sets of 15 test words, one set from each of the three stories, and (c) the type of treatment under which those words were taught (so: within a story, EO: within exercises, or ES: within both exercises and a related story). The independent variable was the improvement between subjects' pre- and post-test scores. The pre- and post-tests measured subjects' knowledge of the three sets of 15 words. A fourth group of subjects acted as a control group.

\section{SUMMARY}

This chapter introduces the problems ESL students face with regard to SL vocabulary. These include the size differences between lexicons of NSs and NNSs, the pitfalls of a small NS lexicon and the advantages of a larger one, and the need for vocabulary teaching and learning methods that will help SL students increase their lexical knowledge. 
The background to this particular study's comparison of three vocabulary teaching methods was given. A brief overview of the project was given and the experiment's hypotheses were stated.

The next chapter discusses the empirical environment within which this study was framed. 
CHAPTER II

REVIEW OF THE LITERATURE

\section{INTRODUCTION}

This chapter discusses in detail the research which led to the initial interest in this project and gives an overview of the research in vocabulary learning in general. In doing so, this section attempts to answer, among others, the following questions: What is a "word"? What is meant by "knowing" a word? Is the difference between acquiring and learning vocabulary important? Is the size difference between NS and NNS mental lexicons important? Can NNSs adopt vocabulary learning strategies used by NSs? Are there better strategies for ESL students to adopt than simply increasing the size of their lexicons? And finally, can a historical perspective on vocabulary learning and teaching shed any light on the problem? The solutions to these questions are highly relevant to aspects of this study and the decisions that were made concerning the construction and execution of materials, based on the principles found in past and current literature. 
THE BACKGROUND OF THE CURRENT STUDY

Similar studies

The Animal Farm Study. The researcher of the current study first became interested in "vocabulary through literature" on reading of a study in which researchers (Ferris, Kiyochi, \& Kowal, 1988) tested students' knowledge of 50 vocabulary items after reading Orwell's Animal Farm (1946). In this study, the students read the novel as homework, while in class the discussions centered on the themes of the book, ignoring vocabulary. Subjects were tested on the 50 vocabulary items eight weeks before and two weeks after reading the book. A control group took both tests but did not read the novel. The book-reading group had significantly higher gains in vocabulary acquisition, according to the results of the post-tests.

The Clockwork Orange study. A study similar to the Animal Farm experiment supports these findings. Saragi, Nation, and Meister (1978) used Anthony Burgess's novel $A$ Clockwork Orange (1967) to test adult NSs' passive vocabulary acquisition abilities. In this novel, Burgess invented a slang called nasdat. The original novel includes a nasdat glossary. Saragi et al. omitted the glossary, then tested their subjects' acquisition of 90 of the 241 nasdat words. The results of their testing showed that a good amount of "incidental" vocabulary learning took place. 
A Pre-Reading Focus on Vocabulary. An interesting twist to the vocabulary-by-reading theme is discussed in Hudson (1982), Taglieber, Johnson, \& Yarborough (1988), and seal (1991). These researchers reported studies in which it appeared that, at least for students at higher ability levels, preteaching vocabulary from a story was actually detrimental to the incidental learning of those words from the reading material. Students at lower levels did not seem to be adversely affected by prereading teaching of the target vocabulary. Prereading teaching of new or difficult vocabulary is a traditional technique and a common practice in ESL pedagogy. However, according to these researchers, if literature reading is to be used for vocabulary acquisition, apparently the focus (at least before reading) should not be on that vocabulary.

These three studies and others like them (for example, Sachs, 1943; Largent, 1959; Cohen, 1968; Cohen, 1969; Twaddell, 1973; and Manning \& Manning, 1984) demand that the question be asked, "Can ESL students acquire, incidentally or passively, any amount of vocabulary through reading?" (Most past studies of vocabulary-learning through reading have involved NSs, thus the emphasis on SL learners.) The three studies discussed above provided the basis for the three treatments in this study. 


\section{Definitions}

Defining "a Word". The first obstacle in a study like this is in defining the entity "a word". To know what constitutes "a word" was an important question for this study to explore and define, since word frequencies and patterns of occurrence determined which words were taught and tested here. The establishment of firm guidelines for determining "wordness" and for choosing words proved to be indispensable to the construction of this study.

ESL teachers want students to know more "words," las do the students themselves), but what is really meant in saying that? On the surface, there seems to be little trouble in defining what constitutes a vocabulary item. However, a closer examination reveals an inherent haziness around the topic. What exactly is a "word"? How should "vocabulary word" be defined? What, are its parameters? Does a word include only the "root," the "lexical stem," or should it include derivations with affixes and compounds? Should one "word" have only one meaning, or only one usage context? Nation (1990) states that a word is a bundle of phonetic, morphologic, syntactic and semantic elements. Add reading (or writing, for that matter) to the $\mathrm{mix}$, and there is an additional orthographic element.

Perhaps the most basic characteristic of words is the semantic element: words carry meaning, and they are generally the smallest possible meaningful units in a 
language. Words then are the basic carriers of meaning in a system of communication of meaning. But the question remains: Where are the boundaries of that carrier?

Most discussions of the problem lead to inconclusive solutions. There is much debate over what makes a "base word," a root or stem simplified in form and meaning. Goulden, Nation, and Read (1990), and Nation (1990), have established workable principles to determine what qualifies as a base word. They clarify the basic question into two decisions to be made: (1) what is to be counted as a word and what is not? Thus, will abbreviations, proper names of people and places, prefixes, and suffixes be "words" or not? These researchers show that typically 30 percent of the basic entries in an unabridged dictionary are of this type of "nonessential" lexical item. (2) Which words should be considered base words and which variations due to inflection or derivation? Clearly, a base word such as walk should be counted as a word, but the syntactic inflections walking, walks, and walked should not be counted as separated words. similarly, the derivations govern, misgovern, government, governor, and ungovernable cannot be counted as different base words, according to the guidelines of Goulden et al. and Nation.

The question of meaning throws yet another parameter into the discussion. Again according to Goulden et al., in the example above, walk as a verb, and walk as a noun would 
not be counted as two different base words, since their basic meanings are so closely related (the noun, a walk, in the senses of walkway, sidewalk, or "to take a walk," involves the action of the verb to walk to such a degree that the meaning of the noun is dependent on an understanding of the verb's meaning). Similarly, governess could be considered another derivation of govern and therefore not a separate base word.

However, the homographs row (a verb, as in "to row a boat") and row (a noun, as in "a row of chairs") have identical forms but very different meanings, even etymologically. "Knowing one meaning of row does not mean that minimal effort is needed to learn the other, so they would be regarded as two base words" (Goulden et al., 1990, p. 344). Similarly, the specialized meaning of walk in the phrase, "people from all walks of life" would qualify as a separate base word, since its meaning (a realm of activity, occupation, social class or standing, etc.) is far enough removed from the common meaning of walk expressed above that "all walks of life" cannot be understood from knowing only the common meaning. That is, there is enough semantic distance between the two, even though they are etymologically related, to qualify as separate base words. Thus, the concept of shared underlying meanings in important in determining the boundaries of a base word. 
In summary, the following definition of "base word" was chosen for the purposes of this study: Base words are those essential, uninflected, underived words of one root meaning. That is, according to the principles established by Goulden et al. (1990) and Nation (1990) as discussed above, abbreviations, proper names, and affixes do not qualify as "essential" base words. Furthermore, base words are syntactically uninflected and affixually underived. Lastly, each base word is also a carrier of only one basic meaning. It follows that a single base word might appear in many different forms throughout a text, for example, as part of a proper name, in many inflected and derived variations, and with different shades of meaning, but that these would all be counted as instances of the one base word, not as separate words. Thus, on the one hand, this definition of base word is exclusive in that only a very limited type of word form can qualify as a base word. On the other hand, it is inclusive in that it allows for related variations of a base word to be counted as occurrences of that base word, rather than as numerous individual words. These guidelines were indispensable in choosing base words and in counting the number of occurrences of words for the experiment in this study.

Defining "Knowing" a Word. Furthermore, what does it mean to "know" a word? Do students know a word when they can merely recognize it, or must they also understand it in 
a sentence? Does knowing a word require productive use? How many derivations or meanings should a student know for that word? In how many contexts should a student be able to use a word?

The question of recognition versus understanding versus production was an important one especially in the development of the pre- and post-tests for this experiment. These can simply be seen as increasing levels of knowledge of a word (Nation, 1990), or as distinct skills, each important and useful in its own right. Either way, clearly, a student need not necessarily be required, for example, to create an original sentence using a vocabulary item in order to demonstrate mastery of that word. Distinctions are often made between receptive (reading lexicons and listening lexicons) and productive (writing lexicons and speaking lexicons) vocabularies. The skill of mere recognition of a word in print falls on the receptive end of the scale, while writing that word in a novel sentence would fall at the productive end. To "know" a word, a student should be able to do something with it or to it, whether it be recognizing it, understanding it, producing it in a sentence, etc., or a combination of all of these tasks.

If one "word" includes inflections and closely-related derivations, then a student should be able to recognize those relationships. Knowing a word should also involve some sort of manipulation of that word within more than one 
context, though the other words that build that context should not be radically different in, for example, a testing situation. These assumptions proved very useful in choosing test words and in writing materials for this experiment.

In answering the question, "What constitutes knowing a word?" there is also Krashen's acquistion/learning distinction to consider. For the purposes of this study, a strict division between acquisition and learning is not necessary. According to Krashen's distinction, vocabulary can be artificially and consciously "learned" from a list of words in a textbook, or naturally and subconsciously "acquired" by reading a story for fun. However, this study also takes the position that words learned can become acquired through natural use and repetition. Furthermore, since the experiment undertaken here technically involves both "artificial" learning and "natural" acquisition processes, "learning" and "acquisition" will be used interchangeably in these discussions. Thus, a word is "known" whether it was learned or acquired.

\section{The Problem of the Small Lexicon}

However "knowing" and "words" are defined, the simple dilemma is that ESL students always want to "know" more of them. Their teachers, too, want them to know more of them. The scope of the problem seems overwhelming, and yet it also seems to be virtually ignored by most contemporary ESL teaching practice. 
The sheer size difference between the NS and NNS lexicons is a daunting problem. After having completed an intensive ESL program, students are "faced with a disastrous shortage of vocabulary resources..." (Twaddell, 1972, p. 268). "Students, upon leaving the sheltered atmosphere of the ESL classroom, often find themselves at a literal 'loss for words' in the uncontrolled English-speaking environment which they encounter in the normal American university" (Judd, 1978, p. 71).

Widely-varying estimates of the disparity in lexicon size between NSs and ESL students abound. Some of the variation is no doubt due to differences in defining the parameters of a word, as discussed above. Depending on the parameters, the same person might be said to know a large or a small number of "words." At any rate, the sheer difference in numbers is interesting. Diller (1972), for example, claims that a mere twelve-year-old NS of English has a vocabulary of approximately 135,000 words. "A nonnative speaker...cannot hope to communicate with a native speaker of English on the basis of a vocabulary restricted to 6,000 words" (Ramsey, 1981, p. 16). Nagy and Herman (1987) summarized a number of studies investigating NSs' lexical acquisition and estimated that by the last year of high school the typical student has learned 40,000 words during 12 years of schooling, an average of around 3,000 words per year. A logical extrapolation is that an ESL 
student who is learning academic English would have to learn on average more words per year than this.

Even if SL learners' rates of vocabulary learning are the same as the rates of NSs, the NNSs will either never catch up, or will for perhaps decades be far behind the NSs in needed lexicon size and complexity. Why? The SL learners "did not bridge the gap between [the size of] their vocabulary... and that of the native speakers that already existed when they entered" the SL (Goulden et al., 1990, p. 341). That is, ESL students must learn the approximately 15,000 base words already known by their peers at the college entrance level (this number, different yet again, according to Goulden et al., 1990), plus continue to simultaneously learn the additional 1000 or so new words per year that their peers will continue to learn. This seems at best an impossible task.

However, the answer may lie, as Krashen believes, in reading. If students spent

25 minutes a day reading at a rate of 200 words per minute for 200 days out of the year, they would read a million words of text annually.....With this amount of reading, students would encounter between 15,000 and 30,000 unfamiliar words and if they learned [only] 1 in 20 of these words, their yearly gain in vocabulary would be between 750 and 1,500 words. (Irvin, 1990, p. 11)

clearly this example is founded on a more inclusive definition of "word," thus producing a larger lexicon to draw from in the first place. Yet the potential for 
acquiring sufficient amounts of vocabulary to keep pace with the continuing growth of the NSs' vocabulary is at least present. Possibly, massive amounts of intensive reading could also bring the NNS lexicon up to par and help it to keep pace with the NS lexicon.

However the numbers compare, one disheartening factor is that ESL vocabulary textbooks generally do not teach more than one thousand words, and this may be over the course of several volumes in a series (Smith \& Mohr, 1991; Goodman \& Mohr, 1991; Nist \& Mohr, 1991; Goodman, Nist, \& Mohr, 1991; Burgmeier, Eldred, \& Zimmerman, 1991; Rogerson, Davis, Hershelman, \& Jasnow, 1988).

\section{Native Speakers and New Words}

How do NSs acquire new words? Can the processes by which NS lexicons grow be helpful to NNSs? Goulden et al. (1990) argue that most words learned by a NS student are not learned by direct teaching in classes. If this is true, then what does that say to teachers of NNS students?

As NSs acquiring a first language, we find (usually unconsciously) that

each encounter with a [new] word occurs in a meaningful context; successive encounters reinforce our grasp of what makes that word special, and help narrow down its range of operations in the language. We slowly develop a "feel" for what kinds of linguistic and sociolinguistic neighborhoods it tends to inhabit. Only gradually do we come to appreciate the subtle distinctions between a given word and its nearest cousins in the lexicon. (Martin, 1984, p. 130) 
Thus, much of the way NSs acquire new words is through naturally repeating natural contexts. However, as Martin (1984) further points out,

the luxury of multiple exposures to words over time and in a variety of meaningful contexts is denied to second and foreign language students. They need prodigious amounts of [vocabulary] within an artificially short time. (p. 131)

Thus, one of the great difficulties in learning vocabulary is the time constraint on the ESL student, coupled with the need for numerous experiences with each word, and with the need for a wide spectrum of contexts, which are not usually available due to time constraints and the deliberately and necessarily simplified nature of much of the linguistic environment in ESL classes.

Another "advantage" that a NS student has over a NNS is that often the words that NSs may learn from reading are words that are already part of their oral/aural vocabulary, but which they have simply never seen (or produced) in print before. The younger a student one speaks of, the more this is true. Irvin (1990) gives the example of a young male NS reading aloud a story about a canary. "Canary" was an entry in the boy's speaking and listening lexicon, but he had apparently never seen it in print before, and could not pronounce it. He could point out that the printed word (whatever it was) referred to the yellow bird in the pictures of the book, but not until after several tries was he able to sound out the word and "connect all the pieces". 
NNSs simply do not have many of the luxuries of time and familiarity that are available to NSs. Most of the words they encounter (in the short time they encounter them) in print and in listening will be equally unfamiliar to them .

This difference creates problems both in comprehension and production. If a word is to be learned only for receptive purposes (listening or reading), then there is one set of things a student must know about the word. If the word is learned for both receptive and productive use (listening, speaking, reading, and writing), then the set of factors doubles (Nation, 1990). In other words, meaning is not the only thing involved in learning a word, even for receptive use alone. Questions of pronunciation, spelling, collocation, frequency, context, appropriateness, register, substitution, and others also arise.

There are a variety of ways that NNSs of English get around these problems. First, the NNS might ask someone else (NS or NNS) the meaning of an unfamiliar word. The informant might be a teacher, classmate, roommate, friend, or other "expert". If no person happens to be present, the NNS might try consulting a dictionary, either a monolingual English dictionary, or a bilingual dictionary. With enough repetition and reinforcement over time, or a suitably impressionable situation, students could possibly acquire 
meanings consciously and perhaps unconsciously under these two strategies.

Other strategies, often used in production situations, include avoidance and substitution. students may avoid a situation or topic in which they need to use certain unknown words (Laufer, 1990b), or substitute "easier" words for the meanings they want to express. A pedagogical solution is for the teacher to give NNS students "decoding" strategies (Goodman, 1982; Gidmark, 1982), as discussed above, though these are good only for comprehension, and are arguably too slow. Finally, the teacher can simply give students "more words to learn". None of these solutions should be considered completely satisfactory.

\section{An Historical Perspective}

Those practitioners who hold to the importance of learning words in "a meaningful context" are in good company historically:

Alexandrian language teachers during the first
century BC commonly taught vocabulary "in
context," a practice which was adopted by the
Roman grammarians and which continued to be used
during the Middle Ages. (Kelly, 1969, p. 27)

In the most basic sense, teaching language is the teaching of a system of meaningful communication. The most basic carriers of that meaning are words. It is in this simple premise, Kelly (1969) argues, that language teaching has been rooted for centuries, even "from the beginning" ( $p$. 29). 
For most of the 25 centuries of teaching language in the western tradition, vocabulary has been at the center of language teaching, perhaps largely because linguistic science has generally regarded language as being just that: mostly just vocabulary, a collection of words (Kelly, 1969). Words, rather than meaning or even form, were seen as central to language. Until recently, vocabulary took center stage in language teaching, but without much success. Vocabulary learning then as now did not necessarily translate into the ability to use that vocabulary (Parry, 1991).

The fascination with vocabulary teaching in early modern times began with the "philologists" and their interest in etymology, the history of words. This forerunner of modern linguistic science was sparked by the discovery of similarities in vocabulary, and the resulting theories of familial relationships, between the ancient Indian language Sanskrit and modern European languages. Language teaching then as now was heavily influenced by linguistics, and philology played its part in molding thencurrent thought and practice in language pedagogy. As the emphasis in linguistics was at that time almost exclusively on vocabulary, so was it also in language teaching (Howatt, 1984). (If, as some researchers and educators claim, there has been but scant attention paid to vocabulary learning in 
recent times, this could also be attributed to the "effects of trends in linguistic theory" [Richards, 1976, p. 77].)

Little can be said historically, however, for the notion that a student might passively acquire SL vocabulary simply by reading in the SL without the intervention of an instructor. The historical consensus seems to be that meanings of individual words were to be taught first, and not necessarily within the environment of the text to be read, before the SL student could engage in extensive reading (Kelly, 1969).

Current research, though, seems to confirm that NNSs can and should learn words by reading. Findings cited by Swaffar (1988) suggest that "limited command of language is not an insurmountable barrier to $\mathrm{SL}$ reading and that our students can use texts to learn both language and subject matter" (p. 125).

\section{SUMMARY}

Research in the field of vocabulary seems to lag behind that in other areas of language learning, according to a number of sources (Meara, 1980; Carter, 1987; Parry, 1991). A little-explored subfield is that of text reading as a source for learning vocabulary. Researchers and educators agree that the need for vocabulary learning is great. The vast differences in size between NNS and NS lexicons cannot possibly be bridged by overt instruction from teachers 
alone. Based on the research discussed in this chapter, the next chapter describes how the experiment was constructed to test whether or not reading could answer the need for more vocabulary . 


\section{CHAPTER III}

\section{METHODOLOGY}

\section{INTRODUCTION}

This study was designed along the principles of the experiments in the passive learning of vocabulary, as discussed in Chapter II, but with two important differences: This study was forced by circumstances to work within a highly compressed time-frame (which necessitated using short stories and abbreviated testing and treatment sessions), and to work with lower ability students than is often the case in ESL studies.

General principles as well as specific advice from several sources informed and guided the process of selecting words and developing materials and tests. These included a number of articles dealing with the use of literature in language classrooms (Smith, 1976; Anastos, 1981; Blachowicz, 1985; Goulden et al., 1990; and Laufer, 1990a), as well as sources of counsel regarding the construction of materials, especially of tests (Harris, 1969; Dieterich, Freeman, \& Griffin, 1978; Dieterich \& Freeman, 1979; Heaton, 1975; Madsen, 1983; Hughes \& Porter, 1983; and Carroll\& Hall, 1985; and Henning, 1987). 
A Brief Preview of the Experimental Design

This study used three groups of subjects, plus a fourth control group. All four groups were given a pre-test. Each of the three treatment groups underwent a series of three treatments. Then all four groups were given a post-test.

The EO (for "exercises only") treatment consisted of four vocabulary exercises and a crossword puzzle only. Each set of exercises used words that came from one of the three short stories used in the so treatment below as the target words for the exercises. The four exercises involved matching words and definitions, completing cloze sentences, marking statements true or false, and finding the unrelated words in lists of triads.

The so (for "story only") treatment involved the reading of one of three short stories only. These stories, selected from Draper (1993a) were: "A Cub-Pilot's Education," (CPE), "The Lady, or the Tiger?" (LOT), and "An Occurrence at Owl Creek Bridge," (OCB).

The ES (for "exercises and story") treatment comprised a combination of the EO and so treatments. Under this treatment, subjects both completed vocabulary exercises (these acted as a pre-reading focus on the vocabulary in the short story that they then read) and read a companion story. Table I below shows the order and type of treatment, with the story used, for each of the three treatment groups. 
TABLE I

ORDER AND TYPE OF TREATMENT FOR EACH TREATMENT GROUP $(N=66)$

\begin{tabular}{|c|c|c|}
\hline $\begin{array}{l}\text { GROUP } 1 \\
(n=24) \\
\end{array}$ & $\begin{array}{l}\text { GROUP } 2 \\
(n=25) \\
\end{array}$ & $\begin{array}{l}\text { GROUP } 3 \\
(n=17) \\
\end{array}$ \\
\hline pre-test & pre-test & pre-test \\
\hline $\begin{array}{c}\frac{\text { treatment }}{\text { exercise only }} \\
+ \\
\text { story } \\
\text { cub Pilot }\end{array}$ & $\begin{array}{l}\frac{\text { treatment }}{\text { story only }} \\
\text { story } \\
\text { Cub Pilot }\end{array}$ & 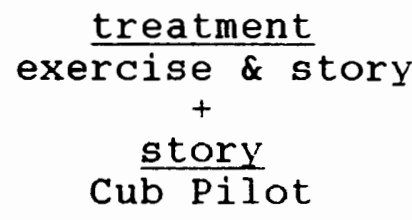 \\
\hline $\begin{array}{c}\frac{\text { treatment }}{\text { exercise on } 1 y} \\
+ \\
\text { story } \\
\text { Lady or Tiger }\end{array}$ & $\begin{array}{c}\frac{\text { treatment }}{\text { exercise \& story }} \\
+ \\
\text { story } \\
\text { Lady or Tiger }\end{array}$ & $\begin{array}{c}\frac{\text { treatment }}{\text { exercise only }} \\
+ \\
\text { story } \\
\text { Lady or Tiger }\end{array}$ \\
\hline $\begin{array}{c}\frac{\text { treatment }}{\text { exercise \& story }} \\
+ \\
\text { Owl Creek Bridge }\end{array}$ & $\begin{array}{c}\frac{\text { treatment }}{\text { exercise only }} \\
+ \\
\text { Owl C } \frac{\text { story }}{\text { Creek Bridge }}\end{array}$ & $\begin{array}{c}\frac{\text { treatment }}{\text { story only }}+{ }_{+} \\
\text {Owl } \frac{\text { story }}{\text { reek Bridge }}\end{array}$ \\
\hline post-test & post-test & post-test \\
\hline
\end{tabular}

The control group, Group 4, took only the pre- and posttests. The control group spent equal amounts of time undergoing the usual lessons in their regular short program 
ESL classes, as that spent by the three treated groups while undergoing the treatments. However, these "alternative treatments" undergone by the control group were not supervised by the researcher. Detailed descriptions of each treatment can be found below. In addition, in the belief that replication is important to the validity and reliability of an experiment, all tests and treatment materials have been included in the Appendices.

DESCRIPTION OF THE SUBJECTS

The subjects in this study were students in the International Exchange Program's Summer study Program at Concordia College, Portland, Oregon, during the summer of 1993. Students in this 15-year-old program come in groups from their high schools or junior colleges to Concordia for two to three weeks of intensive ESL conversation/American culture classes, as well as classes in art, crafts, fashion, science, computers, drama, and sports. Field trips and other activities, as well as a homestay with a local Portland family round out the students' experience. Schools in Japan, Hong Kong, and most recently Taiwan have sent groups of students to Concordia. The students participated in the tests and treatments of this study as part of their usual ESL classes.

A total of 84 students participated in this study. All but two were women. All subjects were Japanese high school 
or junior college students, from four different schools in Japan. All were between 16 and 19 years of age. All spoke Japanese as their first language and had studied English as a foreign language for between 10 and 12 years. Despite their years of exposure to English in school, nearly all were subjectively classified by the researcher and other teachers in the program as well as by program administrators and assistants as being at the Low Beginning to High Beginning level of an American academic-track college-level ESL program. However, for nearly all the subjects, TOEFL (Test of English as a Foreign Language) or other standardized test scores were not available for comparison within and between groups.

Approximately 30 to 40 additional potential subjects, some individuals from the schools below and two entire additional schools, had to be culled from the final subject pool due to a number of unanticipated and uncontrollable factors. These factors included an entire class of unexpectedly low English ability students (dropped altogether from the project after the first treatment), the failure of individual students to take the pre- and/or posttests, the absence of some students from one or more of the treatment sessions, some students' extreme drowsiness during a test or treatment, unforeseen flaws learly on in the project) in the tests, treatment materials, and/or their administration, or scheduling conflicts. Quite by accident, 
some or all of the testing and treatment materials went through what in hindsight was a very useful de facto pilot test: The materials were used on the two culled schools mentioned above, at which time several flaws were found which precluded the inclusion of these students' results in the analysis.

The 84 subjects in this study were divided into four groups: Treatment Groups 1, 2, and 3 had 24, 25, and 17 subjects respectively, for a total of 66 . Group 4, the control group, had 18 subjects. Each subject group contained students from two different ESL classes. Each class had its own primary teacher, who was not necessarily the researcher. In all cases, however, the researcher was responsible for administering tests and treatment materials. Because of the need to preserve classes intact, it was not possible to randomly distribute students among the four groups.

\section{DEVELOPING TESTS AND TREATMENT MATERIALS}

\section{Introduction}

The process of choosing stories and target (test) words, and of developing the materials and tests for this experiment was difficult. A number of potentially confounding difficulties could not be completely solved. Variations in the length of the stories, in the difficulty of the stories relative to each other, in the frequency of 
occurrence of the test words (some stories had greater numbers of more frequently occurring words, some had fewer), and in the number of test words per syntactic class from story to story, were some of these problems. In the end, in order to continue with the experiment, many decisions were made simply for expediency's sake.

\section{Choosing the stories}

Given the time limitation of two to three weeks, short stories, rather than novels (even shortened novels) or other longer pieces of literature had to be used, in contrast to the Animal Farm and Clockwork Orange studies. Also, given the English ability levels of the subjects, stories simplified for ESL students had to be chosen. Reading novels, especially unsimplified novels, for this experiment would not have been practicable.

Furthermore, using simplified short stories tested whether or not an effect was possible with simplified rather than authentic stories. Using simplified short stories also tested whether or not an effect was possible with lower ability students, since Animal Farm or A Clockwork Orange and most other authentic materials would not have been at an appropriate level or length for the available subjects. Finally, by using simplified short stories an attempt was made to determine if some effect could still be obtained with a short story. By definition a short story is of a very limited length, and so would contain fewer repetitions 
of new vocabulary words. The impact of a short story and its vocabulary on a student's memory would be of shorter duration as well, when compared with the impact of a novel (a text of greater length, and with potentially many more recurrences of new vocabulary items than a short story).

The stories from which the test words eventually came were chosen with great care. Four main criteria were established. First, the three stories had to be equal or nearly equal in difficulty and length in comparison with each other. Second, they had to be at a level of difficulty that matched the ability level of the students who would be reading them. Third, they had to be short enough to be usable and interesting enough to hold the students' attention. Finally, they had to contain some words outside the head-word list from which they were written.

A number of sources were considered and rejected. The Longman classics were found to be too long. They are mostly adaptations of novels, simplified and shortened for ESL students, while a few contain short folk stories or fairy tales. However, the shorter stories are all at the 500-word level, and were judged to be too low even for the summer Program students. In addition, especially at that level, they contained few if any words outside their head-word list. Furthermore, those few words often appeared only once or twice within the story. Similar drawbacks led to the 
rejection of other series similar to the Longman Classics, such as the oxford and Cambridge Readers.

Finally, three stories from Great American stories 1: An ESL/EFL Reader, Second Edition (Draper, 1993a) were selected. These stories loosely met all four criteria above. The three stories chosen were: "A Cub-Pilot's Education," (CPE) by Mark Twain, "The Lady, or the Tiger?" (LOT) by Frank Stockton, and "An Occurrence at Owl Creek Bridge," (OCB) by Ambrose Bierce. These three stories were the fifth, sixth, and seventh of the eight stories in Great American Stories 1. Regents/Prentice Hall, the publisher of Great American stories, kindly granted permission to reproduce the stories here. Each story appears in its entirety in Appendix A. (Note: The copies of the stories given to the students were quite different from those that appear in Appendix A. The copies of the stories in Appendix A have all the occurrences of all the test words underlined throughout the stories. Student copies did not, of course, have the test words underlined. Along with Tables XXXIX through XLVI (see Appendix J), which give test word frequencies, orders, and other information regarding the test words, Appendix A gives a visual illustration of the frequency, relative density, and placement of test words within each story. In every other way, the content of the stories remains the same as those which the students actually read.) 
The simplified-for-ESL stories in the two volumes of Great American Stories, because they were so designed, in a small way mimic a novel by recycling the same "difficult" vocabulary items over and over throughout each story, rather than having new vocabulary items appear only infrequently, as might be the case with an unsimplified short story, or even more infrequently with a novel. In fact, Draper (1993a) carefully planned the frequency and usage of vocabulary in these stories:

The book is both graded and progressive--that is, the vocabulary... of the stories increase[s] in difficulty from the first story (which is at the beginning-intermediate level of proficiency) to the last (which is at the intermediate level). [L]exical...controls have been used throughout the book. The head-word list for the first four stories contains 600 words, while that for the final four contains $1000 \ldots$... And words from outside the head-word lists are introduced in a context that helps make their meaning clear; used again within the next 100 words of text; and then repeated at least three more times before the end of the story. (p. v)

Needed: Stories Equal in Difficulty and Length. The three stories used in this study were the first three of the "final four" Draper mentions above, thus they met the first half of the first criterion above, being of nearly equal difficulty with regard to vocabulary. Since the vocabulary of each of the final four stories came from the same 1000word head-word list, it was assumed that the level of difficulty of the vocabulary would be similar among the three stories chosen here. 
Draper does mention that the "grammar, and internal structure" (p. v) also increase with difficulty story by story. This posed a potentially confounding problem. Again, the decision was made to bow to expediency. The three stories being in consecutive order, it was reasoned that their grammar and internal structure would not differ greatly. Indeed, there is little noticeable difference in grammar complexity from CPE to OCB, especially when compared with the quite marked difference in the grammar from the first story in Draper's book to the eighth and final story. Furthermore, it could be argued that in the actual classroom, this would be the case in virtually any ESL textbook. One might in fact question the validity of an ESL text that did not increase in lexical and syntactic difficulty throughout.

Meeting the requirement of equal length was not as easy. A strict word count was conducted to determine the number of individual lexemes in each story (thus it did not follow the principles set forth by Goulden et al. [1990] and Nation [1990] as discussed in Chapter II). This word count, which included conjunctions, articles, prepositions and other function words, as well as titles (e.g., Mr.) and proper names (e.g., Bixby), revealed some differences in length: CPE, by far the longest story, contained 2221 words, 304 more than the 1917 words of OCB, and 450 more than the 1771 words of the shortest story, LOT. The two 
shorter stories differed by only 146 words. This disparity in length may have had a small effect on the results, as will be discussed in Chapter IV.

Although the stories differed in length more than the amount recommended by several advisors of the researcher, again for the sake of expediency they were used as found. A perhaps more satisfying measure of equality than overall length of the stories was the density of test words per story. The total number of test word occurrences as a percentage of the total words in a story was calculated (see Table II below). From this point of view, the three

TABLE II

TEST WORDS AS A PERCENTAGE OF THE TOTAL WORDS IN EACH STORY

\begin{tabular}{cccc}
\hline & $\begin{array}{c}\text { Total \# } \\
\text { of words } \\
\text { in the story }\end{array}$ & $\begin{array}{c}\text { Total \# } \\
\text { of test word } \\
\text { occurrences }\end{array}$ & $\begin{array}{c}\text { Test words as } \% \\
\text { of total words } \\
\text { in the story }\end{array}$ \\
\hline CPE & 2221 & 119 & $5.358 \%$ \\
LOT & 1771 & 98 & $5.534 \%$ \\
OCB & 1917 & 86 & $4.486 \%$ \\
\hline
\end{tabular}

${ }^{\star}$ Note: Differences in test word percentages between stories are as follows:

$$
\begin{aligned}
& \text { CPE vS LOT }=0.176 \% \text { difference } \\
& \text { LOT VS OCB }=1.048 \% \text { difference } \\
& \text { CPE VS OCB }=0.872 \% \text { difference }
\end{aligned}
$$

stories, though rather variable in length, have nearly the same density of test words per unit of text. The greatest 
difference in density was between CPE and OCB, which at slightly more than $1 \%$ is arguably low.

Still, there remains the problem of total number of test word occurrences. LOT had 12 more test word occurrences than did OCB, while CPE had 21 more occurrences than did LOT, and CPE had 33 more than OCB, more than a third as much again as the total for OCB. These discrepancies hardly make for a level playing field among the three stories, and the post-test scores on the words from OCB, the story with the smallest number of test word occurrences and the lowest test word per text density, might be expected to be lowest. The outcome of this prediction will be discussed in Chapter IV.

Although the stories are at the "intermediate level," according to Draper, while the subjects were found subjectively to be at the beginning level, this did not seem to create comprehension problems, judging from the ability of the students in the de facto pilot test to participate in the discussion sessions. Thus the second criterion for the stories, to be of a level of difficulty equal to the ability level of the subjects, was fulfilled.

Needed: Usable, Interesting stories. The three stories also filled the third criterion of being short enough to use and interesting enough to appeal to the students. Each story was short enough to be read and discussed within about an hour. 
Topically, at least two of the stories meshed well with the usual curriculum topic of the summer programs, this being American history, with a special focus that summer on the Oregon Trail and its 150th anniversary. These stories were CPE, a story about piloting steamboats on the Mississippi River in the $1800^{\prime} \mathrm{s}$, and OCB, a fictitious but possible incident in the Civil war. Both fit nicely into the American history theme. LOT, "a long, long time ago" in an obviously non-American setting (with a king, a princess, a kingdom, gladiators and an arena, etc.) did not connect thematically. Nevertheless, though students were genuinely enthusiastic about reading all three stories, overall, they seemed to enjoy reading LOT more than they did the other two.

Another element considered part of the interest criterion was the emotional appeal created by each story as a factor in whether the test words might be learned or not. CPE and LOT could be called "fun" stories, while OCB is anything but fun. OCB could be called rather strange, depressing, even morbid. Should a student not have "enjoyed" reading a story for whatever reason, this could have even in a small way negatively affected the learning of the words from that story. Of course, the mood or emotion generated by a story would be part of the reason for a student liking or disliking that story. Thus, the author's intended mood could have affected vocabulary learning. Just 
as the number of test word occurrences and the test word density might have adversely affected word learning from OCB (as discussed above), so might have students' possible dislike of OCB due to the negative emotions it may have generated. Krashen (1986) would probably predict so: To take his suggestions literally, the story reading should have been purely pleasurable for the students.

\section{Choosing the Test Words}

Initial Considerations. Fifteen test words from each story, for a total of 45 , were carefully chosen. (Test words appear in bold throughout this text.) Fifteen was arbitrarily chosen as a good number with which to work, since any more would have been too many to expect the students to be able to deal with or for the researcher to have time to teach, while any fewer could have been dismissed as coincidentally learned. These 45 "test words," "target words," or "base words" in their basic forms, were selected in a lengthy, careful computerized process of comparison and elimination from a larger original pool of potential test words. Each of the stories was carefully checked to make sure that none of the potential test words appeared in more than one story. There was often overlap between two stories, and frequently even all three stories, for some of these potential test words. When obvious overlap was found, that potential test word was culled. A good number of interesting potential test words, such as 
appear/appearance, bell, criminal, deep (water), fair (complexion and conduct), law, loudness/loud/loudly, noise, peaceful/peacefully, soften, sweet (disposition and scent), and wild, were lost this way. However, that obviously "difficult" vocabulary from one story did happen to appear in other stories simply shows the careful design and construction of Draper's adaptations in Great American Stories. Specific cases of minor overlap that did not result in elimination are dealt with below.

In order to meet the fourth criterion of having enough words outside the head-word list, each story was meticulously read and reread several times for possible "difficult" or "unusual" vocabulary. It was found that the stories did not contain enough testable vocabulary that followed the outside-the-head-word-list pattern explained above by Draper (1993a):

...words from outside the head-word lists are introduced in a context that helps make their meaning clear; used again within the next 100 words of text; and then repeated at least three more times before the end of the story. (p. v)

Therefore, in addition to those that obviously followed this pattern, other words had to be chosen for a full 15 from each story. Additional words were often chosen on the basis of an unusual usage. For example, in CPE the word cool was chosen as a test word, even though it was obviously inside the head-word list for the story (being used only 3 times in CPE), and most subjects already knew the "usual" meaning of 
the word ("a little bit cold"). In the story, however, cool is used as a verb to mean "to gradually become less angry," a meaning with which nearly all of the students were not familiar. The same was true of wheel, which all subjects knew to refer to a circular device upon which vehicles move along the ground. However, in CPE, wheel refers to the wheel by which the pilot steers the steamboat, a meaning that, again, was new to nearly all the students.

Most of these "unusually used" words did not have a high number of occurrences within the text. On the basis of Draper's explanation above, a word outside the head-word list would have to be used a minimum of five times within the story (some of the test words chosen were used as many as 12 or more times). Based on this criterion, the 15 test words from each story were divided into two categories: words that were probably outside the head-word list and appeared 5 times or more, or that mimicked those words by appearing 5 times or more; and words that had unusual usages but which appeared fewer than 5 times and so were definitely inside the 1000-word head-list. (It was judged that for the purposes of this project, this latter type had to appear at least twice in a story, so in this category, words appeared 2 to 4 times).

Next, it was decided that no more than eight words in the second category ( 2 to 4 occurrences) could be chosen from each story. The word sets from both LOT and OCB 
contain eight infrequent occurrers, while the set from $\mathrm{CPE}$ contains only six. It would have been preferable of course that all 15 test words be of the more frequently occurring kind ( 5 or more times), or at least that the balance of words would lean heavily and equally among the stories toward those that appeared more frequently. However, this was not possible to achieve: In the end, the stories had to be accepted "as is," with all their obvious and hidden faults and disparities.

In addition to these general rules guiding the choice of words, some individual cases had to be decided. In nearly all these cases, decisions were made to exclude a word occurrence or a meaning that appeared too infrequently.

In CPE, the base word steamboat appears twice as, technically, an adjective ("a steamboat pilot," "the steamboat landing"). However, since this was such an unusual usage of a word that would normally be considered a noun, and it occurred only two times out of eight occurrences for steamboat, the decision was made to treat these two occurrences, rather than as adjectives, as just the modifying segment of a compound noun. No attempt was made in the vocabulary exercises to include an adjectival or compound noun usage of steamboat.

similarly, the first occurrence of wheel in CPE was ignored: "Her big wheel turned and turned," refers not to the wheel in the pilot-house by which the steamboat is 
steered as do all other occurrences of wheel, but rather to the paddle-wheel of the boat. Thus, this first occurrence was not used in any of the word counts in Tables XXXIX XLVI (see Appendix $J$ ), nor was its meaning replicated in the vocabulary exercises.

Another problem surfaced in the base word point. The usual meaning familiar to the students was that of "pointing to something with the index finger," while the unusual meaning found in the story, "a sharp piece of land going out into a river, a lake, or the ocean," was new to them. In the story, point consistently has this unusual meaning but one time: "The land pointed like a finger into the water." Unfortunately, this verbal usage also appeared twice in OCB: "They cried out and pointed at him." "The soldiers were still pointing their guns at him." Therefore, to avoid duplication between the two stories, the single verbal usage of point in CPE was ignored, and the word was not used at all as a test word in $O C B$.

A similar overlap was found for crime. In LOT, crime appeared twice. The related noun criminal also appeared, once, in LOT. However, criminal also appeared, once, in OCB as well. Thus, the single instance of criminal in LOT could not be counted as a variant of the base word crime. It was ignored, and was not made part of the exercises or analysis.

Final Decisions Regarding Test Words. Decisions had to be made as to the form each base word would finally take. 
As discussed in chapter II, there is wide variance in the literature over the definition of the concept "word." It was advisable, then, to make the arbitrary decision in the case of this study to follow what seemed to be the most reasonable and well thought out guidelines, which were those set out by Goulden et al. (1990) and Nation (1990). According to their two main principles, (1) any "nonessential" words, such as affixes, prepositions, articles, etc., would not be considered when determining which form would qualify as the base form, nor (2) would inflections or derivations be considered separate forms. The only real exception to these rules was in the case of the prefix semiin LOT. In violation of the first principle above, semiwas given the status of a separate test word, partly because the variation barbarism appeared once in LOT without the prefix semi-, and also because it seemed less cumbersome to deal with semi- and barbaric separately in the word analyses, tests, and treatment materials. Also in keeping with the Goulden et al. and Nation rules that were discussed in Chapter II, no proper names were used as base words. However, proper names did appear as occurrences of base words (for example, Six-Mile Point and Apple Bend as occurrences of point and bend respectively, in CPE).

In agreement with further details of the Goulden et al. and Nation guidelines discussed in Chapter II, the base form was determined according to a simplified version of the 
syntactic form (either a noun, verb, adjective, or as in one case in OCB, one of the variations of a base form was an adverb, silently) which appeared most often; thus a simplified noun form would be singular and non-possessive, a verb uninflected, and whichever of the four syntactic forms of that word appeared most often became the base form for that word (see Table XLV and especially Table XLVI for this information). In the rare case that two or more syntactic variations appeared equal numbers of times in a story, the noun form was chosen first, the verb form second (if there was no noun form), and the adjective form third (if there was no noun or verb form) to be the base form. This principle applied in two cases. In LOT, bravery appears once each as bravery (noun) and brave (adjective). Thus, bravery was chosen as the base form. For the word silence in OCB, which appeared two times each as silence (noun), silent (adjective), and silently (adverb), silence was thus chosen as the base form.

Each test word was carefully studied as it appeared throughout a story for context and specific meanings. The vocabulary exercises attempted to duplicate the most common of these features for each word. The stems in the post-test tried to duplicate the one dominant and most basic meaning and context for each test word.

One insoluble test word problem was the variation between the word sets in numbers of nouns, verbs and 
adjectives tested. As one of the variations of one of its base words, OCB even included an adverb, of which the other two stories had none. CPE had the most lop-sided representation, with a total of 97 occurrences of noun, 19 verb, and 3 adjective variations. LOT had 58 nouns, 5 verbs, and 35 adjectives. OCB was perhaps the best balanced at 60 nouns, 12 each of verbs and adjectives, and 2 adverb variations. While the preponderance of base word variations happened to be nouns, the wide deviations in numbers in each syntactic category among the three stories certainly did not enhance the equality of the stories.

Any occurrences of the test words within the titles of the stories were ignored. It was judged that titles provide little or no context for the learning of vocabulary, and therefore, any test word found in a story title should not be included in any word count or analysis. This situation was true for both pilot in the title "A Cub-Pilot's Education," and tiger in the title "The Lady, or the Tiger?".

Finally, careful controls were established and practiced throughout the development of the pre- and posttests and treatment materials, to insure that test words did not cross over from one set of materials to another, or as discussed above, that a test word in one story did not happen to also appear in another story. Some of the 
distractors in the pre-test were also recycled by using them as distractors in the materials and in the post-test.

The extreme lengths to which care was taken in developing the materials and tests would not of course be necessary in a regular classroom setting. In fact, it would be highly desirable for difficult words to reappear from story to story las some difficult words in Great American stories seem to dol and exercise to exercise, so as to reinforce their learning.

Word Tables. Tables XXXIX through XLVI (see Appendix J), as mentioned above, give test word frequencies, orders, and other information regarding the test words. These word 1ists were compiled during the processes of choosing the target words from the stories and of developing the tests and treatment materials for this experiment. These tables were indispensable in carrying out the controls mentioned immediately above. The lists would also have been used in a pre- and post-test item analysis if one had been performed in this study.

\section{Developing the Pre-Test}

The pre-test (see Appendix C) was a 100-item wordrecognition test. The subjects were asked to indicate "yes" or "no" whether they had seen each word before or not. The 45 test words, in random order among themselves, were also distributed randomly throughout the pre-test. Thirty of the 55 distractors were chosen randomly from a 1000-word head- 
word list (Fry, Fountoukidis, \& Polk, 1985, pp. 27-36), to mimic the level of the stories. The other 25 distractors were chosen randomly from a college-level word list (Thorndike \& Lorge, 1944), to insure that there would be at least that many words which the subjects probably had not seen before. Finally, the distractors were randomly distributed in the pre-test, except for the first five (excluding number 2., cool, an "easy looking" test word) and the final six words, which were deliberately chosen from the 30 "easy" distractors to give the students confidence in the beginning, and a positive feeling about the test at the end. The word-recognition format of the pre-test was suggested by advisors to the researcher. It was judged to be a highly valid and effective measure, especially given the parameters of this study. Though some problems did occur (see below and in Chapter IV), it was decided that any other type of test might serve as a de facto treatment session, given the short time lapse between treatments and post-test.

The one flaw in this particular recognition test is that it tested the recognition of orthographic units. There was no provision for variations in the semantic content of those units. (This defect could be seen as a flaw in the test words chosen, rather than in the test itself.) For example, if a student saw the test word bank, of course the student would "recognize" it. The student would recognize 
the orthographic unit $b-a-n-k$, and would think of the meaning usually associated with it, "a place to put money". very few students, during the actual treatments, knew the target meaning, "the land along the sides of a river" (OCB), and were quite surprised to find that the word bank had other meanings than the obvious one with which they were familiar. They had recognized the spelling and accessed the usual meaning, but if they had somehow been given the task of recognizing only meanings, they would not have known the targeted one. In other words, in a number of instances, subjects may have been recognizing meanings other than the target meanings selected to be tested. This could also have happened with landing, wheel, cool, point, bend and lesson from CPE, and hang and current from OCB (see Table III below). Unfortunately, the preponderance of these words were from one story, CPE.

One further problem related to the inability of the recognition test to test for meanings was the problem of being certain that students were really honest on the pretest. There was no real proof of a student's actually having seen a word before. There were no safeguards to keep students, for whatever reason, from indicating that "yes," they had seen even the 25 difficult distractors before (some subjects did indicate on the pre-test that they had "seen," for example, "juxtapose," "kinetic," and "algae"). Even though it was clearly explained to students that the pre- 
TABLE III

TEST WORDS WITH DOUBLE MEANINGS: A "USUAL" MEANING KNOWN BY STUDENTS, AND AN "UNUSUAL" MEANING NOT KNOWN BY STUDENTS

\begin{tabular}{|c|c|c|}
\hline $\begin{array}{l}\text { Test } \\
\text { word }\end{array}$ & $\begin{array}{l}\text { Usual, non-tested meaning, } \\
\text { probably known by students }\end{array}$ & $\begin{array}{l}\text { Unusual, tested meaning, } \\
\text { probably not known by students }\end{array}$ \\
\hline landing & $\begin{array}{l}\text { when a plane comes down to } \\
\text { the ground }\end{array}$ & $\begin{array}{l}\text { a place for boats to stop, } \\
\text { load, and unload }\end{array}$ \\
\hline whee1 & $\begin{array}{l}\text { circular device vehicles } \\
\text { move around on }\end{array}$ & $\begin{array}{l}\text { circular device inside a } \\
\text { vehicle, held by the driver } \\
\text { and used to steer or direct } \\
\text { the vehicle }\end{array}$ \\
\hline $\operatorname{cool}$ & low temperature & calmed emotions \\
\hline point & $\begin{array}{l}\text { to indicate with the index } \\
\text { finger }\end{array}$ & land protruding into water \\
\hline bend & to make something crooked & a curve or turn in a river \\
\hline lesson & $\begin{array}{l}\text { a set of information taught } \\
\text { by a teacher to students }\end{array}$ & 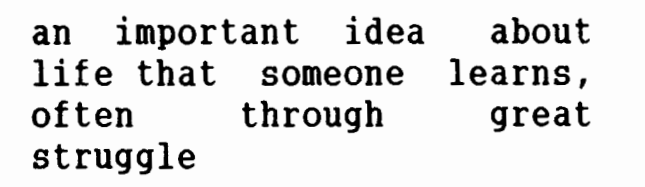 \\
\hline bank & a place to put money & $\begin{array}{l}\text { land along the sides of a } \\
\text { river }\end{array}$ \\
\hline hang & $\begin{array}{l}\text { to put up something (hang a } \\
\text { picture, hang up clothes, } \\
\text { hang up the phone) }\end{array}$ & $\begin{array}{l}\text { to execute by suspending } \\
\text { with a rope around the } \\
\text { neck }\end{array}$ \\
\hline current & now, of the present time & $\begin{array}{l}\text { the swift movement of water } \\
\text { in a river }\end{array}$ \\
\hline
\end{tabular}

test was not graded, was taken anonymously by them, would not be seen by anyone other than the researcher, and was not meant to make them feel bad about their English skills, 
among other reassuring statements meant to encourage honest self-reporting, subjects may still have deliberately or inadvertently misrepresented their knowledge of the words on the pre-test.

Ultimately, the pre-test took the form that it did out of necessity. As discussed above, any other type of test that might have better determined the meanings that the students knew, would also have acted as a teaching device, and this would have skewed the results. Perhaps it is better to fault the necessity of having to resort to the use of test words with special meanings, and the use of students able to misreport themselves, than to fault the design of the pre-test.

Developing the Treatment Materials

In order to guard against skewed test data as a result of interaction between the subject group, story, and treatment type, there were three treatment subject groups total and three stories, to provide the three-by-three matrix in which to test each of the three treatments. Each treatment group received all three treatments, but no two groups received the same treatment on the same story (see Table I above).

The Exercises only Treatment. The EO treatment acted similarly to a control treatment (although the actual control group, Group 4, did not receive any treatments). EO was devised in order to have some measure of the gains in 
vocabulary learning which might be possible under a traditional type of vocabulary teaching, against which the other two treatments, especially the so treatment, could be judged.

Under the EO treatment, subjects were taught the 15 test words for that treatment in the "traditional" manner of teaching vocabulary, in exercises. These exercises were modeled on the formats of several current vocabulary textbooks (Rogerson et al., 1988; Fry, 1989; Burgmeier et al., 1991; Goodman \& Mohr, 1991; Goodman et al., 1991; Nist \& Mohr, 1991; Smith \& Mohr, 1991).

First, a word Form Chart/Definitions and Example Sentences "dictionary" (see Appendix D) was prepared for each set of test words, following the pattern in Rogerson et al. In each Word Form Chart, all 15 base words appear in all their syntactic forms as found in the story from which those words came. For example, the base word imagination appeared in its story, LOT, five times as the noun imagination and three times as the verb imagined. In the word Form Chart for the exercises based on LOT's 15 test words, imagination appears in the noun column and in the verb column (uninflected) as imagine. Similarly, blood appeared as a noun and as an adjective in LOT, and so in LOT's Word Form Chart, blood appears in the noun column, and bloody in the adjective column. 
The Definitions and Example Sentences pages acted as mini-glossaries for the three sets of test words. Each set of Definitions listed the 15 words to be learned, in alphabetical order, each with a standardized, though simplified dictionary definition and at least two example sentences. The definitions were carefully constructed to accurately reflect the meaning(s) of the words as they were used in the story, while the example sentences were crafted with equal care to reflect those same meanings, while studiously avoiding any identification with the story: No sentences from the stories were used in any way as context for the vocabulary words in the word Form Chart/Definitions and Example Sentences pages, nor were any references made to the story as the source of the words.

Next, a teaching component consisting of the actual Exercises (see Appendix E) was developed for the EO treatment. This teaching component included four traditional vocabulary exercise types: matching words and definitions, cloze sentences, true/false sentences, and an exclusion exercise. Each set of exercises was followed with a "fun" activity: a Crossword Puzzle (see Appendix F) using the words and definitions from the exercises. Each test word was used at least two times in the Exercises and once in the Crossword Puzzle. Test words were distributed randomly between the four exercises, but could only appear once per exercise, and twice overall, unless they were used 
as distractors. Again, the exercises were constructed to reflect the meaning(s) of the words as they were used in the stories, without using sentences from the stories, or making any other connections with the stories.

Under the EO treatment, the researcher, as instructor, explained the word Form Chart/Definitions and Example Sentences and its use as a dictionary, explained the example items in the Exercises, and previewed the Exercises and Crossword Puzzle with the students. The subjects were then allowed to complete the materials. After the subjects had completed the materials, the researcher and all the students in the class, reviewed them for correctness, as an in-class activity.

The story only Treatment. The so treatment was designed to test the premises of the Animal Farm (Ferris et a1., 1988) and Clockwork orange (Saragi et al., 1978) studies, as discussed in Chapter II: Namely, that students can learn new vocabulary simply through reading.

Under the so treatment, subjects were each given a copy of the story (see Appendix A) to read silently, as the researcher read the story aloud. Reading aloud held students' attention better, students were less likely to fall asleep, and they were assured of finishing at the same time, so that time constraints could be met. The story reading was followed by a whole-class discussion session, for which 15 questions per story had been prepared (see 
Appendix G). Each list of questions was specifically designed for its story, but with some parallels. Typically, there was not time enough to use all 15 questions.

In treatment so, there was not only no overt focus on vocabulary either before, during or after reading and discussing the story as a class; there was in fact a conscious attempt on the part of the researcher to avoid any reference to the meaning of individual words and phrases in the story. Instead, discussion focused on characters, setting, plot, themes, and other literary aspects of the short story, as facilitated by the discussion questions.

As will be discussed in chapter $v$, pedagogically, it makes no sense to purposely avoid informing students of the learning task (which was in this case to learn new vocabulary from the context of a story by reading that story). However, experimentally, this was absolutely necessary to guarantee the objectivity of the results.

The Exercises and Story Treatment. The Es treatment was constructed to test the notions put forth by Hudson (1982), Taglieber et al. (1988), and Seal (1991), as elaborated in Chapter II. These researchers report that a pre-reading focus on vocabulary helps only lower ability level students learn those words from a text. As mentioned before, pre-teaching vocabulary from a story before reading that story is the traditional practice in most ESL classes, though empirically this practice has been shown to 
negatively affect vocabulary learning for all but the lowest ability students.

The ES treatment combined the vocabulary exercises of treatment EO with the story-reading and discussion of treatment so. Subjects completed the Exercises and Crossword Puzzle in much the same way as they would have in treatment EO. However, in this case, the focus on vocabulary was meant to prepare the subjects for the vocabulary they would then soon encounter in the story. Immediately following completion of the exercise component, the story was read aloud and discussed in the same manner as it would have been under treatment so. As in treatment so, the post-reading discussion's focus was on the literary content of the story, rather than on the vocabulary. There were no additional materials or teaching components for the ES treatment.

Under the ES treatment, no overt attempt was made to point out the individual vocabulary words that had just been learned in the Exercises as those words appeared during the reading of the story. This might have acted as a potentially confounding additional layer of reinforcement that was not specified in the experiment's original design. However, subjects were told specifically that the words they had just learned by doing the exercises were in the story, and that by having done the exercises, they should be able to understand the story better. This is usually the 
rationale for pre-reading vocabulary teaching, though as discussed in Chapter II, this technique, which may indeed boost reading comprehension, does not however boost vocabulary learning.

The discussion questions used in treatments so and ES were purposely formulated so as to reinforce as few of the targeted vocabulary words as possible. The test words were difficult to avoid, but the discussion session had to be kept from becoming another layer of treatment. In retrospect, however, it is possible that subjects could have inadvertently used test words in their discussion responses. Nevertheless, rather than then simply abandoning the discussions altogether, it was felt that some follow-up activity was needed to test story comprehension and create a sense of closure to the story reading.

\section{Developing the Post-Test}

The multiple choice post-test (see Appendix I) used all of and only the 45 words from the three stories. Each item was carefully constructed to reflect the word's original usage in the story from which it was taken and its subsequent usage in the exercises based on that story's words, again without referring to the story in any way or using sentences from the story. In the case where a test word appeared in two or more forms or had two or more variations in meaning, the post-test item tested the most commonly occurring form and meaning of the word, and/or the 
form/meaning variation closest to the base word form and meaning. Each stem was carefully monitored to insure that no test words from other items inadvertently appeared in it.

Stems. Harris (1969) and Madsen (1983) discussed at length the problem of incomprehensible stems. Every effort was made to construct stems which used the simplest vocabulary and grammar possible; as well as which created a clear context for the test item. Each stem was written from the perspective of the subjects' generally low ability and checked for accuracy by a colleague teaching in the same program. Finally, the items were distributed randomly throughout the test, except again for the first and final 5 items, which were felt to be "easier" target words and were meant to boost the students' confidence, as with the pretest's first and final items.

Distractors. Preparing distractors for the post-test items was a difficult task. Harris (1969), Heaton (1975), Madsen (1983) and Carroll \& Hall (1985) recommend avoiding several types of "tricky" distractors, for example, those that mimic the correct answer in spelling, pronunciation, and/or meaning. Harris argued persuasively that language tests are hard enough without making the distractors "tricky." The researcher, however, randomly chose a number of post-test items which were deliberately made "tricky." It was felt that, in fact, the post-test should perhaps be a bit more difficult than necessary, since it followed so soon 
after the treatments. It was feared that students would be able simply to recognize the correct word from the four choices and choose it as the answer without even understanding the stem. A cursory non-statistical item analysis showed that most students were apparently not fooled by the tricky distractors on those questions which had them.

Rules for selecting the distractors were established and carefully followed. Each distractor slot in each test question was randomly assigned to one of these distractorselection principles. These principles included choosing a distractor that was similar to the correct choice in (1) spelling, (2) pronunciation, or (3) meaning; was opposite to the correct choice in (4) meaning; or was unrelated in (5) spelling, pronunciation and meaning (the "non-tricky" option).

\section{ADMINISTERING THE MATERIALS}

Detailed instructions for administering the pre- and post-tests can be found in Appendices $B$ and $H$, respectively. No special instructions were needed to administer the treatment materials (vocabulary exercises, short story, or both). In all cases, the researcher was responsible for pre- and post-testing and for teaching all the treatment materials. The tests and treatments were administered simply as a regular part of the students' daily ESL classes. 
Administering the Tests

Administering the Pre-Test. Students were given simple, but carefully planned and detailed instructions before taking the pre-test. The most important detail in these instructions was the distinction made between the meaning of a "yes" answer and a "no" answer: If students were positive that they had seen the word before, they were instructed to circle YES. If there was any doubt at all, they were instructed to circle No. For example, even if a student felt that there was a slight possibility of having seen a word before, the student was to circle No.

During the test, careful monitoring ensured that no students used dictionaries or consulted other students. As students finished, they handed in their pre-tests and were given quiet written activities to do that had no connection with the pre-test words. Students were given as much time as they needed to finish the pre-test without feeling rushed. Completing the pre-test usually took 15 to 20 minutes once the students actually started. As students finished, their pre-tests were checked to make sure that each student had answered every item and written a first and last name on the test.

Administering the Post-Test. General procedures for administering the post-test were similar to those for the pre-test. Again, as they completed the post-test, students were given quiet written activities to do while their 
classmates finished, and were given as much time as they needed to complete the test, which was usually between 60 and 90 minutes.

Even with the careful directions and close monitoring during post-test taking, some problems slipped through unnoticed. Several post-tests had to be culled entirely because a few of the students were simply too sleepy to finish. This was not a problem on the much shorter pre-test because students were still fresh and energetic at the onset of the program. However, by the end of the program, an hour of quiet concentration over a fairly boring vocabulary test was just too much for some subjects. In addition, despite careful checking to make sure that all items on a post-test had been completed before the end of the testing period, a small number of tests slipped through containing a few unmarked items. In those cases, the items were simply counted wrong.

\section{Administering the Treatments}

Each treatment took about one hour to administer, with the exception of ES, which, since it was actually a combination of EO and SO, should have taken twice as long as EO or so alone. An attempt was made to keep treatment ES to as close to one hour as possible, however, so that the length of exposure to the words would not become a confounding variable. This attempt was not always successful; in fact, usually the ES treatment ended up 
lasting at least one and one-half hours. This may have produced an effect in the results (to be discussed in Chapter IV).

strict safeguards were taken to prevent students from studying any treatment materials further than what was done in class and so perhaps skewing their results on the posttest. Students were not allowed to keep any treatment materials, nor were they allowed to leave the room, with or without treatment materials, once a session had started. After administering a treatment, all treatment materials, including the word Form Chart/Definitions \& Example Sentences pages, Exercises and Crossword Puzzle pages, and/or the copies of the short stories, were carefully collected from the students. In addition, students were not allowed to take notes during any of the treatment sessions. This was frustrating for most students, who wanted to keep the materials and could not understand why they were not allowed to keep them. However, at the end of their stay, after taking the post-test, the students' materials were returned to them, which was a pleasant surprise for them on the whole.

The usual scenario of tests and treatments for any one group was as follows (also see Table I above): The first day of their ESL classes (usually a Monday) the students took the pre-test after brief introductions. The three treatments followed, one per day, over the following three 
days. A typical sequence of treatments looked something like this (for Group 1, in this example): The first day after the post-test, the subjects worked on a set of vocabulary exercises and filled in a crossword puzzle as part of their usual ESL class (the particular exercise set that Group 1 did under this treatment was based on the 15 target words from CPE). The next day, they read a short story (LOT for Group 1). The day after that, they did another set of vocabulary exercises and a crossword puzzle (this time based on the words from $O C B$ ), and then they read another short story (OCB). Finally, they took the post-test on the last day of their ESL classes. The time lapse between the third treatment and the post-test was from 7 to 10 days.

During the course of testing and treatments, the researcher purposely made no overt connections for the students between the pre- and post-tests, nor between the tests and the treatment materials, other than to explain that the post-test was a test of the vocabulary that they might have learned over the course of their classes (vocabulary learning was also a component of the students' regular ESL classes).

\section{The Problem of the Short Time Lapse}

The short lapse of time between the pre- and post-test and between the treatments and the post-test could be seen 
as a confounding factor. However, it can be argued that the intensity of the experience made up for its short duration.

Depending on the group, the students stayed in the U.S. for 2 to 3 weeks. For nearly all of them, this was their first time in the United states, and often their first time outside of Japan. And although they may have been "studying English" since 3 rd or 4 th grade, this was usually also their first experience with the language in real life settings. That is, perhaps for the first time, the students were forced by circumstances to use English to communicate their everyday thoughts, needs, and experiences. Another probable first experience was their having to use English for extended periods of time in the classroom. Rather than just one or two hours a day and perhaps not every day of the week, these students were in ESL classes three hours each day, for 10 to 15 days (not including weekends). Finally, most of these students had what was probably their first experience in using English as the medium of instruction in some other subject. In their 10 to 15 days at Concordia, the students took ESL classes (whose topical focus was American history and culture) either in the mornings or in the afternoons. When they were not taking ESL classes, they were taking some kind of content class. These included classes in art, crafts, fashion, science, computers, drama, and sports. All of these classes were taught in English, and by non-ESL professionals. 
The students also experienced a variety of new and different living situations as well. Most schools stayed in the Concordia dormitories at least one night at the beginning or end of their stay in Portland. Most of their time in Portland the students lived with host families. Most schools also stayed one or two nights at a dude ranch near Portland. Finally, though this could have little effect except for the anticipation, being after the fact, most schools also travelled to a tourist spot at the end of their stay, usually Disneyland, San Francisco, or Vancouver, British Columbia.

There was little time to recover from jet lag before it was time to return to Japan. At the same time, the students seemed to be almost continually busy. If they were not in ESL classes, then they were in content classes, or on a field trip or other structured out-of-class activity, or sightseeing with their host family, or practicing for their end-of-the-stay Bon Voyage Party. This combination of jet lag and almost constant activity in a new culture among new experiences produced in most students a kind of giddy euphoria that carried through until nearly the end of their stay. At that point, a few students were simply too exhausted to do quiet activities (such as taking the posttest, which is why several students had to be dropped altogether from the analysis). 
This wealth of new and diverse experiences, the almost frantic pace of events, the overwhelming volume of English, and the physical, emotional, and mental strain and exhaustion that resulted, combined to produce an effect arguably similar to that which could be experienced by a "regular" ESL student over a longer period of time. Perhaps the most obvious difference would be the lack of any experience with long-term culture shock.

Thus, it can be effectively argued that the intensity of the students' experience made up for its short duration. (It probably felt much longer to the students than its actual two to three weeks' length.) Therefore, the short lapse of time between the pre- and post-tests and between the treatments and the post-test need not be seen as a confounding factor.

DATA ANALYSES USED

After collecting and scoring all test materials over the course of the summer, the data were recorded, tabulated, and analyzed. This section reports the types of data analysis used.

First, ANOVA assumptions of normality and homoscedasticity were checked by examining frequency histograms for each variable, for each group.

"Normality" in this case refers to the normality of the desirable bell-shaped curve of plotted data. Data from this 
type of study that does not fall into a bell-shaped curve in the center of the plotting field, but falls to one side or the other of the field, into another shape of curve, or simply into some other pattern altogether may indicate flaws in subject selection, test design, scoring, or something else. Abnormality may also indicate that the data need to be manipulated differently, as was the case in this study (see below).

"Homoscedasticity" refers to the equality of variances among two or more bell-shaped curves under comparison. That is, two or more curves can be said to be homoscedastic if they have similar shapes.

Thus, two bell-shaped curves might exhibit normality by falling into the center of the plotting field, but one might be flat, while the other is tall. These curves could not also be said to be homoscedastic. On the other hand, two curves might exhibit identical homoscedastic shapes, but one might fall on the right side of the field, the other on the left. These curves could not also be called normal. Two or more curves in comparison that do not exhibit either trait may indicate severe flaws in experimental design and/or data collection.

ANOVA tests cannot be made accurately on abnormal, heteroscedastic data curves. Initially, curves were plotted using the formula "post-test score minus pre-test score" which yielded the number of points of improvement between 
pre-test and post-test. The advantage of this formula is that it is straightforward and easy to explain. The disadvantage is that in this case, plotting its output did not produce normal bell-shaped curves. Curves generally fell to the left of the plotting field, indicating pre- to post-test gains which were not only relatively small, but which were originating from inflated pre-test scores. The curves were, however, of similar homoscedastic shape.

Since these results were not appropriate to ANOVA analyses, a different formula was tried: "post-test score divided by pre-test score," which produced ratios that ranged anywhere from about 0.5 to almost 2 , that is, a 50\% decline from pre-test to post-test, to a $100 \%$ improvement from pre-test to post-test. (Thus, if a student did equally well on both pre- and post-tests, the ratio would be 1 ; if better on the post-test, greater than 1 ; and if worse on the post-test, less than 1.) The disadvantage to this formula is that it is difficult to see its validity and even harder to explain its necessity. However, in this case, the ratio formula did produce bell-shaped curves that were both normal and homoscedastic, and thus appropriate to ANOVA evaluation. The ratio formula was used throughout the analyses of statistical significances, while in nearly all discussions, tables, or graphs of purely descriptive statistics, the gain in points from pre- to post-tests is used. 
The analyses of statistical significance used two tests: the Fisher PLSD and the Scheffe F-test. Two tests, rather than just one, were used simply to guarantee the accuracy and importance of the results. In only two comparisons, comparison of stories CPE and LOT for Group 1 (see Table XVI) and comparison of treatments EO and so for Group 1 (see Table XXII) (this is actually the same comparison, since for Group 1 only, story order and treatment order are identical), did the two tests fail to both show a significant difference. The Fisher test showed a significant difference in these comparisons, while the Scheffe test did not. However, this was not a cause for discounting the significance of the difference. Only if the two tests had disagreed repeatedly throughout the analyses would there have a been a question. The results of the ANOVA analyses are reported and discussed in the next chapter.

SUMMARY

Chapter III described the empirically-informed selection and construction of treatment materials and preand post-tests for this experiment, as well as the processes of their administration. After collecting and scoring all test materials, and tabulating the results, the data were analyzed for significant differences between the three treatments. The results to the question of which method 
lexercises alone, reading alone, or a combination of exercises and reading) would produce the highest vocabulary gains will be reported and discussed in chapter IV. 
CHAPTER IV

\section{RESULTS AND DISCUSSION}

\section{INTRODUCTION}

This chapter reports the results of the statistical analyses of the data, and breaks down and compares the results in a number of different ways. Woven throughout the reporting is a discussion of the meaning of these results and how they relate to the theories and practices examined in Chapter II.

A group-to-group comparison attempts to determine the similarity of ability levels among the groups, while a similar story-to-story comparison seeks to determine the equality of difficulty of the stories' target words. Conclusions are drawn as to the group-by-group and overall effectiveness of each treatment, the possibility of interaction between the dependent variables of group, story and treatment, the effectiveness of the control group, and so on.

The discussion also reviews the experimental hypotheses proposed in Chapter I, details how the data support or refute each hypothesis, and offers arguments why each one was or was not supported. 


\section{An Overview of the Data}

Table IV below gives some basic statistics on the groups' performances on the pre- and post-tests. Each column gives the minimum, maximum, and mean number of points

\section{TABLE IV}

MINIMUM, MAXIMUM, MEAN, AND STANDARD DEVIATION FOR POINTS CORRECT ON ENTIRE PRE- AND POST-TESTS, BY GROUP

\begin{tabular}{|c|c|c|c|}
\hline & & $\begin{array}{c}\text { PRE-TEST } \\
\text { Correct/ } \\
\text { a } 11 \\
100 \\
\text { items }\end{array}$ & $\begin{array}{c}\text { POST-TEST } \\
\text { Correct/ } \\
\text { all } \\
45 \\
\text { items }\end{array}$ \\
\hline GROUP 1 & $\begin{array}{r}n=24 \\
\text { minimum } \\
\text { maximum } \\
\text { mean } \\
\text { SD }\end{array}$ & $\begin{array}{r}61.000 \\
92.000 \\
75.208 \\
8.204\end{array}$ & $\begin{array}{r}24.000 \\
45.000 \\
39.250 \\
5.127\end{array}$ \\
\hline$\underline{\text { GROUP } 2}$ & $\begin{array}{r}n=25 \\
\text { minimum } \\
\text { maximum } \\
\text { mean } \\
\mathrm{SD}\end{array}$ & $\begin{array}{r}61.000 \\
83.000 \\
72.360 \\
6.873\end{array}$ & $\begin{array}{r}19.000 \\
42.000 \\
34.040 \\
5.240\end{array}$ \\
\hline GROUP 3 & $\begin{array}{r}n=17 \\
\text { minimum } \\
\text { maximum } \\
\text { mean } \\
\text { SD }\end{array}$ & $\begin{array}{l}41.000 \\
73.000 \\
57.000 \\
10.863\end{array}$ & $\begin{array}{r}21.000 \\
40.000 \\
29.353 \\
6.499\end{array}$ \\
\hline GROUP 4 & $\begin{array}{r}n=18 \\
\text { minimum } \\
\text { maximum } \\
\text { mean } \\
\text { SD }\end{array}$ & $\begin{array}{r}49.000 \\
82.000 \\
69.667 \\
9.242\end{array}$ & $\begin{array}{r}17.000 \\
35.000 \\
27.167 \\
5.339\end{array}$ \\
\hline & mean SD & 8.796 & 5.551 \\
\hline
\end{tabular}


correct on the pre- and the post-test for each group. (Throughout the analyses, a "yes" response on the pre-test was counted as "correct," while a "no" was "incorrect".) The standard deviation (SD) for each group's performance on each test is also given. Note that the SDs for the posttest are smaller than for the pre-test. The mean SD for the post-test is more than one-third less than the mean SD for the pre-test. This may indicate that the post-test was a slightly more accurate test than the pre-test.

Table $\mathrm{V}$ below gives more detail to the basic statistics in Table IV by breaking the pre-test data out into the 55word non-target item set and the 45-word target item set. This table reveals a notable pattern between these two sets. The percentage correct of the 55 non-target distractors is from almost $5 \%$ to about $13 \%$ higher for all four groups than the percentage correct of the 45 target words (the mean difference is about $7.9 \%$ higher). It would be expected that the two sets would produce nearly identical percentages. This apparent discrepancy may indicate that the pre-test distractors were not, as a whole, of equal difficulty with the 45 test words as a whole, but were actually easier on the average.

Table $V$ also gives mean post-test scores and their percentages for comparison. (Tables to follow show gains and losses between pre- and post-test scores.) Note that all three treated groups posted percentage gains on the 
post-test over both segments of the pre-test, including the target words segment, and over the pre-test as a whole, while the control group (Group 4) lost in each of these cases.

TABLE V

MEAN SCORES (AND THEIR PERCENTAGES) BY GROUP, FOR ENTIRE PRE-TEST, 55 DISTRACTORS AND 45 TARGET WORDS OF PRE-TEST; AND FOR ENTIRE POST-TEST

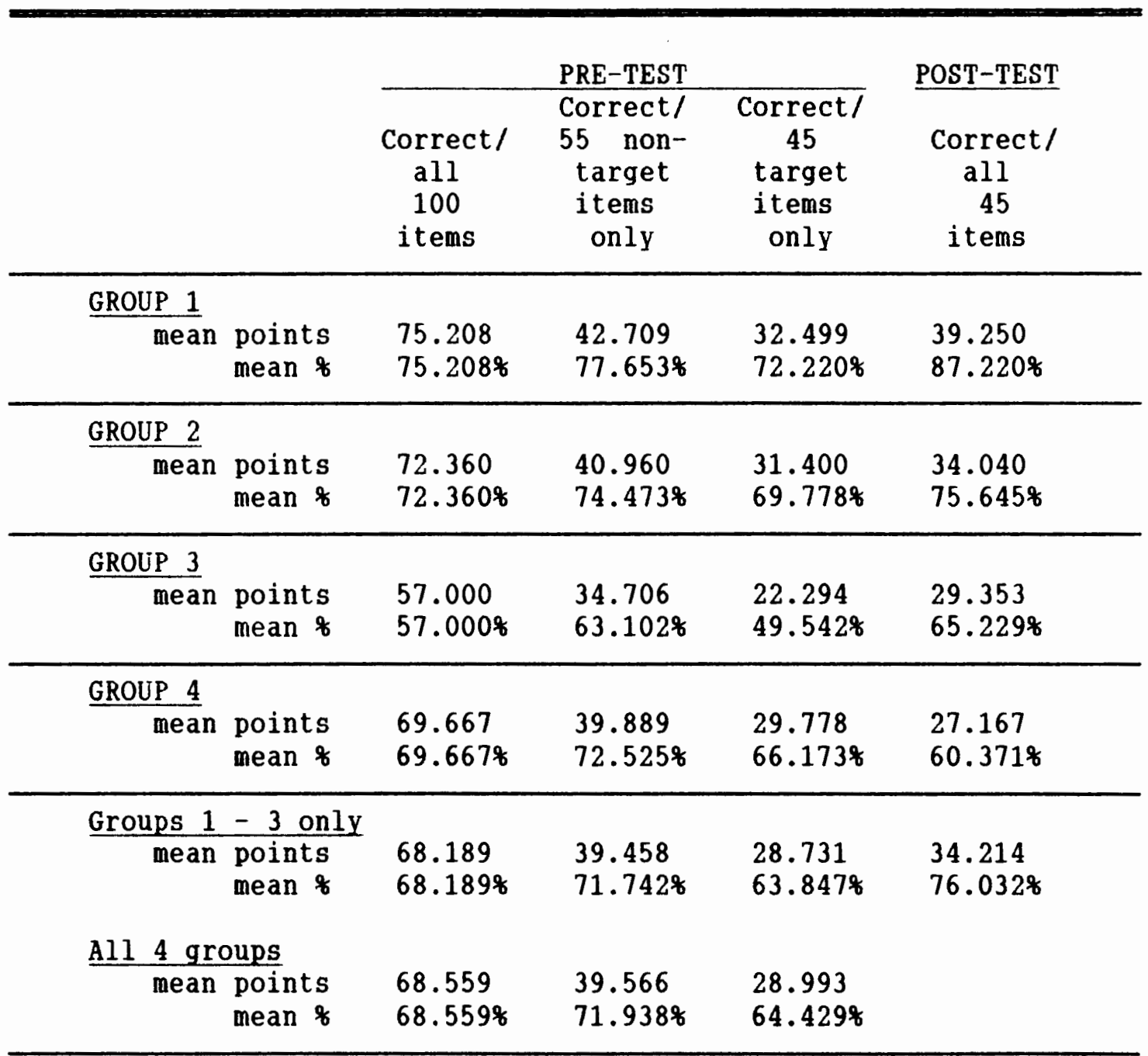


Finally, Table $V$ shows means for each set across the three treatment groups and for all four groups lexcluding an all-group post-test mean, which by including the control group, would have been an invalid measure). The patterns, as discussed above, established by the individual groups hold true for these aggregate figures as well.

Table VI below gives an apportioned overview of all the scores for the entire project. It gives scores for each group by story/treatment in order as the treatments were given to that group (see Table I above for an overview of the treatment sequences for Groups 1 - 3). Table VI shows the total pre-test and post-test means for each group ("total each column" line) broken out into mean performances for that group on the particular 15 words from each story (followed by the type of treatment used with that story). In the line for "mean each column" there is an average of these three means. Finally, the last two columns report the increase or decrease in points from the pre-test to the post-test for each story/treatment mean, and the corresponding percentage that this gain or loss is, out of 15 (15 words per story/treatment set). In the last two lines of these columns, the total mean gain or loss out of all 45 of the target words combined is reported, as well as the average gain or loss lout of 15 words per story/treatment set), each with its percentage. (These two percentages will always be identical.) The means reported 
below, and other calculations derived from them, will be highlighted in the tables that follow.

\section{TABLE VI}

MEAN SCORES ON PRE- AND POST-TESTS IN ORDER BY STORY (WITH TREATMENT TYPE), AND IMPROVEMENT OR DECLINE IN MEAN BETWEEN PRE- AND POST-TESTS FOR GROUPS 1 - 4

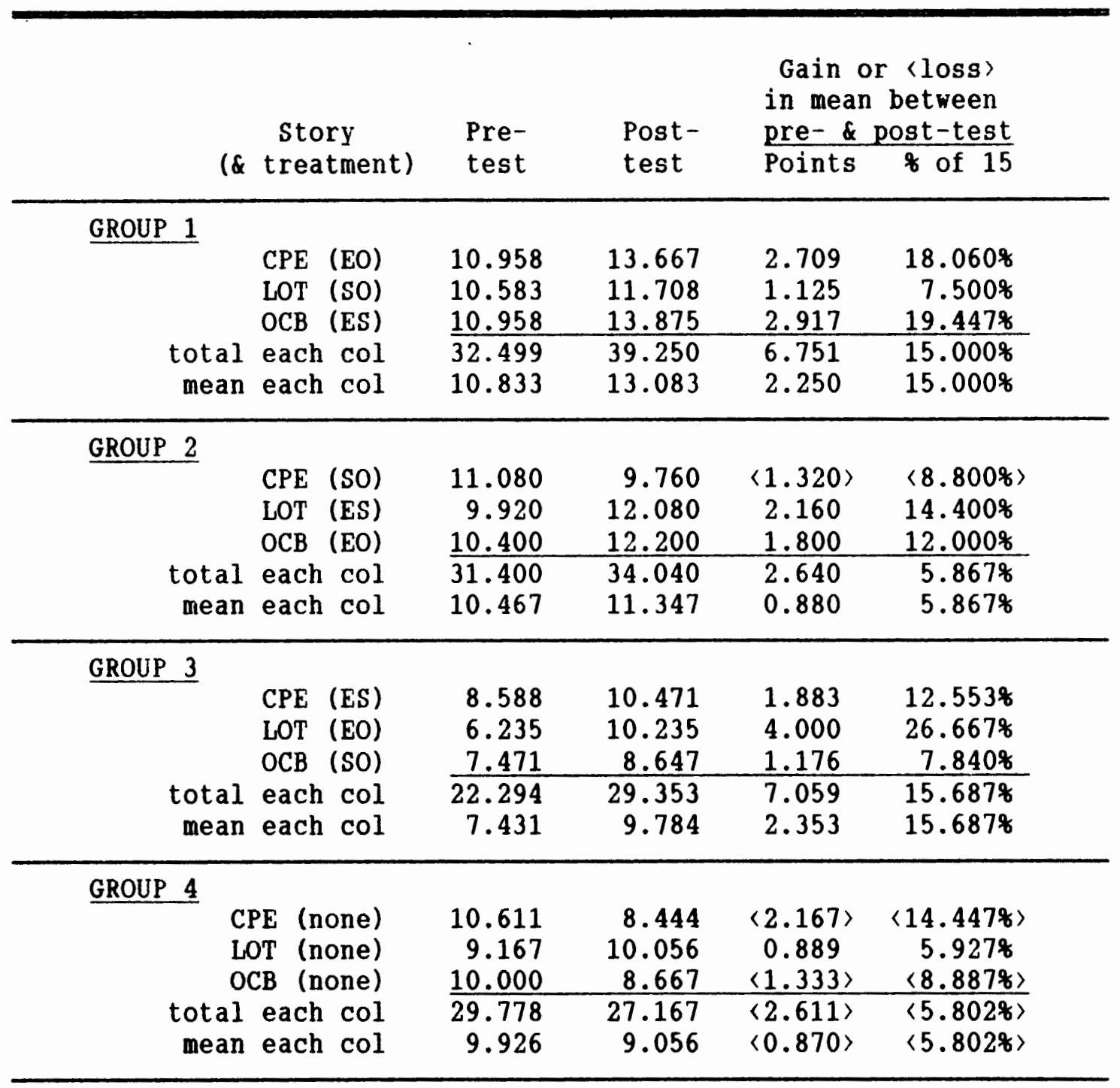


Figures 1 - 4 below illustrate the data in Table VI graphically. Figures 1 - 4 represent results for Groups 1 4, respectively, for pre- and post-test mean scores on each story/treatment set. 


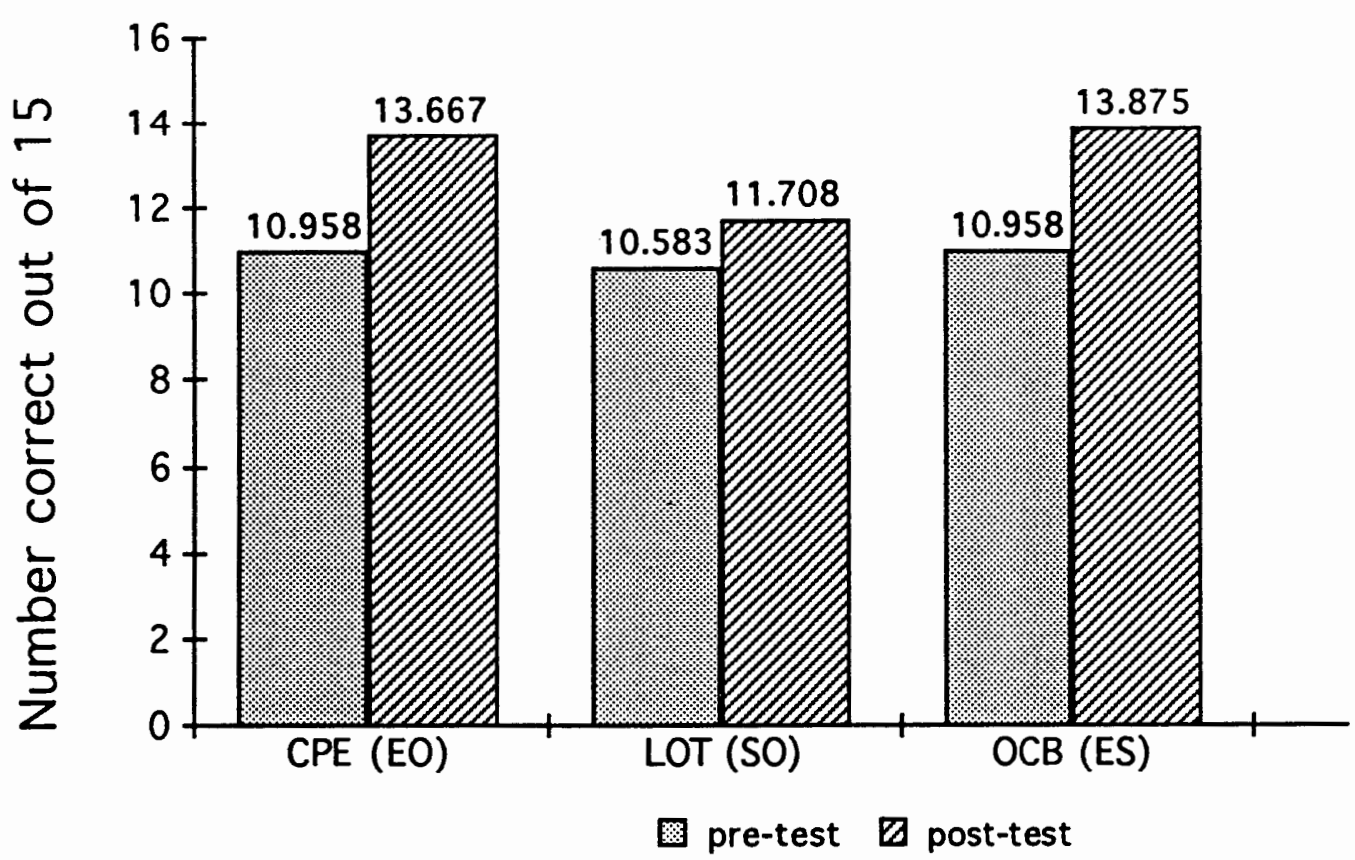

Figure 1. Group 1 mean scores on pre- and posttests by story (with treatment type).

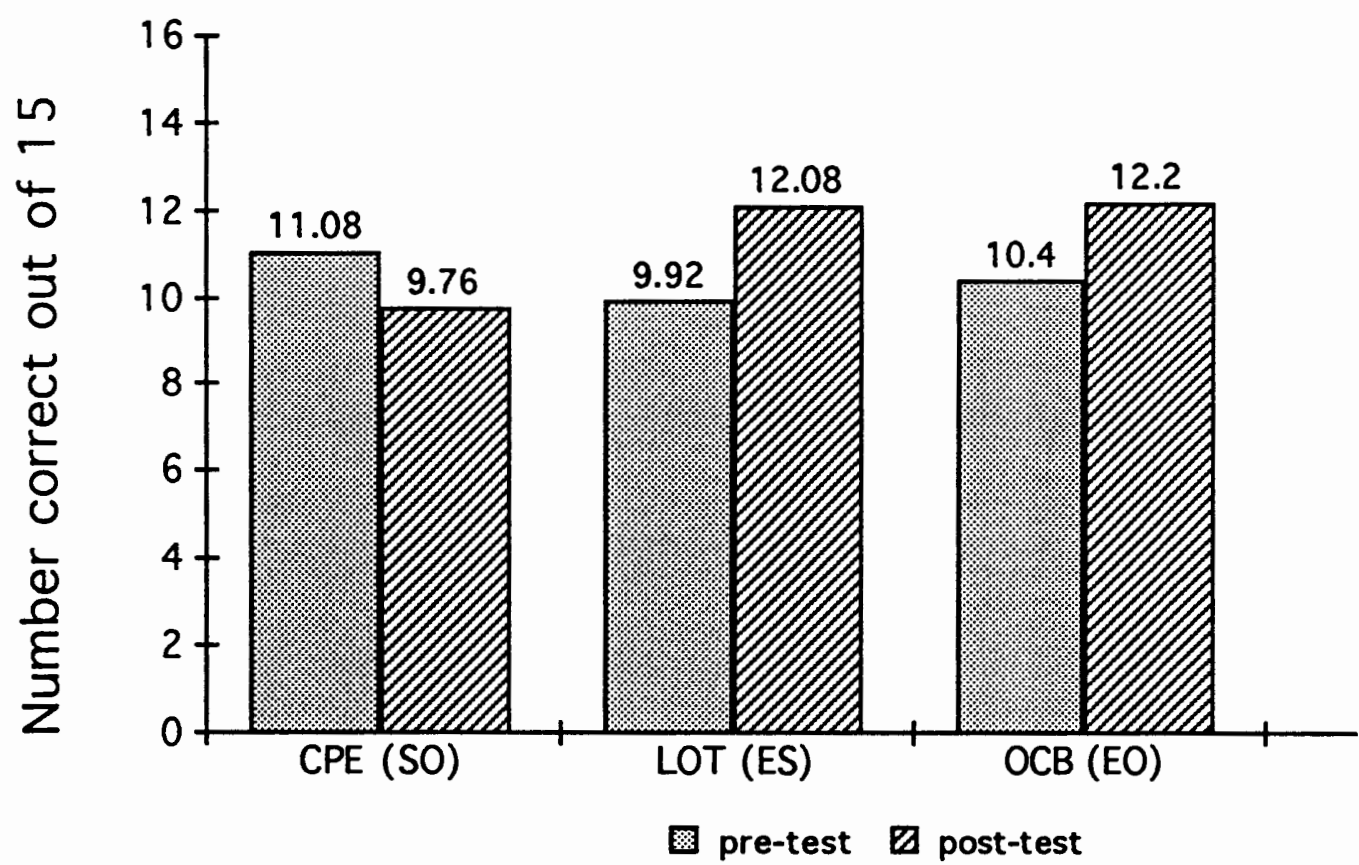

Figure 2. Group 2 mean scores on pre- and posttests by story (with treatment type). 


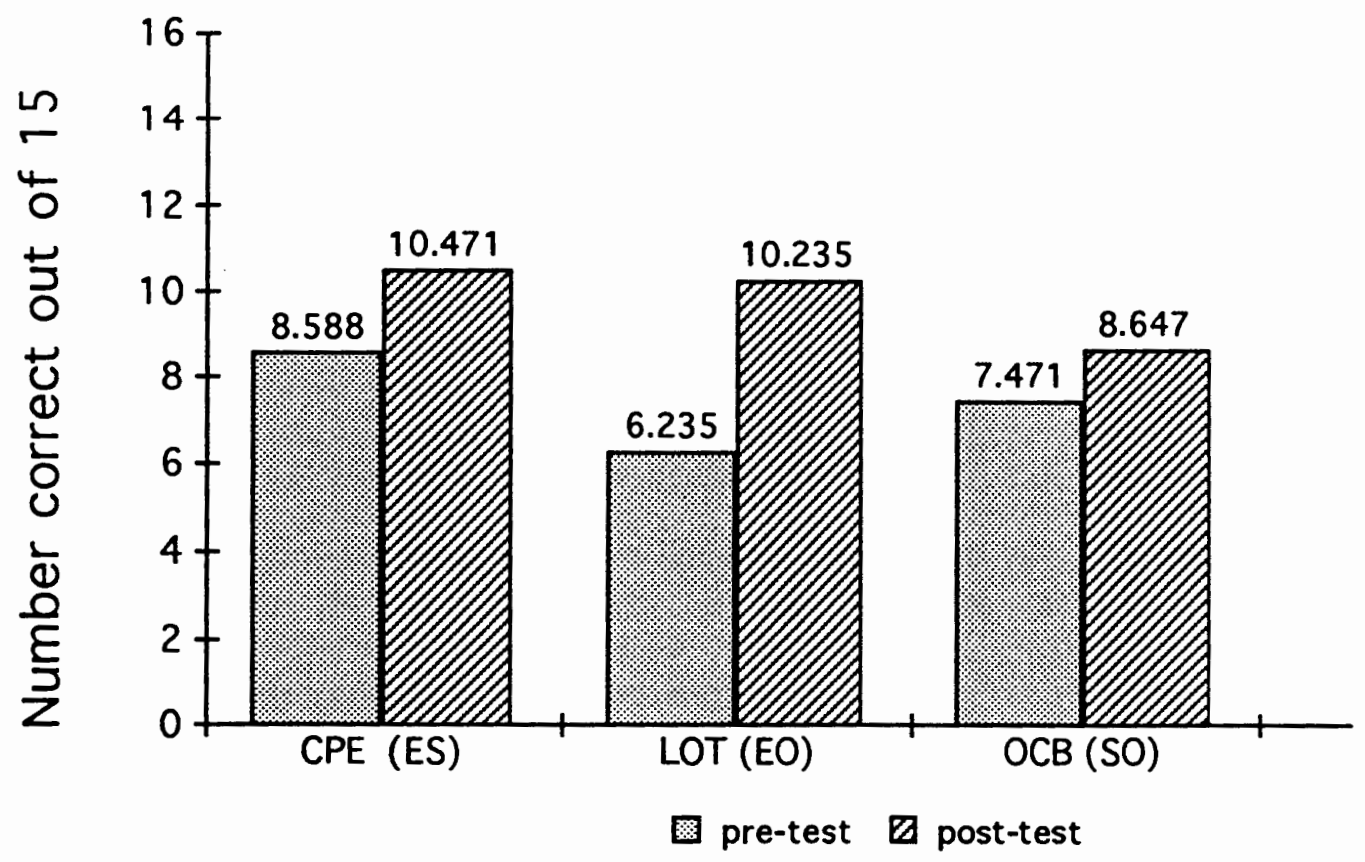

Figure 3. Group 3 mean scores on pre- and posttests by story (with treatment type).

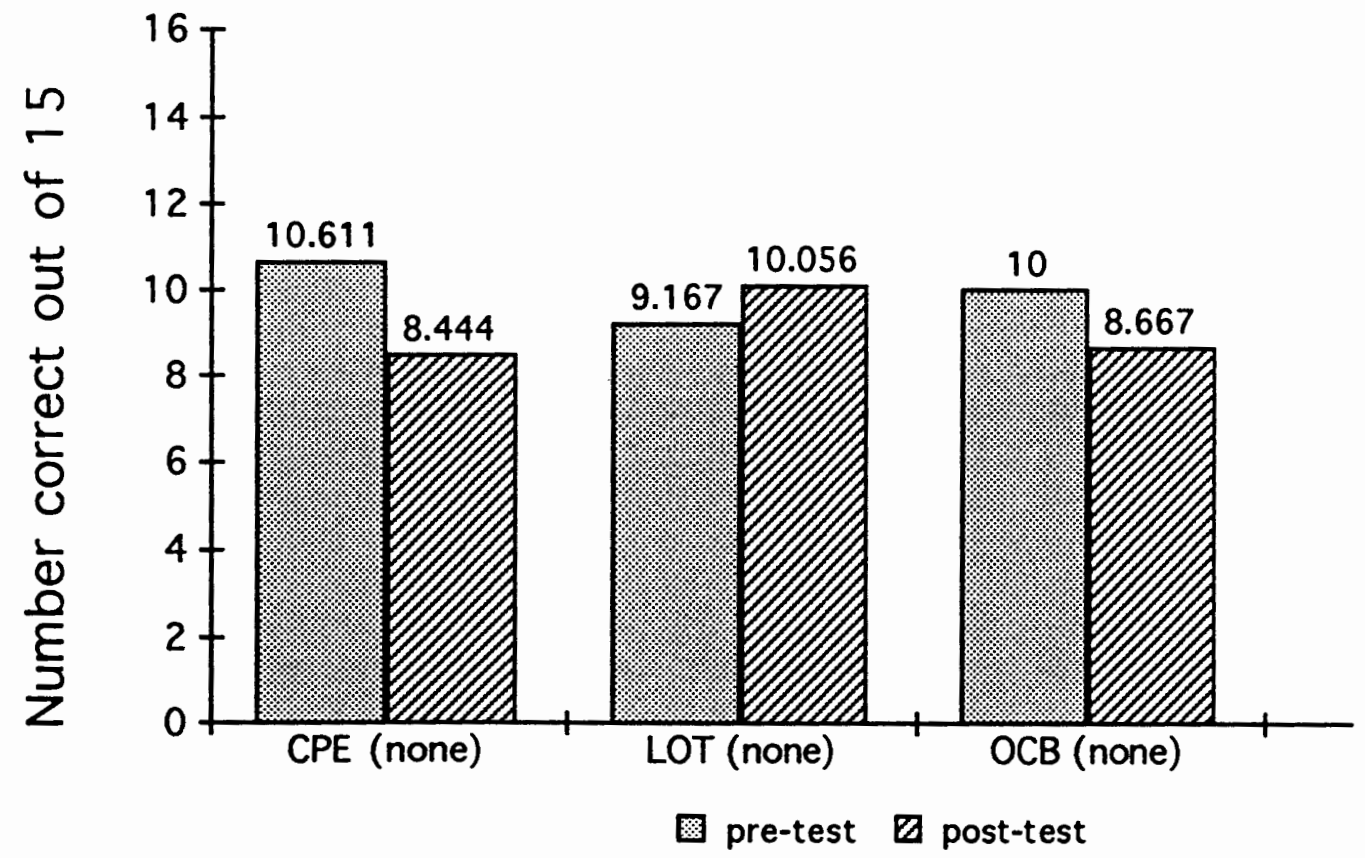

Figure 4. Group 4 (control group) mean scores on pre- and post-tests by story. 


\section{RESTATEMENT OF HYPOTHESES}

As stated in chapter $I$, the main questions posed by this study were whether reading simplified stories alone would help students learn any vocabulary at all, and whether reading alone would help students learn significantly more vocabulary than the other two methods to be compared.

Based on these questions, the following hypotheses were proposed :

1. That mean pre-test scores would not vary significantly among the three sets of test words within the pre-test for any of the treatment or control groups.

2. That the so treatment would produce significantly higher vocabulary learning than the ES treatment, which would produce significantly higher vocabulary learning than the EO treatment, as measured by the post-test.

3. That there would be no significant improvement in vocabulary learning by the control group, as measured by the post-test.

The dependent variables were (a) the three subject groups, (b) the three sets of 15 test words, one set from each of the three stories, and (c) the type of treatment under which those words were taught (SO: within a story, EO: within exercises, or ES: within both exercises and a related story). The independent variable was the improvement between subjects' pre- and post-test scores. The pre- and post-tests tested subjects' knowledge of the three sets of 15 words.

Within the discussion of the data analyses following, attempts are made to relate the results to these hypotheses. 


\section{ANALYSES}

\section{Introduction}

In a three-way experimental design such as the one in this study, there are at least three main combinations in which the data can be compared. This study uses all three of these ways: The analyses compare the numeric expressions of the independent variable (improvement between pre- and post-test scores) between the three dependent variables. Thus, score gains are compared between the three groups, between the three stories, and between the three treatment types. Several other kinds of comparisons are made as well.

\section{Comparison of Groups}

This particular analysis attempted to answer the question whether or not the subjects were all of comparable ability before the experiment began. Since no other basis of comparison, such as TOEFL or other test scores existed, it was necessary to compare subjects' scores on the pretest. Pre-test data reported in several tables (for example, Table VI abovel show the variability in pre-test scores.

Part of the variability in pre-test scores could have been due to the form of the pre-test itself, rather than to variations in the actual English ability of the subjects. One the one hand, the appropriateness of the pre-test for the task of measuring vocabulary knowledge has been 
substantiated; on the other, the form of the pre-test was not necessarily valid for measuring language proficiency level. That is, to judge total language ability from a test of one small aspect of language, as a measure of variability among subjects, might be invalid. Yet, Group 3, which performed significantly lower overall on the pre-test, also performed significantly lower overall on the post-test. As discussed in Chapter III, the paradox is that Group 3 had been judged subjectively the highest ability group by its teachers and by the researcher.

Table VII below gives the data used in ANOVA tests for significance between the pre-test scores. In all cases, ANOVA found significant differences, with $p<.05$. It could be argued that the differences, though statistically significant, were, however, not meaningful differences (or certainly would not be in the realm of the classroom). However, this assertion cannot be, and is not argued here, since the differences among pre-test scores are similar in size to some of the gains between pre- and post-test scores, and these gains must be seen as both statistically significant and meaningful. 
TABLE VII

COMPARISON OF ALL 4 GROUPS, PRE-TESTS ONLY

ANOVA table for a 2-factor ${ }^{\star \star}$ Repeated Measures ANOVA

$\Sigma$ of Mean

\begin{tabular}{lccccc} 
Source & df & Squares & Square & F-test & $p$ value \\
\hline Group (A) & 3 & 396.77 & 132.26 & 17.65 & $.0001^{\star}$ \\
\hline Subjects W/ Groups & 80 & 599.55 & 7.49 & & \\
\hline Repeated Measure (B) & 2 & 64.58 & 32.29 & 24.59 & $.0001^{\star}$ \\
\hline Interaction btwn A\&B & 6 & 20.68 & 3.45 & 2.63 & $.0187^{\star}$ \\
\hline B X Subjects w/ Grps & 160 & 210.07 & 1.31 & & \\
\hline
\end{tabular}

AB Incidence table

\begin{tabular}{lrrrr}
\hline $\begin{array}{l}\text { Repeated } \\
\text { Measure }\end{array}$ & $\begin{array}{c}\text { post } \\
\text { CPE }\end{array}$ & $\begin{array}{c}\text { post } \div \text { pre } \\
\text { LOT }\end{array}$ & $\begin{array}{c}\text { post } \div \text { pre } \\
\text { OCB }\end{array}$ & Totals \\
\hline Group 1 & 24 & 24 & 24 & 72 \\
& 10.96 & 10.58 & 10.96 & 10.83 \\
\hline Group 2 & 25 & 25 & 25 & 75 \\
& 11.08 & 9.92 & 10.40 & 10.47 \\
\hline Group 3 & 17 & 17 & 17 & 51 \\
& 8.59 & 6.24 & 7.47 & 7.43 \\
\hline Group 4 & 18 & 18 & 18 & 54 \\
& 10.61 & 9.17 & 10.00 & 9.93 \\
\hline Totals & 84 & 84 & 84 & 252 \\
& 10.44 & 9.20 & 9.88 & 9.84 \\
\hline
\end{tabular}

\footnotetext{
${ }^{\star \star}$ Factor $1=$ Group (A), factor $2=$ Repeated Measure (B).

* Significant at $p<.05$
} 


\section{Comparison of stories}

The next three tables, VIII, IX, and $X$, compare all four groups' performances on each of the three stories, one story only per table (CPE, LOT, and OCB, respectively). Following these three tables are three figures which represent the information in those tables in graph form. Figures 5 through 7 represent Tables VIII, IX, and X, respectively.

\section{TABLE VIII}

MEAN SCORES ON PRE- AND POST-TESTS IN ORDER BY GROUP, CPE ONLY (WITH TREATMENT TYPE), AND IMPROVEMENT OR DECLINE

IN MEAN BETWEEN PRE- AND POST-TESTS FOR GROUPS 1 - 4

\begin{tabular}{|c|c|c|c|c|c|}
\hline & $\begin{array}{c}\text { story } \\
\text { ( \& treatment) }\end{array}$ & $\begin{array}{l}\text { Pre- } \\
\text { test }\end{array}$ & $\begin{array}{l}\text { Post- } \\
\text { test }\end{array}$ & $\begin{array}{l}\text { Gain } \\
\text { in mea } \\
\text { pre- \& } \\
\text { Points }\end{array}$ & $\begin{array}{r}\begin{array}{r}\langle\text { loss }\rangle \\
\text { between }\end{array} \\
\text { post-test }\end{array}$ \\
\hline GROUP 1 & CPE (EO) & 10.958 & 13.667 & 2.709 & $18.060 \%$ \\
\hline GROUP 2 & $\mathrm{CPE}$ (SO) & 11.080 & 9.760 & $\langle 1.320\rangle$ & $\langle 8.800 \%\rangle$ \\
\hline GROUP 3 & CPE (ES) & 8.588 & 10.471 & 1.883 & $12.553 \%$ \\
\hline GROUP 4 & CPE (none) & 10.611 & 8.444 & $\langle 2.167\rangle$ & $\langle 14.4478\rangle$ \\
\hline \multicolumn{6}{|c|}{ Groups $1-3$ only } \\
\hline
\end{tabular}


TABLE IX

MEAN SCORES ON PRE- AND POST-TESTS IN ORDER BY GROUP, LOT ONLY (WITH TREATMENT TYPE), AND IMPROVEMENT OR DECLINE

IN MEAN BETWEEN PRE- AND POST-TESTS FOR GROUPS 1 - 4

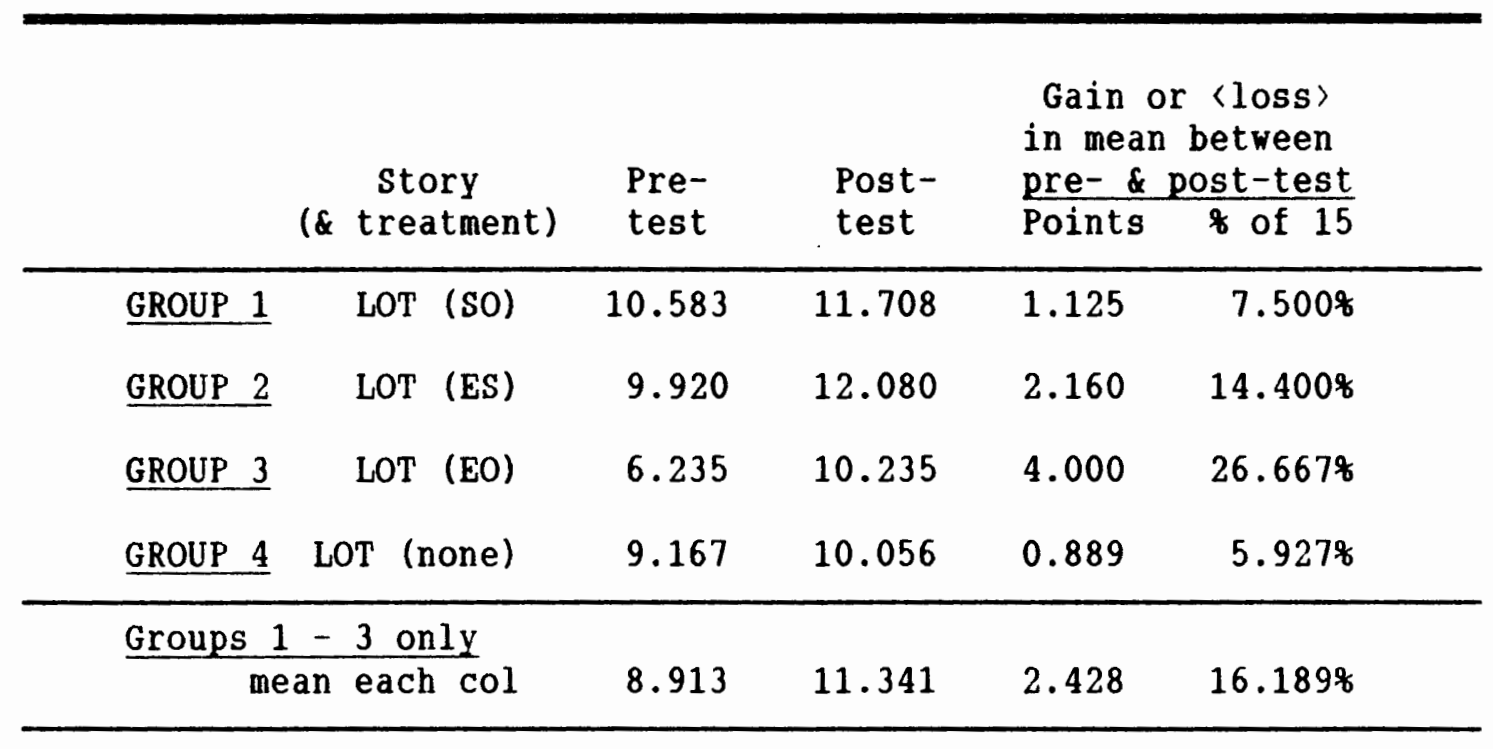

TABLE X

MEAN SCORES ON PRE- AND POST-TESTS IN ORDER BY GROUP, OCB ONLY (WITH TREATMENT TYPE), AND IMPROVEMENT OR DECLINE IN MEAN BETWEEN PRE- AND POST-TESTS FOR GROUPS 1 - 4

\begin{tabular}{|c|c|c|c|c|c|}
\hline & \multirow{2}{*}{$\frac{\begin{array}{c}\text { Story } \\
\text { (\& treatment) }\end{array}}{\text { OCB (ES) }}$} & \multirow{2}{*}{$\begin{array}{l}\begin{array}{l}\text { Pre- } \\
\text { test }\end{array} \\
10.958\end{array}$} & \multirow{2}{*}{$\begin{array}{l}\begin{array}{l}\text { Post- } \\
\text { test }\end{array} \\
13.875\end{array}$} & \multicolumn{2}{|c|}{$\begin{array}{l}\text { Gain or 〈Ioss〉 } \\
\text { in mean between } \\
\text { pre-\& post-test } \\
\text { Points } \% \text { of } 15\end{array}$} \\
\hline GROUP 1 & & & & 2.917 & $19.447 \%$ \\
\hline GROUP 2 & OCB (EO) & 10.400 & 12.200 & 1.800 & $12.000 \%$ \\
\hline GROUP 3 & $\mathrm{OCB} \quad(\mathrm{SO})$ & 7.471 & 8.647 & 1.176 & $7.840 \%$ \\
\hline GROUP 4 & OCB (none) & 10.000 & 8.667 & $\langle 1.333\rangle$ & $\langle 8.8878\rangle$ \\
\hline \multicolumn{6}{|c|}{ Groups $1-3$ only } \\
\hline
\end{tabular}




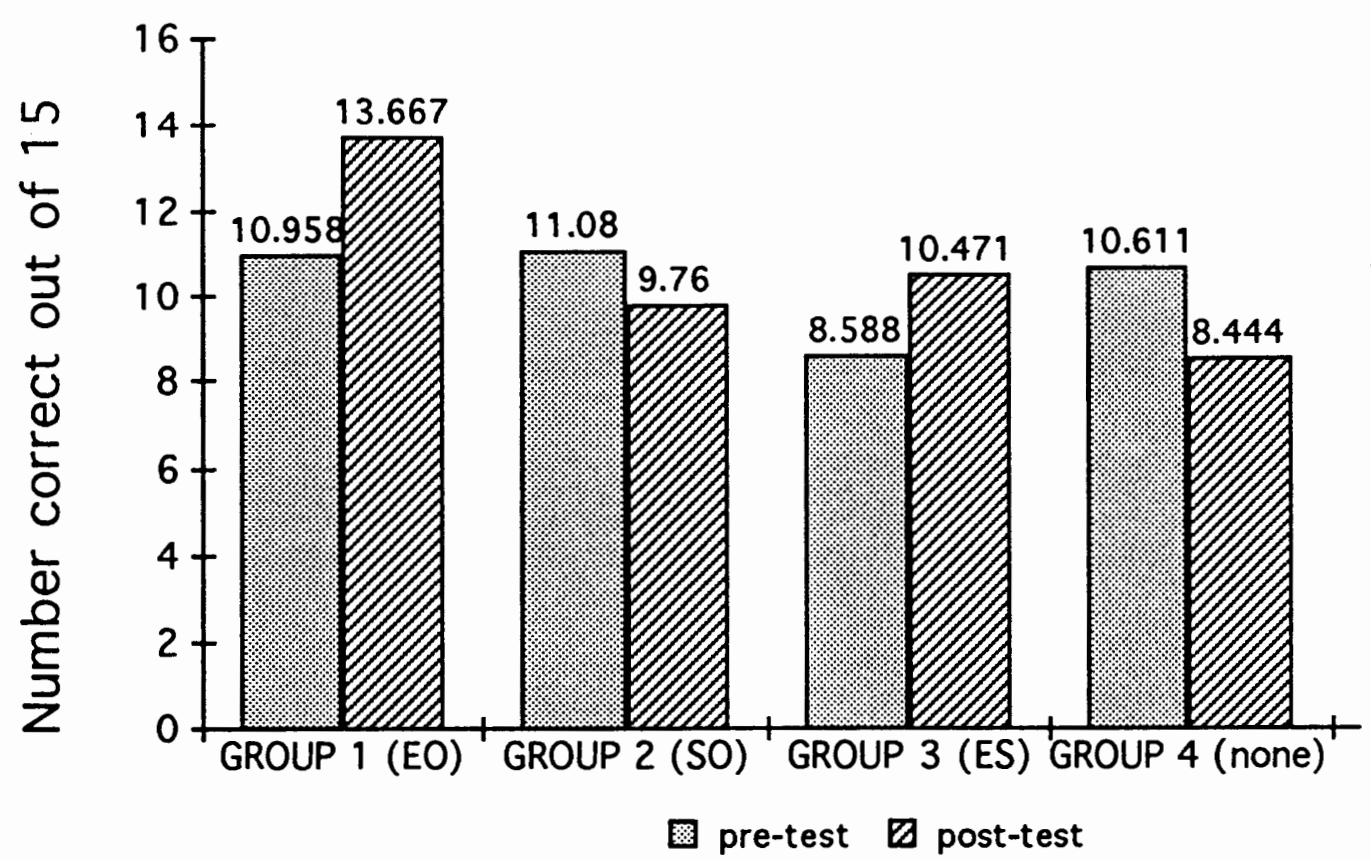

Figure 5. Mean scores on pre- and post-tests for CPE only, by group (with treatment type).

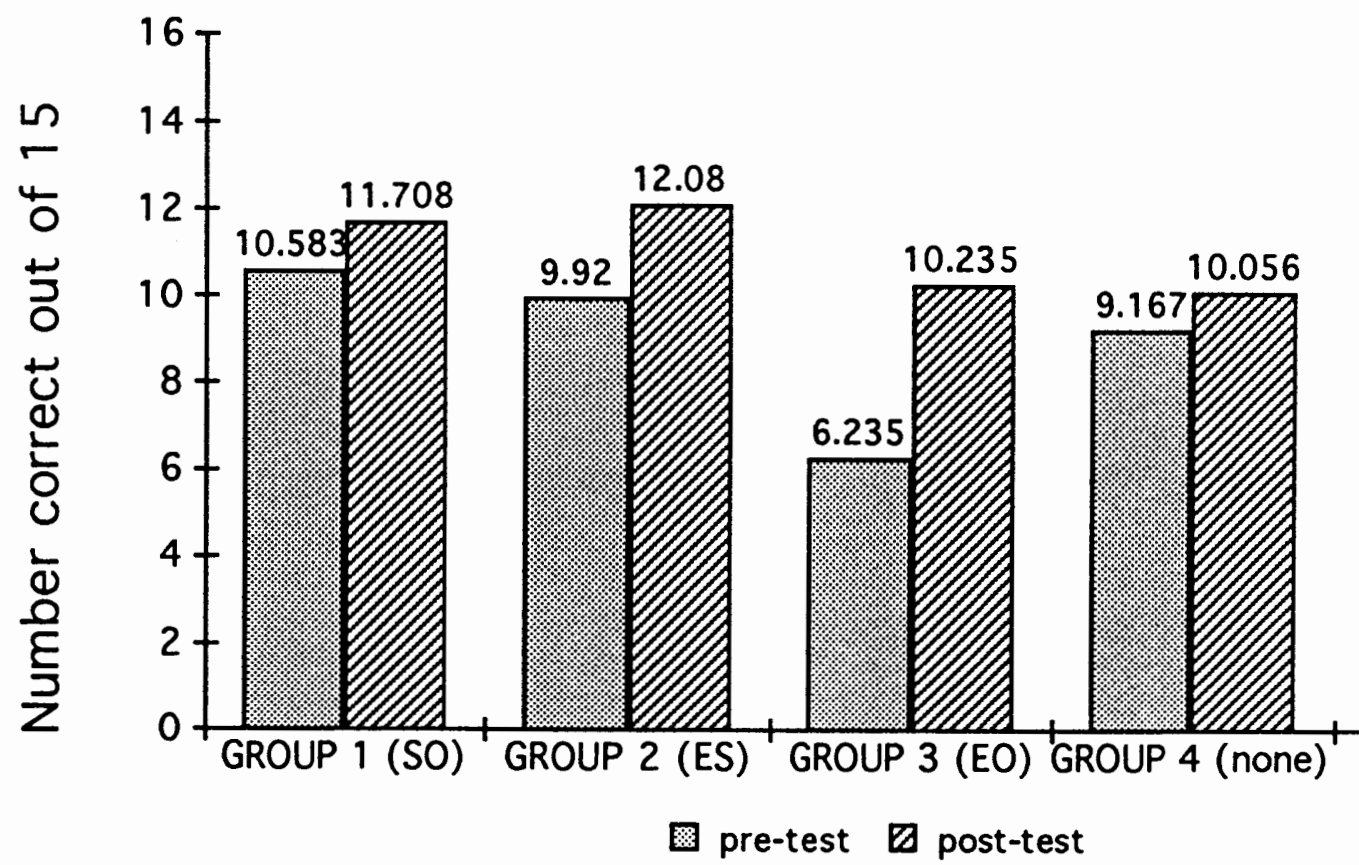

Figure 6. Mean scores on pre- and post-tests for LOT only, by group (with treatment type). 


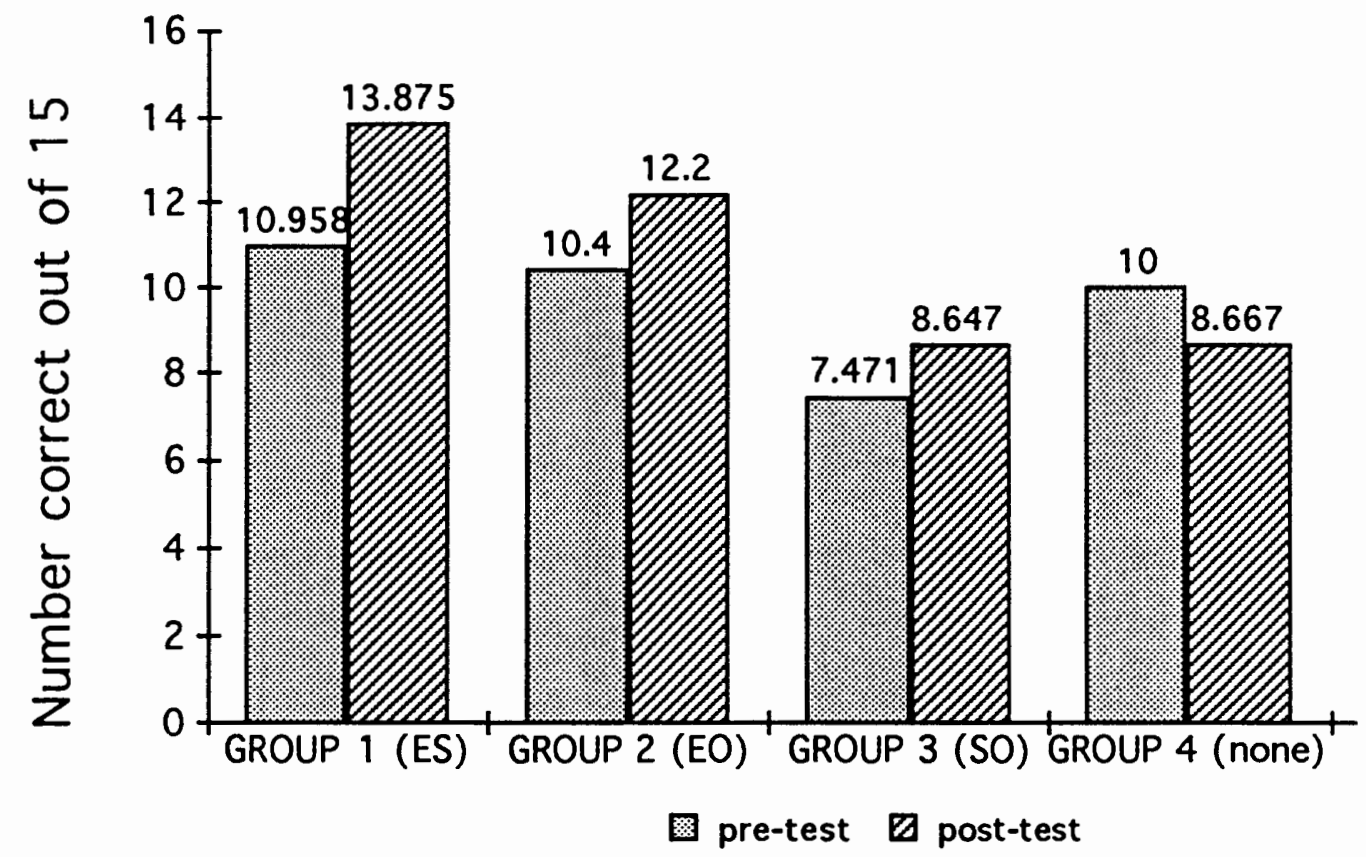

Figure 7. Mean scores on pre- and post-tests for OCB only, by group (with treatment type).

Table XI below summarizes VIII, IX, and X by comparing the total means for each story, excluding the performance of the control group (thus, the data in Table XI comes from the "mean each column" line of Tables VIII, IX, and X). Figure 8 below is a graphic representation of Table XI.

As Table XI shows, CPE produced a lower mean gain across the three treatment groups than did OCB and LOT, which differ by only 3\%. The difference between CPE's gain compared with the gains for $\mathrm{OCB}$ and LOT was found to be significantly lower by an ANOVA test to be discussed below. Part of the reason for CPE's low overall average is that this is the story on which Group 2 had their $8.8 \%$ loss under the so treatment. (That loss, of course, was the only loss 
TABLE XI

MEANS ACROSS THE THREE TREATMENT GROUPS FOR EACH STORY, LOWEST TO HIGHEST GAIN

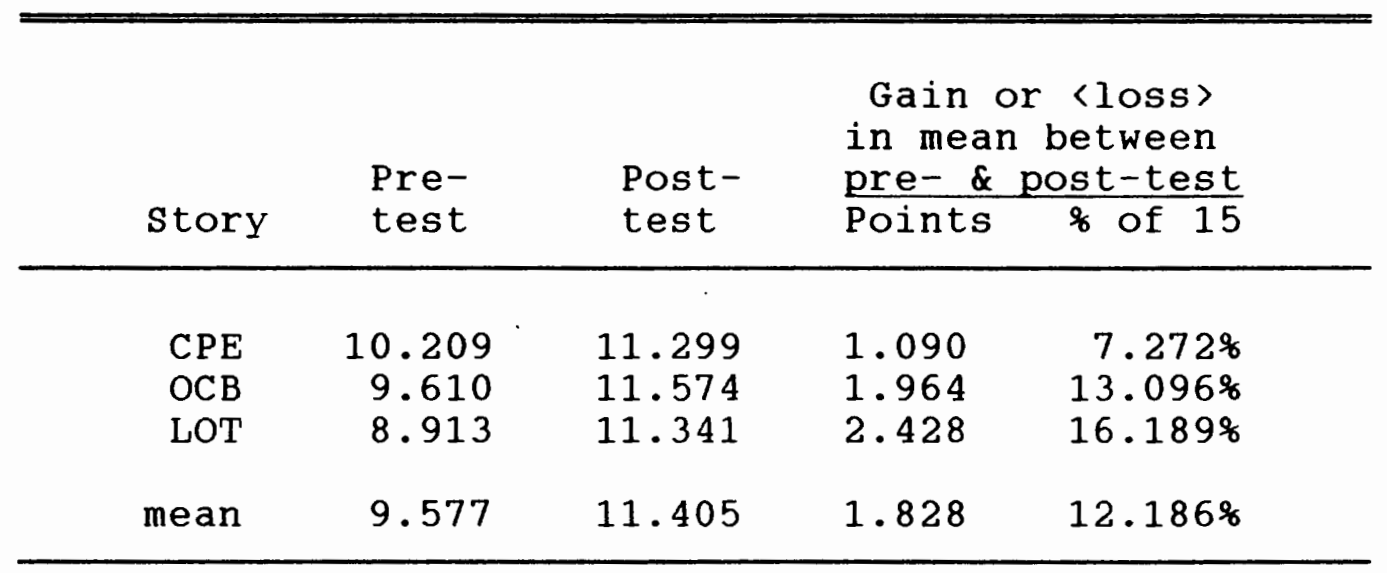

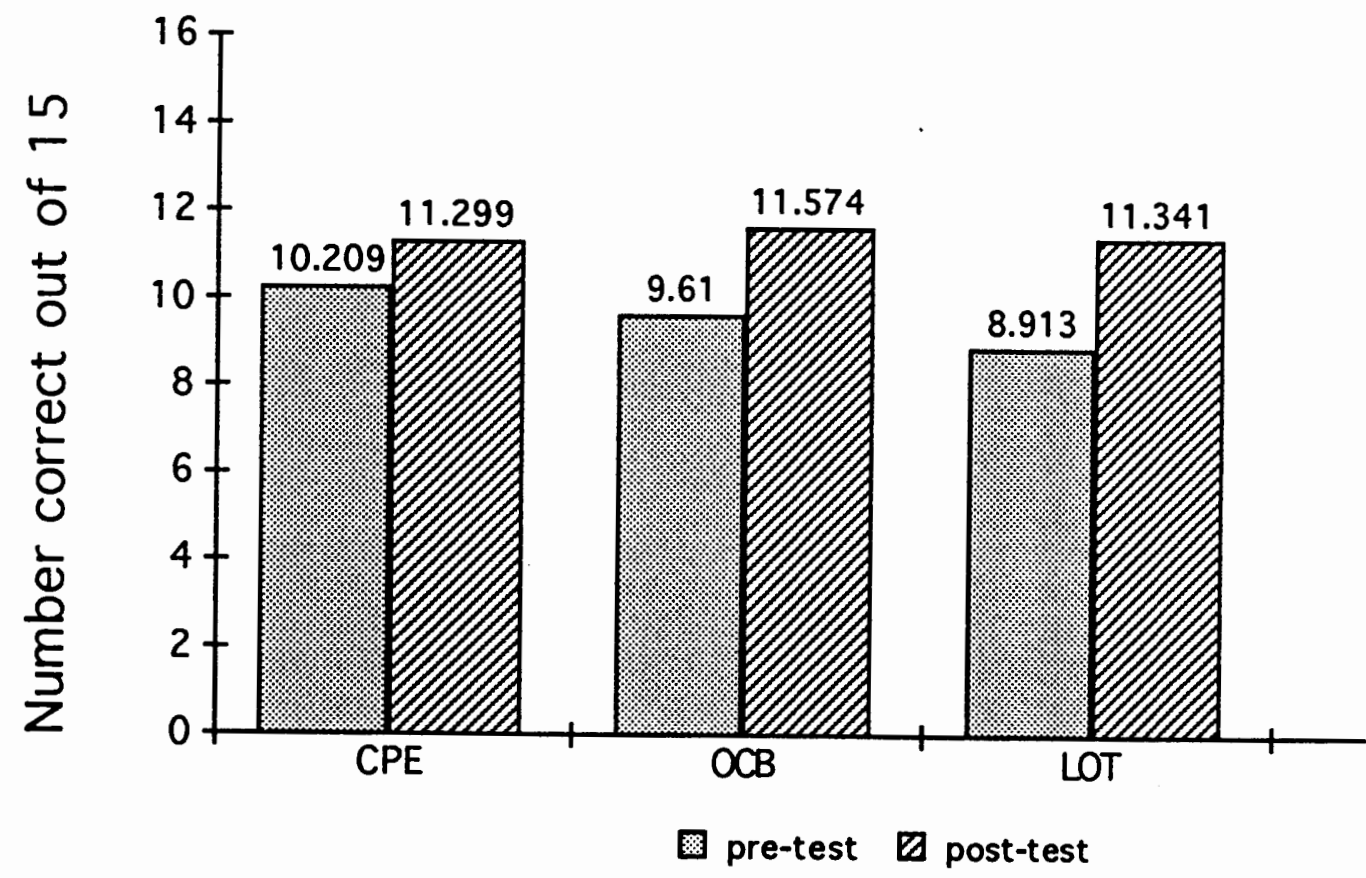

Figure 8. Mean scores on pre- and post-tests, across Groups 1 - 3, by story. 
for a treated group in any 15-word set.) Another factor is that CPE had the highest overall pre-test score, at 10.209, more than a point higher than LOT's, the lowest of the three pre-test story scores. These tables are one way of answering the question whether or not the test words chosen from the three stories were of equal difficulty. objectively the data appear to indicate that CPE was the most difficult story. However, CPE is supposedly the easier of the three, according to Draper's (1993a) guidelines. Furthermore, as shown previously in Table II, CPE was by far the longest story with the most test word occurrences (but the second highest density of test words among test word densities that varied only slightly from each other), and so would have more potential for reinforcing its vocabulary. Perhaps because of the relatively small subject population, the question of equal difficulty cannot be completely and accurately answered in this study.

It was also predicted in chapter III that OCB might have the lowest post-test scores and/or pre- to post-test gains. This prediction was made on the basis of two factors: (1) the density and number of occurrences of test words in OCB was the lowest of the three stories, and thus OCB might not provide adequate context and repetition for the learning of those words; and (2) vocabulary learning from $O C B$ might be negatively affected by the negative mood and emotions generated by the story. As Table XI shows, 
neither of these predictions were fulfilled. In fact, OCB had the highest post-test score and the second-highest score gain across Groups 1 - 3 .

The following four tables, XII, XIII, XIV, and XV, also help to answer the question whether the words from the three stories were all of equal difficulty. Results in certain segments of the pre- and post-tests would be expected to be equal or nearly equal, if the 45 target words chosen for this study were of equal difficulty. Table XII shows the pre-test means across all four groups for the 15 target words from each story. The lowest mean, for LOT at nearly 9 points, differs from the highest mean, for CPE at more than 10 points, by one and one-third points. This is quite a large difference, especially when compared with some of the gains in performance between pre- and post-tests, which were of similar size.

If only the three treatment groups are compared in the same way, the difference between the highest and lowest means for each story is slightly, but not significantly smaller. This comparison is shown in Table XIII (Table XIII uses the means from the "pre-test" column of Table XI above). The difference between high and low means is still nearly one and one-third points. Furthermore, in both cases--all four groups or the three treated groups only--the order of lowest to highest mean remains the same: LOT, OCB, CPE (this pattern can even be seen in the pre-test results 
for each group individually, as reported in the "pre-test" column of Tables XV above, and XXI to follow). This regular pattern and these comparatively high differences seem to suggest that the words from each story were not of equal difficulty. It may also partly be a reflection of the inaccuracy of the pre-test.

Tables XIV and XV look at results exclusive of those for Group 4, the control group. These two tables tell a different story. Among the three treated groups, for the post-test, highest and lowest results between stories differ by a little less than one-third of one point, a very small difference. Post-test means across all three treated groups for each story would be expected to be nearly identical. In fact, they are, as Table XIV shows. (Note: As Table XIII used the means from the "pre-test" column of Table XI above, so Table XIV uses the means from the "post-test" column of Table XI, but with a different outcome.)

Table XV shows the mean pre-test results across the three treated groups for each of the three treatment types. Here, too, since this is the pre-test, results would be expected to be nearly identical for each set. In fact, they are very close, the highest and lowest means differing by only a little more than half a point. Thus, the results reported in Tables XIV and XV appear to indicate that in fact the 45 target words were after all of nearly equal difficulty, or were at least of more equal difficulty than 
the story-by-story pre-test results las shown in Tables XII and XIII and discussed above) would suggest.

Thus, the analyses are divided. Two approaches to the data (shown in Tables XII and XIII) seem to indicate that the test words were not of equal difficulty, while two other approaches (Tables XIV and XV) seem to indicate the opposite. This discrepancy might be due to the nature of the pre-test itself, that it is an inherently less accurate measure than the post-test (which measured more of the student's knowledge of each word than did the pre-test). Thus, the results varied more widely on the pre-test. On the other hand, the regular LOT-OCB-CPE pre-test pattern must also be accounted for. All four groups individually (for Group 1, OCB and CPE have identical pre-test means of 10.958 points) and corporately followed this pattern in the pre-test. Taken literally, the pattern indicates that the words from LOT were the most difficult, from OCB less difficult, and from CPE least difficult. Perhaps over a larger sample of subjects, the differences would equalize and the pattern would disappear. However, for this study, taking these two sets of seemingly contradictory results together, it appears that there can be no conclusive answer to the question of equal difficulty among the 45 target words. 
TABLE XII

MEANS ACROSS ALL 4 GROUPS FOR EACH STORY, LOWEST TO HIGHEST, PRE-TEST ONLY

\begin{tabular}{|c|c|c|}
\hline \multirow[b]{2}{*}{ story } & \multirow{2}{*}{$\begin{array}{l}\text { Pre- } \\
\text { test }\end{array}$} & $\begin{array}{c}\text { Difference between } \\
\text { highest \& lowest } \\
\text { means }\end{array}$ \\
\hline & & Points $\%$ of 15 \\
\hline $\begin{array}{l}\text { LOT } \\
\text { OCB } \\
\text { CPE }\end{array}$ & $\begin{array}{r}8.976 \\
9.707 \\
10.309\end{array}$ & -1.333 \\
\hline mean & 9.664 & \\
\hline
\end{tabular}

TABLE XIII

MEANS ACROSS ONLY THE THREE TREATMENT GROUPS FOR EACH STORY, LOWEST TO HIGHEST, PRE-TEST ONLY

\begin{tabular}{|c|c|c|}
\hline \multirow[b]{2}{*}{ story } & \multirow{2}{*}{$\begin{array}{l}\text { Pre- } \\
\text { test }\end{array}$} & $\begin{array}{c}\text { Difference between } \\
\text { highest \& lowest } \\
\text { means }\end{array}$ \\
\hline & & Points $\quad$ of of 15 \\
\hline $\begin{array}{l}\text { LOT } \\
\text { OCB } \\
\text { CPE }\end{array}$ & $\begin{array}{r}8.913 \\
9.610 \\
10.209\end{array}$ & -1.296 \\
\hline mean & 9.577 & \\
\hline
\end{tabular}


TABLE XIV

MEANS ACROSS THE THREE TREATMENT GROUPS FOR EACH STORY, LOWEST TO HIGHEST, POST-TEST ONLY

\begin{tabular}{|c|c|c|}
\hline \multirow[b]{2}{*}{ story } & \multirow{2}{*}{$\begin{array}{l}\text { Post- } \\
\text { test }\end{array}$} & $\begin{array}{c}\text { Difference between } \\
\text { highest \& lowest } \\
\text { means }\end{array}$ \\
\hline & & \% of 15 \\
\hline $\begin{array}{l}\text { CPE } \\
\text { LOT } \\
\text { OCB }\end{array}$ & $\begin{array}{l}11.299 \\
11.341 \\
11.574\end{array}$ & -0.275 \\
\hline mean & 11.405 & \\
\hline
\end{tabular}

TABLE XV

MEANS ACROSS THE THREE TREATMENT GROUPS FOR EACH TREATMENT, LOWEST TO HIGHEST, PRE-TEST ONLY

\begin{tabular}{|c|c|c|}
\hline \multirow{2}{*}{$\begin{array}{c}\text { Treat- } \\
\text { ment }\end{array}$} & \multirow{2}{*}{$\begin{array}{l}\text { Pre- } \\
\text { test }\end{array}$} & $\begin{array}{c}\text { Difference between } \\
\text { highest \& lowest } \\
\text { means }\end{array}$ \\
\hline & & Points $\quad 8$ of 15 \\
\hline $\begin{array}{l}\text { EO } \\
\text { SO } \\
\text { ES }\end{array}$ & $\begin{array}{l}9.198 \\
9.711 \\
9.822\end{array}$ & -0.624 \\
\hline mean & 9.577 & \\
\hline
\end{tabular}


Tables XVI - XIX below show the results of ANOVA tests between gains in story means for Groups $1-4$, respectively. Table Xx shows the results of ANOVA comparing all 4 stories together. These tables show the significance of differences reported in the more exhaustive tables, such as XV and XXI. Table XVI shows that, for Group 1, gains for $C P E$ and $O C B$ are not significantly different, while LOT is significantly lower than both $C P E$ and $O C B(p<.05)$. (Note that this was one of only two cases in all the analyses of statistical significance in this study in which the scheffe F-test did not show a significant difference when the Fisher PLSD did). Table XVII shows that, for Group 2, gains for LOT and OCB are not significantly different, while CPE is significantly lower than both LOT and OCB $(p<.05)$. Table XVIII shows that, for Group 3, gains for $\mathrm{CPE}$ and $\mathrm{OCB}$ are not significantly different, while LOT is significantly higher than both CPE and $\mathrm{OCB}(p<.05)$. Finally, Table XIX shows that, for Group 4, the control group, losses for CPE and OCB are not significantly different, while the "gain" for LOT is significantly higher than both $C P E$ and $O C B$.

These patterns seem to indicate that there was some interaction between the particular story and the gain or loss. LOT, in Groups 1, 3, and 4 was the story that carried the most significant differences, while CPE and $O C B$ were generally similar in gain or loss. The exception to this pattern was in Group 2; their deviation from the pattern was 
probably due in part to the "loss" they suffered on CPE's scores.

TABLE XVI

COMPARISON OF STORIES, GROUP 1 ONLY

One Factor ANONA-Repeated Yeasures

\begin{tabular}{cccccc} 
Source & df & $\begin{array}{c}\Sigma \text { of } \\
\text { Squares }\end{array}$ & $\begin{array}{c}\text { Mean } \\
\text { Square }\end{array}$ & F-test & $p$ value \\
\hline Between subjects & 23 & 3.04 & 0.13 & 2.47 & $.0041^{\star}$ \\
\hline Within subjects & 48 & 2.57 & 0.05 & & \\
\hline treatments & 2 & 0.41 & 0.20 & 4.34 & $.0188^{\star}$ \\
\hline residual & 46 & 2.16 & 0.05 & & \\
\hline Total & 71 & 5.61 & & & \\
\hline
\end{tabular}

One Factor ANOVA-Repeated Measures

\begin{tabular}{ccccc} 
Test/Treatment & $\begin{array}{c}\text { N of } \\
\text { Subjects }\end{array}$ & Mean & $\begin{array}{c}\text { Std. } \\
\text { Dev. }\end{array}$ & $\begin{array}{c}\text { Std. } \\
\text { Error }\end{array}$ \\
\hline post $\div$ pre CPE & 24 & 1.28 & 0.29 & 0.06 \\
\hline post $\div$ pre LOT & 24 & 1.13 & 0.30 & 0.06 \\
\hline post $\div$ pre OCB & 24 & 1.29 & 0.23 & 0.05 \\
\hline
\end{tabular}

One Factor ANOVA-Repeated Measures

\begin{tabular}{|c|c|c|c|c|}
\hline Comparison & & $\begin{array}{l}\text { Mean } \\
\text { Diff. }\end{array}$ & $\begin{array}{c}\text { Fisher } \\
\text { PLSD }\end{array}$ & $\begin{array}{l}\text { Scheffe } \\
\text { F-test }\end{array}$ \\
\hline post $\div$ pre CPE & vs. post $\div$ pre LOT & 0.15 & $0.13^{\star}$ & 2.97 \\
\hline post $\div$ pre CPE & vs. post $\div$ pre $O C B$ & -0.01 & 0.13 & 0.02 \\
\hline post $\div$ pre LOT & vs. post $\div$ pre $O C B$ & -0.17 & $0.13^{\star}$ & $3.52^{\star}$ \\
\hline
\end{tabular}

* Significant at $p<.05$ 
TABLE XVII

COMPARISON OF STORIES, GROUP 2 ONLY

One Factor ANOVA-Repeated Measures

\begin{tabular}{cccccc} 
Source & df & $\begin{array}{c}\Sigma \text { of } \\
\text { Squares }\end{array}$ & $\begin{array}{c}\text { Mean } \\
\text { Square }\end{array}$ & F-test & $p$ value \\
\hline Between subjects & 24 & 2.71 & 0.11 & 1.31 & .2053 \\
\hline Within subjects & 50 & 4.30 & 0.09 & & \\
\hline story & 2 & 1.73 & 0.87 & 16.19 & $.0001^{\star}$ \\
\hline residual & 48 & 2.57 & 0.05 & & \\
\hline Total & 74 & 7.01 & & & \\
\hline
\end{tabular}

One Factor ANOVA-Repeated Measures

\begin{tabular}{lcccc} 
Test/Treatment & $\begin{array}{c}\text { N of } \\
\text { Subjects }\end{array}$ & Mean & $\begin{array}{c}\text { Std. } \\
\text { Dev. }\end{array}$ & $\begin{array}{c}\text { Std. } \\
\text { Error }\end{array}$ \\
\hline post $\div$ pre CPE & 25 & 0.90 & 0.21 & 0.04 \\
\hline post $\div$ pre LOT & 25 & 1.25 & 0.36 & 0.07 \\
\hline post $\div$ pre OCB & 25 & 1.18 & 0.22 & 0.04 \\
\hline
\end{tabular}

One Factor ANOVA-Repeated Measures

\begin{tabular}{|c|c|c|c|c|}
\hline Comparison & & $\begin{array}{l}\text { Mean } \\
\text { Diff. }\end{array}$ & $\begin{array}{l}\text { Fisher } \\
\text { PLSD }\end{array}$ & $\begin{array}{l}\text { Scheffe } \\
\text { F-test }\end{array}$ \\
\hline post $\div$ pre CPE & vs. post $\div$ pre LOT & -0.35 & $0.13^{\star}$ & $14.53^{\star}$ \\
\hline post $\div$ pre CPE & vs. post $\div$ pre $O C B$ & -0.28 & $0.13^{\star}$ & $9.13^{\star}$ \\
\hline post $\div$ pre LOT & vs. post $\div$ pre $O C B$ & 0.07 & 0.13 & 0.63 \\
\hline
\end{tabular}

太ignificant at $p<.05$ 
TABLE XVIII

COMPARISON OF STORIES, GROUP 3 ONLY

\section{One Factor ANOVA-Repeated Measures}

$\Sigma$ of Mean

Source df Squares Square F-test $p$ value

\begin{tabular}{cccccc}
\hline Between subjects & 16 & 12.48 & 0.78 & 3.39 & .0014 \\
\hline Within subjects & 34 & 7.83 & 0.23 & & \\
\hline story & 2 & 2.76 & 1.38 & 8.74 & $.0009^{\star}$ \\
\hline residual & 32 & 5.06 & 0.16 & & \\
\hline Total & 50 & 20.31 & & & \\
\hline
\end{tabular}

One Factor ANOVA-Repeated Neasures

N of Std. Std.

Test/Treatment Subjects Mean Dev. Error

\begin{tabular}{lllll}
\hline post $\div$ pre CPE & 17 & 1.31 & 0.57 & 0.14 \\
\hline post $\div$ pre LOT & 17 & 1.77 & 0.78 & 0.19 \\
\hline post $\div$ pre OCB & 17 & 1.24 & 0.41 & 0.10 \\
\hline
\end{tabular}

One Factor ANOVA-Repeated Measures

\begin{tabular}{lllll} 
Comparison & $\begin{array}{c}\text { Mean } \\
\text { Diff. }\end{array}$ & $\begin{array}{c}\text { Fisher } \\
\text { PLSD }\end{array}$ & $\begin{array}{c}\text { Scheffe } \\
\text { F-test }\end{array}$ \\
\hline post $\div$ pre CPE & vs. post $\div$ pre LOT & -0.46 & $0.28^{\star}$ & $5.57^{\star}$ \\
\hline post $\div$ pre CPE & vs. post $\div$ pre OCB & 0.07 & 0.28 & 0.13 \\
\hline post $\div$ pre LOT & vs. post $\div$ pre OCB & 0.53 & $0.28^{\star}$ & $7.41^{\star}$ \\
\hline
\end{tabular}

${ }^{\star}$ Significant at $p<.05$ 
TABLE XIX

COMPARISON OF STORIES, GROUP 4 ONLY

\section{One Factor ANONA-Repeated Measures}

\begin{tabular}{cccccc} 
Source & df & $\begin{array}{c}\sum \text { of } \\
\text { Squares }\end{array}$ & $\begin{array}{c}\text { Nean } \\
\text { Square }\end{array}$ & F-test & $p$ value \\
\hline Between subjects & 17 & 1.56 & 0.09 & 2.00 & .0394 \\
\hline Within subjects & 36 & 1.65 & 0.05 & & \\
\hline story & 2 & 0.90 & 0.45 & 20.34 & $.0001^{\star}$ \\
\hline residual & 34 & 0.75 & 0.02 & & \\
\hline Total & 53 & 3.21 & & & \\
\hline
\end{tabular}

\section{One Factor ANOVA-Repeated Measures}

\begin{tabular}{|c|c|c|c|c|}
\hline Test/Treatment & $\begin{array}{c}N \text { of } \\
\text { Subjects }\end{array}$ & Mean & $\begin{array}{l}\text { Std. } \\
\text { Dev. }\end{array}$ & $\begin{array}{l}\text { Std. } \\
\text { Error }\end{array}$ \\
\hline post $\div$ pre CPE & 18 & 0.81 & 0.22 & 0.05 \\
\hline post $\div$ pre LOT & 18 & 1.11 & 0.21 & 0.05 \\
\hline post $\div$ pre $O C B$ & 18 & 0.88 & 0.21 & 0.05 \\
\hline
\end{tabular}

\begin{tabular}{llccc} 
Comparison & $\begin{array}{c}\text { Mean } \\
\text { Diff. }\end{array}$ & $\begin{array}{c}\text { Fisher } \\
\text { PLSD }\end{array}$ & $\begin{array}{c}\text { Scheffe } \\
\text { F-test }\end{array}$ \\
\hline post $\div$ pre CPE & vs. post $\div$ pre LOT & -0.30 & $0.10^{\star}$ & $18.63^{\star}$ \\
\hline post $\div$ pre CPE & vs. post $\div$ pre OCB & -0.07 & 0.10 & 1.05 \\
\hline post $\div$ pre LOT & vs. post $\div$ pre OCB & 0.23 & $0.10^{\star}$ & $10.82^{\star}$
\end{tabular}

${ }^{\star}$ Significant at $p<.05$ 
TABLE XX

COMPARISON OF STORIES, GROUPS 1, 2, 3, AND 4

ANOVA table for a 2-factor ${ }^{\star \star}$ Repeated Measures ANOVA

$\Sigma$ of $\quad$ Mean

\begin{tabular}{lccccc} 
Source & df & Squares & Square & F-test & $p$ value \\
\hline Group (A) & 3 & 7.31 & 2.44 & 9.85 & $.0001^{\star}$ \\
\hline Subjects w/ Groups & 80 & 19.79 & 0.25 & & \\
\hline Repeated Measure (B) & 2 & 2.03 & 1.01 & 15.38 & $.0001^{\star}$ \\
\hline Interaction btwn A\&B & 6 & 3.77 & 0.63 & 9.55 & $.0001^{\star}$ \\
\hline B x Subjects w/ Grps & 160 & 10.54 & 0.07 & & \\
\hline
\end{tabular}

AB Incidence table

\begin{tabular}{lrrrr}
\hline $\begin{array}{l}\text { Repeated } \\
\text { Measure }\end{array}$ & $\begin{array}{c}\text { post } \div \text { pre } \\
\text { EO }\end{array}$ & $\begin{array}{c}\text { post } \div \text { pre } \\
\text { SO }\end{array}$ & $\begin{array}{c}\text { post } \div \text { pre } \\
\text { ES }\end{array}$ & Totals \\
\hline Group 1 & 24 & 24 & 24 & 72 \\
& 1.28 & 1.13 & 1.29 & 1.23 \\
\hline Group 2 & 25 & 25 & 25 & 75 \\
& 0.90 & 1.25 & 1.18 & 1.11 \\
\hline Group 3 & 17 & 17 & 17 & 51 \\
& 1.31 & 1.77 & 1.24 & 1.44 \\
\hline Group 4 & 18 & 18 & 18 & 54 \\
& 0.81 & 1.11 & 0.88 & 0.93 \\
\hline Totals & 84 & 84 & 84 & 252 \\
& 1.07 & 1.29 & 1.16 & 1.17 \\
\hline
\end{tabular}

${ }_{\star \star \star}^{*}$ Factor $1=$ Group $(\mathrm{A})$, factor $2=$ Repeated Measure (B).

${ }^{\star}$ Significant at $p<.05$ 
Comparison of Treatments

Introduction. Most of the discussion in this section refers to tables in which gains from pre- to post-test are measured simply in points. However, as discussed previously, when analyzing statistical significance in score differences for the three treated groups, gains between preand post-test scores for each treatment were treated as post-test score divided by pre-test score ratios. These ratios were then compared within and between groups for significance. It is important to keep in mind that statistical significance in this analysis is based on the comparison of gains between pre- and post-tests, rather than on comparisons of post-test performance alone, which could be misleading. (see the discussion under "DATA ANALYSES USED" at the end of the previous chapter.)

Furthermore, it was important not to focus on relationships between post-test scores alone, but on relationships between gains from pre- to post-test. For example, hypothetically, treatment $x$ could produce a pretest score of 2 and a post-test score of 7 , for a gain of 5 points; while treatment $Y$ could produce pre- and post-test scores of 11 and 12 respectively for a gain of only 1 point. A 5-point gain would be significantly higher than a 1-point gain. Yet, treatment $Y^{\prime} s$ post-test score of 12 seems significantly higher ( 5 points higher) than treatment $X$ 's of only 7 points. However, treatment $Y$ did not have "as far to 
go" to achieve a post-test score higher than treatment $\mathrm{X}^{\prime} \mathrm{s}$ post-test score. Therefore, to get an accurate picture of a treatment's success relative to other treatments, gains were compared in determining meaningful differences, as were gain ratios as discussed above in determining statistical significance.

order of Treatments. The question might be raised whether the order of the story or treatment within the sequence of tests and treatments had any effect on the scores for that story or treatment. In other words, perhaps Group $A$ had treatment $X$ first, treatment $Y$ next, and treatment $\mathrm{Z}$ last. Since $\mathrm{X}$ was given farther away in time from the post-test, there would be more time for any effect from $X$ to decay. Similarly, since $Z$ was given closer in time to the post-test, there would be less time for $Z^{\prime}{ }^{\prime}$ effect to decay. Thus, we might expect to see lower posttest scores on the $\mathrm{X}$ set, middle scores on the $\mathrm{Y}$ set, and the highest scores on the $\mathrm{Z}$ set, as effects of time-distance from the post-test. The order of story/treatment sets may have had a slight effect on the post-test scores. ISee Table VI above, which shows each group's story/treatment sets in order as the treatments were given. Also see Table I above, which shows an overview of the sequence of tests and treatments.) Though a clear pattern due to treatment order alone does not emerge, the possible interaction between story, treatment, and story/treatment order is 
discussed below. Other factors, to be discussed below, were more clearly responsible for the success or failure of particular treatments.

Success of Treatments. Table XXI below is essentially the same as Table XV above. However, here the 3 story/treatment means are ordered within each group by their success. The treatment with the smallest gain from pre- to post-test appears first. The treatment with the largest appears last.

It is here that a definite pattern begins to emerge. For all three treated groups, so was the least successful treatment. In fact, it was so unsuccessful in Group 2, that it actually produced a loss of nearly 9\%. This is the main cause, incidentally, of Group 2's low overall gain of only about $6 \%$ (as opposed to the overall gains of $15 \%$ for Group 1 and nearly $16 \%$ for Group 3). This loss, the only loss in any of the nine 15-word sets of the treated groups, was one of three "irregularities" in the otherwise regular pattern established by the data.

The second exception is found in Group 3's results. The pattern established by Groups 1 and 2 is that so produced the lowest scores, EO the middle scores, and ES the highest scores. However, as Table XXI notes, in Group 3 the treatments were ordered SO, ES, and EO for least to most successful. ES was not the most successful treatment for Group 3; rather, EO was. 
The third deviation from the expected norm appears in the data for Group 4, the control group. While Group 4's total mean was a loss of almost $6 \%$ from the pre- to the post-test, the results for the 15 words from LOT showed a gain of about 6\%. Ideally, there should be no gains in a control group, even one as small as 6\% (which at least was smaller than any single gain of the treated groups). Ideally, of course, a control group should show little or no gain or loss between tests. The fact that some segments of their performance posted losses and one segment posted a gain, points to the problem of having to use (for expediency's sake) a word-recognition format in the pretest. Perhaps with a more accurate pre-test, the "gain" and "losses" of the control group would have been much closer to zero. Similarly, perhaps Group 2 would not have suffered its "loss" under the so treatment. On the other hand, the format of the pre-test can be defended by pointing out that a pattern according to treatment type did emerge among the treatment groups.

Thus, a clear pattern of less-successful so versus more successful EO/ES did appear, although there were minor aberrations from the pattern in all of the groups except Group 1 .

Figures 9 - 12 below illustrate Table XXI in graph form, one figure per group. 
TABLE XXI

MEAN SCORES ON PRE- AND POST-TESTS IN ORDER BY SUCCESS OF TREATMENT, LEAST TO MOST SUCCESSFUL (WITH STORY), AND IMPROVEMENT OR DECLINE IN MEAN BETWEEN

PRE- AND POST-TESTS FOR GROUPS 1 - 4

\begin{tabular}{|c|c|c|c|c|c|}
\hline & $\begin{array}{l}\text { Treatment } \\
\text { (\& story) }\end{array}$ & $\begin{array}{l}\text { Pre- } \\
\text { test }\end{array}$ & $\begin{array}{l}\text { Post- } \\
\text { test }\end{array}$ & $\begin{array}{l}\text { Gain } \\
\text { in mea } \\
\text { pre- \& } \\
\text { Points }\end{array}$ & $\begin{array}{c}\begin{array}{c}\langle\text { loss }\rangle \\
\text { between }\end{array} \\
\text { post-test } \\
g \text { of } 15\end{array}$ \\
\hline $\begin{array}{l}\text { GROUP } 1 \\
\begin{array}{r}\text { total } \\
\text { mean }\end{array}\end{array}$ & $\begin{array}{l}\text { SO (LOT) } \\
\text { EO (CPE) } \\
\text { ES (OCB) } \\
\text { each col } \\
\text { each col }\end{array}$ & $\begin{array}{l}10.583 \\
10.958 \\
10.958 \\
32.499 \\
10.833\end{array}$ & $\begin{array}{l}11.708 \\
13.667 \\
13.875 \\
39.250 \\
13.083\end{array}$ & $\begin{array}{l}1.125 \\
2.709 \\
2.917 \\
6.751 \\
2.250\end{array}$ & $\begin{array}{r}7.500 \% \\
18.060 \% \\
19.447 \% \\
15.000 \% \\
15.000 \%\end{array}$ \\
\hline $\begin{array}{l}\text { GROUP } 2 \\
\begin{array}{r}\text { total } \\
\text { mean }\end{array}\end{array}$ & $\begin{array}{l}\text { SO (CPE) } \\
\text { EO (OCB) } \\
\text { ES (LOT) } \\
\text { each col } \\
\text { each col }\end{array}$ & $\begin{array}{r}11.080 \\
10.400 \\
9.920 \\
31.400 \\
10.467\end{array}$ & $\begin{array}{r}9.760 \\
12.200 \\
12.080 \\
34.040 \\
11.347\end{array}$ & $\begin{array}{c}\langle 1.320\rangle \\
1.800 \\
2.160 \\
2.640 \\
0.880\end{array}$ & $\begin{array}{l}\langle 8.800 \%\rangle \\
12.000 \% \\
14.400 \% \\
5.867 \% \\
5.867 \%\end{array}$ \\
\hline $\begin{array}{r}\text { GROUP } 3 \\
\begin{array}{r}\text { total } \\
\text { mean }\end{array}\end{array}$ & $\begin{array}{l}\text { SO (OCB) } \\
\text { ES (CPE) } \\
\text { EO (LOT) } \\
\text { each col } \\
\text { each col }\end{array}$ & $\begin{array}{r}7.471 \\
8.588 \\
6.235 \\
22.294 \\
7.431\end{array}$ & $\begin{array}{r}8.647 \\
10.471 \\
10.235 \\
29.353 \\
9.784\end{array}$ & $\begin{array}{l}1.176 \\
1.883 \\
4.000 \\
7.059 \\
2.353\end{array}$ & $\begin{array}{c}7.840 \% \\
12.553 \% \star \\
26.667 \% \text { * } \\
15.687 \% \\
15.687 \%\end{array}$ \\
\hline $\begin{array}{r}\text { GROUP } 4 \\
n \\
n \\
\text { total } \\
\text { mean }\end{array}$ & $\begin{array}{l}\text { one (CPE) } \\
\text { one (OCB) } \\
\text { one (LOT) } \\
\text { each col } \\
\text { each col }\end{array}$ & $\begin{array}{r}10.611 \\
10.000 \\
9.167 \\
29.778 \\
9.926\end{array}$ & $\begin{array}{r}8.444 \\
8.667 \\
10.056 \\
27.167 \\
9.056\end{array}$ & $\begin{array}{c}\langle 2.167\rangle \\
\langle 1.333\rangle \\
0.889 \\
\langle 2.611\rangle \\
\langle 0.870\rangle\end{array}$ & $\begin{array}{r}\langle 14.447 \%\rangle \\
\langle 8.887 \%\rangle \\
5.927 \% \\
\langle 5.802 \%\rangle \\
\langle 5.802 \%\rangle\end{array}$ \\
\hline
\end{tabular}

*For group 3 only, the treatments were ordered SO, ES, and EO for least to most successful, whereas the pattern established by the two other treatment groups was SO, EO, and ES for least to most successful. 


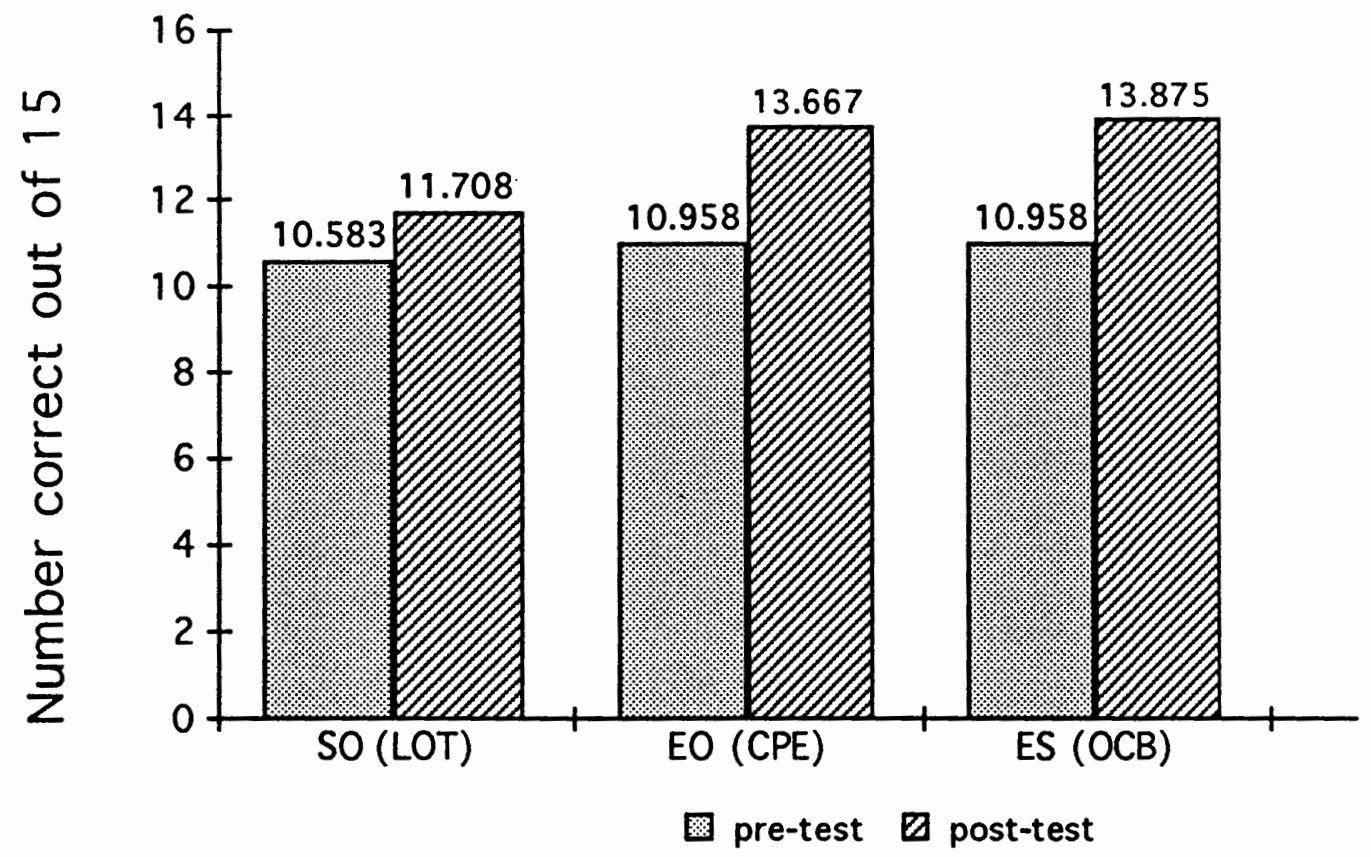

Figure 9. Group 1 mean scores by treatment type from so to ES -- overall least to most successful (with story).

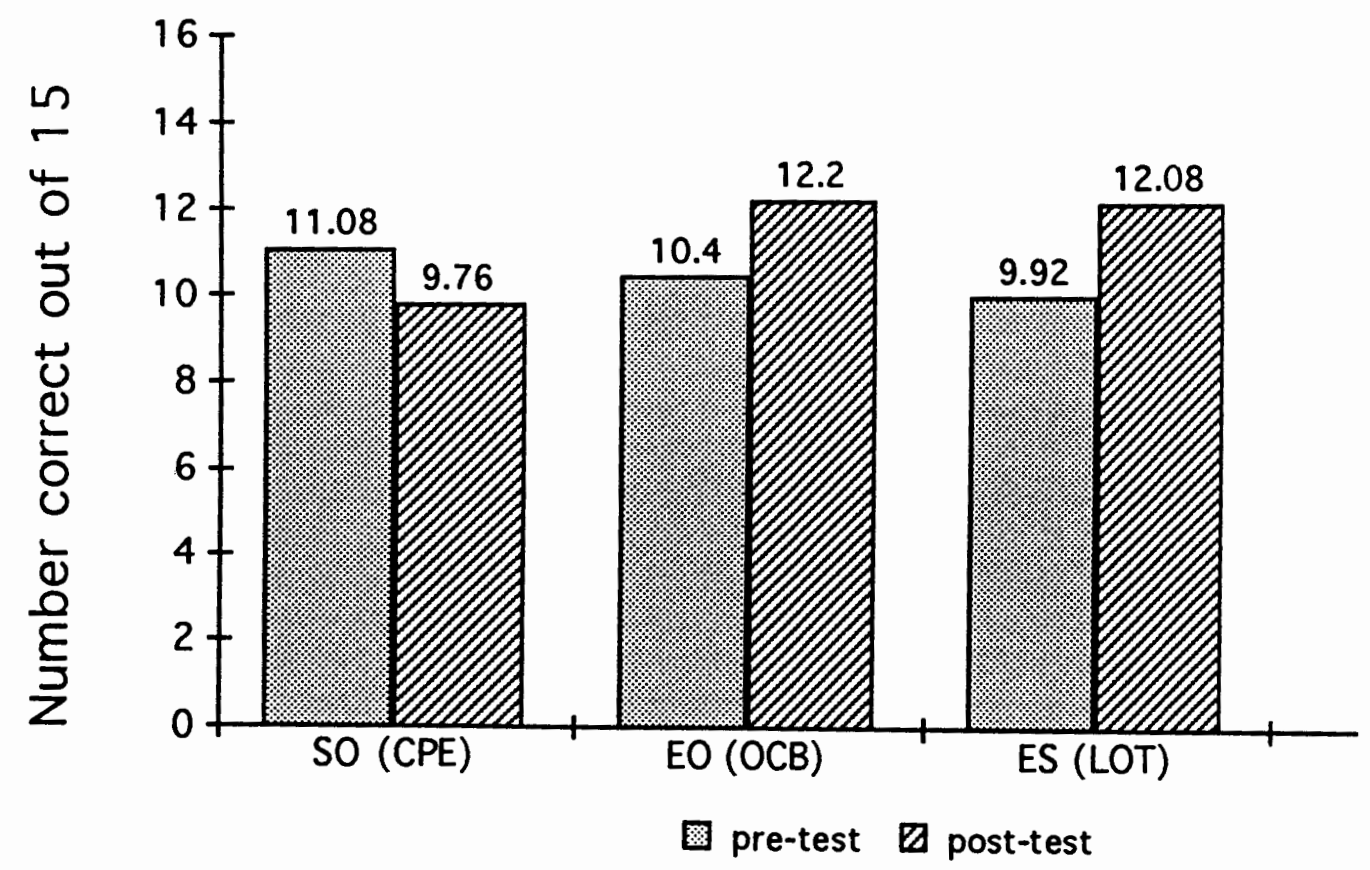

Figure 10. Group 2 mean scores by treatment type from so to ES -- overall least to most successful (with story). 


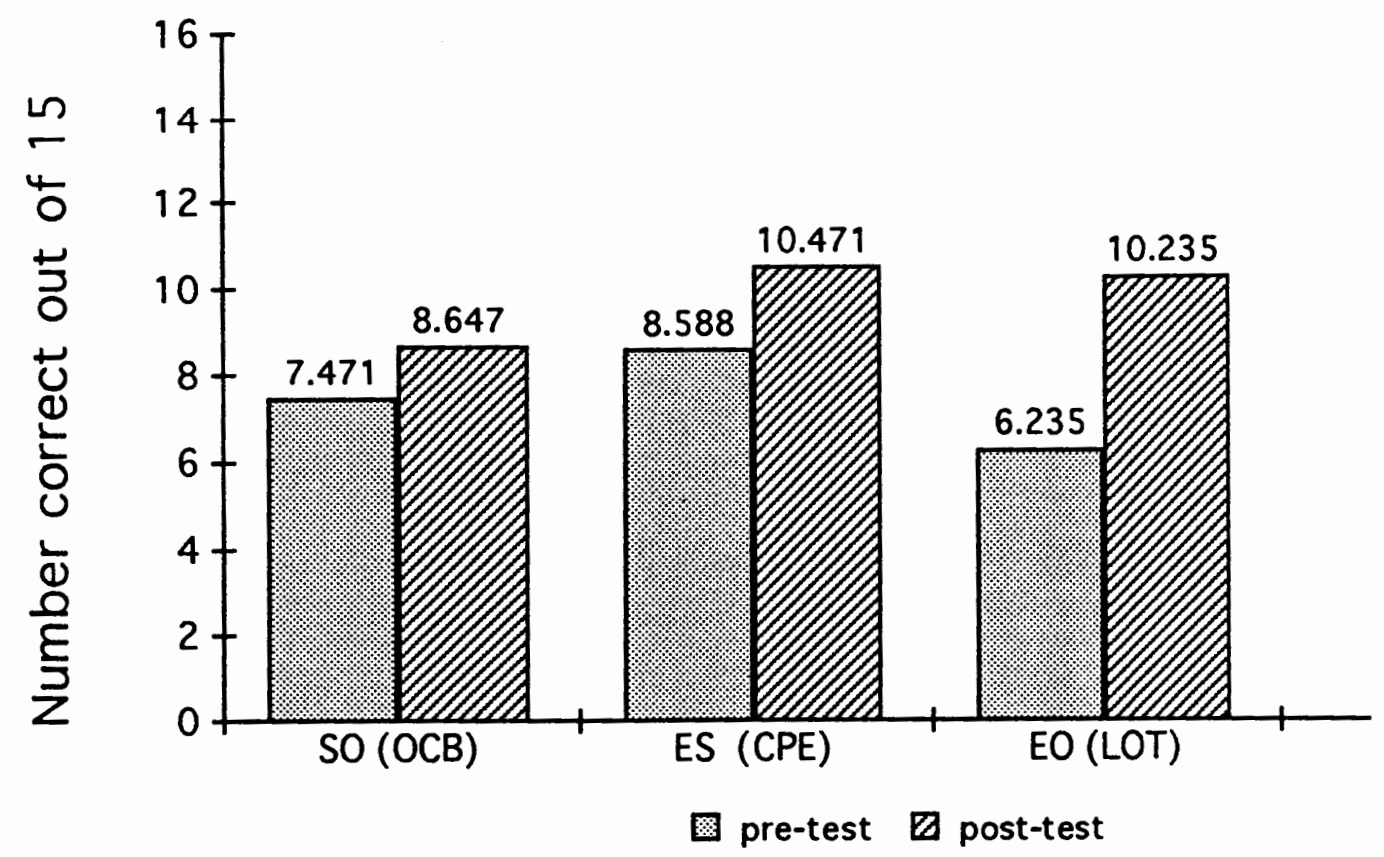

Figure 11. Group 3 mean scores by treatment type from SO to EO - overall least to most successful (with story).

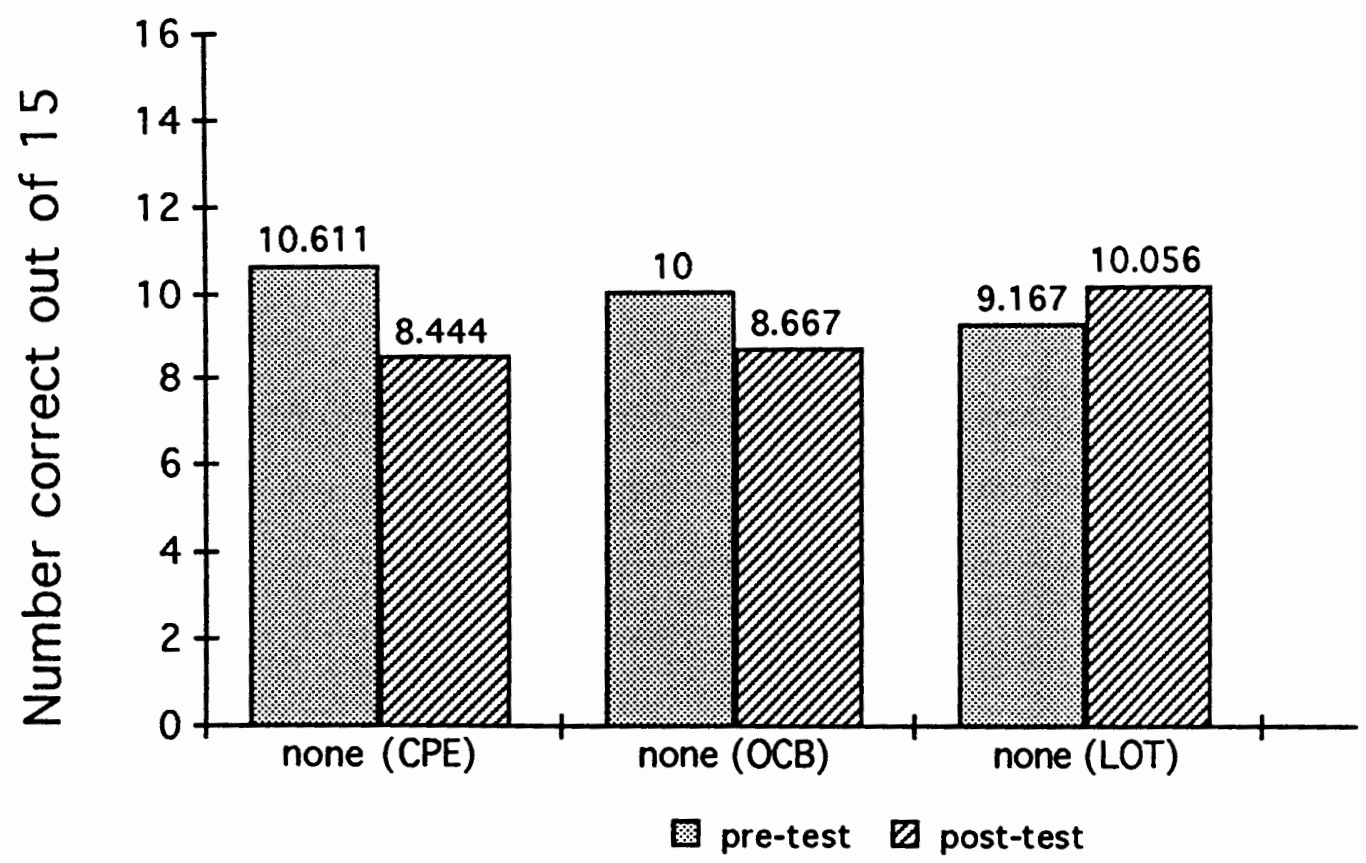

Figure 12. Group 4 mean scores - overall least to most successful (with story). 
The four tables below show the statistical significance of the relationships detailed in Table XXI and its discussion above. These relationships include differences between treatments within each group, and among all three treated groups.

For Tables XXII - XXIV, the results of both the Fisher PLSD and the Scheffe F-tests were used to determine statistical significance. (Note that in Table XXII, the EO versus so comparison showed a significant difference under the Fisher PLSD, but not under the Scheffe F-test. This was the only other time in any of the analyses that the scheffe F-test failed to produce a measure of statistical significance when the Fisher PLSD had.) Tables XXII and XXIII cover the treatment results for Groups 1 and 2 . They show that some of the differences between treatment results were statistically significant. In the least- to mostsuccessful treatment pattern discussed above (SO, EO, ES for Groups 1 and 2), so was found to be significantly worse than EO and ES for both Groups 1 and $2(p<.05)$, but there was no significant difference between the two treatments using exercises, EO and ES, for those two groups.

To summarize, for Groups 1 and 2 , the so treatment produced significantly lower gains than EO or ES. EO and ES produced gains similarly high to each other.

For Group 3 (see Table XXIV), the least- to mostsuccessful pattern as discussed above was slightly 
different: SO, ES, EO. Statistically, Group 3 followed suit with regard to so. For Group 3, so posted the smallest gain. However, the two exercise-using treatments were not both significantly better than so, as they were for Groups 1 and 2: Only EO, the best treatment for Group 3, produced significantly higher gains $(p<.05)$ than treatment so. Treatment ES produced gains similarly small to so, though treatment so still posted the smallest gain.

Finally, Table XXV below shows the results of ANOVA analyses comparing Groups 1,2 , and 3 together. 
TABLE XXII

COMPARISON OF TREATMENTS, GROUP 1 ONLY

\section{One Factor ANOVA-Repeated Yeasures}

\begin{tabular}{cccccc} 
Source & df & $\begin{array}{c}\sum \text { of } \\
\text { Squares }\end{array}$ & $\begin{array}{c}\text { Mean } \\
\text { Square }\end{array}$ & F-test & $p$ value \\
\hline Between subjects & 23 & 3.04 & 0.13 & 2.47 & .0041 \\
\hline Within subjects & 48 & 2.57 & 0.05 & & \\
\hline treatments & 2 & 0.41 & 0.20 & 4.34 & $.0188^{\star}$ \\
\hline residual & 46 & 2.16 & 0.05 & & \\
\hline Total & 71 & 5.61 & & & \\
\hline
\end{tabular}

One Factor ANOVA-Repeated Neasures

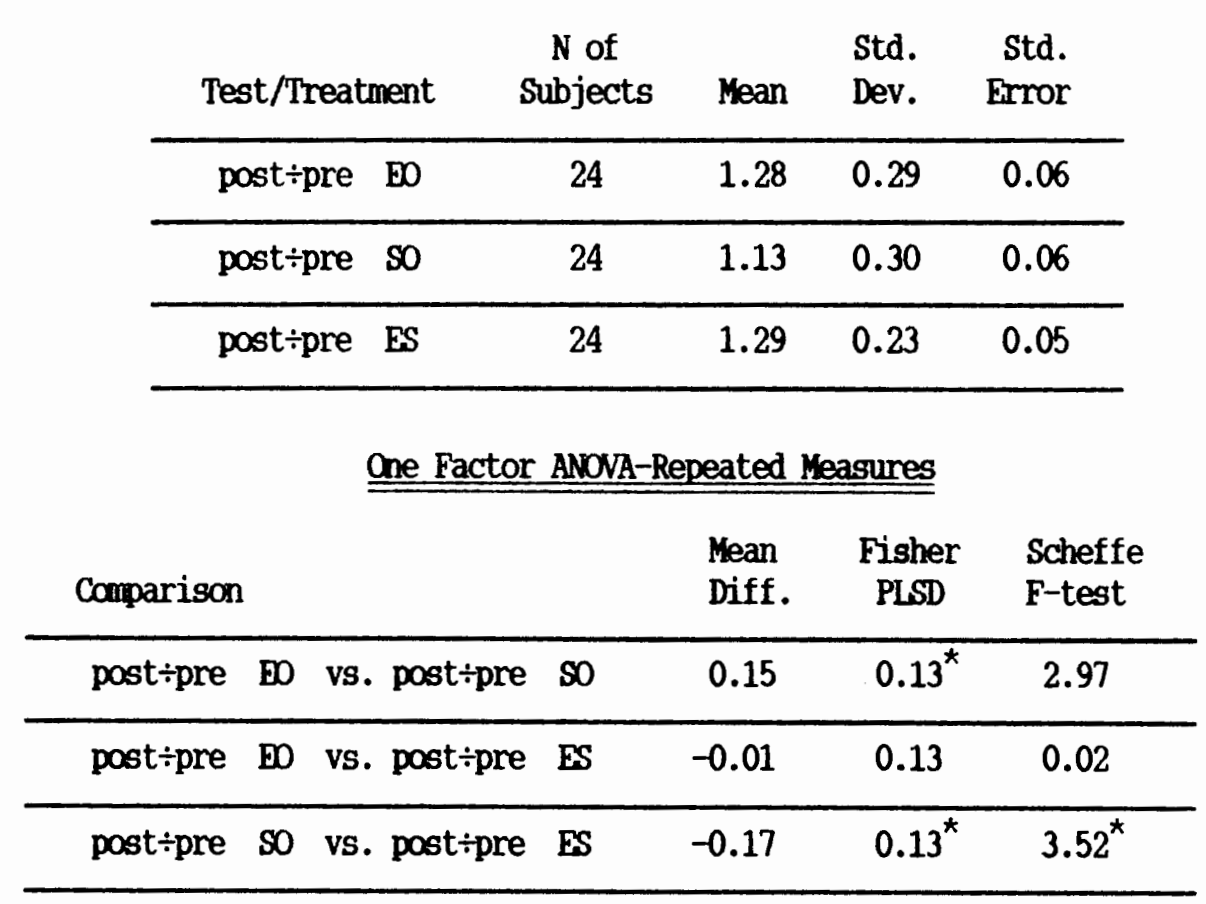

${ }^{\star}$ Significant at $p<.05$ 
TABLE XXIII

COMPARISON OF TREATMENTS, GROUP 2 ONLY

One Factor AlOVA-Repeated Measures

\begin{tabular}{cccccc} 
Source & df & $\begin{array}{c}\sum \text { of } \\
\text { Squares }\end{array}$ & $\begin{array}{c}\text { Mean } \\
\text { Square }\end{array}$ & F-test & $p$ value \\
\hline Between subjects & 24 & 2.71 & 0.11 & 1.31 & .2053 \\
\hline Within subjects & 50 & 4.30 & 0.09 & & \\
\hline treatments & 2 & 1.73 & 0.87 & 16.19 & $.0001^{*}$ \\
\hline residual & 48 & 2.57 & 0.05 & & \\
\hline Total & 74 & 7.01 & & & \\
\hline
\end{tabular}

one Factor ANONA-Repeated Measures

\begin{tabular}{cccccc} 
Test/Treatment & $\begin{array}{c}\text { N of } \\
\text { Subjects }\end{array}$ & Mean & $\begin{array}{c}\text { Std. } \\
\text { Dev. }\end{array}$ & $\begin{array}{c}\text { Std. } \\
\text { Error }\end{array}$ \\
\hline post $\div$ pre & EO & 25 & 1.18 & 0.22 & 0.04 \\
\hline post $\div$ pre & SO & 25 & 0.90 & 0.21 & 0.04 \\
\hline post $\div$ pre ES & 25 & 1.25 & 0.36 & 0.07 \\
\hline
\end{tabular}

One Factor ANOVA-Repeated Measures

\begin{tabular}{|c|c|c|c|c|c|c|}
\hline Comparison & & & & $\begin{array}{l}\text { Mean } \\
\text { Diff. }\end{array}$ & $\begin{array}{l}\text { Fisher } \\
\text { PISD }\end{array}$ & $\begin{array}{l}\text { Scheffe } \\
\text { F-test }\end{array}$ \\
\hline post $\div$ pre & EO & vs. post $\div$ pre & SO & 0.28 & $0.13^{\star}$ & $9.13^{\star}$ \\
\hline post $\div$ pre & EO & vs. post $\div$ pre & ES & -0.07 & 0.13 & 0.63 \\
\hline post $\div$ pre & SO & vs. post $\div$ pre & ES & -0.35 & $0.13^{\star}$ & $14.53^{\star}$ \\
\hline
\end{tabular}

${ }^{\star}$ Significant at $p<.05$ 
TABLE XXIV

COMPARISON OF TREATMENTS, GROUP 3 ONLY

\section{One Factor ANOVA-Repeated Measures}

$\Sigma$ of Mean

Source df Squares Square F-test $p$ value

\begin{tabular}{cccccc}
\hline Between subjects & 16 & 12.48 & 0.78 & 3.39 & $.0014^{\star}$ \\
\hline Within subjects & 34 & 7.83 & 0.23 & & \\
\hline treatments & 2 & 2.76 & 1.38 & 8.74 & $.0009^{\star}$ \\
\hline residual & 32 & 5.06 & 0.16 & & \\
\hline Total & 50 & 20.31 & & & \\
\hline
\end{tabular}

One Factor ANOVA-Repeated Measures

N of Std. Std.

Test/Treatment subjects Mean Dev. Error

\begin{tabular}{llllll}
\hline post $\div$ pre & EO & 17 & 1.77 & 0.78 & 0.19 \\
\hline post $\div$ pre & SO & 17 & 1.24 & 0.41 & 0.10 \\
\hline post $\div$ pre & ES & 17 & 1.31 & 0.57 & 0.14 \\
\hline
\end{tabular}

One Factor ANONA-Repeated Neasures

\begin{tabular}{llllll} 
Comparison & & $\begin{array}{c}\text { Mean } \\
\text { Diff. }\end{array}$ & $\begin{array}{c}\text { Fisher } \\
\text { PLSD }\end{array}$ & $\begin{array}{l}\text { Scheffe } \\
\text { F-test }\end{array}$ \\
\hline post $\div$ pre ED vs. post $\div$ pre & SO & 0.53 & $0.28^{\star}$ & $7.41^{\star}$ \\
\hline post $\div$ pre & EO & vs. post $\div$ pre ES & 0.46 & $0.28^{\star}$ & $5.57^{\star}$ \\
\hline post $\div$ pre SO vs. post $\div$ pre ES & -0.07 & 0.28 & 0.13 \\
\hline
\end{tabular}

${ }^{\star}$ Significant at $p<.05$ 
TABLE XXV

COMPARISON OF TREATMENTS, GROUPS 1,2 , AND 3 ONLY

\begin{tabular}{|c|c|c|c|c|c|}
\hline \multirow[b]{2}{*}{ Source } & \multicolumn{2}{|c|}{2 -factor ${ }^{\star \star}$ Rep } & \multicolumn{3}{|c|}{ peated Measures ANOVA } \\
\hline & df & $\begin{array}{l}\sum \text { of } \\
\text { Squares }\end{array}$ & $\begin{array}{l}\text { Mean } \\
\text { Square }\end{array}$ & F-test & $p$ value \\
\hline Group (A) & 2 & 3.24 & 1.62 & 5.60 & $.0058^{\star}$ \\
\hline Subjects w/ Groups & 63 & 18.23 & 0.29 & & \\
\hline Repeated Measure (B) & 2 & 3.08 & 1.54 & 19.82 & $.0001^{\star}$ \\
\hline Interaction btwn $A \& B$ & 4 & 1.82 & 0.46 & 5.87 & $.0002^{\star}$ \\
\hline B $\times$ Subjects $w /$ Grps & 126 & 9.79 & 0.08 & & \\
\hline
\end{tabular}

$A B$ Incidence table

\begin{tabular}{crrrr}
\hline $\begin{array}{l}\text { Repeated } \\
\text { Measure }\end{array}$ & $\begin{array}{c}\text { post } \div \text { pre } \\
\text { EO }\end{array}$ & $\begin{array}{c}\text { post } \div \text { pre } \\
\text { SO }\end{array}$ & $\begin{array}{c}\text { post } \div \text { pre } \\
\text { ES }\end{array}$ & Totals \\
\hline Group 1 & 24 & 24 & 24 & 72 \\
& 1.28 & 1.13 & 1.29 & 1.23 \\
\hline Group 2 & 25 & 25 & 25 & 75 \\
& 1.18 & 0.90 & 1.25 & 1.11 \\
\hline Group 3 & 17 & 17 & 17 & 51 \\
& 1.77 & 1.24 & 1.31 & 1.44 \\
\hline Totals & 66 & 66 & 66 & 198 \\
& 1.37 & 1.07 & 1.28 & 1.24 \\
\hline
\end{tabular}

${ }^{\star *}$ Factor $1=$ Group $(A)$, factor $2=$ Repeated Measure (B).
${ }^{*}$ Significant at $p<.05$ 
Success of Treatments: Discussion. Tables XXVI and XXVII below are highly-condensed versions of Tables XXI and XXII - XXIV. Table XXVI shows only the pattern of degree of treatment success expected in Hypothesis 2. of this study, as compared with the pattern established by each group in the actual data, while XXVII shows the statistically significant differences in the pattern. Hypothesis 2. predicted that the EO treatment would produce significantly lower vocabulary learning than the ES and so treatments, and the so treatment would produce significantly higher vocabulary learning than the EO and ES treatments, as measured by the post-test.

\section{TABLE XXVI}

EXPECTED AND ACTUAL PATTERNS OF SUCCESS

FOR THE THREE TREATMENT METHODS, LEAST - TO MOST-SUCCESSFUL

\begin{tabular}{ccccc}
\hline & $\begin{array}{c}\text { Hypothe- } \\
\text { sized } \\
\text { pattern }\end{array}$ & $\begin{array}{l}\text { Group 1 } \\
\text { pattern }\end{array}$ & $\begin{array}{l}\text { Group 2 } \\
\text { pattern }\end{array}$ & $\begin{array}{l}\text { Group 3 } \\
\text { pattern }\end{array}$ \\
\hline Least & EO & SO & SO & SO \\
Most & ES & EO & EO & ES \\
& SO & ES & ES & EO \\
\hline
\end{tabular}


TABLE XXVII

EXPECTED AND ACTUAL PATTERNS OF SUCCESS

FOR THE THREE TREATMENT METHODS,

LEAST- TO MOST-SUCCESSFUL, WITH

SIGNIFICANT DIFFERENCES MARKED

\begin{tabular}{|c|c|c|c|c|}
\hline Success & $\begin{array}{l}\text { Hypothe- } \\
\text { sized } \\
\text { pattern }\end{array}$ & $\begin{array}{l}\text { Group } 1 \\
\text { pattern }\end{array}$ & $\begin{array}{l}\text { Group } 2 \\
\text { pattern }\end{array}$ & $\begin{array}{l}\text { Group } 3 \\
\text { pattern }\end{array}$ \\
\hline Least & $\Gamma_{\star}^{\mathrm{EO}} \stackrel{\mathrm{ES}}{\wedge}$ & $\Gamma_{*}^{\mathrm{SO}}$ & $\prod_{*}^{\text {SO }}$ & $\Gamma_{*}^{S O}$ \\
\hline Most & Lso_^ & $L_{E S}$ & LES & LEO_^ \\
\hline
\end{tabular}

${ }^{\star}$ Significant at $p<.05$

Hypothesis 2. proposed that EO would be least successful because exercises are one of the least effective ways to teach vocabulary (Gidmark, 1982; Krashen, 1986). Exercises often have little context, and so of ten do not promote true comprehension or learning, especially not the learning of collocations (stoller \& Grabe, 1993). Furthermore, ES would be next highest in success because, as Hudson (1982), Taglieber et al. (1988), and Seal (1991) reported, it is a successful vocabulary learning technique, but only with lower ability students. Finally, on the enthusiastic recommendation of Krashen's (1986) "hooked-onbooks" reading solution to the need for more vocabulary, it was hoped that so would prove to be the most successful method. Hypothesis 2. was not supported, either in whole 
or in part. Rather, as discussed above, a different pattern of less-successful so vs. more successful EO/ES emerged. The hoped-for success of the so method was found to be the exact opposite. Likely explanations for this pattern do exist.

First, there are a number of very plausible reasons why the subjects performed poorest on the story-only treatment. The students were probably not aware of the task, nor did the researcher state the task, which was to learn vocabulary from the context of the story. Without a learning goal in mind, the students may have been totally unaware of most of the new vocabulary. Next, their ability level may have been too low to have benefitted from something as unstructured as learning solely from context. Furthermore, it may have been the fault of the stories: Because they were short stories, the students' length of exposure to the words was too short and too infrequent. Finally, other subject-dependent or material-dependent factors, or interactions of these factors may have come into play, such as the influence of gender, learning styles, first language, the Hawthorne effect, or others. None of these variables were controlled for or measured in this study.

Second, subjects may have done better under the vocabulary-only treatment because learning vocabulary from exercises is a task to which they were probably accustomed. Exercise types and the tasks within them would be familiar. 
Even very low ability students would most likely already have experienced learning vocabulary from exercises. Furthermore, vocabulary exercises are highly structured, and their goals are clear and quite obvious. Even without explicit direction, students would realize the goals of a vocabulary exercise. However, it is quite probable that few students would implicitly realize that the goal of reading a story could be to learn new vocabulary from it, as was expected of them under the so treatment.

Finally, treatment ES, combining vocabulary exercises with a related story, seemed to give the students the extra reinforcement they needed to learn the words exceptionally we11. For Groups 1 and 2, the highest scores were produced under this treatment. Apparently, just as Hudson (1982), Taglieber et al. (1988), and seal (1991) would predict, for these lower ability students, rather than interfering with vocabulary learning, the ES combination enhanced it. The initial task of learning vocabulary from the exercises was quite clear. This fresh learning was immediately reinforced with the rich, and now more meaningful context of the story, made more understandable, perhaps, by the pre-reading exercises.

Another reason for ES's success may have been that it made productive/receptive vocabulary connections: The exercises first taught productive (in a sense) vocabulary, then used it receptively in reading the story. Perhaps for 
the proficiency level of the students here, a second set of follow-up exercises to be completed after the story reading, would have improved retention even more. Treatment so did not involve productive vocabulary at all, so perhaps the "productive" use in both EO and in ES gave the students the extra edge. Furthermore, the post-test task called for a receptive use of vocabulary. Perhaps the words learned both receptively and "productively" under ES were easier than those learned only receptively (under $\mathrm{SO}$ ), when the test task called only for receptive use of those words.

Finally, an additional factor in the success of ES might have been the fact that the exposure time to the words under ES was usually a little longer than in the other two treatments. As discussed in Chapter III, the researcher attempted to keep the three treatments to one hour each, so that length of exposure to the words would not become a confounding factor. However, since ES was a combination of the materials in EO and SO, it was very difficult to hold ES to the same length of time, and in fact, ES usually lasted an extra half hour.

Whatever the reasons, perhaps the most important aspect of the treatment success pattern is that for all three groups, results were better when there were vocabulary exercises involved in the treatment (EO or ES), and not as good when there were only stories to read ( $\mathrm{SO}$ ). 
One final approach to the data for treatments is to look at each treatment as a phenomenon across all three groups combined. Tables XXVIII, XXIX, and XXX each detail one of the 3 different treatments. Each table compares the results from the three treated groups for one treatment type only. Then Table XXXI compares the overall across-groups means from Tables XXVIII, XXIX, and XXX. Table XXXI reveals an interesting trend in the data. Looking at each group's performance individually, as in Table XXI above, it appears that at least for Groups 1 and 2 , the ES treatment is slightly more successful than the EO treatment. However, taken together, as in Table XXXI, EO appears to be slightly more successful for the treated groups as a whole. Even though the ES treatment produced a slightly higher overall across-groups average post-test score (12.142 points) than did the EO treatment $(12.034$ points), EO still produced a higher across-groups point/percentage gain (almost 19\% versus about $15.5 \%$ for ES). This seeming discrepancy with the results of the groups individually is partly due perhaps to the very high gain in the results of Group 3's EO treatment of nearly $27 \%$.

Figures 13 - 16 following portray in graph form Tables XXVIII, XXIX, XXX, and XXXI below, respectively. 
TABLE XXVIII

MEAN SCORES ON PRE- AND POST-TESTS IN ORDER BY GROUP, SO TREATMENT ONLY (WITH STORY), AND IMPROVEMENT OR DECLINE IN MEAN BETWEEN PRE- AND POST-TESTS FOR GROUPS $1-3$ ONLY

\begin{tabular}{|c|c|c|c|c|c|}
\hline & $\begin{array}{l}\text { Treatment } \\
\text { (\& story) }\end{array}$ & $\begin{array}{l}\text { Pre- } \\
\text { test }\end{array}$ & $\begin{array}{l}\text { Post- } \\
\text { test }\end{array}$ & $\begin{array}{l}\text { Gain } \\
\text { in mea } \\
\text { pre- } 8 \\
\text { Points }\end{array}$ & $\begin{array}{l}\langle\text { loss }\rangle \\
\text { between } \\
\text { ost-test } \\
8 \text { of } 15\end{array}$ \\
\hline \multirow[t]{2}{*}{ GROUP 1} & & & & & \\
\hline & So (LOT) & 10.583 & 11.708 & 1.125 & $7.500 \%$ \\
\hline \multirow[t]{2}{*}{ GROUP 2} & & & & & \\
\hline & SO (CPE) & 11.080 & 9.760 & $\langle 1.320\rangle$ & $\langle 8.800 \%\rangle$ \\
\hline \multirow[t]{2}{*}{ GROUP 3} & & & & & \\
\hline & SO (OCB) & 7.471 & 8.647 & 1.176 & $7.840 \%$ \\
\hline \multicolumn{2}{|c|}{ mean each col } & 9.711 & 10.038 & 0.327 & $2.180 \%$ \\
\hline
\end{tabular}

TABLE XXIX

MEAN SCORES ON PRE- AND POST-TESTS IN ORDER BY GROUP, EO TREATMENT ONLY (WITH STORY), AND IMPROVEMENT OR DECLINE IN MEAN BETWEEN PRE- AND POST-TESTS FOR GROUPS $1-3$ ONLY

\begin{tabular}{|c|c|c|c|c|}
\hline & $\begin{array}{l}\text { Treatment } \\
\text { ( \& story) }\end{array}$ & $\begin{array}{l}\text { Pre- } \\
\text { test }\end{array}$ & $\begin{array}{l}\text { Post- } \\
\text { test }\end{array}$ & $\begin{array}{l}\text { Gain or 〈loss> } \\
\text { in mean between } \\
\text { pre-\& post-test } \\
\text { Points \& of } 15\end{array}$ \\
\hline \multicolumn{5}{|l|}{ GROUP 1} \\
\hline & EO (CPE) & 10.958 & 13.667 & $18.060 \%$ \\
\hline \multicolumn{5}{|l|}{ GROUP 2} \\
\hline & EO (OCB) & 10.400 & 12.200 & $12.000 \%$ \\
\hline \multicolumn{5}{|l|}{ GROUP 3} \\
\hline & EO (LOT) & 6.235 & 10.235 & $26.667 \%$ \\
\hline mean & each col & 9.198 & 12.034 & 18.9098 \\
\hline
\end{tabular}


TABLE XXX

MEAN SCORES ON PRE- AND POST-TESTS IN ORDER BY GROUP, ES TREATMENT ONLY (WITH STORY), AND IMPROVEMENT OR DECLINE IN MEAN BETWEEN PRE- AND POST-TESTS

FOR GROUPS 1 - 3 ONLY

$\begin{array}{lll} & & \begin{array}{l}\text { Gain or 〈loss〉 } \\ \text { in mean between }\end{array} \\ \text { Treatment } & \begin{array}{l}\text { Pre- } \\ \text { (\& story) }\end{array} & \begin{array}{l}\text { Post }- \\ \text { pre- \& post-test }\end{array} \\ \text { test } & \text { Points } \% \text { of } 15\end{array}$

\begin{tabular}{lllllll}
\hline GROUP 1 & ES (OCB) & 10.958 & 13.875 & 2.917 & 19.4478 \\
\hline \begin{tabular}{l} 
GROUP 2 \\
\hline GROUP 3
\end{tabular} & ES (LOT) & 9.920 & 12.080 & 2.160 & 14.4008 \\
\hline mean each col & 9.822 & 12.142 & 2.320 & 15.4678 \\
\hline
\end{tabular}

TABLE XXXI

MEANS ACROSS THE THREE TREATMENT GROUPS FOR EACH TREATMENT, LEAST TO MOST SUCCESSFUL

\begin{tabular}{|c|c|c|c|c|}
\hline $\begin{array}{c}\text { Treat- } \\
\text { ment }\end{array}$ & $\begin{array}{l}\text { Pre- } \\
\text { test }\end{array}$ & $\begin{array}{l}\text { Post- } \\
\text { test }\end{array}$ & \multicolumn{2}{|c|}{$\begin{array}{l}\text { Gain or 〈loss> } \\
\text { in mean between } \\
\text { pre- \& post-test } \\
\text { Points \& of } 15\end{array}$} \\
\hline $\begin{array}{l}\text { SO } \\
\text { ES } \\
\text { EO }\end{array}$ & $\begin{array}{l}9.711 \\
9.822 \\
9.198\end{array}$ & $\begin{array}{l}10.038 \\
12.142 \\
12.034\end{array}$ & $\begin{array}{l}0.327 \\
2.320 \\
2.836\end{array}$ & $\begin{array}{r}2.180 \% \\
15.467 \% \\
18.909 \%\end{array}$ \\
\hline mean & 9.577 & 11.405 & 1.828 & $12.186 \%$ \\
\hline
\end{tabular}




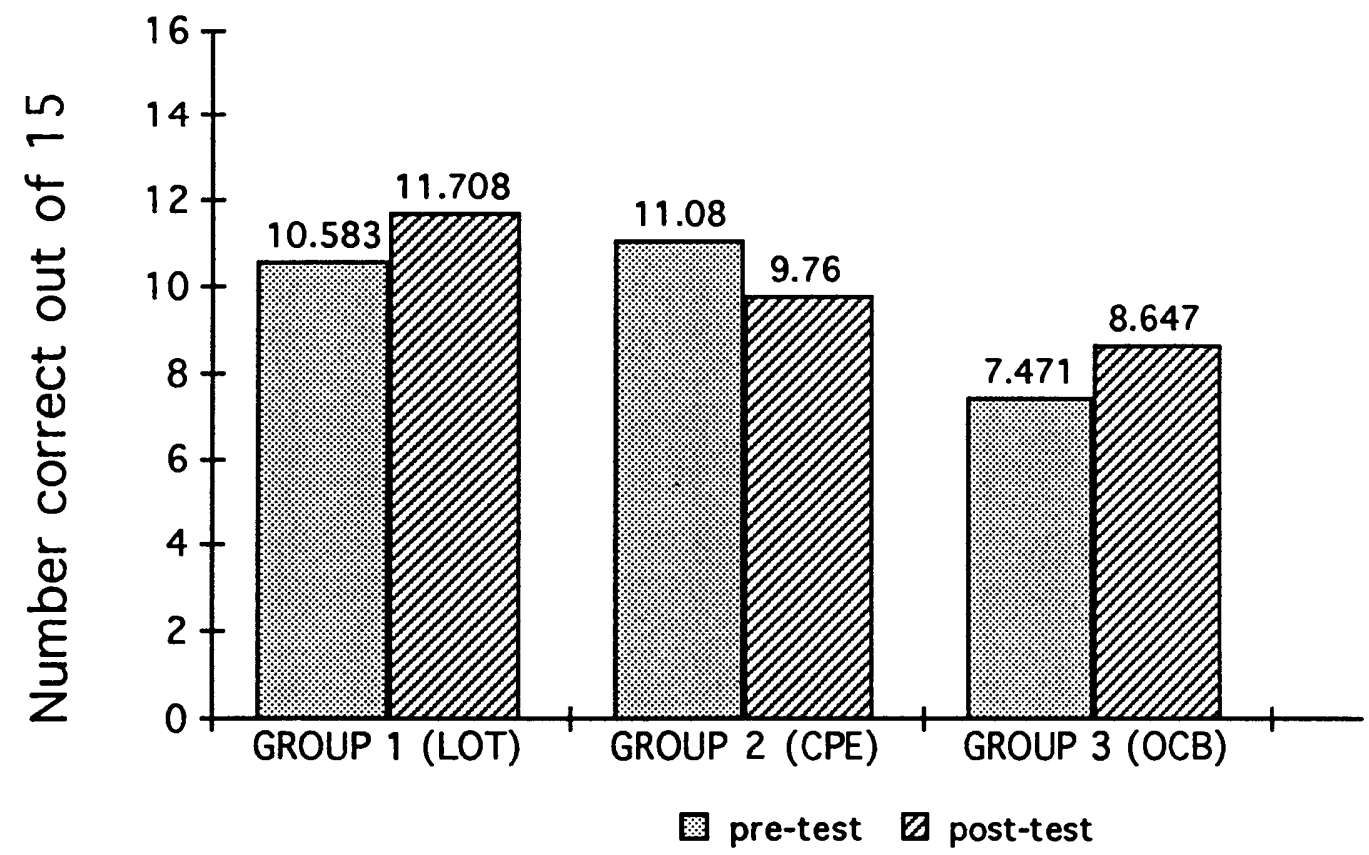

Figure 13. Mean scores for performance under the so treatment only, by group (with story).

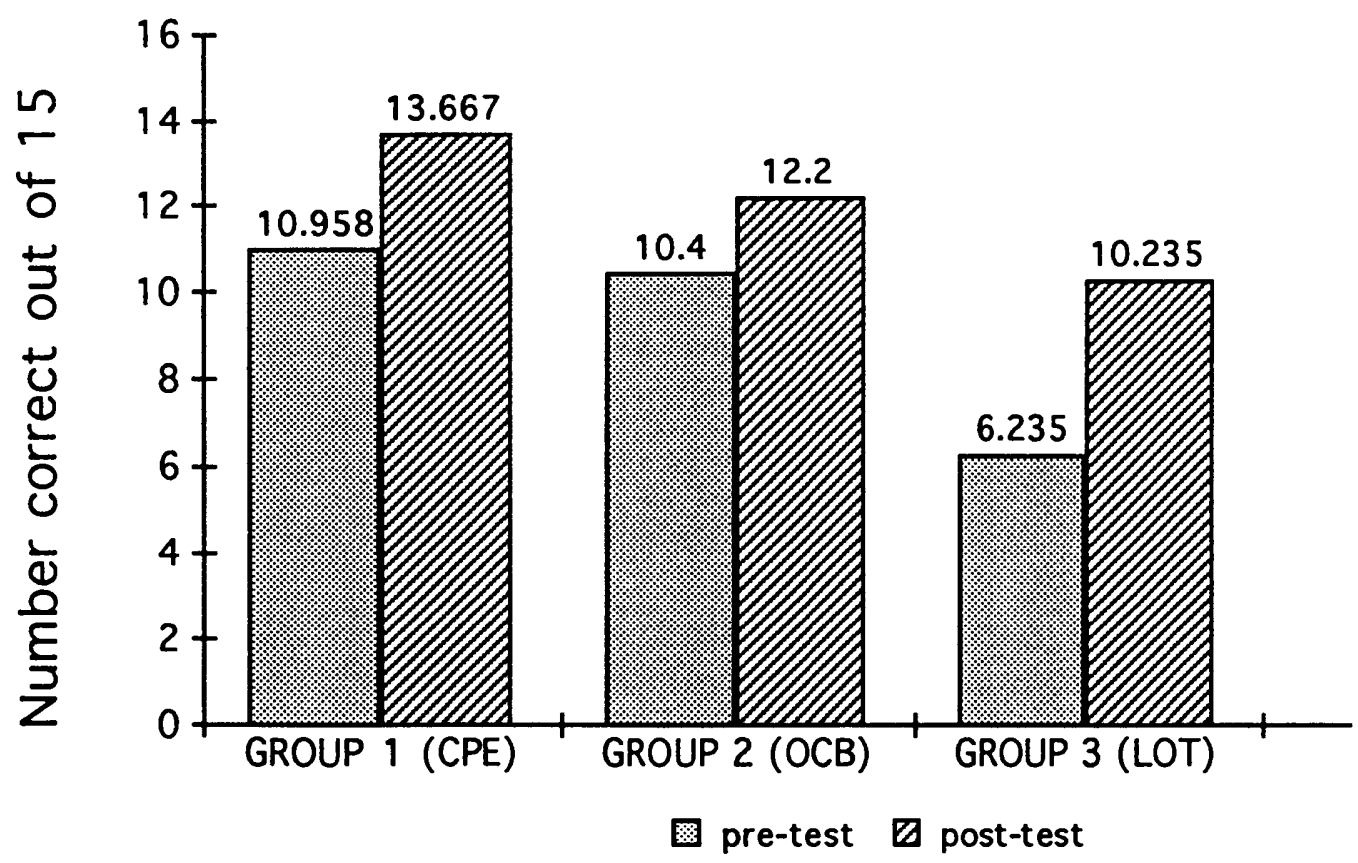

Figure 14. Mean scores for performance under the EO treatment only, by group (with story). 


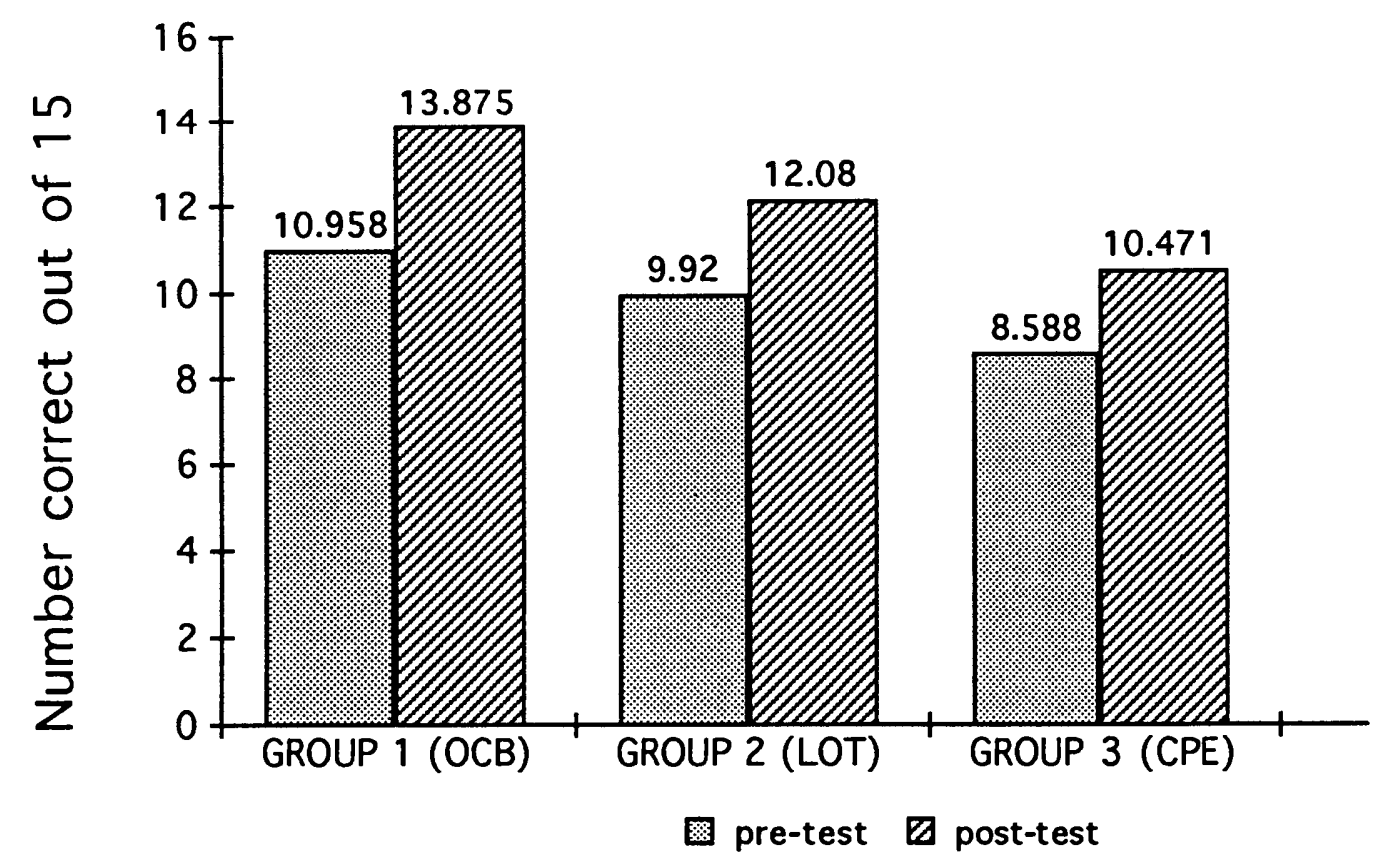

Figure 15. Mean scores for performance under the ES treatment only, by group (with story).

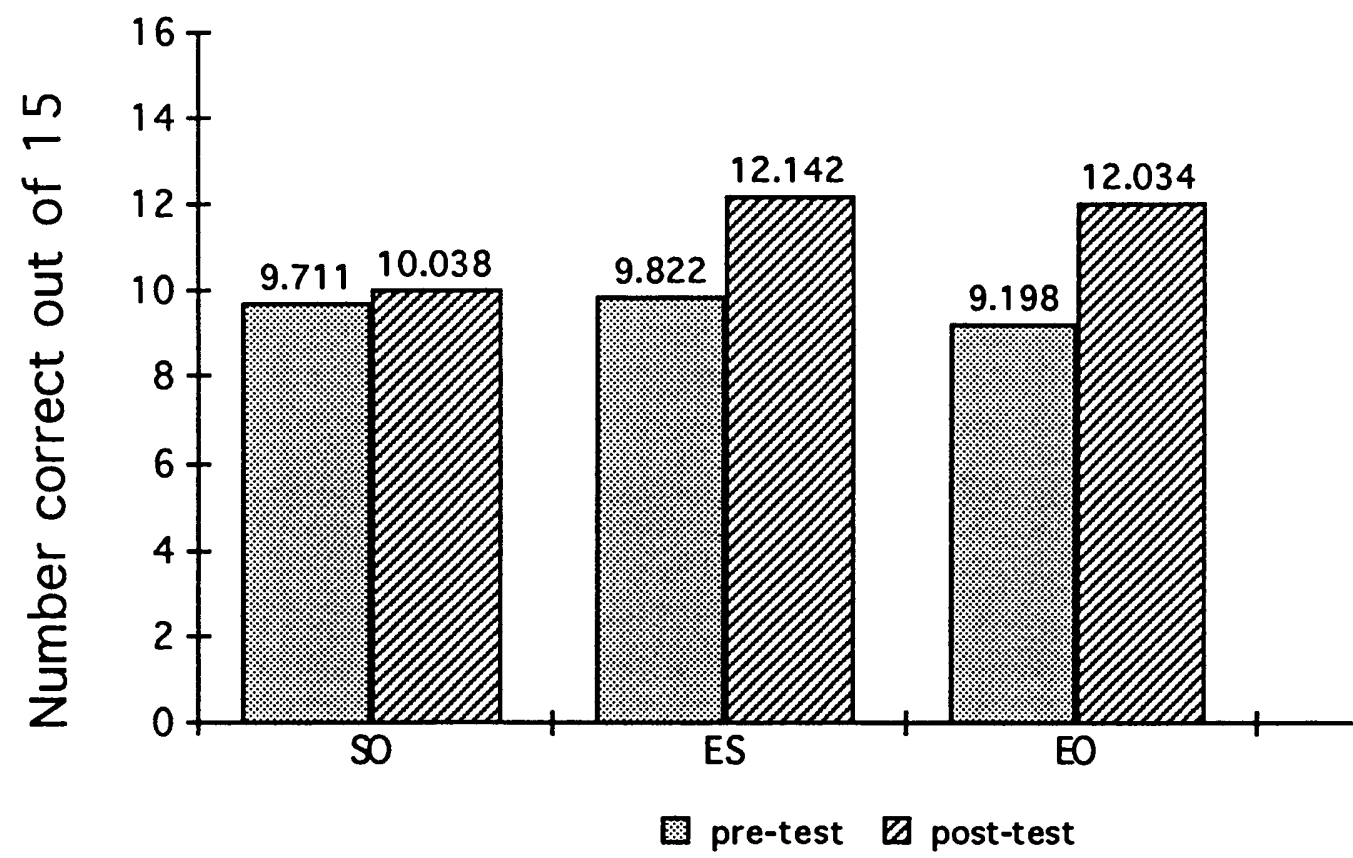

Figure 16. Mean scores across all three treatment groups for each treatment, least to most successful overall. 


\section{Summational Comparisons}

Interaction. As a final caveat before asserting the overall success of the treatment groups, Tables XXXII and XXXIII below are offered. A case might be made for the possibility of interaction between the dependent variables of story, treatment, and their order of administration.

Table XXXII shows the hypothesized order of success of the story/treatment sets. Here of course, there is no pattern to the success of the treatment types according to the order of their administration. However, Table XXXIII, which shows the actual order of success for the treatment types, does appear to show some interaction between the dependent variables of story and treatment type, according to the order in which these were given to each group. Note that the most successful treatments for both Groups 2 and 3 used LOT. Also, the most successful treatments (ES for Groups 1 and 2, and EO for Group 3) were given closer to the post-test. Since this interaction does not form a very regular pattern across the entire matrix, it is not possible to say with absolute certainty whether the proximity of a treatment to the post-test or the story used with a treatment had a meaningful effect on that treatment's relative success. 
TABLE XXXII

HYPOTHESIZED ORDER OF SUCCESS OF TREATMENTS, LEAST TO MOST SUCCESSFUL

\begin{tabular}{c} 
GROUP 1 \\
\hline Eirst given \\
EO \\
+ \\
CPE \\
\hline third given \\
ES \\
+ \\
OCB \\
\hline second given \\
SO \\
+ \\
LOT
\end{tabular}

GROUP 2

third given

EO

$+$

OCB

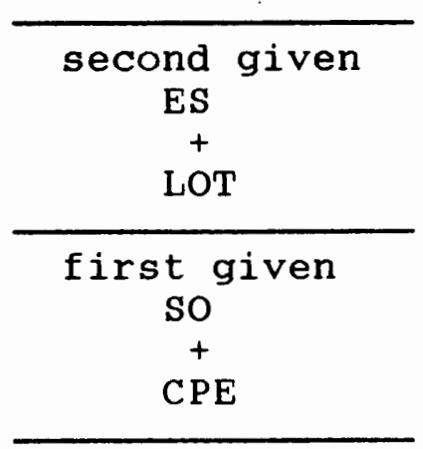

GROUP 3

second given

EO

$+$

LOT

first given

ES

$+$

CPE

third given

so

$+$

OCB

TABLE XXXIII

ACTUAL ORDER OF SUCCESS OF TREATMENTS, LEAST TO MOST SUCCESSFUL

\begin{tabular}{c}
\hline GROUP 1 \\
\hline second given \\
SO \\
+ \\
LOT \\
\hline first given \\
EO \\
+ \\
CPE \\
\hline third given \\
ES \\
+ \\
OCB
\end{tabular}

GROUP 2

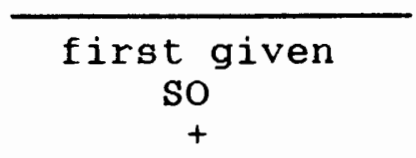

CPE

third given

EO

$+$

OCB

second given

ES

$+$

LOT
GROUP 3

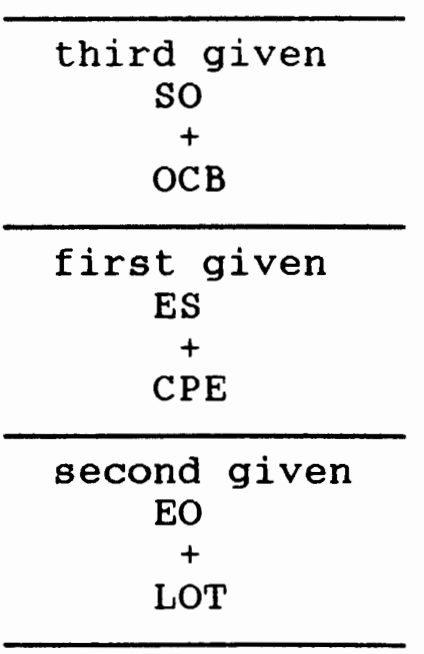


By Groups. Table XXXIV below compares the three treated groups from overall least- to overall mostsuccessful group. Group 2, partly due to their previously discussed "loss," performed poorest overall. Group 1 was the median. Lastly, Group 3 achieved the highest gain overall (though they had the lowest pre- and post-test means), partly due to their large gain of 4 points (26.667\%) on LOT under the EO treatment.

\section{TABLE XXXIV}

MEANS (OUT OF 15) ACROSS THE THREE TREATMENTS, FOR EACH GROUP, LEAST TO MOST SUCCESSFUL GROUP

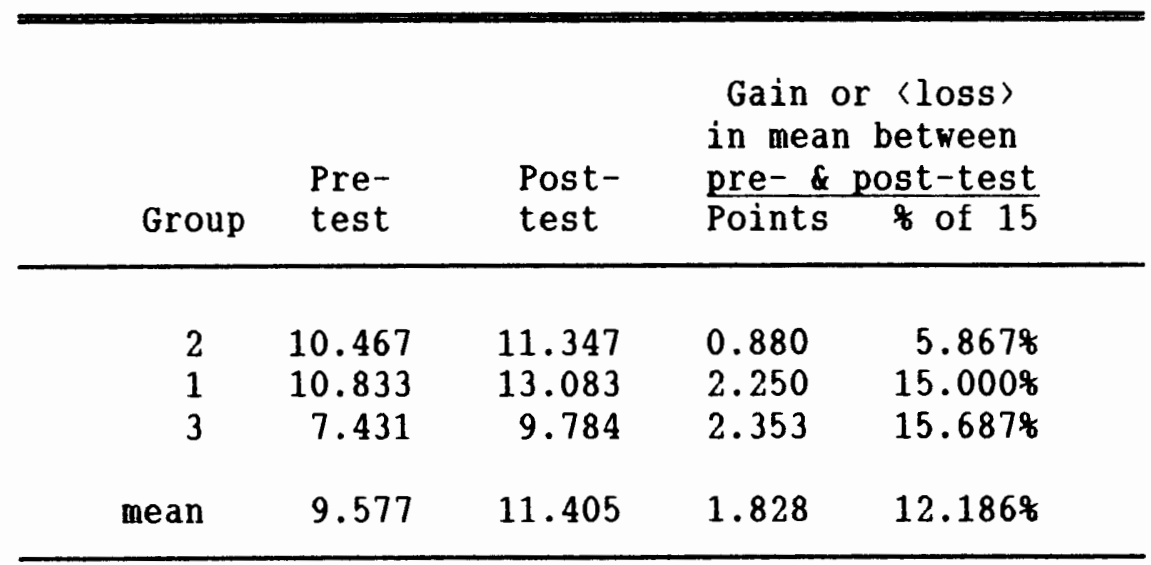

Table XXXV shows essentially the same information found in Table XXXIV, but in greater detail. Table XXXV gives the mean points out of 15 as in Table XXXIV, but it also gives the mean points out of the 45 total test words, and the percentages that these represent. 
TABLE XXXV

MEAN SCORES AND THEIR PERCENTAGES ON PRE- AND POST-TESTS AND IMPROVEMENT OR DECLINE IN MEAN BETWEEN PRE- AND POST-TESTS FOR GROUPS $1-4$

\begin{tabular}{|c|c|c|c|}
\hline & $\begin{array}{l}\text { Pre- } \\
\text { test }\end{array}$ & $\begin{array}{l}\text { Post- } \\
\text { test }\end{array}$ & $\begin{array}{l}\text { Sain or 〈loss〉 } \\
\text { in mean } \\
\text { between pre- } \\
\text { \& post-test }\end{array}$ \\
\hline $\begin{array}{r}\text { GROUP } 1 \\
\text { mean points } / 45^{1} \\
\text { mean points } / 15^{2} \\
\text { mean } \%\end{array}$ & $\begin{array}{l}32.499 \\
10.833 \\
72.2208\end{array}$ & $\begin{array}{l}39.250 \\
13.083 \\
87.2208\end{array}$ & $\begin{array}{c}6.751 \\
2.250 \\
15.000 \%\end{array}$ \\
\hline $\begin{array}{r}\text { GROUP } 2 \\
\text { mean points } / 45^{1} \\
\text { mean points } / 15^{2} \\
\text { mean } \%\end{array}$ & $\begin{array}{l}31.400 \\
10.467 \\
69.7788\end{array}$ & $\begin{array}{l}34.040 \\
11.347 \\
75.645 \%\end{array}$ & $\begin{array}{l}2.640 \\
0.880 \\
5.867 q\end{array}$ \\
\hline $\begin{array}{r}\text { GROUP } 3 \\
\text { mean points } / 45^{1} \\
\text { mean points } / 15^{2} \\
\text { mean } \%\end{array}$ & $\begin{array}{c}22.294 \\
7.431 \\
49.542 \%\end{array}$ & $\begin{array}{c}29.353 \\
9.784 \\
65.2298\end{array}$ & $\begin{array}{c}7.059 \\
2.353 \\
15.6878\end{array}$ \\
\hline $\begin{array}{r}\text { GROUP } 4 \\
\text { mean points } / 45^{1} \\
\text { mean points } / 15^{2} \\
\text { mean } \&\end{array}$ & $\begin{array}{c}29.778 \\
9.926 \\
66.1738\end{array}$ & $\begin{array}{r}27.167 \\
9.056 \\
60.371\end{array}$ & $\begin{array}{l}\langle 2.611\rangle \\
\langle 0.870\rangle \\
\langle 5.8028\rangle\end{array}$ \\
\hline
\end{tabular}

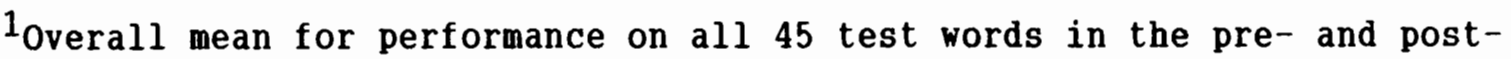
tests.

${ }^{2}$ Overall mean for performance on any one set of 15 words in the pre- and post-tests.

Treatment Groups Only, Combined. Table XXXVI following, takes the by-group data in Table XXXV and condenses it into the overall means for all three treatment groups combined. Here it can be seen that the three treated groups gained an overall average of almost five and one-half 
points from the pre- to the post-test, or an overall average of almost 2 points on any one 15-item set, for an average gain of just over 12\%. Another way to view this gain is to say that at $63.847 \%$, the average pre-test grade for Groups 1 - 3 was a "D," in fact, almost a "D-," while their average post-test grade, at $76.032 \%$, was a solid "C," almost a "C+" . To improve slightly more than one whole grade might be considered an enviable achievement in a classroom setting.

\section{TABLE XXXVI}

OVERALL MEANS FOR ALL 45 TEST WORDS AND ANY 15-WORD SET, THREE TREATMENT GROUPS ONLY

\begin{tabular}{rccc}
\hline & $\begin{array}{l}\text { Pre- } \\
\text { test }\end{array}$ & $\begin{array}{c}\text { Post- } \\
\text { test }\end{array}$ & $\begin{array}{c}\text { Gain in mean } \\
\text { between } \\
\text { pre- \& } \\
\text { post-test }\end{array}$ \\
\hline mean points $/ 45^{1}$ & 28.731 & 34.214 & 5.483 \\
mean points/15 & 9.577 & 11.405 & 1.828 \\
\hline
\end{tabular}

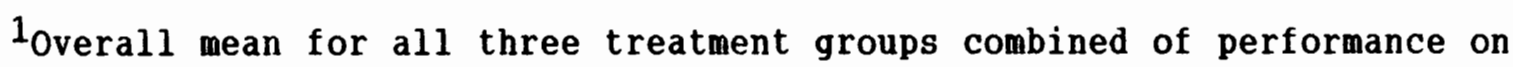
all 45 test words in the pre- and post-tests.

2 Overall mean for all three treatment groups combined of performance on any one set of 15 words in the pre- and post-tests. 
Control Group only. By comparison, Table XXXVII shows the overall loss in mean for Group 4, the control group, only. In similar terms, Group 4 lost an average of more than two and on-half points on the post-test, or a little more than four-fifths of a point on any one 15-item set, for an average loss of almost 6\%. Thus, Group 4's average pretest grade, at $66.173 \%$, was nearly a "D+," but it dropped on the post-test to $60.371 \%$, a low "D-". That Group 4 dropped a little more than half a grade in percentage terms seems to indicate that it was working as a control group. Had the control group shown an overall gain across its three story sets, aside from the one story set that did post a small individual gain, the control group's efficacy would have been in question.

Hypothesis 3 . proposed that there would be no real improvement in the control group's results. Taken together, the argument immediately above and the others put forth previous to that show that Group 4 was acting as a control. That it experienced an actual loss between pre- and posttests certainly seems to support Hypothesis 3 . 
TABLE XXXVII

OVERALL MEAN FOR ALL 45 TEST WORDS AND ANY 15-WORD SET, CONTROL GROUP (GROUP 4) ONLY

\begin{tabular}{rccc}
\hline & $\begin{array}{c}\text { Pre- } \\
\text { test }\end{array}$ & $\begin{array}{c}\text { Post- } \\
\text { test }\end{array}$ & $\begin{array}{c}\text { Loss in mean } \\
\text { between } \\
\text { pre- \& } \\
\text { post-test }\end{array}$ \\
\hline mean points $/ 45^{1}$ & 29.778 & 27.167 & $\langle 2.611\rangle$ \\
mean points/15 & 9.926 & 9.056 & $\langle 0.870\rangle$ \\
mean $\%$ & $66.173 \%$ & $60.371 \%$ & $\langle 5.802 \%\rangle$ \\
\hline
\end{tabular}

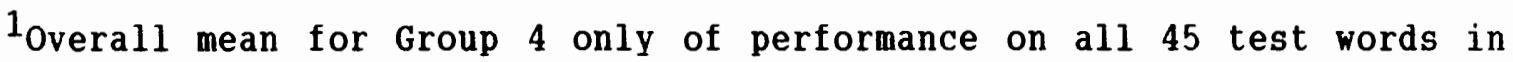
the pre- and post-tests.

$2^{2}$ Overall mean for Group 4 only of performance on any one set of 15 words in the pre- and post-tests.

Treatment Groups Combined versus Control Group. Finally, Table XXXVIII compares the losses shown by Group 4 , as found in Table XXXVII, with the average gains posted by Groups 1 - 3 combined, as found in Table XXXVI. Table XXXVIII also gives the point and percentage differences. 
TABLE XXXVIII

COMPARISON OF THE OVERALL LOSS IN MEAN FOR GROUP 4 WITH THE OVERALL GAIN IN MEAN FOR GROUPS 1, 2, AND 3 COMBINED

\begin{tabular}{rccc}
\hline & $\begin{array}{c}\text { 〈Loss in } \\
\text { mean btwn } \\
\text { pre- \& } \\
\text { post-test } \\
\text { Group 4 }\end{array}$ & $\begin{array}{c}\text { Gain in } \\
\text { mean btwn } \\
\text { pre- \& } \\
\text { post-test } \\
\text { Group 1-3 }\end{array} \quad$ Difference \\
\hline mean points/45 & $\langle 2.611\rangle$ & 5.483 & +8.094 \\
mean points/15 & $\langle 0.870\rangle$ & 1.828 & +2.698 \\
mean 8 & $\langle 5.8028\rangle$ & $12.186 \%$ & +17.9888 \\
\hline
\end{tabular}

\section{SUMMARY}

This chapter reported the outcomes of the experimental procedures described in chapter III. In brief, the results showed that overall the treated groups did show some increase in vocabulary learning over the pre-test, while the control group did not. The expected pattern in this increase for the three treated groups did not appear, however. Rather, a different pattern of success among treatments was perceived. The one treatment, so, that was expected to out-perform the other two was, instead, the least successful. Thus, Hypothesis 2., the most central to this study, was not supported. Furthermore, Hypothesis 1., which predicted that several data comparisons would show equality of ability among the groups before the treatments 
took place, was also not supported. The results of these particular comparisons pointed toward non-support of Hypothesis 1. but were not completely conclusive. Hypothesis 3. , that there would be no significant improvement in vocabulary learning by the control group, was supported: The control group actually declined slightly in performance. The next chapter will further discuss the results of this study from the perspective of the limitations of its design. Also in light of the results reported here, the implications for teaching ESL will be discussed. Suggestions for further research will be offered, as well. Lastly, the next chapter will conclude with a summary of the entire study. 
CHAPTER V

SUMMARY AND CONCLUSIONS

INTRODUCTION

This final chapter will discuss in detail the limitations of this study, the implications of the results of this investigation for the teaching of ESL, and avenues for further research in the area of vocabulary learning. Following these discussions, the chapter concludes with a summary of the entire project.

\section{LIMITATIONS}

The original research questions of this study were based on certain general assumptions, namely, that ESL students can learn vocabulary simply through reading, and through reading fiction more or less just for pleasure. Although this particular study gave little statistically significant support to these assumptions, the results do show that the subjects did learn some vocabulary just by reading fiction, when compared with the control group, who did not learn any vocabulary. However, when compared with the two other methods that were expected to produce lower results, reading alone proved to be the least successful way to learn vocabulary. These seemingly contradictory results 
-- on the one hand, some vocabulary was learned through reading alone, but on the other hand, reading alone was the least effective of three ways to learn that vocabulary -must be seen within the context of the study. The basic assumptions discussed above still stand. However, there must be a reconciling between those assumptions and the particular results of this experiment. Thus, a discussion of the limitations of this study is in order.

\section{Design-Related Limitations}

Of course, this study does not recommend story reading to be the best way in general to learn vocabulary for the type of subjects in this study. obviously, the evidence refuted that. The data also showed story reading not to be the best in comparison with two other specific methods. However, in comparison with the control group's performance, story reading was a better method than no method at all. The low results for story reading alone do suggest that Krashen's (1986, 1989) "Natural Approach" to reading as a means to learning vocabulary should not be applied to the particular type of students used as subjects in this project. other studies achieved different results by using subjects of different (higher) ability levels, and by exposing the subjects to the words for longer periods of time (that is, through reading novels, rather than short stories). It seems that Krashen's theory does not hold when applied to summer Program students. 
Broader generalizations cannot be made based on the parameters of this study. From a scientific point of view, this study is limited by a number of factors. Perhaps chief among these is that the application of the results is limited to the three vocabulary learning methods tested here. There is no basis for comparing these three methods with any other vocabulary learning methods. Perhaps if all possible methods were to be compared, these would fall at the bottom. Perhaps they would be at the top. Perhaps they would be somewhere between, or even have other methods between them on a continuum of success. Perhaps the continuum of success would change depending on variations in other factors (gender, age, first language, etc.). These possibilities are far beyond the scope of this investigation.

Another important limitation to the study's design is the short time span over which the experiment was conducted. This defect was unavoidable given the type of student used in this study. As short a lag as it was, it was as long as could possibly be. still, the question remains (as it would for the treatments in any experimental study, but is even more pointed in this casel, what effect did the treatments have over a longer period of time? Rather than one week later, was there any effect after one month, or one school term? Ultimately, how useful were the treatments over the long run? 
Subject-Related Limitations

The outcomes of this study are also limited almost exclusively to women students, and exclusively to Japanese students. Although there should intuitively be little or no difference in results according to gender or nationality/first language for a study like this, there can be no generalizations to Japanese males, nor to either gender of any other nationality or first language. These are only a few of the disadvantages to a small and homogeneous subject population.

There is also no allowance in this study for the interference of incidental learning. Although, because of the short time period over which this experiment took place, there was probably little danger of this, it is possible but unlikely that incidental learning of some of the test words could have occurred in the ESL curriculum materials, in content classes, on field trips, or in host family situations.

The results of this study are also limited to other subject-specific factors, most notably the age range of the subjects, their English ability level, and the length of time spent in EFL classes.

\section{Materials-Related Limitations}

The results are further limited by materials-specific factors. For example, not just short stories, but three specific short stories were used. Whether a similar effect 
could be achieved using different stories is still in question, although again, intuitively it seems that similar results could be obtained. Furthermore, the disparity in length among the stories remains another irreconcilable materials-related factor.

Another is the disparity in the frequency of occurrence of the test words within the stories. Since word frequency differed among words not only within one story, but also among the three stories (see Tables XXXIX - XLVI, in Appendix J, for word frequencies and patterns of occurrence), it is possible that these differences were a confounding variable. However, in the everyday situations of ESL teaching, word frequency in and between stories varies. It would be nearly impossible to find or construct three stories of precisely the same length in which all the words outside the head-word list occurred with exactly the same frequencies. Word frequency varies, even in stories carefully designed and simplified specifically for ESL students. Furthermore, this study does not seek to deny or ignore the problem of this variability.

Other materials doubts arise. It may be invalid, for example, to say that a subject's "knowledge" of a word can be accurately measured by performance on one post-test cloze sentence where the word is used once, in only one context (Gass, 1988). Along these same lines, it may be invalid to force the so subjects to pick the correct answer from a 
post-test stem which, though attempting to preserve the meaning of the context from which the test word came, purposely used different words from those words used in the story to create that context. In other words, so subjects were already beginning to build up contextual systems for the so words, but these contexts did not necessarily exactly match those in the post-test stems. By design, the contexts found in the stories were not duplicated in the post-test. For example, CPE's context for point included words like land; like a finger; into the water; Six-, Nine-, TwelveMile (names of points); and islands, towns, bends, but not fishing, walked out onto, end, and catch fish, which are the words that make up the context for point in the post-test.

It was necessary to use different words as the context in the post-test to guard against the possibility that students might simply recognize the correct answers merely by remembering which of the four word choices had appeared in the context of that stem when they saw that stem or something nearly identical to it in the story. The posttest actually asked the subjects to make a leap from remembering the environment of a word to really understanding the meaning of that individual word in isolation and then being able to plug that word back into a new, though similar, environment. This leap may be the most important factor in why subjects did significantly poorer on 
So: They had had no vocabulary exercises which asked them to do this sort of mental activity.

Finally, the results of this experiment are faced with the formidable challenge of unknown reliability. There can be no evidence from this study either way that the procedures performed in this study would produce similar results on similar groups of students. Although the procedures and materials used in this study have high validity (as mentioned in chapter III), there is no guarantee that they are also reliable.

\section{The value of this study}

Considering these limitations, what then can be said about the value of this study? Two important justifications for this study can be confidently made. The first, in applying these results to the practice of teaching ESL, will be discussed in the next section. The second is this study's pioneering use of ESL short-termers. There has been little, if any, research on, or using, short program students. Short-termers are not only a large and valuable potential subject pool, but as ESL learners, have needs, goals, and learning difficulties of their own which should be researched and investigated. One of the values of this study, then, is that it demonstrates that research in TESOL can successfully employ short term students.

Nevertheless, the question of whether or not the problems inherent in using such short term subjects outweigh 
the benefits naturally arises at this point. The time between pre-test and treatment and treatment and post-test is so short as to invalidate the application of any results of this research to other types of students, if not to invalidate the results of this study itself. Furthermore, if the testing does show any effects, there is no easy way to determine their duration. It may be possible to assert that if the so treatment appears to be even minutely successful leven though it posted smaller gains than the other treatments) with short term students such as these, that it should be even more successful with long-term, academic-track ESL students (which it is really designed to assist). One may very well wonder why then not use subjects who are of the long-term higher-level type. The attraction of the "Summer Program subjects" is that they are very eager and willing to participate in just about any kind of language learning activity, and especially that they constitute a very large pool of subjects, a luxury that is not of ten found in language studies.

\section{IMPLICATIONS FOR TEACHING ESL}

One of the more important lessons to be learned from this study is that explicit learning tasks give students goals to achieve. Without the explicit tasks, students do not naturally know what the goals are, and so do not as readily, if at all, achieve them. Thus, if literature alone 
is to be used for the purpose of learning vocabulary, the results of this study strongly suggest that the learning task be made very clear to the students. As discussed in Chapter III, it was necessary to avoid explaining the learning task under the so treatment, so that students would not focus solely and diligently on trying to learn words from the story and so skew the results for that treatment. That the students had no inkling of the purpose of reading the stories under so was perhaps one of the main reasons why that treatment so clearly failed in comparison with the other two. In hindsight, it may seem rather unfair in a way not to have told the students the purpose of so, since they would know the task under EO and ES exercises, just by virtue of having done vocabulary exercises before. Perhaps students who understood the purpose of the so treatment would have performed better, though how much better is not determinable. At any rate, students must explicitly know the teacher's expectations if story reading alone is ever used for purposes of vocabulary learning.

Because of the low generalizability of this study's results, the implications for TESOL are equally limited. However, it can be argued that the results show promise for short-term students, that apparently some vocabulary can be learned in a relatively short time. The results suggest that if the ESL teacher wishes to choose among the three methods of vocabulary teaching tested here, then pre-reading 
exercises followed by the reading of a related story should be the preferred method. This does not mean, however, that this method is to be preferred over other vocabulary teaching methods that were not included in this study, such as picture dictionaries, flash cards, word webs, oral drills, spelling bees, songs, and cloze passages to name only a few. This study. can make no judgements relative to other methods outside the three that it compares.

What this thesis can assert, however, is that young Japanese women students in short-term ESL programs can learn meaningful amounts of vocabulary through a combination of vocabulary exercises and related short story reading. Though the ES strategy tested here is probably not the best vocabulary learning method of all the possible methods that exist within the realm of ESL pedagogy, it has been shown to be a useful one. Perhaps teachers of short-term ESL students will want to consider how they can integrate exercise/story work into their curricula.

Furthermore, if the exercises and reading were followed by additional post-reading exercises, the learning and retention of vocabulary items should be even more successful, according to Anastos (1981). In the present study, the lack of follow-up exercises specifically geared to vocabulary was perhaps made up for in part by the discussion questions following the story reading. But, as discussed in the section on materials development in chapter 
III, those discussion questions deliberately avoided focusing on or eliciting the target vocabulary. postreading discussion questions could, however, be written so as to require the target words to be used in answering them. This would break the monotony of using exercises both before and after reading. Journal writing or written answers to discussion questions could also reinforce the learning of the test words. Speaking and writing about the story in these ways would also facilitate the movement of the new words from the receptive (passive) lexicon to the productive (active) lexicon (Laufer, 1990b).

Further questions about crossover between the passive and the active lexicon would need to be addressed eventually. Of course every ESL teacher wants to give students "more vocabulary." But what does this really mean? Trying to pin it down, the problem becomes much more complex than just "more vocabulary." what type of vocabulary: receptive or productive? Which receptive or productive skill: reading or listening; or writing or speaking? And can a word learned in one skill area cross over into another? (For example, can a student who has picked up a word from reading a novel then use that word correctly in an essay?) Intuitively, the answer is, yes, of course. But, are there techniques which students could learn that could facilitate the crossover process, either in how the word is learned originally or in how it is accessed in the other 
skill area? And can words really cross over the manualvisual/oral-aural barrier, and vice versa? (For example, can a word learned by reading a story be used correctly in a conversation?) And what are the techniques that can facilitate this type of crossover?

At some point the question of what texts to use might also arise. The importance of contextual richness emphasized in Schouten-van Parreren's theory of word acquisition, as discussed in Mondria and Wit-De Boer (1991), with an insistence on text as the vehicle of that learning, suggests the need for a whole series of graded readers similar to Draper's (1993a, 1993b) short story collection duo, in which "structural, lexical, and sentence-length controls" (1993a, p. v) have been carefully established and implemented throughout the texts. As proposed by Krashen (1986) and confirmed empirically by Irvin (1990), Goulden et al. (1990), and others, massive amounts of text would be required. Perhaps a dozen or so stories per volume, and a dozen or so volumes, with stories increasing in difficulty in small increments would prove successful. Coupled with these stories would be accompanying pre- and post-reading vocabulary exercises, at least at the lower levels.

A call might be issued then for, rather than a vocabulary textbook full of exercises, a vocabulary-reading textbook full of exercises and stories, and a realization that any reading done by SL learners or assigned by their 
teachers should have, at least as a secondary purpose, that of learning new words.

Vocabulary research in general suggests that researchers and educators should continue to look for and invent new, creative, enjoyable ways of learning and teaching vocabulary, but that these should be attendant to a focus on reading for vocabulary learning. Whether an exercise is designed for pre-, during-, or post-reading, it should not be an end in itself.

Aside from using literature-reading to promote vocabulary growth, literature has other values in the ESL/EFL classroom. McKay (1982) and Hill (1986) offer the merits of practicing reading skills learned in the classroom, building real-world knowledge in content areas and cultural practices, and fostering positive attitudes toward reading, among others.

Summary. Students want an answer to their question, "How can I get more vocabulary?" students may not like the answer: "Read more." They may prefer a quick-fix answer, a formula to memorize, an easy technique to use. That there probably is no such thing for increasing the lexicon will be disheartening to many students, to say the least. Nor will there probably be any radically "new" ways of teaching/learning vocabulary discovered.

Some may see technology as a solution. One of the current bandwagons in many areas of ESL teaching, including 
vocabulary, seems to be a growing fascination with computers, video, and other high-technology gadgetry (Brown, 1993). However, a caution is due. This fascination poses the hazard that seems to plague language teaching with alarming frequency: When the bandwagon fails to produce the desired effect, then it, like the proverbial baby, is thrown out with the bathwater. The truth is probably somewhere between mindless fascination and categorical rejection. Technology may help students learn more vocabulary, but it is probably not the cure-all that some might wish it were; and just because technology is not a cure-all does not mean that it should be abandoned outright, either.

There will probably be no "magic pill" to help students quickly and effortlessly learn the vast amounts of vocabulary they need to learn. The simple fact may be what many educators of NNSs and NSs have known intuitively all along land what much research now shows to be probable even for SL learners): vocabulary learning takes time and work, and one of the best vehicles for it may still be reading.

\section{AVENUES FOR FURTHER RESEARCH}

There is a need for more research in all aspects of vocabulary learning and teaching (Huckin \& Haynes, 1993), not only in passive methods, such as story reading as studied here, but in active ones as well. There seems to be a new awareness and interest in vocabulary within TESOL 
circles. Vocabulary learning is sometimes felt to be a much-neglected area within SL research (Stoller \& Grabe, 1993). Again, considering the vast gap in size between vocabularies of NSs and NNSs, some drastic steps need to be taken. Students need to be given ways to learn many more words, and to learn them in as short a time as possible, with as much chance for long-term retention as possible. Because of the limitations discussed above, this research does not purport to be a sole solution to these basic needs, but simply argues that for the type of students involved, a pre-reading vocabulary focus plus a story will maximize vocabulary learning as compared with each of those methods alone.

Laufer $(1990 \mathrm{~b})$ points out that most research in the area of vocabulary has so far concentrated on the management of learning vocabulary en masse: Reducing the vocabulary load, handling specific difficulties, and teaching specific learners. Still fewer works have been concerned, like this study, with the relative success of various vocabulary teaching methods. Despite the apparent renaissance of interest vocabulary teaching is currently enjoying (Coady, 1993), Laufer argues that "the amount of research on lexis still lags behind most areas of language learning" (1990b, p. 294). She believes that one of the reasons for this neglect is because "vocabulary is not a closed, rulegoverned system, but an open set, and as such has probably 
been less attractive as a research topic" (1990b, p. 294). with that characteristic in mind, she offers the following suggestions for research into the learning of specific words and the processes which govern that learning: More research is needed to determine (1) why some words seem to be inherently more difficult to learn than others, (2) what differences and similarities exist between vocabulary acquisition in the first language and the second language, (3) whether there is a Krashenesque "natural order," or any sort of order in vocabulary acquisition, and finally (4) what factors cause learners to seem to prefer some SL words over others (the avoidance/substitution phenomenon). These four suggestions depend in some way on viewing vocabulary through the "messy" window of the "open domain," but for the researcher who has a high tolerance for ambiguity, these areas should prove to be fruitful for many years.

As well as these general areas discussed above, there are a number of still unanswered research questions specific to the types of vocabulary teaching/learning methods studied in this project.

An item analysis would perhaps reveal further instructive patterns: The 55 distractors in the pre-test were divided between those words inside the 1000-word headword list used to construct the pre-test, and those outside this head-word list. An item analysis could examine the 
"easy" and the "difficult" distractors to determine which ones students actually found easy or difficult.

similarly, the 45 test words in the post-test were divided among those which appeared infrequently in the stories (2-4 occurrences), and those which appeared more frequently ( 5 or more occurrences). An item analysis along these parameters could look at whether infrequent occurrers were learned less well than frequent occurrers, regardless of which treatment they were learned under. It is possible that such a closer $100 k$ at the 45 words as two sets -frequent and infrequent occurrers -- could actually affect the determination of which treatments were effective and which were not.

The post-test analysis could also be improved by including some items that were not part of the 45 test words. These items could be based on some of the difficult distractors of the pre-test. An item analysis comparing pre- and post-test performances on these might more accurately determine whether the subjects had actually seen some of the pre-test's difficult distractors or not, and might help in determining subjects' proficiency levels.

Furthermore, this study examines only three methods of teaching vocabulary, and compares them only relative to each other. As discussed before, there is no comparison of these methods with other approaches to vocabulary teaching. In fact, this is also the case with the studies after which 
this one is modeled and which were discussed at length in Chapter II (Ferris et al., 1988; Saragi et al., 1978; Hudson, 1982; Taglieber et al., 1988; and Seal, 1991). Further inquiry should compare a wide variety of vocabulary teaching and learning strategies for their effectiveness relative to each other. This ranking also needs to compare the relative success of the different strategies over the short and long term, and at several levels of language proficiency.

Not only could other strategies be compared, but also further levels of treatment could be added to a design similar to the one in this experiment. Further levels of treatment in this study were considered, but for the sake of design simplicity, were rejected under limitations of materials development labor and performance time. Some further treatments to consider would include the following: Anastos (1981) suggests that a dramatization by the teacher improves students' understanding of the story. Given a large enough class, the teacher could also involve the students and act as narrator. Though the stories chosen here, along with adequate numbers of students in most of the classes used, would aptly lend themselves to dramatization by the teacher and/or students, this was regrettably not part of the treatment sequences. An alternate or even additional suggestion would be to have students watch video dramatizations of the stories. There does exist an 
excellent black and white film adaptation of "An Occurrence at Ow l Creek Bridge" (Ichac \& de Roubaix, 1964), also available on video (CBS Video/Fox Video, 1992). To the researcher's knowledge, no motion picture or video productions of the other two stories used in this study exist. Students who read OCB under either so or ES treatments did not of course watch the film version of $O C B$, as this would have invalidated the results for OCB. If film or video adaptations of stories were used in further research (or in the classroom), pre- and post-viewing (or pre- and post-dramatization) exercises or discussion could supplement the pre- and post-reading exercises.

Varying the length of the stories might also be a parameter worth examining, not necessarily in the sense of equalizing the length (though that should be a future consideration), but of using three stories equally shorter or equally much longer than those used here. Along these lines, an attempt could be made to equalize the frequency of occurrence within and among stories of each vocabulary item under examination, although, as discussed above, this would not be a very realistic goal.

Yet another parameter to examine is that of context. Would varying the density of difficult words per story produce drastically different results? Where is the threshold at which difficult words become too numerous and 
too frequent to be supported by their context? Testing this parameter would, too, take much painstaking work.

Research could also focus on the interaction of comprehension of the text and vocabulary learning. If it could be demonstrated that at lower proficiency levels under the ES method, students comprehend better what they read, as well as learn more vocabulary, that would be an added benefit to the practice of pre-reading exercises. Furthermore, at what level of comprehension could passive vocabulary acquisition still take place? Less than $75 \%$ comprehension, for example? And, at what level of comprehension does vocabulary acquisition become inefficient, ineffective, and impossible?

Another unexplored parameter of this study is variation in the language abilities of the subjects. These students were at a "beginning" level of English proficiency. They had not yet reached the level of fluency, at the intermediate stage, "where vocabulary multiplies at a dizzying pace" (Gidmark, 1982, p. 173). The students were still at a stage of language learning where the lexicon and its growth needs are manageable. Two questions central to the topic of ability would be: At what level of proficiency does a pre-reading focus on vocabulary begin to interfere with vocabulary learning? And, are there factors other than proficiency level that seem to affect this change? 
Further research could also vary the length of time between treatment and post-testing, vary the number, length, and types of pre-reading exercises, vary the setting (ESL as opposed to EFL) and experiment with groups more heterogeneous in regard to gender, ability level, and nationality and first language.

\section{PROJECT SUMMARY}

This thesis attempted to reproduce some of the effects of other studies (Ferris et al., 1988; Saragi et al., 1978; Hudson, 1982; Taglieber et al., 1988; and Seal, 1991) which examined passive vocabulary learning through story reading. However, three important differences set this study apart from other studies. First, it used short stories rather than novels; second, it was conducted over a much shorter time period than previous studies; and third, it employed a fairly unusual type of subject, namely participants in a short-term summer ESL program.

This study used three carefully chosen short stories to test which of three vocabulary learning strategies would produce better results on a post-test. It was found that the method expected to produce the highest scores, story reading alone, actually produced the lowest post-test scores, and the lowest gains between pre- and post-tests. The two other methods, each of which included a vocabulary exercise component, produced higher scores and higher gains. 
Several reasons were discussed for this unexpected pattern of results. Chief among these reasons was the possibility that a combination of vocabulary exercises and story reading gave students extra practice in learning those words. Vocabulary exercises alone were an apparently familiar, if perhaps less appealing way to learn words, but students still managed to perform better there than with stories alone. Apparently, story reading alone did not provide enough context, nor was the learning task clear. students learned the fewest words under this method.

Limitations of the study were discussed. Briefly, these included applicability of the results only to similar subjects using similar materials and treatments. No statements of broad applicability could safely be made. Based on the narrow limits of applicability discussed, recommendations for teaching ESL were made. Within the context of the type of students and materials used, these included continuing the use of the traditional pre-reading vocabulary exercises with stories, and if using stories alone, the importance of pointing out the learning task and purpose to the students. Finally, the need was stressed for further research in the specific area of passive vocabulary learning through story reading, as well as in the field of vocabulary learning and teaching in general. Research into the special needs of short program students was suggested. Last, based upon the apparent success of this study's use of 
short-term students, their inclusion as subjects of future language learning experiments was also urged. 


\section{REFERENCES}

Brown, C. (1993). Factors affecting the acquisition of vocabulary: Frequency and saliency of words. In $T$. Huckin, M. Haynes, \& J. Coady (Eds.), Second language reading and vocabulary learning (pp. 263-286). Norwood, NJ: Ablex Publishing Corporation.

Brown, T. S., \& Perry, F. L., Jr. (1991). A comparison of three learning strategies for ESL vocabulary acquisition. TESOL Quarter1y, 25(4), 655-670.

Burgess, A. (1963). A Clockwork Orange. New York: Norton.

Burgmeier, A., Eldred, G., \& Zimmerman, C. B. (1991). Lexis: Academic vocabulary study. Englewood Cliffs, NJ: Prentice Hall Regents.

Carroll, B. J., \& Hall, P. J. (1985). Make your own language tests: A practical guide to writing language performance tests. Oxford: Pergamon Press.

Carter, R. (1987). Vocabulary. London: Allen and Unwin.

Carter, R. \& McCarthy, M. (Eds.) (1988). Vocabulary and language teaching. London: Longman.

CBS Video/Fox Video. (1992). Treasures of the twilight zone: $A$ collection of special episodes and rare footage (video cassette). Los Angeles, CA: CBS Video/Fox Video.

Coady, J. (1993). Research on ESL/EFL vocabulary acquisition: Putting it in context. In T. Huckin, $M$. Haynes, \& J. Coady (Eds.), second Ianguage reading and vocabulary learning (pp. 3-23). Norwood, NJ: Ablex Publishing Corporation.

Cohen, A., \& Aphek, E. (1980). Retention of secondlanguage vocabulary over time: Investigating the role of mnemonic associations. System 8, 221-235.

Cohen, D. (1968). The effect of literature on vocabulary and reading achievement. Elementary English, 45, 209213. 
Cohen, D. (1969). Word meaning and the literary experience in early childhood. Elementary English, 46, 914-925.

Dieterich, T., \& Freeman, C. (1979). A linguistic guide to English proficiency testing in the schools. Arlington, VA: Center for Applied Linguistics.

Dieterich, T., Freeman, C., \& Griffin, P. (1978). Assessing comprehension in a school setting. Arlington, VA: Center for Applied Linguistics.

Diller, K. (1972). Bilingualism and the lexicon. In N. Hasselmo (Ed.), Studies for Einar Haugen. The Hague: Mouton.

Draper, C. G. (1993a). Great American stories 1: An $E S L / E F L$ reader, Second Edition. Englewood Cliffs, NJ: Regents/Prentice-Hall.

Draper, C. G. (1993b). Great American stories 2: An $E S L / E F L$ reader, Second Edition. Englewood Cliffs, NJ: Regents/Prentice-Hall.

Elkhatib, A. S. A. (1984). A classification of the lexical problems of EFL/ESL students. (ERIC document, ED 246 691$.

Ferris, D., Kiyochi, E., \& Kowal, K. (1988). Second language vocabulary acquisition from extensive reading. Paper presented at the 22nd Annual TESOL Convention, Chicago, IL.

Finocchiaro, M., \& Sako, S. (1983). Foreign language testing: A practical approach. New York: Regents Publishing Company.

Fry, E. B. (1989). Vocabulary drills: Advanced level. Providence, RI: Jamestown.

Fry, E. B., Fountoukidis, D. L., \& Polk, J. K. (1985). The new reading teacher's book of lists. Englewood Cliffs, NJ: Prentice-Hall.

Gairns, R., \& Redman, S. (1986). Working with words: A guide to teaching and learning vocabulary. Cambridge: Cambridge University Press.

Gass, S. M. (1988). Second language vocabulary acquisition. Annual Review of Applied Linguistics, 9, 92-106. 
Gidmark, J. B. (1982). Tailoring reading and vocabulary courses to the needs of non-native speakers of English. Alternative Higher Education, 6(3), 172-183.

Goodman, D. J., \& Mohr, C. (1991). Building vocabulary skills. Marlton, NJ: Townsend Press.

Goodman, D. J., Nist, S. L., \& Mohr, C. (1991). Advancing vocabulary skills. Marlton, NJ: Townsend Press.

Goulden, R., Nation, I. S. P., \& Read, J. (1990). How large can a receptive vocabulary be? Applied Linguistics, 11(4), 341-363.

Harris, D. P. (1969). Testing English as a second language. New York: McGraw-Hill.

Hatch, E. M. (1978). Second language acquisition. Rowley, MA: Newbury House.

Haynes, M. (1993). Patterns and perils of guessing in second language reading. In $T$. Huckin, M. Haynes, \& J. Coady (Eds.), Second language reading and vocabulary learning (pp. 46-64). Norwood, NJ: Ablex Publishing Corporation.

Heaton, J. B. (1975). Writing English language tests: A practical guide for teachers of English as a second or foreign language. London: Longman Group.

Henning, G. (1987). A guide to language testing. Cambridge, MA: Newbury House.

Henning, G. (1991). A study of the effects of contextualization and familiarization on responses to the TOEFL vocabulary test items (TOEFL Research Report No. 35). Princeton, NJ: Educational Testing Service.

Hill, J. (1986). Using literature in language teaching. London: Macmillan.

Howatt, A. P. R. (1984). A history of English language teaching. Oxford: Oxford University Press.

Huckin, T. \& Haynes, M. (1993). Summary and future directions. In T. Huckin, M. Haynes, \& J. Coady (Eds.), Second language reading and vocabulary learning (pp. 289-298). Norwood, NJ: Ablex Publishing Corporation. 
Huckin, T., Haynes, M., \& Coady, J. (Eds.) (1993). Second language reading and vocabulary learning. Norwood, $\mathrm{NJ}$ : Ablex Publishing Corporation.

Hudson, T. (1982). The effects of induced schemata on the "short circuit" in $L 2$ reading: Non-decoding factors in L2 reading performance. Language Learning, 32(2), 131 .

Ichac, M., \& de Roubaix, P. (Producers) (1964). An occurrence at Owl Creek Bridge (motion picture). In CBS Video/Fox Video. (1992). Treasures of the twilight zone: A collection of special episodes and rare footage (video cassette). Los Angeles, CA: CBS Video/Fox Video.

Irvin, J. L. (1990). Vocabulary knowledge: Guidelines for instruction. Washington, D.C.: National Education Association.

Judd, E. L. (1978). Vocabulary teaching and TESOL: A need for reevaluation of existing assumptions. TESOL Quarter1y, 12(1), 71-75.

Julkunen, K. (1990). Affective properties of open and closed vocabulary tasks in individualistic and cooperative learning situations. (ERIC document, ED 322752$.

Kelly, L. G. (1969). 25 centuries of language teaching: An inquiry into the science, art, and development of language teaching methodology 500 B.C.-1969. Rowley, MA: Newbury House.

Kerim-Zade, I., \& Pavlov, V. (1989). The semanticofunctional variability of words and the teaching of vocabulary to advanced EFL students. Applied Linguistics, 10(4), 382-391.

Krashen, S. D. (1986). We acquire vocabulary by reading. In Papalia, A. (Ed.), Teaching our students a second language in a proficiency-based classroom. Schenectady, NY: New York State Association of Foreign Language Teachers.

Krashen, S. D. (1989). We acquire vocabulary and spelling by reading: Additional evidence for the input hypothesis. Modern Language Journal, 73(4), 440-464.

Largent, M. (1959). My third graders are eager readers. NEA Journal, 48, 64-65. 
Laufer, B. (1990a). Ease and difficulty in vocabulary learning: Some teaching implications. Foreign Language Annals, 23(2), 147-155.

Laufer, B. (1990b). Why are some words more difficult than others? - - Some intralexical factors that affect the learning of words. IRAL, 28(4), 293-307.

Laufer, B. (1991). Some properties of the foreign language learner's lexicon as evidenced by lexical confusions. IRAL, 29(4), 317-330.

Madsen, H. S. (1983). Techniques in testing. oxford: Oxford University Press.

Manning, G., \& Manning, M. (1984). What models of recreational reading make a difference? Reading World, May, 1984, 375-380.

Martin, M. (1984). Advanced vocabulary teaching: The problem of synonyms. The Modern Language Journal, $68(2), 130-137$.

McKay, S. (1982). Literature in the ESL classroom. TESOL Quarterly, 16(4), 529-536.

Mckeown, M. G., \& Curtis, M. E. (Eds.) The nature of vocabulary acquisition. Hillsdale, NJ: Lawrence Erlbaum Associates.

Meara, P. M. (1980). Vocabulary acquisition: A neglected aspect of language learning. Language Teaching \& Linguistics: Abstracts, 13, 221-246.

Mendelsohn, D. (1992, March). Listening comprehension: A "strategy-based" approach. Paper presented at the 26 th Annual TESOL Convention, Vancouver, BC.

Mondria J.-A., \& Wit-De Boer, M. (1991). The effects of contextual richness on the guessability and the retention of words in a foreign language. Applied Linguistics, 12(3), 249-267.

Na, L., \& Nation, I. S. P. (1985). Factors affecting guessing vocabulary in context. RELC Journal, 16(1), $33-42$.

Nagy, W. E., \& Herman, P. A. (1987). Breadth and depth of vocabulary knowledge: Implications for acquisition and instruction. In M. G. McKeown \& M. E. Curtis (Eds.), The nature of vocabulary acquisition. Hillsdale, NJ: Lawrence Erlbaum Associates. 
Nagy, W. E., Herman, P. A., \& Anderson, R. C. (1985). Learning words from context. Reading Research Quarterly, 20(2), 233-253.

Nation, I. S. P. (1990). Teaching and learning vocabulary. New York: Newbury House.

Nist, S. L., \& Mohr, C. (1991). Improving vocabulary skills. Marlton, NJ: Townsend Press.

Orwell, G. (1946). Animal farm. New York: Harcourt Brace.

Papalia, A. (Ed.) (1986). Teaching our students a second language in a proficiency-based classroom. Schenectady, NY: New York State Association of Foreign Language Teachers.

Parry, K. (1991). Building vocabulary through academic reading. TESOL Quarter1y, 25(4), 629-653.

Paulston, C. B. \& Bruder, M. N. (1976). Teaching English as a second language: Techniques and procedures. Cambridge, MA: Winthrop Publishers.

Ramsey, R. M. (1981). A technique for interlingual lexicosemantic comparison: The lexigram. TESOL Quarterly, $15(1), 16-24$.

Richards, J. (1976). The role of vocabulary teaching. TESOL Quarterly, 10(1), 77-89.

Robinett, B. W. (1978). Teaching English to speakers of other languages: Substance and technique. Minneapolis, MN: University of Minnesota Press.

Rogerson, H. D., Davis, B., Hershelman, S. T., \& Jasnow, C. (1988). Words for students of English: A vocabulary series for ESL, Volume 1. Pittsburgh, PA: University of Pittsburgh Press.

Sachs, H. (1943). The reading method of acquiring vocabulary. Journal of Educational Research, 36, 457464 .

Saragi, T., Nation, I. S. P., \& Meister, G. (1978). Vocabulary learning and reading. System, 6, 70-78.

Seal, B. D. (1991). Vocabulary learning and teaching. In M. Celce-Murcia (Ed.), Teaching English as a second or foreign language, Second Edition, (pp. 296-311). Boston, MA: Heinle \& Heinle. 
Smith, R. K., \& Mohr, C. (1991). Groundwork for a better vocabulary. Marlton, NJ: Townsend Press.

Smith, V. L. (1983). Vocabulary building for universitybound ESL students. (ERIC document, ED 230 037.)

Stoller, F. L., \& Grabe, w. (1993). Implications for L2 vocabulary acquisition and instruction from L1 vocabulary research. In T. Huckin, M. Haynes, \& J. Coady (Eds.), Second language reading and vocabulary learning (pp. 24-45). Norwood, NJ: Ablex Publishing Corporation.

Swaffar, J. K. (1988). Readers, texts, and second languages: the interactive processes. The Modern Language Journal, 72(2), 123-149.

Taglieber, L. K., Johnson, L. L., \& Yarborough, D. D. (1988). Effects of pre-reading activities on EFL reading by Brazilian college students. TESOL Quarterly, 22(3), 455-472.

Taylor, L. (1990). Teaching and learning vocabulary. New York: Prentice Hall.

Thorndike, E. L., \& Lorge, I. (1944). The teacher's word book of 30,000 words. New York: Columbia University Press.

Twaddell, F. (1972). Linguistics and language teachers. In K. Croft (Ed.), Readings on English as a second language. Cambridge, MA: Winthrop.

Twaddell, F. (1973). Vocabulary expansion in the TESOL classroom. TESOL Quarterly, 7, 61-78.

Wallace, M. (1982). Teaching vocabulary. London: Heinemann.

Wilkins, D. A. (1976). Linguistics in language teaching. Cambridge: MIT Press. 
APPENDIX A

STORIES 
Note: In this appendix, all occurrences of the test words are underlined throughout the story. The word list below contains the 15 base words from this story, in order by each base word's first appearance in the story, followed by the number of times the word appears in the story. (This information can also be found in Tables XXXIX - XLVI which list all occurrences of all test words for all three stories.) The story copies given to the subjects did not, of course, have this information, nor were the base words underlined throughout the story itself as they have been here. Permission to copy the story was kindly granted by Regents/Prentice Hall.

$\begin{array}{lrlrlr}\text { village } & 2 & \text { steer } & 13 & \text { bend } & 13 \\ \text { steamboat } & 8 & \text { cool } & 3 & \text { shape } & 17 \\ \text { pilot } & 16 & \text { point } & 12 & \text { shadow } & 4 \\ \text { landing } & 4 & \text { mist } & 4 & \text { lesson } & 3 \\ \text { wheel } & 6 & \text { voice } & 8 & \text { engine } & 6\end{array}$

\section{A CUB-PILOT'S EDUCATION \\ adapted from the story by \\ Mark Twain}

Mark Twain's real name was samuel Langhorne Clemens. He was born in 1835 in the state of Missouri. As a boy, he lived in a small town on the Mississippi River. His most famous books, The Adventures of Tom Sawyer and The Adventures of Huckleberry Finn, are about boyhood and the Mississippi River. Because of these books and others, Mark Twain became America's most famous and best-loved writer. He died in 1910. The following story is from his book Life on the Mississippi.

All the boys in my village wanted to be the same thing: a steamboat pilot. our village lay on the great Mississippi River. Once a day, at noon, a steamboat came up from $\mathrm{st}$. Louis. Later, at one o'clock, another came down from Keokuk. Before these hours, the day was full and bright with waiting. After them, the day was a dead and empty thing.

I can see that old time now. The white town sleeps in the morning sun. The streets are empty. Some animals walk near the buildings. The waters of the Mississippi are quiet and still. A man who has drunk too much lies peacefully near the river. Other men sit outside their stores in chairs. They look at the town and don't talk much. 


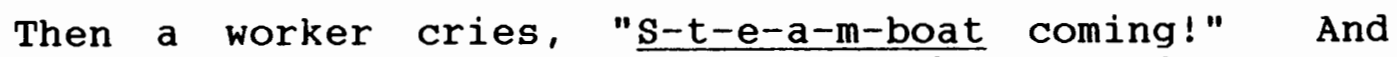
everything changes! The man who has drunk too much gets up and runs. Suddenly the streets are full. Men, women, and children run to the steamboat landing. The animals make a hundred different noises. The town wakes up!

The steamboat that comes toward the town is long and pretty. Her big wheel turns and turns. Everybody looks at her and at the men who live on her. The pilot stands tallest, the center of everything, the king. slowly the steamboat comes to the landing. Men take things off the boat and bring other things on. In ten minutes she is gone again. The town goes back to sleep. But the boys of the town remember the boat. They remember the pilot. And they don't forget.

I was fifteen then, and I ran away from home. I went to New Orleans. There I met a pilot named Mr. Bixby. I said I wanted to be his cub-pilot, or learner. He said no-but only once. I said yes a hundred times. So in the end I won. He said he would teach me the river. He didn't smile or laugh, but I was the happiest boy in that city.

We left New Orleans at four o'clock one afternoon. Mr. Bixby was at the wheel. Here at the beginning of the river, there were a lot of steamboats. Most of them were at landings on the sides of the river. We went past them quickly, very close to them. Suddenly Mr. Bixby said, "Here. You steer her." And he gave me the wheel. My heart was in my mouth. I thought it was very dangerous, close to those other boats. I began to steer into the middle of the river. In the middle, there was enough water for everybody.

"What are you doing?" Mr. Bixby cried angrily. He pushed me away and took the wheel again. And again he steered us near the other boats. After a while, he became a little cooler. He told me that water runs fast in the middle of a river. At the sides, it runs slow. "So if you're going up-river, you have to steer near the sides. You can go in the middle only if you're going down-river." Well, that was good enough for me. I decided to be a downriver pilot only.

Sometimes Mr. Bixby showed me points of land. "This is Six-Mile Point," he said. The land pointed like a finger into the water. Another time, he said, "This is Nine-Mile point." It looked like six-Mile Point to me. Later, he said, "This is Twelve-Mile point." Well, this wasn't very interesting news. All the points seemed the same.

After six hours of this, we had dinner and went to bed. Even bed was more interesting than the "points." At midnight, someone put a light in my eyes. "Hey, let's go!"

Then he left. I couldn't understand this. I decided to go back to sleep. Soon the man came again with his light; now he was angry. "Wake up!" he called. I was angry, too, and said, "Don't put that light in my eyes! How can I sleep if you wake me up every minute?" 
All the men in the room laughed at this. The man left again, but came back soon with Mr. Bixby. One minute later I was climbing the steps to the pilot-house. Some of my clothes were on me. The rest were in my hands. Mr. Bixby walked behind me, angry. Now, here was something interesting: pilots worked in the middle of the night!

And that night was a bad one. There was a lot of mist on the river. You could not see through it. Where were we going? I was frightened. But Mr. Bixby turned the wheel easily and happily. He told me we had to find a farm. Jones Farm. To myself I said, "Okay, Mr. Bixby. You can try all night. But you'll never find anything in this mist."

Suddenly Mr. Bixby turned to me and said, "What's the name of the first point above New Orleans?"

I answered very quickly. I said I didn't know.

"Don't know?"

The loudness of his voice surprised me. But I couldn't answer him.

"Well, then," he said, "What's the name of the next point?"

Again I didn't know.

"Now, look! After Twelve-Mile Point, where do you cross the river?"

"I-I-I don't know."

"You-you-you don't know? Well, what do you know?"

"I--nothing, it seems."

"Nothing? Less than nothing! You say you want to pilot a steamboat on the river? My boy, you couldn't pilot a cow down a street! Why do you think I told you the names of those points?"

"Well, to-to--be interesting, I thought."

"What?! To be interesting?" Now he was very angry. He walked across the pilot-house and back again. This cooled him down. "My boy," he said more softly, "You must get a little notebook. I will tell you many names of places on this river. You must write them all down. Then you must remember them. All of them. That is the only way to become a pilot."

My heart fell. I never remembered things easily in school. But also I didn't fully believe Mr. Bixby. No one, I thought, could know all of the Mississippi. No one could put that great river inside his head.

Then Mr. Bixby pulled a bell. A worker's voice came up from below.

"What's this, sir?"

"Jones Farm," Mr. Bixby said.

I could see nothing through the mist. And Mr. Bixby could see nothing. I knew that. So I didn't believe him. How could I? We were in the middle of nowhere! But soon the boat's nose softly hit the landing. Workers' voices 
came up to us. I still couldn't believe it, but this was Jones Farm!

And so, slowly, I began to put the Mississippi River inside my head. I filled a notebook--I filled two notebooks--with names from the river. Islands, towns, points, bends in the river. The names of all these things went into my notebooks. And slowly some of them began to go into my head. Then more of them. I began to feel better about myself. I was beginning to learn the river.

Then one day Mr. Bixby said to me, "What is the shape of Apple Bend?"

"The shape of Apple Bend?"

"Yes, of course."

"I know the name of Apple Bend. I know where it is. Don't tell me I have to know the shape of it, too!"

Mr. Bixby's mouth went off like a gun, bang! He shot all his bad words at me. Then, as always, he cooled. "My boy," he said, "You must learn the shape of this river and everything on it. If you don't know the shape, you can't steer at night. And of course the river has two shapes. one during the day, and one at night."

"Oh, no!"

"Oh, yes. Look: How can you walk through a room at home in the dark? Because you know the shape of it. You can't see it."

home?"

"You mean I must know this river like the rooms at home."

"No. I mean you must know it better than the rooms at "I want to die."

"My boy, I don't want you to be sad or angry. But there is more."

"All right. Tell me everything. Give it to me!"

"I'm sorry, but you must learn these things. There is no other way. Now, a night with stars throws shadows. Dark shadows change the shape of the river. You think you are coming to a bend, but there is no bend. And this is different from a night with no stars. On a night with no stars, the river has a different shape. You think there are no bends, but there are bends. And of course, on a night with mist, the river has no shape. You think you are going to steer the boat onto the land. But then suddenly you see that it's water, not land. Well. Then you have your moonlight nights. Different kinds of moonlight change the shape of the river again. And there are different kinds of shadows, too. Different shadows bring different shapes to the river. You see--"

"Oh, stop!" I cried. "You mean I have to learn the thousand million different shapes of this river?" 
"No, no! You only learn the shape of the river. The one shape. And you steer by that. Don't you understand? You steer by the river that's in your head. Forget the one that's before your eyes."

"I see. And you think that's easy."

"I never said it was easy. And of course the river is always, always changing shape. The river of this week is different from the river of last week. And next week it will be different again."

"All right. Goodbye. I'm going home."

But of course I didn't go home. I stayed. I wanted to learn. I needed to learn. And day by day, month by month, I did learn. The river was my school. Slowly I began to think I was a good student. I could steer the boat alone, without $\mathrm{Mr}$. Bixby's help. I knew the river like the rooms of my house--no, better. I could steer at night, by the shape of the river in my head. No cub-pilot was better. I thought. Oh, my nose was very high in the air!

of course, Mr. Bixby saw this. And he decided to teach me another lesson.

One beautiful summer's day we were near the bend above Island 66. I had the wheel. We were in the middle of the river. It was easy water, deep and wide.

Mr. Bixby said, "I am going below for a while. Do you know how to run the next bend?"

A strange question! It was perhaps the easiest bend in the river. I knew it well. It began at a little island. The river was wide there, and more than a hundred feet deep. There was no possible danger. closed!"

"Know how to run it? Why, I can run it with my eyes

"How much water is there in it?"

"What kind of question is that? There's more water there than in the Atlantic Ocean."

"You think so, do you?"

He left, and soon I began to worry. There was something in his voice....

I didn't know it, but Mr. Bixby had stayed close to the pilot-house. I couldn't see him, but he was talking to some of the men. Soon a worker came and stood in front of the pilot-house. He looked a little worried. We were near the island at the beginning of the bend. Another man came and stood with the first. He looked worried, too. Then another. They looked at me, then at the water, then at me again. Soon there were fifteen or twenty people out there in front of me. No one said anything. The noise of the engines suddenly seemed loud to me. Bixby?"

Then one of them said in a strange voice, "where is Mr. more.

"Below," I said. The man turned away and said nothing 
Now I became very worried. I steered a little to the right. I thought I saw danger! I steered to the left. More danger! I wanted to go slower. I wanted to stop the engines. I didn't know what I wanted.

In the end I called down to the engine room. "How deep is it here? Can you tell me soon? please be quick!"

"Forty feet," came the voice. He had the answer already! Forty feet! It couldn't be! Why, the water there was as deep as....

"Thirty-five," he said in a worried voice. "Thirtytwo! Twenty-eight!"

I couldn't believe it! I ran to the wheel, pulled a bell, stopped the engines.

Ten!"

"Eighteen!" came the voice. "Fifteen! Thirteen!

Ten feet! I was filled with fear now. I did not know what to do. I called loudly down to the man in the engine room. "Back!" I called. "Please, Ben, back her! Back her! Oh, Ben, if you love me, back her now!"

I heard the door close softly. I looked around, and there stood Mr. Bixby. He smiled a sweet smile at me. Then all the people in front of the pilot-house began to laugh. $I$ understood it all now, and $I$ felt two feet tall. I started the engines again. I steered to the middle of the river without another word. After a while, I said, "That was kind and loving of you, wasn't it? I think I'll hear that story the rest of my life."

"Well, perhaps you will. And that won't be a bad thing. I want you to learn something from this. Didn't you know there was a hundred feet of water at that bend?"

"Yes, I did."

"All right, then. If you know a thing, you must believe it--and deeply. The river is in your head, remember? And another thing. If you get into a dangerous place, don't turn and run. That doesn't help. You must fight fear, always. And on the river there is always fear." It was a good lesson, perhaps his best lesson. And I never forgot it. But I can tell you, it cost a lot to learn it. Every day for weeks and weeks I had to hear those difficult words: "Oh, Ben, if you love me, back her!" 
Note: In this appendix, all occurrences of the test words are underlined throughout the story. The word list below contains the 15 base words from this story, in order by each base word's first appearance in the story, followed by the number of times the word appears in the story. (This information can also be found in Tables XXXIX - XLVI which list all occurrences of all test words for all three stories.) The story copies given to the subjects did not, of course, have this information, nor were the base words underlined throughout the story itself as they have been here. Permission to copy the story was kindly granted by Regents/Prentice Hall.

$\begin{array}{lrlrlr}\text { semi- } & 10 & \text { arena } & 16 & \text { crime } & 2 \\ \text { barbaric } & 11 & \text { bravery } & 2 & \text { tiger } & 9 \\ \text { modern } & 4 & \text { blood } & 4 & \text { princess } & 14 \\ \text { imagination } & 8 & \text { chance } & 2 & \text { jealous } & 4 \\ \text { pleasant } & 3 & \text { accused } & 6 & \text { castle } & 3\end{array}$

\section{The Lady, or the Tiger? \\ adapted from the story by Frank Stockton}

Frank R. Stockton was born in 1834. His most famous stories are in the form of fairy tales, ghost stories, or romances. But in all of them, his humor has an edge like a knife. When "The Lady, or the Tiger?" was published in Century Magazine in 1882, it caused excitement all over the country. Hundreds of people wrote letters to the magazine or to their newspapers about it. Many letters demanded an answer to the question which the story asks. Others asked if the story was really about government, or psychology, or something else. Wisely, stockton never answered any of the letters. The story is as fresh today as it was then. Frank stockton died in 1902 .

A long, long time ago, there was a semi-barbaric king. I call him semi-barbaric because the modern world, with its modern ideas, had softened his barbarism a little. But still, his ideas were large, wild, and free. He had a wonderful imagination. Since he was also a king of the greatest powers, he easily turned the dreams of his imagination into facts. He greatly enjoyed talking to himself about ideas. And, when he and himself agreed upon a thing, the thing was done. He was a very pleasant man when everything in his world moved smoothly. And when something went wrong, he became even more pleasant. Nothing, you see, pleased him more than making wrong things right. 
One of this semi-barbaric king's modern ideas was the idea of a large arena. In this arena, his people could watch both men and animals in acts of bravery.

But even this modern idea was touched by the king's wild imagination. In his arena, the people saw more than soldiers fighting soldiers, or men fighting animals. They enjoyed more than the sight of blood. In the king's arena, the people saw the laws of the country at work. They saw good men lifted up and bad men pushed down. Most important they were able to watch the workings of the first law of Chance.

Here is what happened when a man was accused of a crime. If the king was interested in the crime, then the people were told to come to the arena. They came together and sat there, thousands of them. The king sat high up in his king's chair. When he gave a sign, a door below him opened. The accused man stepped out into the arena. Across from the accused man, on the other side of the arena, were two other doors. They were close together and they looked the same. The accused man would walk straight to these doors and open one of them. He could choose either one of the doors. He was forced by nothing and led by no one. Only Chance helped him or didn't help him.

Behind one of the doors was a tiger. It was the wildest, biggest, hungriest tiger that could be found. Of course, it quickly jumped on the man. The man quickly--or not so quickly--died. After he died, sad bells rang, women cried, and the thousands of people walked home slowly.

But, if the accused man opened the other door, a lady would step out. She was the finest and most beautiful lady that could be found. At that moment, there in the arena, she would be married to the man. It didn't matter if the man was already married. It didn't matter if he was in love with another woman. The king did not let little things like that get in the way of his imagination. No, the two were married there in front of the king. There was music and dancing. Then happy bells rang, women cried, and the thousands of people walked home singing.

This was the way the law worked in the king's semibarbaric country. Its fairness is clear. The criminal could not know which door the lady was behind. He opened either door as he wanted. At the moment he opened the door, he did not know if he was going to be eaten or married.

The people of the country thought the law was a good one. They went to the arena with great interest. They never knew if they would see a bloody killing or a lovely marriage. This uncertainty gave the day its fine and unusual taste. And they liked the fairness of the law. Wasn't it true that the accused man held his life in his own hands?

This semi-barbaric king had a daughter. The princess was as beautiful as any flower in the king's imagination. 
She had a mind as wild and free as the king's. She had a heart like a volcano. The king loved her deeply, watched her closely, and was very jealous of her. But he could not always watch her. And in his castle lived a young man. This young man was a worker. He was a good worker, but he was of low birth. He was brave and beautiful, and the princess loved him, and was jealous of him. Because of the girl's semi-barbarism, her love was hot and strong. of course, the young man quickly returned it. The two lovers were happy together for many months. But one day the king discovered their love. Of course he did not lose a minute. He threw the young man into prison and named a day for his appearance in the arena.

There had never been a day as important as that one. The country was searched for the strongest, biggest, most dangerous tiger. With equal care, the country was searched for the finest and most beautiful young woman. There was no question, of course, that the young man had loved the princess. He knew it, she knew it, the king knew it, and everybody else knew it, too. But the king didn't let this stand in the way of his excellent law. Also, the king knew that the young man would now disappear from his daughter's life. He would disappear with the other beautiful lady. Or he would disappear into the hungry tiger. The only question was, "Which?"

And so the day arrived. Thousands and thousands of people came to the arena. The king was in his place, across from those two doors that seemed alike but were truly very different.

All was ready. The sign was given. The door below the king opened, and the lover of the princess walked into the arena. Tall, beautiful, fair, he seemed like a prince. The people had not known that such a fine young man had lived among them. Was it any wonder that the princess had loved him?

The young man came forward into the arena, and then turned toward the king's chair. But his eyes were not on the king. They were on the princess, who sat to her father's right. Perhaps it was wrong for the young lady to be there. But remember that she was still semi-barbaric. Her wild heart would not let her be away from her lover on this day. More important, she now knew the secret of the doors. Over the past few

days, she had used all of her power in the castle, and much of her gold. She had discovered which door hid the tiger, and which door hid the lady.

She knew more than this. She knew the lady. It was one of the fairest and loveliest ladies in the castle. In fact, this lady was more than fair and lovely. She was thoughtful, kind, loving, full of laughter, and quick of mind. The princess hated her. She had seen, or imagined she had seen, the lady looking at the young man. She 
thought these looks had been noticed and even returned. once or twice she had seen them talking together. Perhaps they had talked for only a moment. Perhaps they had talked of nothing important. But how could the princess be sure of that? The other girl was lovely and kind, yes. But she had lifted her eyes to the lover of the princess. And so, in her semi-barbaric heart, the princess was jealous, and hated her.

Now, in the arena, her lover turned and looked at her. His eyes met hers, and he saw at once that she knew the secret of the doors. He had been sure that she would know it. He understood her heart. He had known that she would try to learn this thing which no one else knew--not even the king. He had known she would try. And now, as he looked at her, he saw that she had succeeded.

At that moment, his quick and worried look asked the question: "Which?" This question in his eyes was as clear to the princess as spoken words. There was no time to lose. The question had been asked in a second. It must be answered in a second.

Her right arm rested on the arm of her chair. She lifted her hand and made a quick movement towards the right. No one saw except her lover. Every eye except his was on the man in the arena.

He turned and walked quickly across the empty space. Every heart stopped beating. Every breath was held. Every eye was fixed upon that man. Without stopping for even a second, he went to the door on the right and opened it.

Now, the question is this: Did the tiger come out of that door, or did the lady?

As we think deeply about this question, it becomes harder and harder to answer. We must know the heart of the animal called man. And the heart is difficult to know. Think of it, dear reader, and remember that the decision is not yours. The decision belongs to that hot-blooded, semibarbaric princess. Her heart was at a white heat beneath the fires of jealousy and painful sadness. She had lost him, but who should have him?

Very often, in her thoughts and in her dreams, she had cried out in fear. She had imagined her lover as he opened the door to the hungry tiger.

And even more often she had seen him at the other door! she had bitten her tongue and pulled her hair. she had hated his happiness when he opened the door to the lady. Her heart burned with pain and hatred when she imagined the scene: He goes quickly to meet the woman. He leads her into the arena. His eyes shine with new life. The happy bells ring wildly. The two of them are married before her eyes. Children run around them and throw flowers. There is music, and the thousands of people dance in the streets. And the princess's cry of sadness is lost in the sounds of happiness! 
Wouldn't it be better for him to die at once? Couldn't he wait for her in the beautiful land of the semi-barbaric future?

But the tiger, those cries of pain, that blood!

Her decision had been shown in a second. But it had been made after days and nights of deep and painful thought. she had known she would be asked. She had decided what to answer. She had moved her hand to the right.

The question of her decision is not an easy one to think about. Certainly I am not the one person who should have to answer it. So I leave it with all of you: Which came out of the opened door--the lady, or the tiger? 
Note: In this appendix, all occurrences of the test words are underlined throughout the story. The word list below contains the 15 base words from this story, in order by each base word's first appearance in the story, followed by the number of times the word appears in the story. (This information can also be found in Tables XXXIX - XLVI which list all occurrences of all test words for all three stories.) The story copies given to the subjects did not, of course, have this information, nor were the base words underlined throughout the story itself as they have been here. Permission to copy the story was kindly granted by Regents/Prentice Hall.

$\begin{array}{lrllll}\text { rope } & 12 & \text { silence } & 6 & \text { float } & 4 \\ \text { neck } & 12 & \text { respect } & 3 & \text { escape } & 3 \\ \text { wood } & 8 & \text { hang } & 8 & \text { bullet } & 3 \\ \text { guard } & 4 & \text { condemned } & 4 & \text { conscious } & 5 \\ \text { bank } & 7 & \text { board } & 4 & \text { current } & 3\end{array}$

\title{
An Occurrence at Owl Creek Bridge
}

\author{
adapted from the story by
}

Ambrose Bierce

Ambrose Bierce was born in the state of ohio in 1842 . He went to school, a military academy, for just one year. In 1864, during the American Civil war between the North and the South, Bierce joined the Army. After the war he went to California. He wrote political pieces for newspapers. His first short story was published in 1871. That same year he married and went to live in London. After five years in London he returned to the United states. He worked for the Hearst Newspaper Company on the West coast. He went to Mexico to write about the Mexican war in 1914, where he disappeared in the fighting. "An Occurrence at Owl Creek Bridge" appeared in a collection of short stories called Tales of Soldiers and Civilians in 1891. A second collection, Can Such Things Be?, was published in 1893.

A man stood upon a railroad bridge in northern Alabama. He looked down into the river below. The man's hands were tied behind his back. A rope circled his neck. The end of the long rope was tied to part of the wooden bridge above his head.

Next to the man stood two soldiers of the Northern army. A short distance away stood their captain. Two soldiers guarded each end of the bridge. On one bank of the 
river, other soldiers stood silently, facing the bridge. The two guards at each end of the bridge faced the banks of the river. None of the soldiers moved. The captain, too, stood silent. He watched the work of the two soldiers near him, but he made no sign. All of them were waiting silently for Death. Death is a visitor who must be met with respect. Even soldiers, who see so much death, must show respect to Death. And in the army, silence and stillness are signs of respect.

The man with the rope around his neck was going to be hanged. He was about thirty-five years old. He was not dressed like a soldier. He wore a well-fitting coat. His face was a fine one. He had a straight nose, strong mouth, and dark hair. His large eyes were grey, and looked kind. He did not seem like the sort of man to be hanged. clearly he was not the usual sort of criminal. But the Army has laws for hanging many kinds of people. And gentlemen are not excused from hanging.

When the two soldiers were ready, they stepped away. The captain faced the condemned man. They stood face to face on a piece of wood. The middle of the board rested against the edge of the bridge. When the captain stepped off the board, the piece of wood would fall down into the river. The condemned man would fall down after the board. only the rope around his neck would stop him. He would be hanged by the neck until dead. The man's face had not been covered. His eyes were open. He looked down at the river below. He saw a small piece of wood floating along with the river. How slowly it moved! what a gentle river!

He closed his eyes and thought of his wife and children. Until now, other things had filled his mind: the water, painted gold by the sun . . . the soldiers . . . the floating wood. After a little while he heard a new sound. A strange metallic sound kept beating through the thoughts of his family. He wondered what it was. It sounded far away, and yet very close. It was as slow as a death-bell ringing. The sound came louder and louder. It seemed to cut into his brain like a knife. He was afraid he would cry out. But it was only his own watch making its little sound. He opened his eyes. He saw again the water below him. "If I could free my hands," he thought, "I might throw off the rope. I could jump into the river. If I swam quickly underwater, I could escape the bullets. I would reach the river bank, run into the woods and go home. My home, thank God, is still safe from the Northern Army." These thoughts must be written in words here. But they passed as quickly as light through the condemned man's mind. And then the captain stepped off the board. 
The condemned man's name was Peyton Farquhar. He was a rich farmer, the last son in an old Alabama family. He owned slaves who worked on his farm. Like other Southern farmers, he believed that slaves were necessary to Southern farming. The Northern government had said that it was against the law to have slaves. Now, the North and the South were at war.

Certain work had kept Peyton Farquhar from joining the Southern Army at the beginning of the war. But he was at heart a soldier. He did everything he could to help the South. No job was too low, no adventure too dangerous. One evening, Farquhar and his wife were sitting in the garden. A soldier rode up to the house. He was dressed like other soldiers in the Southern Army. While Mrs. Farquhar went to get him a drink of water, the soldier spoke with Farquhar.

"The Northerners are rebuilding the railroads," the soldier said. "They are getting ready for another advance. They've reached Owl Creek Bridge. They've fixed the bridge and moved in a lot of soldiers. Anyone who attacks the railroad or tries to destroy the bridge will be hanged."

"How far is it to Owl Creek Bridge?" Farquhar asked.

"About thirty miles."

"Are there soldiers on this side of the bridge?"

"Only a few guards."

"Suppose that a man went around the guards?" Farquhar smiled. "What could he do to stop the advance?"

The soldier thought a moment. Then he said, "I was at the bridge a month ago. I saw a lot of wood that the river had washed against one end of the bridge. It's very dry now, and the wood would burn quickly and well."

The lady had now brought the water. The soldier drank. He thanked her, bowed to Farquhar, and rode away. An hour later, after nightfall, he passed Farquhar's farm again. He went North in the direction he had come from. He was a Northern soldier.

\section{III}

Peyton Farquhar fell down from the bridge. He lost consciousness. He was like one already dead. He was awakened--hours later, it seemed to him--by the great pain in his neck. Pain passed through his body like rivers of fire. He was conscious of a fullness in his head. He could not think. He could only feel. He was conscious of motion. He seemed to be falling through a red cloud. Then suddenly the light flew upward with the noise of a loud splash. A fearful noise was in his ears. All was cold and dark. The power of thought came back to him. He knew the rope had broken, and he had fallen into the river. The rope around his neck was cutting off the air. To die of hanging at the bottom of a river! No! Impossible! He opened his eyes in 
the darkness. He saw light far, far above him. He was still going down, for the light grew smaller and smaller. But then it grew brighter, and he knew he was coming back up to the top of the river. Now he felt sorry to be coming out of the water. He had been so comfortable. "To be hanged and drowned," he thought. "That is not so bad. But I do not want to be shot. No, I will not be shot. That's not fair!"

He was not conscious of his actions until he felt pain in his hands. Then he realized that he was trying to free his hands. At last the rope fell off. His arms floated upward; he could see his hands. He watched with interest. His hands were trying to untie the rope around his neck. They pulled off the rope and it floated away. "Put it back, put it back," he felt himself crying. His neck hurt badly. His mind was on fire, his heart beat wildly enough to leave his body. His whole body was in great pain. But his hands pushed him up out of the water. And he took a great breath of air.

Now he was fully conscious. His five senses seemed unusually clear. The pain his body had felt made him see and feel the beauty around him. He felt the water against his skin. He heard the soft sound as it hit his neck and shoulders. He looked into the forest on the bank and could see each tree, each leaf. He could even see small forest animals between the trees. A fish swam before his eyes. He noticed how the sunlight shone on the fish's silver skin.

He was facing away from the bridge when his head came out of the water. Now he turned around. He saw small men on the bridge, dark against the blue sky. They cried out and pointed at him. The captain took out his gun but did not shoot.

Then, suddenly, he heard a loud bang. Something hit the water near his head. Water splashed in his face. He heard a second shot and a light blue cloud rose from the gun. Then Farquhar heard the captain call to the men: "Ready, men . . . Shoot!"

Farquhar swam deep under the water. The water sounded loud in his ears. But even above the sound of the water he heard the shots. He swam down the river.

Later he swam to the top again. He saw he was quite far from the bridge. The soldiers were still pointing their guns at him.

"The captain will not order them to shoot together again," he thought. "It's as easy to escape many bullets as one. He'll order them to shoot as they wish. God help me, I cannot escape them all."

suddenly he was caught by a strong current in the river. The current pulled him under the water. It carried him down the river and turned him over and over. At last the force of the current pushed him up onto the bank. 
He lay on the bank, crying with happiness and tiredness. He dug his fingers into the river bank. The small stones felt like jewels. The trees looked to him like a forest of gold. The air smelled clear and sweet, and a pink light shone through the trees.

The sound of bullets in the trees awoke him. He rose to his feet, frightened again, and disappeared into the forest.

All that day he traveled. The forest seemed endless. He could find no road. He hadn't realized before now that he lived near such a wild place.

When night began to fall, he was very tired and hungry. The thought of his wife and children helped him to continue. At last he found a road that seemed to lead in the right direction. It was as wide and straight as a city street. But it seemed untraveled. There were no fields, no houses nearby. The big black trees formed a straight wall on both sides. Overhead, great golden stars shone in the sky. The stars looked unfamiliar. He was sure that they were grouped in some strange order which meant bad luck. From inside the forest came strange noises. Among them he heard people talking in an unknown language.

His neck was in pain. He knew that the rope had left a black circle on his skin. He could not close his eyes. His tongue was dry; he felt very thirsty. Grass seemed to cover the road now; it was soft under his feet.

Did he fall asleep while he was walking? Now he sees something else. Perhaps he was wakened from a dream. Now he stands not far from the door of his own house. Everything looks just as he left it, bright and beautiful in the morning sunshine. He must have traveled through the whole night. As he walks toward the door, his wife appears to meet him. She stands waiting, soft and sweet, silent and still. She holds out her arms to him with a smile of happiness. Ah! how beautiful she is! He moves toward her with open arms. He moves slowly, closer, closer. At the moment he touches her, he feels a great pain at the back of his neck. A white light flames all about him... darkness...

There was a loud bang, then silence. All was

Peyton Farquhar was dead. His body, with a broken neck, hung from a rope beneath Owl Creek Bridge. 
APPENDIX B

DIRECTIONS FOR ADMINISTERING THE PRE-TEST 


\section{Directions for administering the pre-test:}

1. Have the students close their notebooks, put away any papers they have out, and put away their dictionaries.

2. Write the following on the board:

$\begin{array}{lll}\text { mother } & \text { YES } & \text { NO } \\ \text { once } & \text { YES } & \text { NO } \\ \text { quilt } & \text { YES } & \text { NO }\end{array}$

3. Read the following to the students:

"Before we begin our classes, I would like you to answer some questions for me. On these two pages [show the two pages of the pre-test to the students] you will see many, many words. This is not a test. It's a questionnaire. You will not get a score or a grade on this. There are no right answers and there are no wrong answers. There is only YES or NO. Beside every word is YES and NO [point to the YES and NO columns on the pre-test]. This is the question: 'Have you seen these words before?' For every word, you must ask, 'Have I seen this word before?' If the answer is, 'Yes,' then circle YEs. If the answer is, 'No,' then circle No. You must not use your dictionary. You must not talk to another student. I just want to know, have you seen these words before."

4. Hand out the pre-tests. Have the students write their full names at the tops of their papers. Read and explain the directions from the pre-test:

"Have you seen these words before?

"This is not a test. You will not get a score or a grade. There are no correct or incorrect answers. I just want to know if you think you have seen these words before or not.

If you think:

then circle:

'Yes, 100\%, I know I have seen that word before.'

'Yes, I am sure I have seen that word before.'

'Maybe yes, I have seen that word before.'

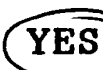

NO

YES

NO

YES

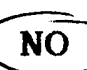


'Maybe no, I have not seen

that word before.'
'No, I have not seen that
word before.'

YES

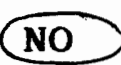

"[Point out the words on the board.] For example, if you see 'mother,' you must ask, 'Have I seen this word before?' You will think, 'Yes, 100\%, I know I have seen that word before. Yes, I am sure!' If you are sure, then you will circle YEs. [Circle YES after 'mother' on the board.]

"Another example: If you see 'once,' you must ask, 'Have I seen this word before?' If you think, 'Maybe yes, I have seen that word before,' then circle No. And if you think, 'Maybe no, I have not seen that word before,' then circle No. So, if you are not sure yes or no, then circle No. [Circle NO after 'once' on the board.]

"Another example: If you see 'quilt,' you must ask, 'Have I seen this word before?' Probably you have never seen this word before. If you think, 'No, I have not seen that word before,' then circle No. If you are sure, then you will circle No. [Circle No after 'quilt' on the board.]

"So, if you are sure, 'Yes, I know that word,' circle YES.

"If you think, Maybe, yes. Maybe I do know that word,' circle NO.

"If you think, 'Maybe, no. Maybe I don't know that word,' circle No.

"And if you think, 'No, I don't know that word,' circle No.

"If you have many No answers -- no, no, no, no, no -- that is good. NO is a good answer. If you have many YES answers -- yes, yes, yes -- that is good, too. YEs is a good answer, too. Many No, many YES -- both are good answers! If you have more NO answers than YES answers, that is o.k.! Remember, no score and no grade on this."

5. Ask the students if they know what they should do. If they do, have them begin. If not, repeat the appropriate part of the directions. Just before they start, reemphasize: 
"Please do not use your dictionary. Please do not talk to your classmates."

6. Have the students begin. Monitor their progress, but not so closely that they feel nervous. Make sure there are no notebooks, papers, dictionaries, or other books out, and that students are not helping each other or copying from each other.

7. As students finish, collect their pre-tests and give them in exchange a word-find, crossword puzzle, blank U.S. map, or other quiet written exercise unrelated to the words on the pre-test. Give students as much time as needed to complete all the items (usually 15 20 minutes).

8. As students finish, check to make sure that they have answered every item and written their full names at the top.

9. If for some reason a student misunderstands the directions and suddenly discovers that fact after finishing some or all of the pre-test, simply give that student a fresh copy and have the student do it again, in the hallway, if necessary, all the while stressing that it's "no problem, not to worry." Keep both pretests with "second try" noted on the second one. If the reason for the confusion is apparent, note that, too.

10. Thank the students for their cooperation and hard work. 
APPENDIX C

PRE-TEST 
Concordia College Summer Study

Name:

Have you seen these words before?

This is not a test. You will not get a score or a grade. There are no correct or incorrect answers. I just want to know if you think you have seen these words before or not.

If you think:

"Yes, 1008, I know I have seen that word before."

then circle:

"Yes, I am sure I have seen that word before."

"Maybe yes, I have seen that word before."

"Maybe no, I have not seen that word before."

"No, I have not seen that word before."

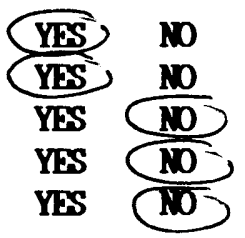

Please do not use your dictionary. Please do not talk to your classmates.

1. again

[CPE, 24.] 2. 0001

3. am

4. sing

5. school

[CPE, 3.] 6. bend

7. army

8. seeds

[OCB, 6.] 9. wood

[LOT, 40.] 10. semi-

11. island

12. nail

13. forest

[OCB, 22.] 14. silent

[CPE, 45.] 15. shape

[OCB, 33.] 16. respect

[CPE, 42.] 17. engine
YES NO

YES NO

YFS NO

YES NO

YES No

YES NO

YFS NO

YES NO

YFS NO

YES NO

YES NO

YES NO

YES

no

YES NO

YES NO

YES NO

YES NO
[LOT, 20.] 31. accused

[OCB, 38.] 18. rope

19. soon

20. married

21. juxtapose

[CPE, 15.] 22. steamboat

[LOT, 25.] 23. bravery

[CPE, 29.] 24. point

25. shock

26. decision

27. interference

[OCB, 31.] 28. bank

29. volunteer

30. reason

32. square

33. else

34. has
YES NO

YES NO

YES NO

YES NO

YES NO

YES No

YES NO

YES NO

YES NO

YES NO

YES NO

YES NO

YES NO

YES NO

YES NO

YES NO

YES NO 
35. young

[LOT, 32.] 36. crime

[OCB, 2.] 37. neck

[CPE, 12.] 38. voice

39. tone

40. hurtle

41. card

42. angry

43. finest

[LOT, 19.] 44. modern

45. $\tan$

[LOT, 41.] 46. chance

[LOT, 23.] 47. blood

48. unit

[CPE, 37.] 49. landing

50. bridge

[CPE, 14.] 51. mist

52. secret

53. captain

[LOT, 43.] 54. tiger

55. yell

56. scale

[OCB, 10.] 57. bullets

58. rake

[OCB, 26.] 59. conscious

[OCB, 17.] 60. escape
YES NO

YES M

YES ND

YES NO

YES No

YES NO

YES NO

YES NO

YES NO

YES NO

YES NO

YES NO

YES NO

YES NO

$[O C B, 34$.$] 74. board$

YES NO

[CPE, 30.] 75. steer

76. lovely

YES No [OCB, 35.] 77. hang

YES NO

[LOT, 4.] 78. imagine

YES NO

YES

No

[CPE, 5.] 79. wheel

80. my

[CPE, 44.] 81. pilot

[CPE, 27.] 82. lesson

83. wrong

[CPE, 39.] 84. shadows

85. idea

86. loud

YES

No

YES NO

YES No

YES NO

YES NO

YES NO

YES No

YES No

YES $\mathbf{N}$

YES No

YES NO

YES NO

YES N

YES NO

YES NO

YES NO

YES NO

YES NO

YES NO

YES NO

YES NO

YES NO

YES NO

YES NO

YES NO

YES No

YES NO

YES No 


$\begin{array}{cccccc}\text { [OCB, 28.] 87. current } & \text { YES } & \text { NO } & \text { [LT, 1.] 94. princess } & \text { YES } & \text { No } \\ \text { [LOT, 16.] 88. arena } & \text { YES } & \text { No } & 95 . \text { game } & \text { YES } & \text { No } \\ \text { 89. large } & \text { YES } & \text { No } & 96 . \text { live } & \text { YES } & \text { No } \\ \text { [OCB, 36.] 90. conderned } & \text { YES } & \text { No } & 97 . \text { color } & \text { YES } & \text { No } \\ \text { 91. quality } & \text { YES } & \text { No } & 98 . \text { against } & \text { YES } & \text { No } \\ \text { [LOT, 18.] 92. barbaric } & \text { YES } & \text { No } & 99 . \text { care } & \text { YES } & \text { No } \\ \text { 93. faced } & \text { YES } & \text { No } & 100 . \text { road } & \text { YES } & \text { No }\end{array}$

[Note: (1) This version of the pre-test shows which 45 of the 100 pre-test itens are actually the target words. Preceding each target word is the story from which the word came, and the corresponding item number in the post-test for that word, both in brackets. This information did not of course appear on the actual pre-test given to the subjects. (2) The original version of the pre-test was printed in 12 point (10 cpi) type on only two pages. The type size here is 8 point $(15 \mathrm{cpi})$, much smaller than on the version given to the students. The use of smaller type and an additional page was necessary in preserving the form of the original colums while at the same time staying within the wider margins required herein.] 
APPENDIX D

WORD FORM CHARTS/DEFINITIONS AND EXAMPLE SENTENCES PAGES 
[Word Form Chart/Definitions and Example Sentences for

"A Cub-Pilot's Education":]

Concordia College summer study

Name:

Let's learn some vocabulary!

NO DICTIONARIES!!!

Word Form Chart:

NOUN

bend

engine

landing

lesson

mist

pilot

point

shadow

shape

steamboat

-..--

village

voice

wheel
VERB

cool

----

-.--

pilot

pilot

-..--

-.--

-...-

steer

-.---

--..-
ADJECTIVE

cool (er)

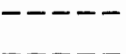

-...-

-.--

-..--

-.--

-...-

-.-.-

-.-.-

…‥

-...-

-..--

\section{Definitions and Example Sentences:}

1. bend [1. noun: a curve, or a change in direction] 1a. We could not see around the bend in the road.

1b. The slow, quiet river had many bends in it.

2. cool [1. verb: to become less angry; 2. adj: (when someone has become) less angry]

1. I was very angry, but after a few minutes $I$ cooled a little.

2. My brother was angry with me, but I said that I was sorry, and this made him cooler.

3. engine [1. noun: the machine that makes a car, airplane, boat, train, etc., move]

1a. Her car has a big engine and can go very fast. 
1b. On large jet airplanes, the engines are under the wings.

4. landing [1. noun: a place along a river or lake for boats to stop at]

1a. The boat came over to the landing so that the passengers could get of $f$.

1b. There were many boat landings along the side of the lake.

5. lesson [1. noun: a. information that a teacher gives to students; b. important ideas that a person learns about life]

1a. Our professor gave an interesting lesson on American history yesterday.

1b. I learned an important lesson from the car accident: Always wear your seatbelt.

6. mist [1. noun: fog, a cloud near the ground, or small pieces of water in the air near the ground, sometimes making it difficult to see]

1a. The airplane cannot leave; there is too much mist at the airport.

1b. A: Can you see the town down in the valley? B: No, I can't. There's too much mist down there.

7. pilot [1. noun: the driver of a boat or airplane; 2 . verb: to drive a boat or airplane]

1. My brother is an airplane pilot.

2. My sister pilots a small boat in the Navy.

8. point [1. noun: a sharp piece of land going out into a river, a lake, or the ocean]

1a. The man stood on the end of the point and caught many fish from the lake.

1b. The government built a large warning light on the point to warn the ships in the ocean of the dangerous rocks nearby.

9. shadow [1. noun: a cool, dark place on the ground, made by something stopping the sunlight]

1a. The big tree made a big shadow on the ground.

1b. The tall building made a long shadow over the children's playground.

10. shape [1. noun: the form or outline of something]

1a. My boyfriend made a cake for me. He made the cake in the shape of a heart and put red sugar on the outside.

1b. His kitchen is in the shape of an " $\mathrm{L}$ ". 
11. steamboat [1. noun: a large boat that moves by steam, usually used on big, slow rivers, very popular in America in the $1800^{\prime} \mathrm{s}$ ]

1a. In 1807, an American named Robert Fulton made the first steamboat.

1b. Now, there are only a few steamboats left; most of them are used only as restaurants or hotels.

12. steer [1. verb: to guide, direct, or move a car, boat, airplane, etc., so that it goes where the driver wants it to go]

1a. Be careful! steer the car away from the other cars!

1b. If there is ice or water on the street, it can be difficult to steer your car.

13. village [1. noun: a very small town]

1a. She lives in a village of only 200 people.

1b. The farmer sold his vegetables in the village.

14. voice [1. noun: the sound people make when they talk]

1a. Should a teacher have a loud voice or a quiet voice?

1b. When everyone was talking, the room was full of the sound of many voices.

15. wheel [1. noun: a. the circular part of a car, truck, bicycle, etc., that moves along the ground; $b$. the circular part of a car, boat, etc., that the driver turns to make the car, boat, etc., turn]

1a. Some very large trucks have 18 wheels.

1b. When you are driving a car, you should put your hands at "10:00 0'clock" and "2:00 $\mathrm{o}^{\prime}$ clock" on the wheel. 
[Word Form Chart/Definitions and Example Sentences for

"The Lady, or the Tiger?":]

Concordia College Summer study Name:

Let's learn some vocabulary!

NO DICTIONARIES!!!

Word Form Chart:

NOUN

arena

barbarism

blood

bravery

castle

chance

crime

imagination

jealousy

-...-

-

prince (ss)

semi- [prefix]

tiger
VERB

accuse

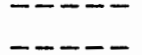

-..-

-....

-....-

-...-

-...-

imagine

-..--

please (d)

-...-

-...-
ADJECTIVE

accused

barbaric

bloody

brave

-...-

-...-

-.--

jealous

modern

pleasant

-...--

semi- [prefix]

\section{Definitions and Example Sentences:}

1. accuse [1. verb: to say that a person did something wrong or bad; 2 . adj.: (a person) who did something wrong or bad]

1. The police accused the man of taking the money.

2. The accused man was taken to jail.

2. arena [1. noun: a large building where thousands of people can sit and watch other people play sports]

1a. Thousands of people went to the arena to watch the baseball game.

1b. Many sports, such as basketball, boxing, football, and soccer, can be played in an arena. 
3. barbarism [1. noun: being wild, not highly developed, not civilized; 2. adj.: (a person) who is wild, not civilized]

1. Barbarism is unusual now; most people in the world are civilized.

2. The wild, barbaric people lived under the trees in a forest.

4. blood [1. noun: the red liquid inside the body of a person or animal; 2. adj.: with blood on it]

1. If you cut your finger with a knife, blood will come out.

2. The little boy fell down and hit his face on the floor; he got a bloody nose.

5. bravery [1. noun: (when a person) has no fear; 2 . adj.: having no fear]

1. It is important for soldiers to have bravery.

2. The brave fireman carried the baby out of the burning building.

6. castle [1. noun: the big stone house where a king and queen live]

1a. The king and queen had a big party in their castle; hundreds of people went to the party.

1b. That old castle has more than 100 rooms in it.

7. chance (sometimes Chance) [1. noun: a. something that happens without planning it; b. something you do but you cannot know the end of it; c. luck]

1a. I did not know that I would meet Joe at the baseball game; I did not plan to meet him there; however, by chance I met Joe at the baseball game.

1b. She did not know the winning number, but by chance, she picked the winning number.

1c. "I hope that Chance will be good to me," said the gambler.

8. crime [1. noun: bad things that people do, for example, killing another person, taking money from another person, etc.]

1a. Crime is a big problem in some American cities.

1b. If you do a crime, the police might find you and put you in jail.

9. imagination [1. noun: the ability to see a picture in your head; 2. verb: to see a picture in your head]

1. A writer needs a lot of imagination to write good stories. 
2. When I am afraid, I often imagine things that are not true.

10. jealous [1. noun: a feeling of envy toward someone; 2 . adj.: a. when you want something that someone else has, but that you do not have; $b$. when you want to have someone all to yourself]

1. I was filled with jealousy when my sister got better grades than I got.

2a. My uncle was jealous when he heard that my father got a new car.

$2 b$. Judy was very jealous of her boyfriend--she didn't want him to talk to other girls, or sit next to other girls, or even look at other girls.

11. modern [1. adj.: a. new, not old-fashioned; b. of the present time]

1a. Most modern cars are smaller than cars of fifty years ago.

1b. A: Do you like modern art?

B: No, I prefer classical artists, such as Michelangelo and da Vinci.

12. please (often past tense: pleased) / pleasant [ 1 . verb: (to make someone) feel good, happy; 2 . adj.: good, nice]

1. I pleased my teacher when I came to class early.

2. A: I like Maria. She's a pleasant person. B: Yes. She's very nice. She's always smiling and friendly.

13. prince [1. noun: the son of a king and queen] princess [2. noun: the daughter of a king and queen]

1. The prince will become the new king when the old king is dead.

2. A king can have many daughters; all the daughters of the king are princesses, but there is only one king and queen.

14. semi- (prefix) [1. can be used with a noun (a.), meaning: half; or with an adj. (b.), meaning: partly] 1a. We put our chairs in a semi-circle on one side of the room.

1b. Tropical weather is usually very hot and very rainy all year. The weather in Hawaii is not completely tropical; it is only semi-tropical weather. 
15. tiger [1. noun: an animal that looks like a very big cat, has orange hair with black stripes, and lives in Asia]

1a. When a tiger is hungry or angry, it can be very dangerous.

1b. When I go to the zoo, I like to watch the tigers running and jumping. 
[Word Form Chart/Definitions and Example Sentences for "An Occurrence at Owl Creek Bridge":]

Concordia College Summer study

Name:

Let's learn some vocabulary!

NO DICTIONARIES!!!

\section{Word Form Chart:}

\begin{tabular}{|c|c|c|c|}
\hline NOUN & VERB & ADJECTIVE & ADVERB \\
\hline bank & ----- & ---- & $\cdots-\cdots$ \\
\hline board & ----- & ---- & ---- \\
\hline bullet & ----- & ----- & ---- \\
\hline---- & [condemn] & condemned & ----- \\
\hline consciousness & ---- & conscious & ----- \\
\hline current & ----- & ----- & ---- \\
\hline---- & escape & ----- & ----- \\
\hline$----\cdots$ & float & ----- & ----- \\
\hline guard & guard & ---- & ----- \\
\hline hanging & hang (ed) & ---- & $-\cdots--$ \\
\hline neck & ---- & $---\cdots$ & ----- \\
\hline respect & [respect] & $-\cdots$ & ----- \\
\hline rope & ---- & ----- & ----- \\
\hline silence & ---- & silent & silently \\
\hline wood $(s)$ & $-\cdots-\cdots$ & wooden & ----- \\
\hline
\end{tabular}

\section{Definitions \& Example Sentences:}

1. bank [1. noun: the land along the sides of a river]

1a. The fisherman stood on the river bank, and tried to catch fish.

1b. The boy slipped down the bank and fell into the river.

2. board [1. noun: a flat piece of material from a tree]

1a. The little bridge was made of boards.

1b. We bought some boards to make into a table.

3. bullet [1. noun: the small piece of metal that is shot from a gun]

1a. The police found a bullet near the dead man.

1b. Some people use guns and bullets to kill animals in the forest. 
4. condemned [1. verb: to order that someone be punished; 2. adj.: (a person) who will be punished]

1. The bad man was condemned to die.

2. The condemned man will go to jail for ten years.

5. consciousness [ 1 . noun: being awake]

conscious [2. adj: awake; understanding, knowing]

1. A: What happened to that woman?

B: She was just in a car accident. I think she has lost consciousness.

2. The doctor gave the man some pain medicine. The man was still conscious, but he could not feel any pain.

6. current [1. noun: a strong or fast moving of water in a river or in the ocean]

1a. strong water currents can be difficult to swim in.

1b. The Japan current is a current in the Pacific Ocean.

7. escape [1. verb: to get away from a place where you do not want to be]

1a. Yesterday, a man escaped from jail; I don't know how he got out.

1b. Many people want to escape from the city on the weekends. They do not want to be in the city; they want to go to the seaside or to the mountains.

8. float [1. verb: to stay on top of water]

1a. Ducks and other birds can float on water.

1b. A boat floats on the sea.

9. guard [1. noun: someone who watches carefully and keeps other people safe; 2. verb: to watch carefully and keep other people safe]

1. The guards carefully watched the bank.

2 . The police guarded the president.

10. hang [1. noun: the act of when a person is hanged (see verb form); 2 . verb: to execute or kill by putting a rope around a person's neck and dropping the person down into the air]

1. Hanging can be a slow, painful way to die.

2. Many years ago, criminals were of ten hanged.

11. neck [1. noun: the part of the body between the head and the shoulders]

1. The queen had a string of beautiful diamonds around her neck. 
2. I studied too long today; now my neck hurts!

12. respect [1. noun: the feeling that a person or a thing is important; 2 . verb: the action of showing that a person or a thing is important]

1. A: I don't have any respect for that man. B Oh, but you should! He's a very famous doctor.

2. We should always respect older people.

13. rope [1. noun: a long, strong, thick cord, like a thick string, sometimes used to tie things]

1a. Rope is thicker and stronger than string.

1b. The bad man tied a rope to his bed, put the rope out the window, climbed down the rope, and ran away from the jail.

14. silence [1. noun: no sounds, quiet]

silent [2, adj.: not making sounds, being quiet]

silently [3, adv.: (doing something) with no sounds]

1. There should always be silence in a library.

2. The teacher told the students to be silent during the test.

3. The cat walked silently up to the mouse.

15. wood [1. noun: a. material from trees, used to make houses, furniture, etc.; b. a small forest]

1a. Many houses in the United States are made of wood.

1b. The little children were frightened when they got lost in the dark woods. 
APPENDIX E

EXERCISES 
[Exercises for "A Cub-Pilot's Education":]

Concordia College Summer Study

Name:

Vocabulary Exercises

No dictionaries! Please write with a pen.

\section{Exercises :}

1. Match each word with its definition. On the line, write the letter of the correct word. The first one is an example.
A. bend
B. lesson
1. a small town
C. wheel
2. someone who steers a boat or airplane
D. village
3. dark area on the ground
E. pilot
4. important idea about life
F. engine
5. a curve or turn
G. steamboat
6. large, old-fashioned boat
H. shadow
7. for boats to stop at
J. landing
8. machine that makes something move
9. you hold this when you steer a car

2. Write words on the blanks in the sentences. Use the words from the word list (you will use only 8 of the 15 words). Use a word only once. Sometimes, you might have to change the word a little to make it work in the sentence (for example, shadow $->$ shadows, or pilot $->$ piloting). Sometimes, you do not have to change the word. The first one is an example.

1. A square, a circle, and a triangle are examples of different shapes.

2. Sometimes on cold mornings, there is fog, or , in the air.

3. When she talks, she has a beautiful can sing well? - I wonder if she

4. My teacher was very angry when I was late to class. But later, she

5. If you walk out onto the on to the right and to the left. , you can see water ahead and

6. The pilot the boat close to the at the side of the lake. After the boat stopped, many people walked off the boat.

7. The small had only two streets. 
3. True or false? Circle "T" if the sentence is True, or "F" if the sentence is False. The first one is an example.

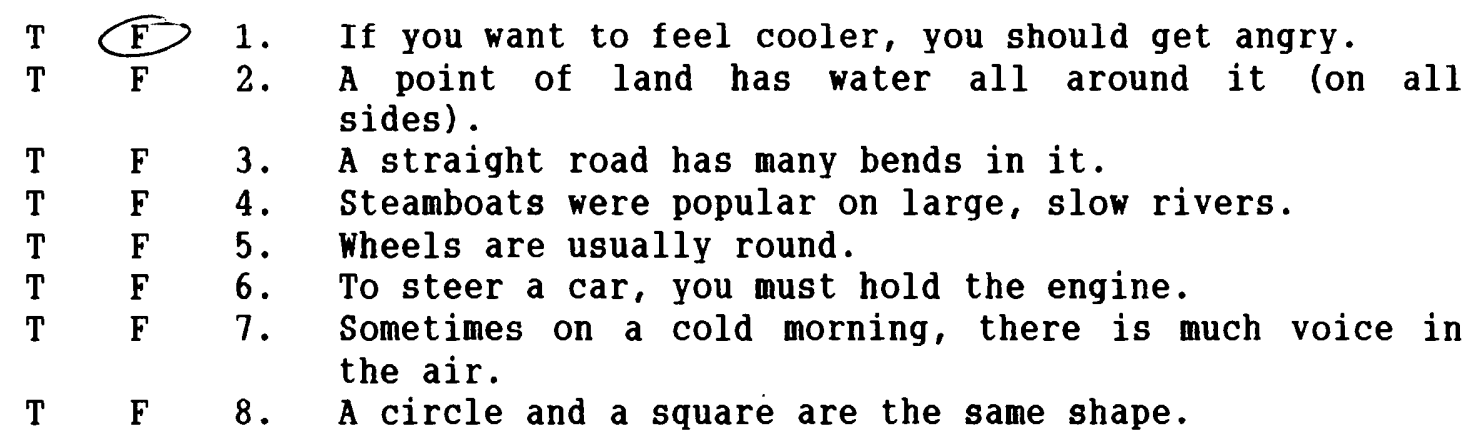

4. Circle the one word which does not go together with the other two. The first one is an example.

$\begin{array}{lll}\text { 1. landing } & \text { bend } & \text { side } \\ \text { 2. country } & \text { village } & \text { town } \\ \text { 3. machine } & \text { engine } & \text { steer } \\ \text { 4. dark } & \text { playground } & \text { shadow } \\ \text { 5. lesson } & \text { idea } & \text { angry } \\ \text { 6. mist } & \text { curve } & \text { cloud } \\ \text { 7. turn } & \text { shape } & \text { square } \\ \text { 8. pilot } & \text { doctor } & \text { driver } \\ \text { 9. peaceful } & \text { cool } & \text { angry }\end{array}$

[Note: The original version was printed in 12 point (10 cpi) type. The type size here is 10 point $(12 \mathrm{cpi})$, slightly smaller than on the version given to the students. The use of smaller type was necessary in preserving the format of the original while at the same time staying within the wider margins required herein.] 
[Exercises for "The Lady, or the Tiger?":]

Concordia College Summer Study

Name:

Vocabulary Exercises

No dictionaries! Please write with a pen.

\section{Exercises :}

1. Match each word with its definition. On the line, write the letter of the correct word. The first one is an example.
A. modern
B. accuse
$G$ 1. a large, Asian cat
C. prince
2. red liquid inside the body
D. blood
3. new; now
E. barbaric
4. king's son
F. imagine
5. to see it in your head
6. tiger
6. house for a king and queen
H. castle
7. to say that someone did something bad
J. semi-
8. half, not all
9. wild, not civilized

2. Write words on the blanks in the sentences. Use the words from the word list (you will not use all of the words). Use a word only once. Sometimes, you might have to change the word a little to make it work in the sentence (for example, tiger $\rightarrow$ tigers, or please --> pleased). Sometimes, you do not have to change the word. The first one is an example.

1. If you tell me about your family, I can imagine what they look
like.

2. We went to the to watch the basketball game.

3. My husband is very of me: He doesn't want me to talk to other men, or be friends with other men, because he wants to be the only man in my life.

4. I saw Professor Thompson by when I was downtown.

5. A soldier is not afraid of fighting.

6. The police catch people who do and put them in jail.

7. A person who is always very nice is a person.

8. My sister me of eating all the cake. 
3. True or false? Circle "T" if the sentence is True, or "F" if the sentence is False. The first one is an example.

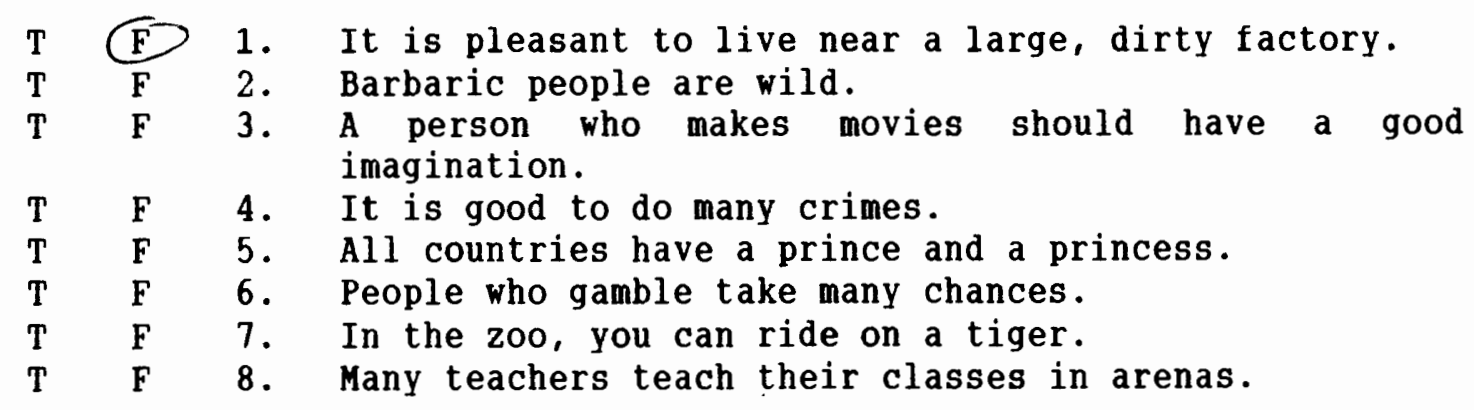

4. Circle the one word which does not go together with the other two. The first one is an example.

$\begin{array}{ll}\text { 1. } & \text { accused } \\ 2 . & \text { jealousy } \\ 3 . & \text { half } \\ \text { 4. } & \text { pleased } \\ \text { 5. } & \text { red } \\ 6 . & \text { envy } \\ \text { 7. } & \text { castle } \\ \text { 8. } & \text { safe } \\ \text { 9. } & \text { modern }\end{array}$

princess
envy
all
happy
blood
bravery
small
tiger
old

crime happiness

semi-

angry

imagine

jealousy

king

wild

new

[Note: The original version was printed in 12 point (10 cpi) type. The type size here is 10 point $(12 \mathrm{cpi})$, slightly smaller than on the version given to the students. The use of smaller type was necessary in preserving the format of the original while at the same time staying within the wider margins required herein.] 
[Exercises for "An Occurrence at Owl Creek Bridge":]

Concordia College Summer Study

Name:

Vocabulary Exercises

No dictionaries! Please write with a pen.

Exercises:

1. Match each word with its definition. On the line, write the letter of the correct word. The first one is an example.
A. rope
F 1. flat piece of tree material
B. wood
2. between head and shoulders
C. bank
watch and keep safe
D. bullet
. watch and keep safe
E. guard
X. board
G. escape
H. conscious
J. neck
4. material from a tree, or a forest
5. long, strong, thick cord
6. awake, knowing, understanding
7. small metal piece from a gun
8. to go away from somewhere
9. land on the sides of rivers

2. Write words on the blanks in the sentences. Use the words from the word list (you will not use all of the words). Use a word only once. Sometimes, you might have to change the word a little to make it work in the sentence (for example, bullet $\rightarrow$ bullets, or float $\rightarrow$ floating). Sometimes, you do not have to change the word. The first one is an example.

1. In America, some Wooden farm buildings, called barns, are painted red.

2. Oil stays on top of water because oil on water.

3. You should show to an important person.

4. When I got to my house, no one was there. It was and empty.

5. You must not swim here! The is too fast and dangerous.

6. I saw an old movie about cowboys. A bad cowboy was until he was dead, because he had been taking horses from other cowboys.

7. The police put the bad man in jail. The police said that the man must die. The man was very sorry.

8. The door has a hole in it. I need a to put over the hole. 
3. True or false? Circle "T" if the sentence is True, or " $F$ " if the sentence is False. The first one is an example.

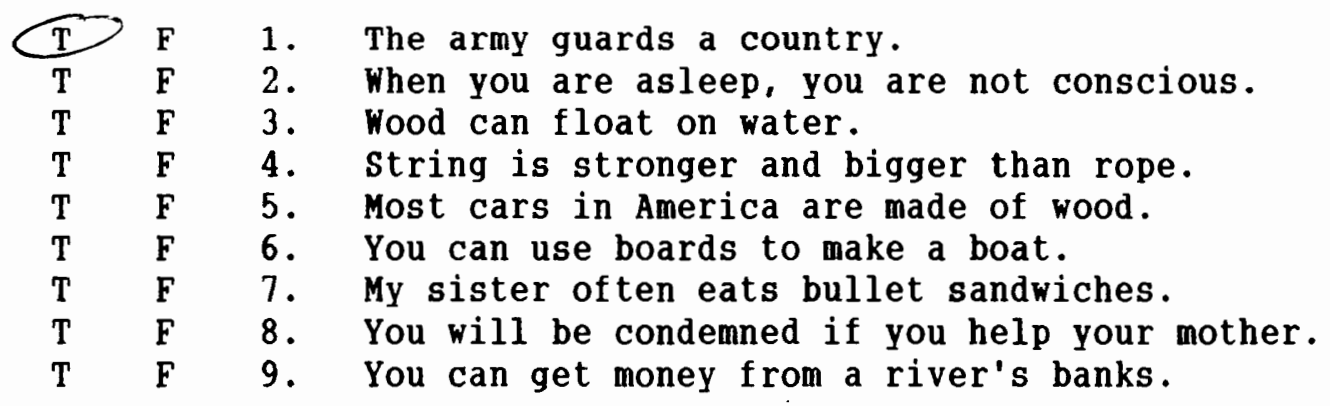

4. Circle the one word which does not go together with the other two. The first one is an example.

$\begin{array}{ll}\text { 1. } & \text { knowing } \\ \text { 2. } & \text { escape } \\ \text { 3. } & \text { neck } \\ \text { 4. } & \text { hang } \\ \text { 5. } & \text { laugh } \\ \text { 6. } & \text { river } \\ \text { 7. } & \text { silence } \\ \text { 8. } & \text { guard }\end{array}$

$\begin{array}{ll}\text { sleeping } & \text { conscious } \\ \text { stay } & \text { get away } \\ \text { hang } & \text { escape } \\ \text { hold } & \text { die } \\ \text { respect } & \text { president } \\ \text { current } & \text { slow } \\ \text { loud } & \text { noise } \\ \text { punish } & \text { safe }\end{array}$

[Note: The original version was printed in 12 point (10 cpi) type. The type size here is 10 point $(12 \mathrm{cpi})$, slightly smaller than on the version given to the students. The use of smaller type was necessary in preserving the format of the original while at the same time staying within the wider margins required herein.] 
APPENDIX F

CROSSWORD PUZZLES 
[Crossword Puzzle for "A Cub-Pilot's Education":]

Crossword Puzzle:

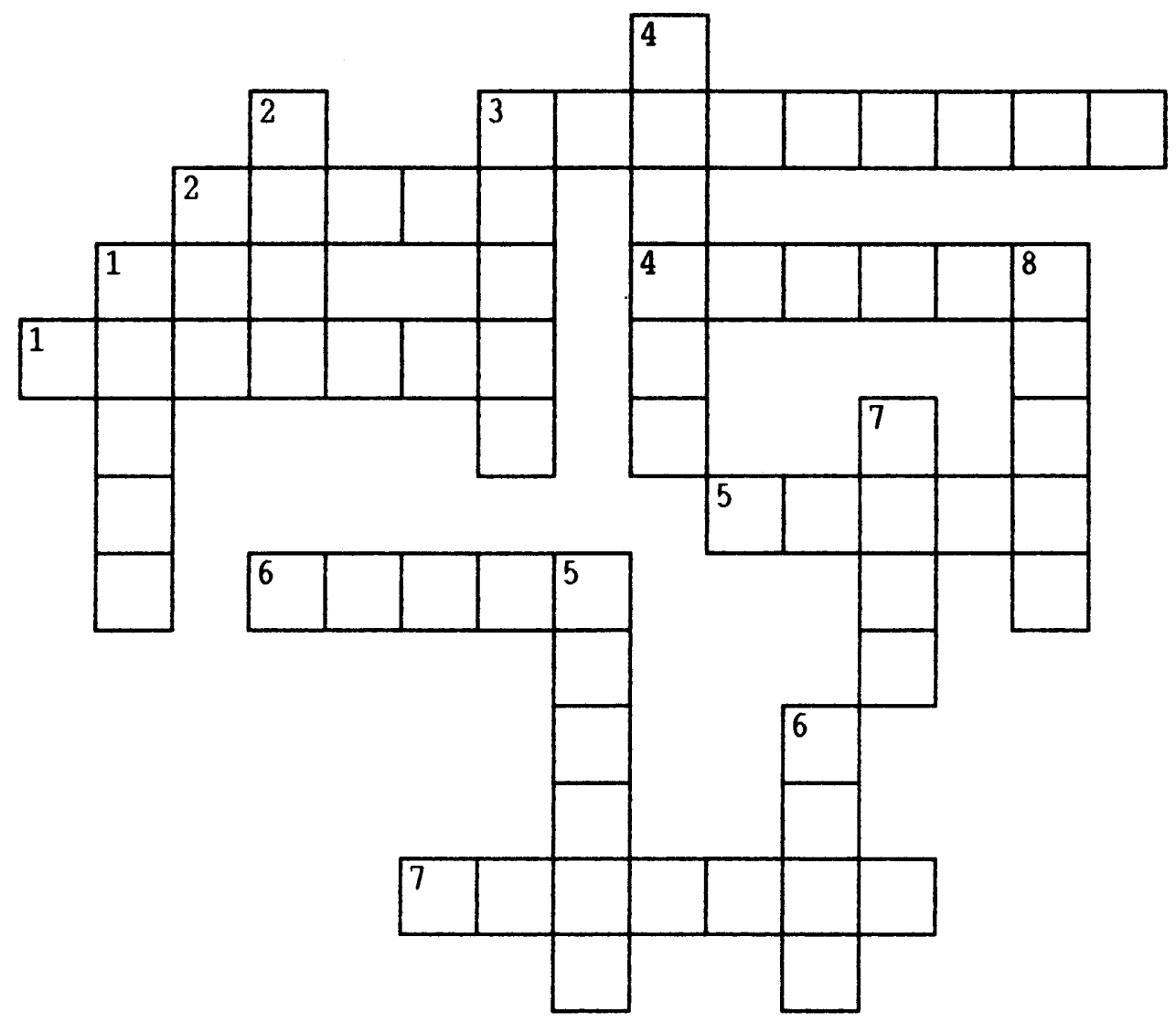

\section{Across}

1. small town

2. sharp piece of land

3. old-fashioned boat

4. dark place

5. sound when speaking

6. examples: square, circle

7. boats stop here
Down

1. driver

2. not angry

3. guide, direct

4. important idea learned

5. machine

6. turn or curve

7. fog

8. steer with a

[Note: The original version was printed in 12 point (10 cpi) type. The type size here is 10 point $(12$ cpi), slightly smaller than on the version given to the students. The use of smaller type was necessary in preserving the format of the original while at the same time staying within the wider margins required herein.] 
[Crossword Puzzle for "The Lady, or the Tiger?":]

Crossword Puzzle:

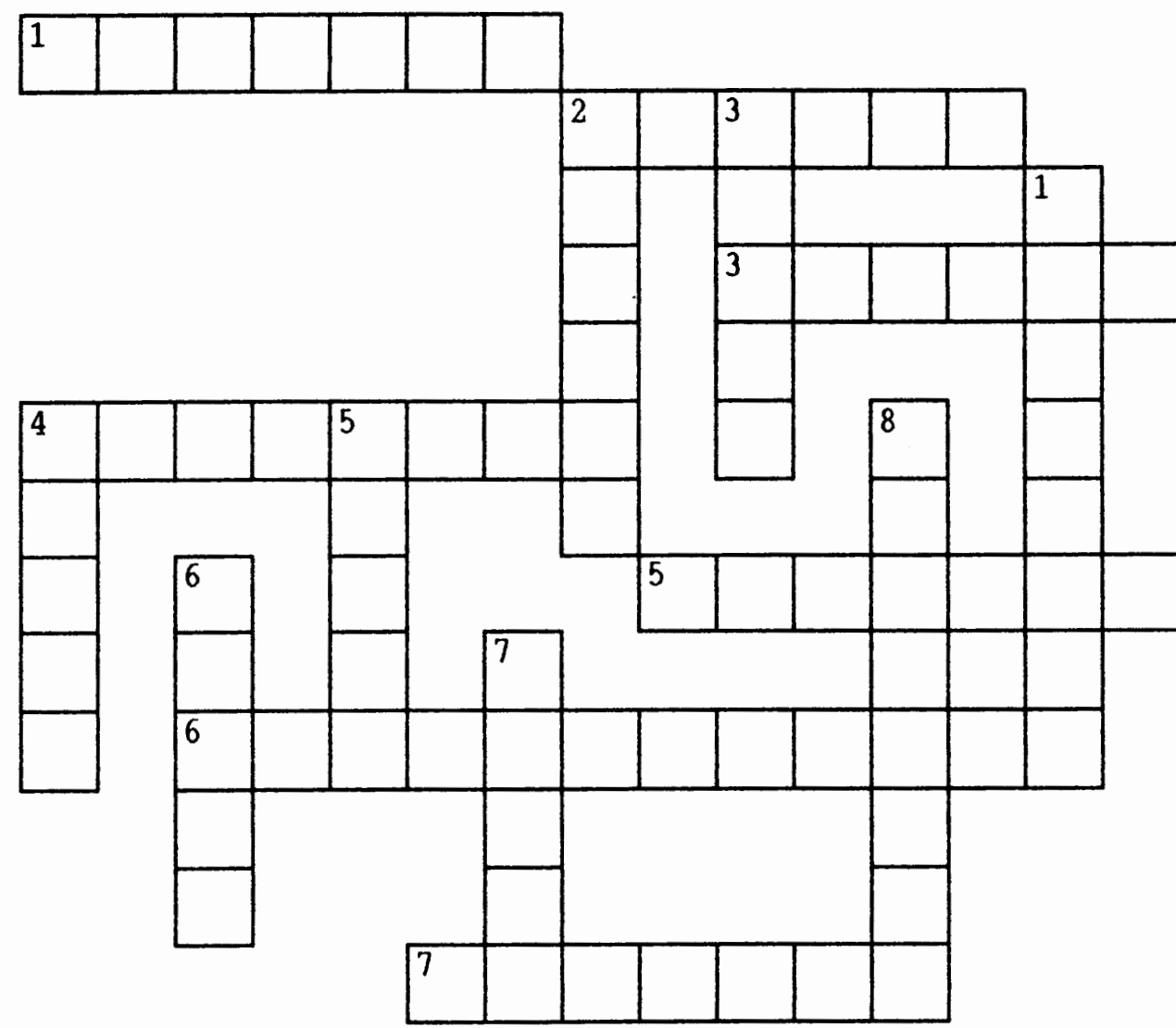

Across

Down

1. if I said that you did something bad, I you

2. king and queen live here

3. new, of the present

4. wild, not civilized

5. happy

6. use your

7. being without fear
1. king's daughter

2. luck; it just happens

3. partly; half

4. red liquid in your body

5. big building for sports

6. example: taking money

7. large, Asian cat

8. feeling of envy

[Note: The original version was printed in 12 point (10 cpi) type. The type size here is 10 point (12 cpi), slightly smaller than on the version given to the students. The use of smaller type was necessary in preserving the format of the original while at the same time staying within the wider margins required herein.] 
[Crossword Puzzle for "An Occurrence at Owl Creek Bridge":] Crossword Puzzle:

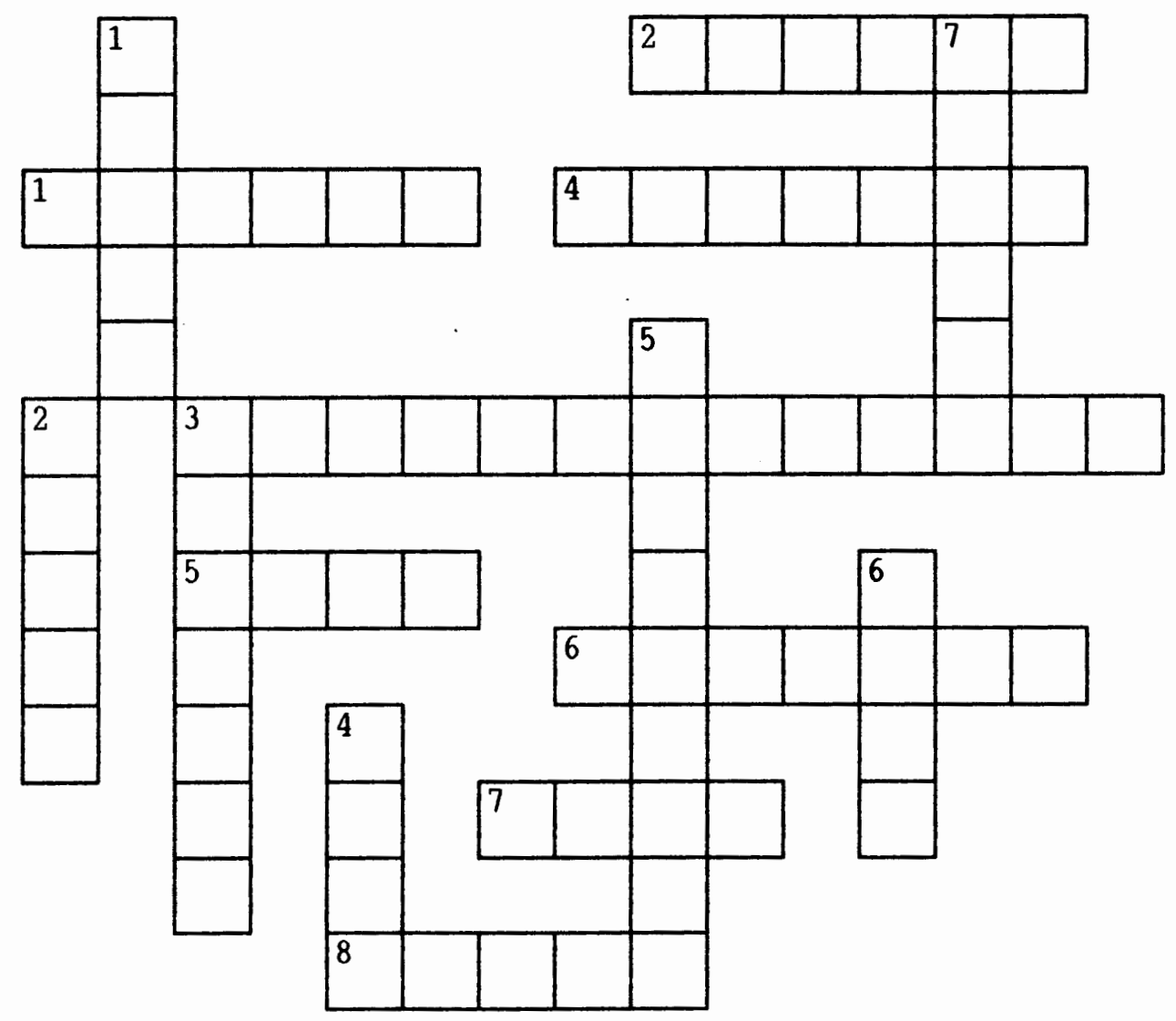

\section{Across}

1. made from tree material

2. it comes out of a gun

3. when you are awake, you have

4. when there is no sound

5. you can use it to tie things

6. you should show this to an important person

7. along the sides of a river

8. person who watches and protects
Down

1. to stay on top of water

2. a flat piece of tree material

3. water moving in a river

4. to kill with a rope

5. a person who will be punished is

6. part of the body under the head

7. to get away

[Note: The original version was printed in 12 point (10 cpi) type. The type size here is 10 point $(12 \mathrm{cpi})$, slightly smaller than on the version given to the students. The use of smaller type was necessary in preserving the format of the original while at the same time staying within the wider margins required herein.] 
APPENDIX G

DISCUSSION QUESTIONS 


\section{Discussion questions for "A Cub-Pilot's Education":}

1. Who are the characters in this story?

2. What is the setting of this story?

3. From what point of view is this story written?

4. How are these three things (characters, setting, point of view) important to the story? If we change them, for example, to: the pilot of a container ship, and a young man who is learning to be a pilot; Japan, in the present time; in the third person point of view ("outside" the story, looking "in"), how does this change the story? Does it still work? Can you change the story enough to make it work?

5. Would you want to be a steamboat pilot? Why or why not? What were some of the reasons why the cub-pilot wanted to learn how to be a steamboat pilot? Before he became a cub-pilot, did the cub-pilot ever think that it would be difficult or that he would have to work hard to be a pilot?

6. Many of Mark Twain's stories are humorous. A CubPilot's Education is humorous, too. Find some places that made you laugh and explain why they are funny.

7. How did Mr. Bixby find Jones Farm? Do you think that this is really possible? Can you find things in your house at night, for example, in the same way?

8. Do you think Mr. Bixby is a good teacher? Why or why not?

9. Several times in the story, the cub-pilot wants to quit or do only part of the job of piloting. Why? In fact, the cub-pilot always stays and always learns to work at the next highest level. Why do you think he stays? Would you stay, or would you leave? Why?

10. Do you think the cub-pilot is a good student? Why or why not? What does Mr. Bixby think? Why does Mr. Bixby want to keep the cub-pilot?

11. At the end of the story, the cub-pilot is worried. What are some of the things that Mr. Bixby and the other men on the boat say and do that make the cubpilot worried? 
12. When the cub-pilot is worried, he decides to call down to the engine room to ask how deep the river is. The man in the engine room answers, "40 feet... 35... $32 ! \ldots 28 ! \ldots 18 ! \ldots, 15 ! \ldots, 13 ! \ldots, 10 ! "$ Why is the cub-pilot "filled with fear"? What does the cub-pilot think is happening? What is actually happening?

13. At the end of the story, the cub-pilot learns a very important lesson about believing in what he knows is true, and about fighting fear. However, something bad happens to him to teach him this lesson. Describe what happens. Describe the cub-pilot's feelings.

14. Why does Mr. Bixby think that he should teach this lesson to the cub-pilot? How does the cub-pilot act, or what does the cub-pilot do that makes $\mathrm{Mr}$. Bixby think this?

15. Have you ever had to learn an important lesson in a difficult or embarrassing way? Explain. 
Discussion questions for "The Lady, or the Tiger?":

1. Who are the characters in this story?

2. What is the setting of this story?

3. From what point of view is this story written?

4. How are these three things (characters, setting, point of view) important to the story? If we change them, for example, to: a rich businessman, his daughter, and a poor young man; Japan, in the present time; in the first person point of view of the daughter, how does this change the story? Does it still work? Can you change the story enough to make it work?

5. What was your first thought when you read about the king's "excellent law"?

6. The story says that the people "liked the fairness of the law". Is the law really "fair"? What if the accused man was actually not guilty--but when he went to the arena he just happened to open the door with the tiger? An innocent man would have been punished by death for nothing. What do you think? Is the law really "fair"?

7. Can you think of or remember any reasons from the story why the king did not want the princess and the young man to be friends? If a man and woman want to get married today, are any of these reasons still good reasons for them not to get married?

8. If the young man was "tall, beautiful, fair," "seemed like a prince," and was "such a fine young man," then why was the king so against the young man and the princess getting married? Discuss.

9. How many children did the king have? Is it possible that the princess was his only child? What happens to a country when its king dies (who becomes the new leader)? How could this influence (change) the king's decision?

10. In the story, the princess thinks that her boyfriend, the young man, has maybe talked to the beautiful young lady that will be behind one of the doors. Do you think that this is really true? Do you think that the beautiful young lady and the young man are actually in love (the young man would then have 2 girlfriends--the princess and the beautiful young lady)? How could this influence (change) the princess's decision? 
11. Have you ever heard of "Lady Luck"? Explain. How could the idea of "Lady Luck" go with this story? Discuss.

12. In the story, the princess moves her hand to the right. So, the young man goes to the door on the right. You know a little bit about the princess's heart and mind. Do you think the young man made a good decision by going to the same door that the princess pointed to?

13. Which do you think came out of the open door--the lady, or the tiger? Why?

14. At first, you might think that there are only two ways for the story to end: (1) the lady comes out of the open door, she and the young man are married, and the princess is sad, or (2) the tiger comes out of the open door, it eats the young man, and the princess is sad. But, are there other possibilities? Are there other ways that the story could end? Discuss.

15. Why did Frank stockton, the writer, choose not to tell us the ending of the story? Can we really say that there is one, true ending to the story? 
Discussion questions for "An Occurrence at Owl Creek Bridge" :

1. Who are the characters in this story?

2. What is the setting of this story?

3. From what point of view is this story written?

4. How are these three things (characters, setting, point of view) important to the story? If we change them, for example, to: a rich businessman, his wife, and some local policemen; Japan, in the present time; in the first person point of view of the businessman, how does this change the story? Does it still work? Can you change the story enough to make it work?

5. What do you know about the American Civil War? What were the two sides? Why were they fighting? What was the result? Discuss.

6. This story shows one very, very small part of the American Civil War. Do you think that it really happened? If not, do you think that it could have happened? Why or why not?

7. When you had read only part $I$, why did you first think the man was going to be hanged?

8. Have you ever been very worried or afraid? Why? What did it feel like? What happened in the end?

9. What strange thing happens to the man while he is standing on the bridge? Why does this happen?

10. Explain part II. Why is it a bad thing that the soldier in part II is actually "a Northern soldier"?

11. When does part II happen--before or after part I? Put parts I, II, and III in the order that they actually happen in time. Is any part of the "whole picture" missing? Tell about what might have happened in the missing part. Can you think of any reasons why the writer might have put part II "out of order" with the rest of the story?

12. In the first half of part III, Peyton Farquhar is in "great pain". Why? What happens to his senses because of the pain? Describe some of the things he sees, hears, and feels. Is this different from normal life? 
13. What are some strange things about the scene near the end of part III in which Farquhar is walking down a road with "big black trees" that form "a straight wall on both sides"? Has the story seemed real and possible until this scene? Why or why not? Does this scene seem real and possible? Why or why not?

14. Explain part III. What really happens in part III?

15. How does this story make you feel? Do you think the writer, Ambrose Bierce, was a happy person or a sad person? Why? Can you find anything in his life or in the story that shows happiness or sadness? 
APPENDIX H

DIRECTIONS FOR ADMINISTERING THE POST-TEST 


\section{Directions for administering the post-test:}

1. Have the students close their notebooks, put away any papers they have out, and put away their dictionaries.

2. Read the following to the students:

"We have studied many new vocabulary words this summer. We read stories, studied from the workbook, read poems and tongue twisters, played games, did vocabulary exercises, did word puzzles, listened to songs, sang songs, watched videos, and talked to people. In all these different things we used new words, and I hope that you learned some of these new words. I would like you to do these vocabulary exercises for me [show posttest]. Please do not think, "This is a test!" You will not get a score or a grade on this. Your teachers and chaperones will never see this. This is mostly for me -- for me to see if I have been a good teacher and if I have helped you to learn some new words. So, please do your best, but don't be afraid and don't worry."

3. Hand out the post-tests. Have the students write their full names at the tops of their papers. Read and explain the example from the post-test:

"This is a multiple choice exercise. 'Multiple choice' means choose the correct word from the four words and circle the letter by that word. Look at the example at the top of the first page. It says:

"1. It was lunch time. I was very hungry. I went into the kitchen. There was some bread, meat, cheese, and a few pickles. I took two pieces of bread, a piece of meat, a piece of cheese, and three pickles and I made a

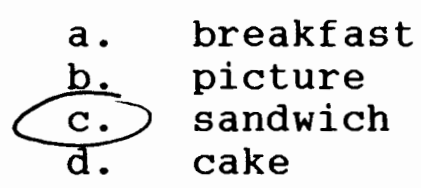

"What word should go on the blank line? 'I made a...breakfast?' No! 'I made a...picture?' No! 'I made a...cake?' No! 'I made a...sandwich?' Yes! So, you would circle the letter 'c.' for 'sandwich'. O.K.? O.K.! Let's do some vocabulary!" 
4. Ask the students if they know what they should do. If they do, have them begin. If not, repeat the appropriate part of the directions. Just before they start, emphasize:

"Please do not use your dictionary. Please do not talk to your classmates."

5. Have the students begin. Monitor their progress, but not so closely that they feel nervous. Make sure there are no notebooks, papers, dictionaries, or other books out, and that students are not helping each other or copying from each other.

6. As students finish, collect their post-tests and give them in exchange a word-find, crossword puzzle, blank U.S. map, or other quiet written exercise. Give students as much time as needed to complete all the items (usually 50 - 70 minutes).

7. As students finish, check to make sure that they have answered every item and written their full names at the top.

8. If for some reason a student misunderstands the directions and suddenly discovers that fact after finishing some or all of the post-test, simply give that student a fresh copy and have the student do it again, in the hallway, if necessary, all the while stressing that it's "no problem, not to worry." Keep both post-tests with "second try" noted on the second one. If the reason for the confusion is apparent, note that, too.

9. If a student falls asleep before completing the test, or because of sleepiness has difficulty completing the test, either try step 8 above, or note the problem on the test and simply eliminate it from the analysis.

10. Thank the students for their cooperation and hard work. 
APPENDIX I

POST-TEST 
Concordia College Summer study Name :

\section{Vocabulary -- Multiple Choice}

Example:

1. It was lunch time. I was very hungry. I went into the kitchen. There was some bread, meat, cheese, and a few pickles. I took two pieces of bread, a piece of meat, a piece of cheese, and three pickles and I made a

$\begin{array}{ll}\text { a. } & \text { breakfast } \\ \text { b. } & \text { picture } \\ \text { c. } & \text { sandwich } \\ \text { d. } & \text { cake }\end{array}$

O.K.? O.K.! Let's do some vocabulary!

1. The king and queen had only one child, a little boy. The queen said, "When our son is older, I want him to get married. I want him to marry the from a country near to us."
a. princess [LOT, 94.]
b. army
c. embassy
d. fortress

2. The giraffe is a very tall animal. It lives in Africa. It eats grass and tree leaves. It has long legs, and a very long

a. neck [OCB, 37.]

b. trunk

c. seed

d. fleece

3. I was riding in my friend's car, but my stomach did not feel good. In fact, I felt very sick. There were too many and curves in the road.

a. strikes

b. bends [CPE, 6.]

c. straights

d. cartons 
4. My father's job is making pictures of houses. other people look at the pictures and then make the houses. My father needs a lot of to see the house inside his head and then make a picture of it.
a. imitation
b. architect
c. melody
d. imagination [LOT, 78.]

5. The boat was on the sea. There was bad weather all around. The boat was going up and down, up and down on the water. Peter was driving the boat. He put both of his hands on the to drive the boat. It was very difficult for Peter to drive the boat.
a. messenger
b. passenger
c. wheel
d. attorney
[CPE, 79.]

6. The chairs and tables in this room are made of beautiful from India.
a. arrows
b. furniture
c. frowns
d. wood [OCB, 9.]

7. Annie is a very kind person. I really enjoy talking with her. She is never angry. She is always smiling. Annie is a very person.
a. juxtaposed
b. separate
c. conditioned
d. pleasant [LOT, 69.]

8. There were many famous and expensive paintings in the art museum. There were many watching carefully. They were looking for bad people who might take away the paintings.
a. guards
$[\mathrm{OCB}, 66$.
b. sifters
c. sections
d. thieves

9. Last summer, I went to France. I visited my friend, Henri. Henri lives in a small small that Henri knows everyone who lives there.
a. vintage
b. nation
c. knell
d. village
[CPE, 72.] 
10. The cowboy was shooting his gun. Suddenly, the gun stopped shooting. The cowboy could not shoot his gun. There were no more in his gun.

a. equalizers

b. equations

c. bullets [OCB, 57.]

d. shields

11. In Europe, there are many old made of stone. Many years before, kings and queens lived in these old buildings.
a. castles
b. vectors
$[\mathrm{LOT}, 6.5$.
c. victories
d. empires

12. Yesterday, I called my mother on the phone. We talked for about one hour. It was good just to listen to her - I miss her very much.
$\begin{array}{ll}\text { a. } & \text { hush } \\ \text { b. } & \text { voice } \\ \text { c. } & \text { nail } \\ \text { d. } & \text { noise }\end{array}$

$[\mathrm{CPE}, 38$.

13. It was a beautiful, sunny day. Tom and Becky went to the lake. There were many boats water.
a. scouring
b. sinking
c. observing
d. floating
$[\mathrm{OCB}, 63$.

14. One cold morning, I was driving to work. It was difficult to see the road, because there was a lot of

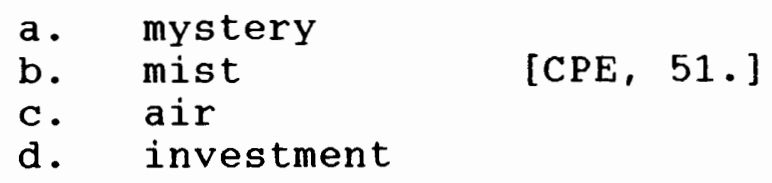

15. My family had a very good vacation last year. For two weeks, we stayed on a . I was very excited! We traveled on the Columbia River. It was a beautiful trip.
a. grapple
b. dirigible
c. vigilant
d. steamboat

$[\mathrm{CPE}, 22$. 
16. When the olympics were in Los Angeles, the city had to make a big, new that would be big enough for thousands of people. People watched many different sports being played in it.
a. arena
[LOT, 88.]
b. pattern
c. aorta
d. chamber

17. The bad man was in jail. He waited for night to come. When it was dark, he carefully opened the window and came out. He ran away and into the night.
a. captured
b. escaped
c. foiled
d. frilled
$[\mathrm{OCB}, 60$.

18. A small group of people lived under the trees. They did not live in houses. They did not wear clothes. These of now.
a. barbaric
b. shocked
c. moderate
d. representative people were very different from people

19. Many years ago, most women did not have jobs outside their homes. They worked only at home. But, now, homes. women often work at jobs outside their
a. archaic
b. joined
c. modern
d. ancient
$[\mathrm{LOT}, 44$.

20. Last night, all the stores were closed. The police were looking for bad people who wanted to take something from the stores. At 11:00 p.m., the police found a man taking something from a store. The police said that the man took an expensive watch from the store. The police said that the man was a bad person. The police took the man to jail.
a. relieved
b. accused
c. released
d. objective
[LOT, 31.] 
21. John must always go to bed at $8: 00 \mathrm{p.m.,}$ but his older brother always goes to bed at 10:00 p.m.. John is of his older brother because John wants to stay awake until 10:00 p.m., too!
a. jealous [LOT, 68.]
b. modified
c. joyful
d. generous

22. All the students were reading. No one was speaking. There were no sounds in the room. The classroom was

\begin{tabular}{lll}
\hline a. & silent \\
b. & loud \\
c. brash & [OCB, 14.] \\
d. & rude
\end{tabular}

23. Two men were driving their cars very fast. One car hit the other car. It was very bad! The two men had many cuts on their arms and faces. There was on the men and on the cars.
a. hurtle
b. molecule
c. heart
d. blood [LOT, 47.]

24. My little sister was riding my bicycle. I was very angry, because she did not ask me if she could ride it. But she said that she was sorry, so I felt after a few minutes.
a. kinetic
b. cooler
c. upset
d. furious
$[\mathrm{CPE}, 2$.

25. A house was on fire. A young woman was walking by the house. She heard an old man inside the house. The old man was calling for help. The woman went in and helped the old man out of the house. She was not afraid to go into the fire.
a. brazen
b. cowardly
c. brave
d. mauve
[LOT, 23.] 
26. The little boy fell down from the tree and hit his head. When I picked him up, he looked like he was asleep. He was still alive, but he was not _. a. ironic

b. augmented

c. conscious [OCB, 59.]

d. suggested

27. My father wanted me to learn about saving money. He gave me a box and said that I must put 25 cents in the box every day. In one year, I saved almost $\$ 100 !$ My father gave me a good
a. lesson
b. pleasure
c. leisure
d. zone about saving money.

28. Ben and Jerry were in their boat. Their boat was on the river. The river was quiet. But, suddenly, the water began to move very fast. The fast caught the boat and turned it around and around.
a. smoothly
b. current
$[O C B, 87$.
c. division
d. quarry

29. On a map, the country of Italy looks like a tall shoe. At the end of the shoe, one of land makes the toe of the shoe, and another sharp piece of land makes the other end of the shoe.
a. crest
b. point
c. harbor
d. yell
[CPE, 24.]

30. I was riding my bicycle in the middle of the street. I saw a car coming. So, I turned my bicycle and a. starred

b. glided

c. collided

d. steered

$[\mathrm{CPE}, 75$.

31. On saturday, I went fishing. I went to the river and stood on the river water. I caught many fish!
a. bank
b. slab
$[O C B, 28$.
c. scale
d. flood 
32. A bad man took a lot of money from an old woman. The bad man did a The old woman called the police. The bad man tried to run away. But, the police saw the bad man and took him away.
a. blameless
b. crime [LOT, 36.]
c. smudge
d. score

33. Children must be nice to their parents. They must do what their parents tell them to do. And they must believe that their parents are important people. Children must always have for their parents.
a. deception
b. respect
c. ridicule
d. fractions
$[O C B, 16$.

34. Some people in Oregon work in the forest. Their job is cutting down trees. Other people take the cut trees and cut them into long, flat pieces. People use these to build houses, chairs, and tables.
a. rakes
b. loggers
c. positions
d. boards

$$
[O C B, 74 .]
$$

35. A bad man took the cowboy's horse. But the cowboy saw the bad man. The cowboy took the bad men to the police. The police said that the bad man must die. They said that the bad man must be_from a tree until he died.
a. hanged
b. dismissed
$[O C B, 77$.
c. prepared
d. tarred

36. The police wanted to lock the man in jail. The man was waiting to go to the jail. He would go to the jail in three hours. This want to live in the jail. man was sad. He did not
a. executive
b. redundant
c. condemned
d. poetic
$[O C B, 90$. 
37. Sally and Jim walked down to the river. They stood at the side of the river. They waited for a boat to come to them. Soon, a boat came. The boat came to the and stopped. Sally and Jim got on the boat.
a. exodus
b. quadrant
c. docket
d. landing

$[\mathrm{CPE}, 49$.

38. The cowboy had a long piece of in his hand. He tied one end of it to his horse. Then he tied the other end of it to a tree.
a. rope
b. saddle
$[\mathrm{OCB}, 18$.
c. yarn
d. paddle

39. It was a very hot day. There were no clouds in the sky. The sun was shining, hot and clear. We looked for a tree so that we could rest in the darkness of the tree's
a. overcast
b. willow
c. brightness
d. shadow

[CPE, 84.]

40. Alfred went to the hospital. He wanted to have a private room, with only himself in the room. But, the hospital was full, so Alfred was in a room with two other men. Alfred had a private room in the hospital.
a. super-
b. ambi-
c. semi-
d. pro-
[LOT, 10.]

41. One night, a man and his friends were playing cards. The man did not know that he would win the card game. But that night, he was very lucky. He won five card games! was very good to him that night.
a. Gravel
b. Unit
c. Intent
d. Chance
[LOT, 46.] 
42. My car was making very bad sounds. Smoke was coming out of the front. I took my car to the car repair shop. The man in the shop said that the car had a problem in the

$\begin{array}{lll}\text { a. engine } & \text { [CPE, 17.] } \\ \text { b. atmosphere } & \\ \text { c. energy } & \\ \text { d. automobile } & \end{array}$

43. My favorite animals in the zoo are the their hair, they have beautiful orange and black lines. They are very strong, and they look dangerous.
a. algae
b. electricians
c. tigers
d. keepers
[LOT, 54.]

44. The boat was moving through bad weather. The wind was very strong. The water was very dangerous. It was very difficult for the to control the boat. Finally, the boat came to the land, and everyone was safe.
a. sponsor
b. pilot
$[C P E, 81$.
c. ship
d. compass

45. Many tables are rectangular in , other tables are round or square.
a. size
b. color
c. shape
d. dimension
[CPE, 15.]

[Note: This version of the post-test shows which of the four answer choices in each item is actually the target word. Following each target word is the story from which the word came, and the corresponding item number in the pretest for that word, both in brackets. This information did not of course appear on the actual post-test given to the subjects.] 
APPENDIX J

WORD TABLES 
TABLE XXXIX

TEST WORDS IN BASE FORM IN ORDER BY INITIAL APPEARANCE IN EACH STORY, BY APPEARANCE IN THE PRE-TEST,

AND BY APPEARANCE IN THE POST-TEST

Base Words in Order by Initial Appearance in Each Story

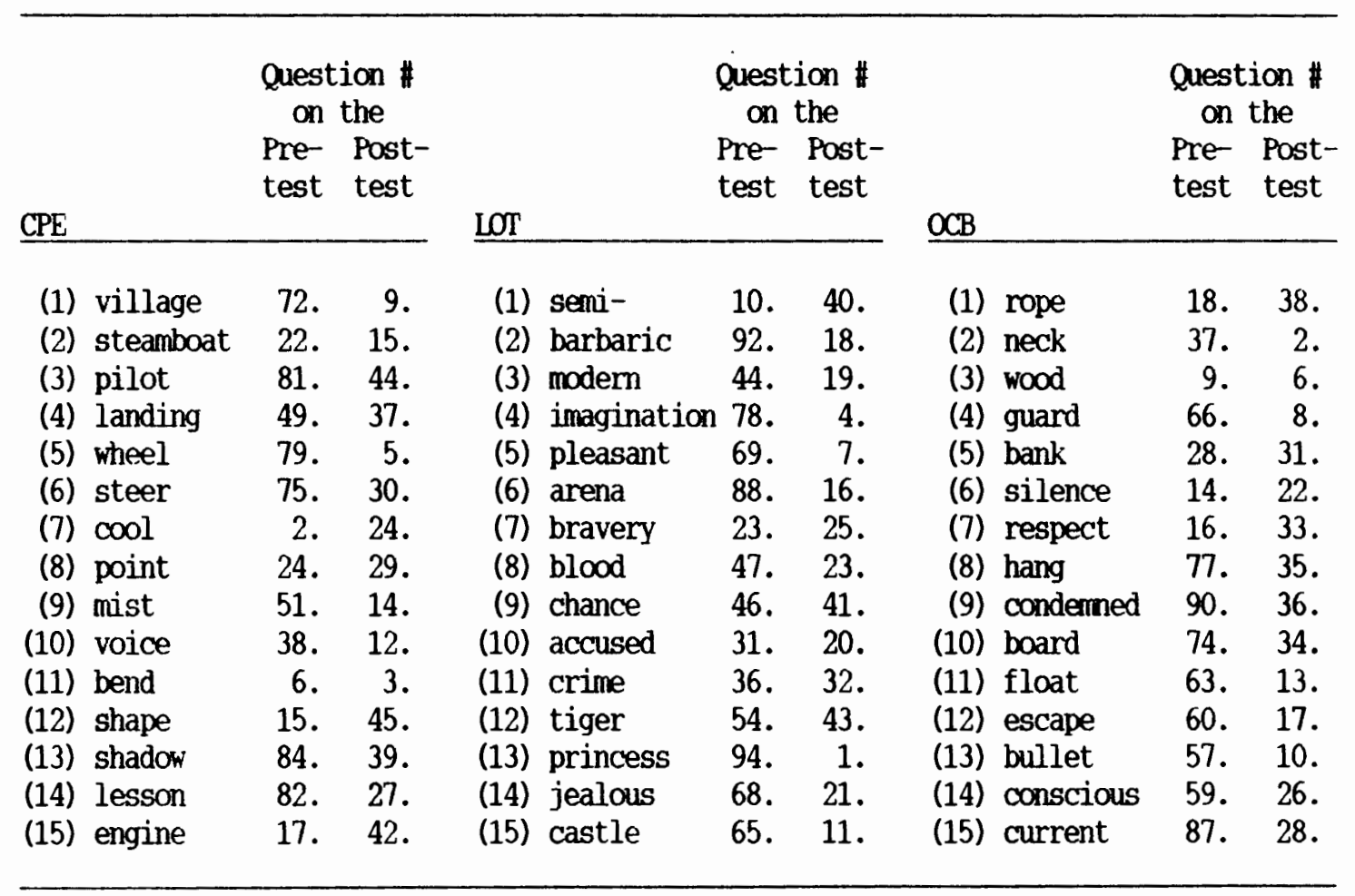

Base Words in Order by Appearance in the Pre-test

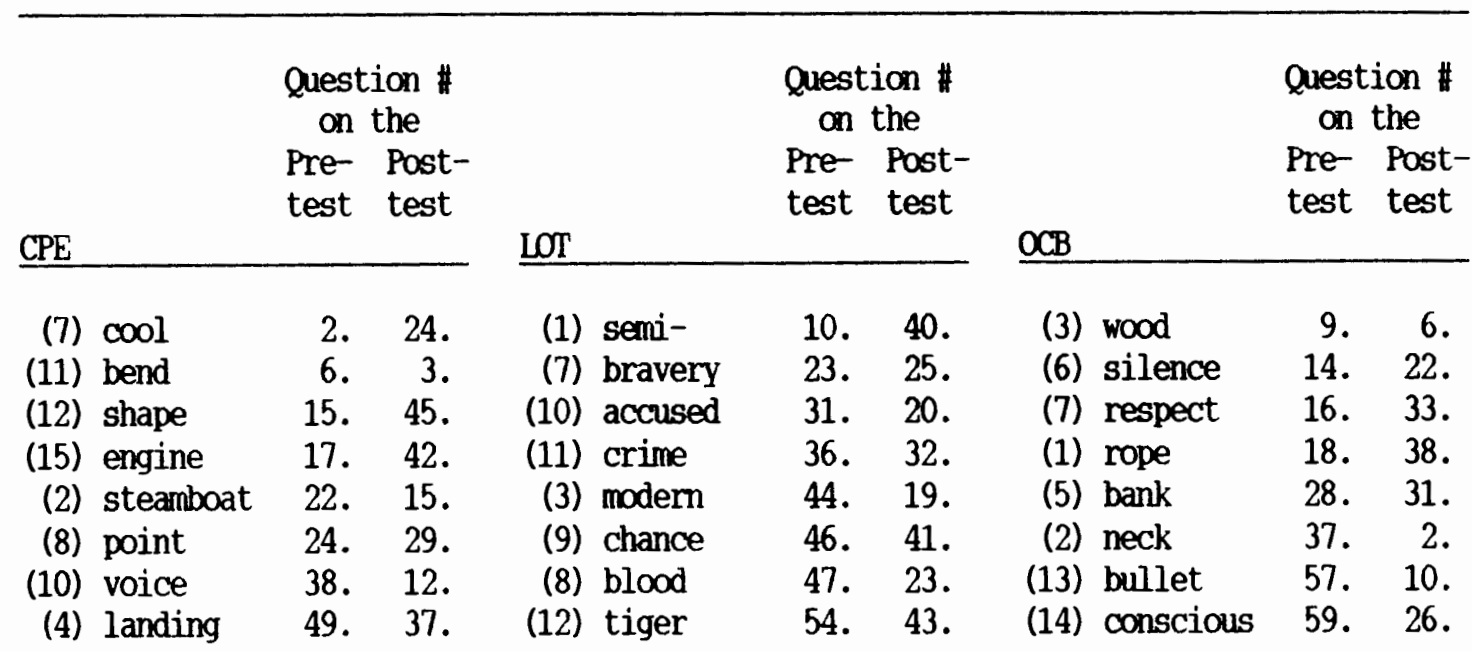


TABLE XXXIX

TEST WORDS IN BASE FORM IN ORDER BY INITIAL APPEARANCE IN EACH STORY, BY APPEARANCE IN THE PRE-TEST,

AND BY APPEARANCE IN THE POST-TEST

(continued)
(9) mist
51. 14 .
(15) castle
65. 11.
(12) escape
60. 17.
(1) village
72. 9.
(14) jealous
(11) float
63. 13.
(6) steer
75. 30 .
(5) pleasant
(4) guard
(5) wheel
79. 5.
(4) imagination 78.4.
(10) board
(3) pilot
81. 44 .
(6) arena
88. 16.
82. 27.
(2) barbaric
(8) hang
66. 8.
(14) lesson
84. 39 .
(13) princess
92. 18.
(15) current
74. 34 .
(13) shadow
94.1 .
(9) conderned
77. 35.
87. 28.

Base Words in Order by Appearance in the Post-test

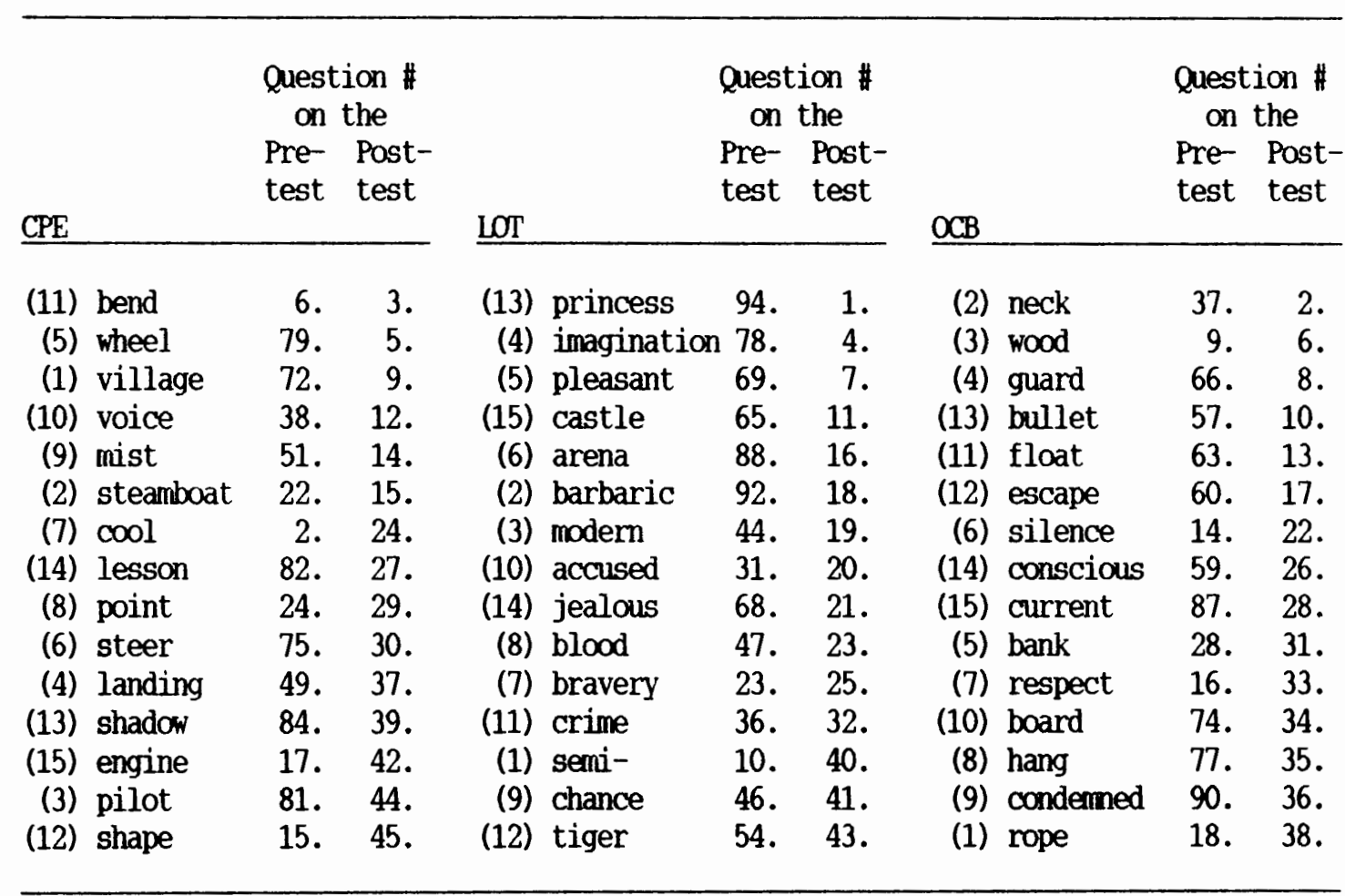

Note: By using Table XXXIX, any test word can immediately be located according to (1) its order of initial appearance in a story, (2) its place in the pre-test, and (3) its place in the post-test. (The ordinal numbering in parentheses of the base words corresponds to that used in the lists in Tables XL, XLIII, XLV, and XLVI below). 
TABLE XL

TEST WORDS IN BASE FORM IN ORDER BY

INITIAL APPEARANCE IN EACH STORY

WITH FREQUENCY OF OCCURRENCE

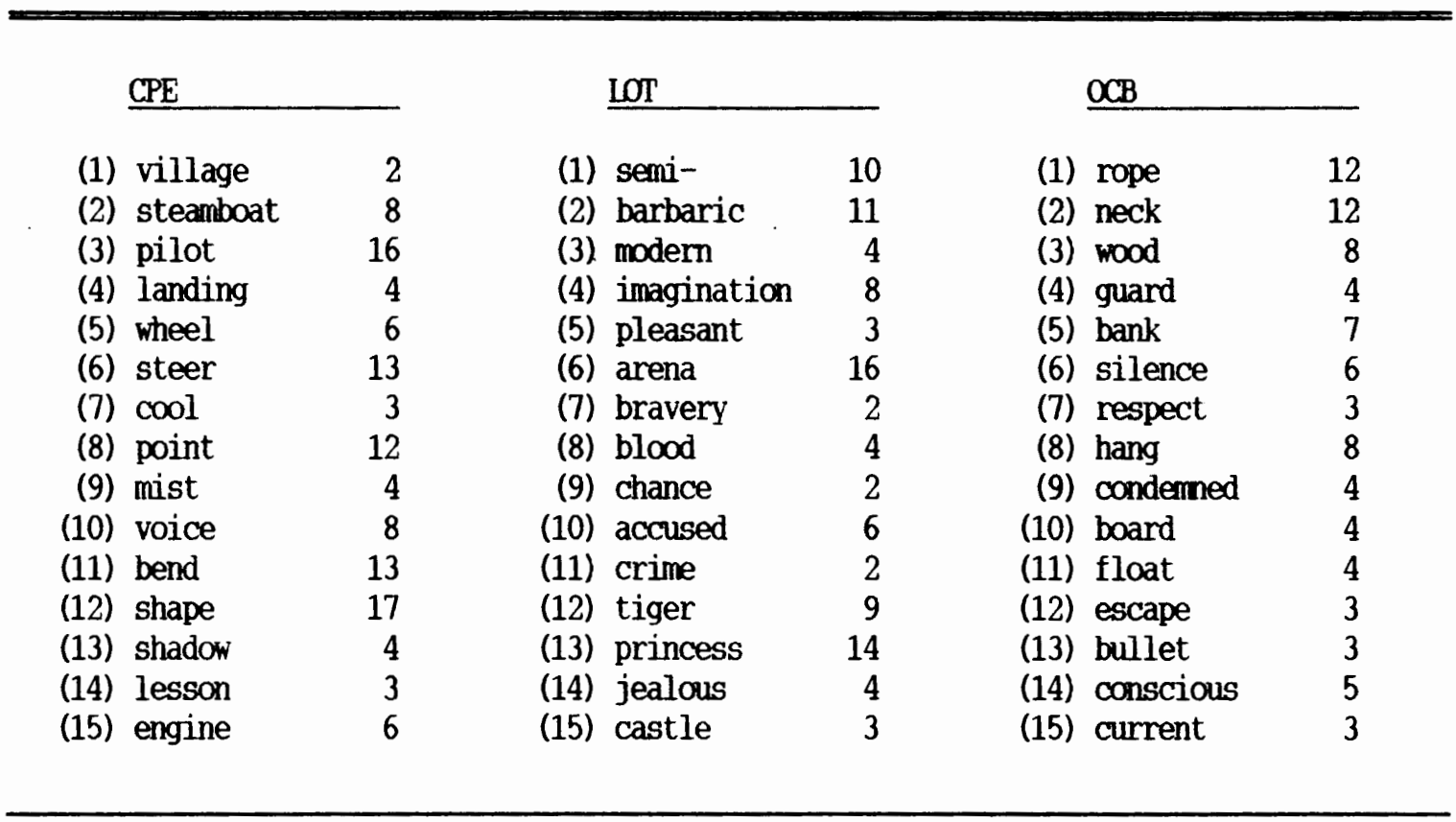

Note: Each list above shows the test words (in base form) in order by each word's first appearance within each story (the ordinal numbering of the base words corresponds to that used in the lists in Table XXXIX above, and Tables XLIII, XLV, and XLVI below).

TABLE XLI

TEST WORDS IN BASE FORM IN ALPHABETICAL ORDER WITH FREQUENCY OF OCCURRENCE

\begin{tabular}{lr} 
CPE \\
\hline bend & 13 \\
cool & 3 \\
engine & 6 \\
landing & 4 \\
lesson & 3 \\
mist & 4 \\
pilot & 16
\end{tabular}

LOT

accused

arena

barbaric

blood

bravery

castle

chance

\section{$\underline{O C B}$}

$\begin{array}{ll}\text { bank } & 7 \\ \text { board } & 4 \\ \text { bullet } & 3 \\ \text { condemned } & 4 \\ \text { conscious } & 5 \\ \text { current } & 3 \\ \text { escape } & 3\end{array}$


TABLE XLI

TEST WORDS IN BASE FORM IN ALPHABETICAL ORDER WITH FREQUENCY OF OCCURRENCE (continued)

$\begin{array}{lr}\text { point } & 12 \\ \text { shadow } & 4 \\ \text { shape } & 17 \\ \text { steamboat } & 8 \\ \text { steer } & 13 \\ \text { village } & 2 \\ \text { voice } & 8 \\ \text { wheel } & 6\end{array}$

$\begin{array}{lr}\text { crime } & 2 \\ \text { imagination } & 8 \\ \text { jealous } & 4 \\ \text { modern } & 4 \\ \text { pleasant } & 3 \\ \text { princess } & 14 \\ \text { seni- } & 10 \\ \text { tiger } & 9\end{array}$

$\begin{array}{lr}\text { float } & 4 \\ \text { guard } & 4 \\ \text { hang } & 8 \\ \text { neck } & 12 \\ \text { respect } & 3 \\ \text { rope } & 12 \\ \text { silence } & 6 \\ \text { wood } & 8\end{array}$

TABLE XLII

TEST WORDS IN BASE FORM IN ORDER BY FREQUENCY OF OCCURRENCE WITH FREQUENCY OF OCCURRENCE

\begin{tabular}{|c|c|c|c|c|c|}
\hline CPE & & LOT & & $\underline{O C B}$ & \\
\hline village & 2 & bravery & 2 & bullet & 3 \\
\hline cool & 3 & chance & 2 & current & 3 \\
\hline lesson & 3 & crime & 2 & escape & 3 \\
\hline landing & 4 & castle & 3 & respect & 3 \\
\hline mist & 4 & pleasant & 3 & board & 4 \\
\hline shadow & 4 & blood & 4 & condemned & 4 \\
\hline wheel & 6 & jealous & 4 & float & 4 \\
\hline engine & 6 & modern & 4 & guard & 4 \\
\hline steamboat & 8 & accused & $\overline{6}$ & conscious & 5 \\
\hline voice & 8 & imagination & 8 & silence & 6 \\
\hline point & 12 & tiger & 9 & bank & 7 \\
\hline bend & 13 & semi- & 10 & hang & 8 \\
\hline steer & 13 & barbaric & 11 & wood & 8 \\
\hline pilot & 16 & princess & 14 & neck & 12 \\
\hline shape & 17 & arena & 16 & rope & 12 \\
\hline
\end{tabular}

Note: Each list above shows the test words (in base form) in order by the number of occurrences of each word within each story (words above the line are "infrequent occurrers," 2-4 times within the story; words below the line are "frequent occurrers," 5 or more times within the story). 
TABLE XLIII

ALL OCCURRENCES OF ALL FORMS OF THE TEST WORDS IN ORDER AS THE FORMS APPEARED THROUGHOUT THE STORIES

CPE
(1) village
(2) steamboat
(3) pilot
village
steamboat
$S-t-e-a-m-b o a t$
steamboat
(4) landing
steamboat
pilot
steamboat
landing
pilot
pilot
cub-pilot

(5) wheel

steamboats

landings

(6) steer

wheel

steer

wheel

steered

(7) cooler

steer

pilot

(8) points

Six-Mile Point

Nine-Mile Point

Six-Mile Point

Twelve-Mile Point

points

points

pilot-house

pilots

(9) mist

wheel

mist

point

(10) voice

point

Twelve-Mile Point

pilot

\section{LOT}

(1) semi-

(2) barbaric

semi-

barbaric

(3) modern

modern

barbarism

(4) imagination

imagination

(5) pleasant

pleasant

pleased

semi-

barbaric

modern

(6) arena

arena

(7) bravery

modern

imagination

arena

(8) blood

arena

(9) Chance

(10) accused

(11) crime

crime

arena

accused

arena

accused

arena

accused

Chance

(12) tiger

tiger

accused

arena

imagination

semi-

barbaric

arena

bloody
$O C B$

(1) rope

(2) neck

rope

(3) wooden

(4) guarded

(5) bank

(6) silently guards banks

silent silently

(7) respect

respect

silence

respect

rope

neck

(8) hanged

hanged

hanging

hanging

(9) condemned

wood

(10) board

board

wood

condermed

board

rope

neck

hanged

neck

wood

(11) floating

floating

wood

rope

(12) escape

(13) bullets

bank

woods

condemed

board 
TABLE XLIII

ALL OCCURRENCES OF ALL FORMS OF THE TEST WORDS IN ORDER AS THE FORMS APPEARED THROUGHOUT THE STORIES (continued)

steamboat

pilot

points

pilot-house

cooled

pilot

voice

mist

landing

voices

points

(11) bends

(12) shape

Apple Bend

shape

Apple Bend

Apple Bend

shape

cooled

shape

shape

steer

shapes

shape

(13) shadows

shadows

shape

bend

bend

shape

bends

bends

mist

shape

steer

shape

shadows

shadows

shapes

shapes

shape

shape

steer

steer

shape

steer accused

semi-

barbaric

(13) princess

imagination

(14) jealous

(15) castle

brave

princess

jealous

semi-

barbarism

arena

tiger

princess

tiger

arena

princess

arena

prince

princess

arena

princess

semi-

barbaric

castle

tiger

castle

princess

imagined

princess

princess

semi-

barbaric

princess

jealous

arena

princess

arena

tiger

hot-blooded

semi-

barbaric

princess

jealousy

imagined condemed

hanged

guards

guards

wood

wood

(14) consciousness

neck

conscious

conscious

rope

rope

neck

hanging

hanged

conscious

rope

floated

rope

neck

rope

floated

neck

conscious

neck

bank

escape

bullets

escape

(15) current

current

current

bank

bank

bank

bullets

neck

rope

silent

neck

silence

neck

rope 
TABLE XLIII

ALL OCCURRENCES OF ALL FORMS OF THE TEST WORDS IN ORDER AS THE FORMS APPEARED THROUGHOUT THE STORIES (continued)

steer shape cub-pilot

(14) lesson bend wheel

bend

bend

voice

pilot-house pilot-house bend

(15) engines voice steered steered engines engine voice voice wheel engines voice engine pilot-house engines steered bend lesson lesson tiger imagined arena princess's semibarbaric tiger blood tiger

Note: Each list above shows all the occurrences of all the forms of the base words, in order as the words appeared in each story. The numbers (1) through (15) denote the first occurrence of each test word (in whatever form that happened to be) in the story. These numbers also therefore correspond to the ordinal numbering of the test words in Tables XXXIX and XL above, and in Tables XLV and XLVI below. 
ALL OCCURRENCES OF ALL FORMS OF THE TEST WORDS

IN ALPHABETICAL ORDER

\begin{tabular}{|c|c|c|}
\hline CPE & ⺊OT & $\underline{O C B}$ \\
\hline Apple Bend & accused & bank \\
\hline Apple Bend & accused & bank \\
\hline Apple Bend & accused & bank \\
\hline bend & accused & bank \\
\hline bend & accused & bank \\
\hline bend & accused & banks \\
\hline bend & arena & board \\
\hline bend & arena & board \\
\hline bend & arena & board \\
\hline bend & arena & board \\
\hline bends & arena & bullets \\
\hline bends & arena & bank \\
\hline bends & arena & bullets \\
\hline cooled & arena & bullets \\
\hline cooled & arena & condemned \\
\hline cooler & arena & condemed \\
\hline cub-pilot & arena & conderned \\
\hline cub-pilot & arena & condemed \\
\hline engine & arena & conscious \\
\hline engine & arena & conscious \\
\hline engines & arena & conscious \\
\hline engines & arena & conscious \\
\hline engines & barbaric & consciousness \\
\hline engines & barbaric & current \\
\hline landing & barbaric & current \\
\hline landing & barbaric & escape \\
\hline landing & barbaric & escape \\
\hline landings & barbaric & escape \\
\hline lesson & barbaric & current \\
\hline lesson & barbaric & floated \\
\hline lesson & barbaric & floated \\
\hline mist & barbarisn & floating \\
\hline mist & barbarism & floating \\
\hline mist & blood & guarded \\
\hline mist & blood & guards \\
\hline Nine-Mile Point & bloody & guards \\
\hline pilot & brave & hanged \\
\hline pilot & bravery & hanged \\
\hline pilot & castle & hanged \\
\hline pilot & castle & hanged \\
\hline pilot & castle & hanged \\
\hline pilot & Chance & hanging \\
\hline pilot & Chance & hanging \\
\hline
\end{tabular}




\section{ALL OCCURRENCES OF ALL FORMS OF THE TEST WORDS IN ALPHABETICAL ORDER (continued)}

\begin{tabular}{|c|c|c|}
\hline pilot & crime & hanging \\
\hline pilot-house & crime & neck \\
\hline pilot-house & hot-blooded & neck \\
\hline pilot-house & imagination & neck \\
\hline pilot-house & imagination & neck \\
\hline pilot-house & imagination & neck \\
\hline pilots & imagination & neck \\
\hline point & imagination & neck \\
\hline point & imagined & neck \\
\hline points & imagined & neck \\
\hline points & imagined & neck \\
\hline points & jealous & neck \\
\hline points & jealous & neck \\
\hline points & jealous & respect \\
\hline shadows & jealousy & respect \\
\hline shadows & modern & respect \\
\hline shadows & modern & rope \\
\hline shadows & modern & rope \\
\hline shape & moderm & rope \\
\hline shape & pleasant & rope \\
\hline shape & pleasant & rope \\
\hline shape & pleased & rope \\
\hline shape & prince & rope \\
\hline shape & princess & rope \\
\hline shape & princess & rope \\
\hline shape & princess & rope \\
\hline shape & princess & rope \\
\hline shape & princess & rope \\
\hline shape & princess & silence \\
\hline shape & princess & silence \\
\hline shape & princess & silent \\
\hline shape & princess & silent \\
\hline shapes & princess & silently \\
\hline shapes & princess & guards \\
\hline shapes & princess & silently \\
\hline Six-Mile Point & princess's & wood \\
\hline Six-Mile Point & semi- & wood \\
\hline steamboat & semi- & wood \\
\hline steamboat & semi- & wood \\
\hline steamboat & semi- & wood \\
\hline steamboat & semi- & wood \\
\hline steamboat & semi- & wooden \\
\hline steamboat & semi- & woods \\
\hline$s-t-e-a-m-b o a t$ & semi- & \\
\hline steamboats & semi- & \\
\hline steer & semi- & \\
\hline
\end{tabular}


TABLE XLIV

ALL OCCURRENCES OF ALL FORMS OF THE TEST WORDS IN ALPHABETICAL ORDER

(continued)

$\begin{array}{lr}\text { steer } & \text { tiger } \\ \text { steer } & \text { tiger } \\ \text { steer } & \text { tiger } \\ \text { tiger } \\ \text { steer } & \text { tiger } \\ \text { steer } & \text { tiger } \\ \text { steer } & \text { tiger } \\ \text { steer } & \text { tiger } \\ \text { steer } & \text { tiger } \\ \text { steered } & \\ \text { steered } & \\ \text { steered } & \\ \text { steered } & \\ \text { Twelve-Mile Point } & \\ \text { Twelve-Mile Point } & \\ \text { village } & \\ \text { village } & \\ \text { voice } & \\ \text { voice } & \\ \text { voice } & \\ \text { voice } & \\ \text { voice } & \\ \text { voice } & \\ \text { voice } & \\ \text { voices } \\ \text { wheel } \\ \text { wheel } \\ \text { wheel } \\ \text { wheel } \\ \text { wheel } \\ \text { wheel }\end{array}$

Note: Each list above shows all the occurrences of all the forms of the base words. Thus Table XLIV gives the same words that are found in Table XLIII, but in alphabetical order. 
ALL OCCURRENCES OF ALL FORMS OF THE TEST WORDS GROUPED BY BASE WORD IN ORDER BY INITIAL APPEARANCE IN EACH STORY

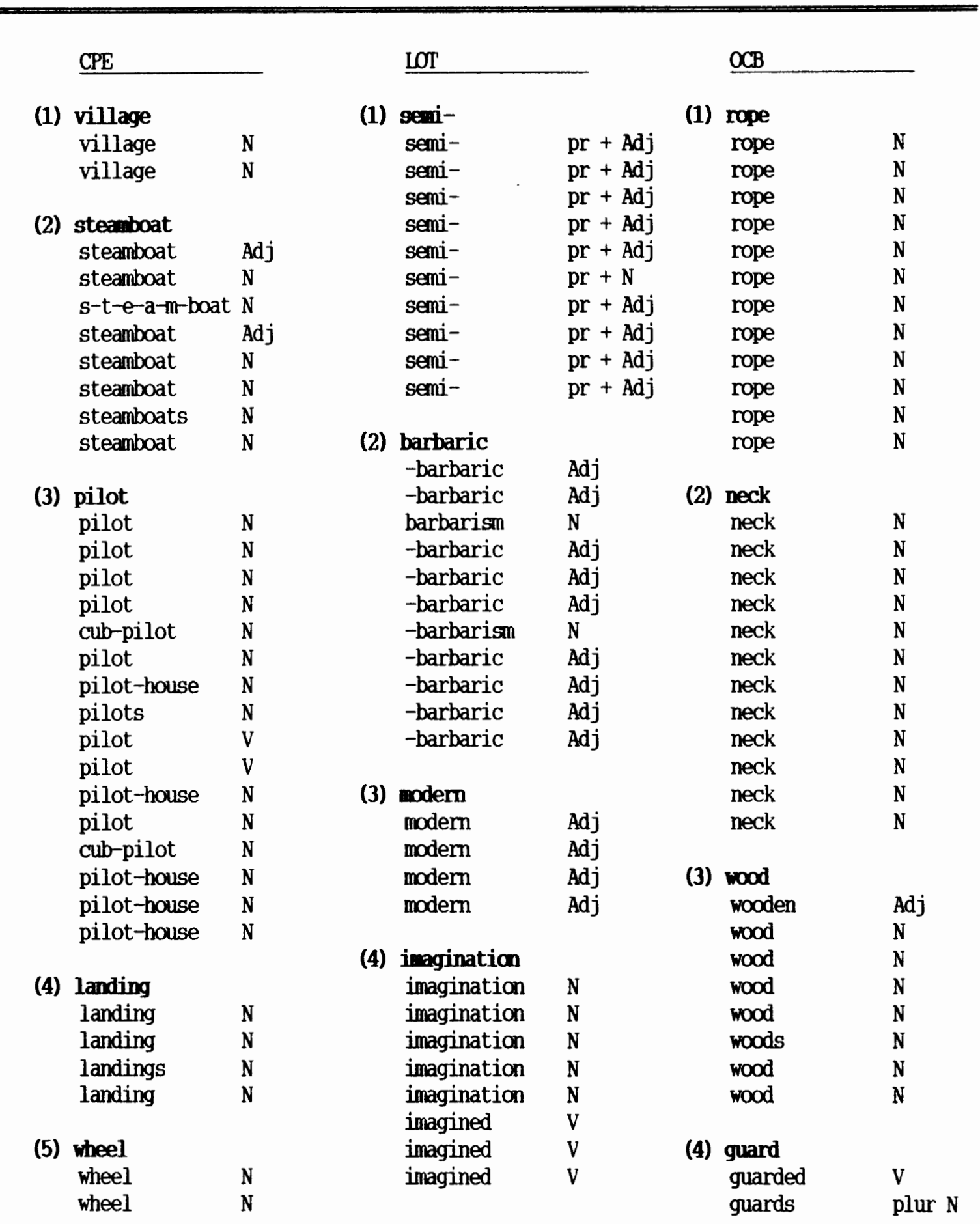


ALL OCCURRENCES OF ALL FORMS OF THE TEST WORDS GROUPED BY
BASE WORD IN ORDER BY INITIAL APPEARANCE IN EACH STORY
(continued)

wheel

wheel

wheel

wheel

(6) steer

steer

steer

steered

steer

steer

steer

steer

steer

steer

steer

steered

steered

steered

(7) $\mathrm{col}$

cooler

cooled

cooled

(8) point

points

Point

Point

Point

Point

points

points

point

point

Point

points

points

(9) mist

mist

mist

mist

mist
(5) pleasant pleasant pleasant pleased

$\mathrm{N}$

(6) arena

arena

arena

arena

arena

arena

arena

arena

arena

arena

arena

arena

arena

arena

arena

arena

arena

(7) bravery

bravery

brave

(8) blood

blood

bloody

hot-blooded

blood

(9) chance

Chance

Chance

(10) accused

accused

accused

accused

accused

accused

accused
Adj

Adj

$\mathrm{N}$

Adj

N

Adj

Adj

N

prop N

prop N

V

Adj

Adj

Adj

Adj

Adj guards

guards

(5) bank

bank

banks

river bank

bank

bank

bank

river bank $\mathrm{N}$

(6) silence

silently

silent

silently

silence

silent

silence

(7) respect

respect

respect

respect

plur N

plur N

plur $\mathrm{N}$

$\mathrm{N}$

$\mathrm{N}$

$\mathrm{N}$

$\mathrm{N}$

Adv

Adj

Adv

$\mathrm{N}$

Adj

$\mathrm{N}$

(8) hang

hanged

hanged

hanging

hanging

hanged

hanged

hanging

hanged

$\mathbf{N}$
$\mathrm{N}$
$\mathrm{N}$

N

(9) condened

condemed Adj

conderned Adj

condemed Adj

condemed Adj

(10) board

board

board

board
N

$\mathrm{N}$ 
TABLE XLV

ALL OCCURRENCES OF ALL FORMS OF THE TEST WORDS GROUPED BY BASE WORD IN ORDER BY INITIAL APPEARANCE IN EACH STORY (continued)

(10) voice

voice

voice

voices

voice

voice

voice

voice

voice

(11) bend

bends

Bend

Bend

Bend

bend

bend

bends

bends

bend

bend

bend

bend

bend

(12) shape

shape

shape

shape

shape

shape

shapes

shape

shape

shape

shape

shape

shapes

shapes

shape

shape

shape

shape
(11) $\mathrm{crin}$

crime

crime

(12) tiger

tiger

tiger

tiger

tiger

tiger

tiger

tiger

tiger

tiger

(13) princess

princess

princess

princess

princess

prince

princess

princess

princess

princess

princess

princess

princess

princess

princess's

(14) jealous

jealous

jealous

jealous

jealousy

(15) castle

castle

castle

castle board

(11) float

floating

floating

floated

floated

(12) escape

escape

escape

escape

(13) bullet

bullets

bullets

bullets plur N plur N

(14) canscious consciousness $\mathrm{N}$ conscious Adj

conscious Adj

conscious Adj

conscious Adj

(15) current

current N

current N

current $\mathrm{N}$ poss $\mathrm{N}$

Adj

Adj

Adj

N

N

$\mathrm{N}$

N 
TABLE XLV

ALL OCCURRENCES OF ALL FORMS OF THE TEST WORDS GROUPED BY

BASE WORD IN ORDER BY INITIAL APPEARANCE IN EACH STORY (continued)

(13) shadow

shadows $\mathrm{N}$

shadows N N

shadows N

shadows $\quad \mathrm{N}$

(14) lesson

lesson

lesson

lesson

N

$\mathrm{N}$

N

(15) engine

engines $\mathrm{N}$

engines $\quad N$

engine room Adj

engines $\quad N$

engine room Adj

engines $N$

Note: Each list above shows all occurrences of all forms of each base word, in order under each base word (in bold) as the forms occur within the story (the ordinal numbering of the base words corresponds to that used in the lists in Tables XXXIX, XL, and XLIII above, and Table XLVI below). Table XLV also shows each word form's grammatical category.

\section{TABLE XLVI}

ALL OCCURRENCES OF ALL FORMS OF THE TEST WORDS GROUPED BY BASE WORD WITH NUMBER OF OCCURRENCES OF FORMS IN ORDER BY INITIAL APPEARANCE IN EACH STORY

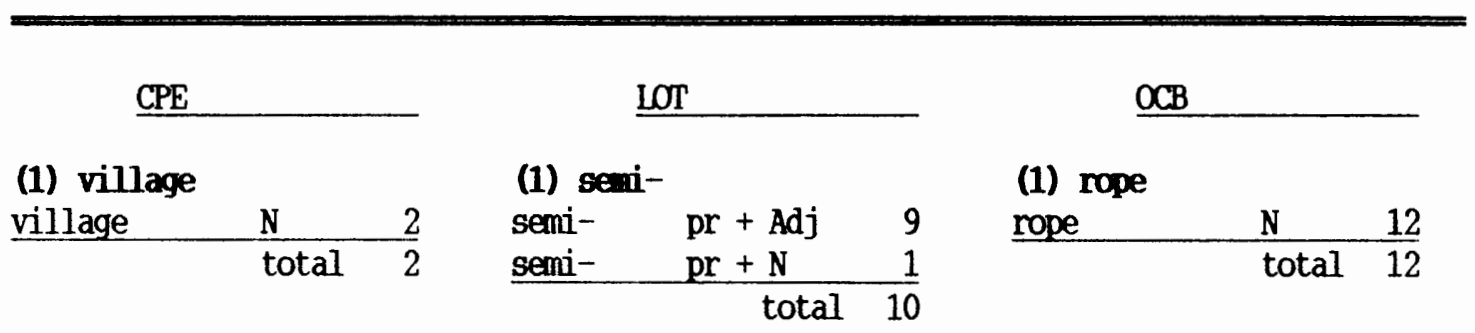


ALL OCCURRENCES OF ALL FORMS OF THE TEST WORDS GROUPED BY BASE WORD WITH NUMBER OF OCCURRENCES OF FORMS IN ORDER BY INITIAL APPEARANCE IN EACH STORY (continued)

(2) steamboat

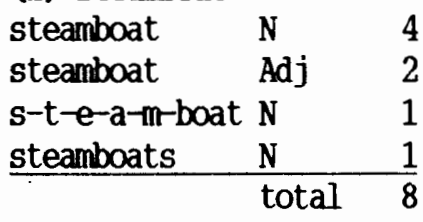

(3) pilot \begin{tabular}{llr} 
pilot & $\mathrm{N}$ & 6 \\
pilot-house & $\mathrm{N}$ & 5 \\
cub-pilot & $\mathrm{N}$ & 2 \\
pilot & $\mathrm{V}$ & 2 \\
pilots & $\mathrm{N}$ & 1 \\
\hline & total & $\mathbf{1 6}$
\end{tabular}

(4) landing

\begin{tabular}{lll} 
landing & $\mathrm{N}$ & 3 \\
landings & $\mathrm{N}$ & 1 \\
\hline & total & 4
\end{tabular}

(5) wheel

wheel

$\begin{array}{ll}\mathrm{N} & 6 \\ \text { total } & 6\end{array}$

(6) steer

\begin{tabular}{llr} 
steer & $\mathrm{V}$ & 9 \\
steered & $\mathrm{V}$ & 4 \\
\hline & total & 13
\end{tabular}

(7) $\mathrm{cool}$

\begin{tabular}{lll} 
cooled & $\mathrm{V}$ & 2 \\
cooler & Adj & 1 \\
\hline & total & 3
\end{tabular}

(8) point

\begin{tabular}{llr} 
Point & prop N & 5 \\
points & $\mathrm{N}$ & 5 \\
point & $\mathrm{N}$ & 2 \\
\hline & total & 12
\end{tabular}

(9) mist

mist \begin{tabular}{ll}
$\mathrm{N}$ & 4 \\
\hline total & 4
\end{tabular}
(2) barbaric

-barbaric barbarism -barbarism Adj N 1 $\begin{array}{lr}\mathrm{N} & 1 \\ \text { total } & 11\end{array}$

(3) modern

modern $\begin{array}{ll}\text { Adj } & 4 \\ \text { total } & 4\end{array}$

(4) imagination imagination $\mathrm{N}$ imagined

\begin{tabular}{ll}
$\mathrm{N}$ & 5 \\
$\mathrm{~V}$ & 3 \\
\hline total & 8
\end{tabular}

(5) pleasant pleasant pleased \begin{tabular}{ll} 
Adj & 2 \\
$\mathrm{~V}$ & 1 \\
\hline total & 3
\end{tabular}

(6) arena arena \begin{tabular}{ll}
$\mathrm{N}$ & 16 \\
\hline total & 16
\end{tabular}

(7) bravery bravery brave N 1 Adj 1
total

(8) blood

\begin{tabular}{lll} 
blood & N & 2 \\
bloody & Adj & 1 \\
hot-blooded & Adj & 1 \\
\hline & total & 4
\end{tabular}

(9) chance

Chance $\frac{\text { prop N } 2}{\text { total } 2}$

(10) accused

\begin{tabular}{lll} 
accused & Adj & 5 \\
accused & $\mathrm{V}$ & 1 \\
\hline & total & 6
\end{tabular}

(2) neck

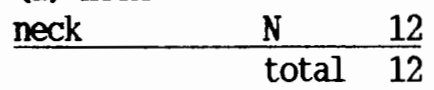

(3) wood

\begin{tabular}{lll} 
wood & $N$ & 6 \\
wooden & Adj & 1 \\
woods & $\mathrm{N}$ & 1 \\
\hline & total & 8
\end{tabular}

(4) guard guards plur N 3 $\begin{array}{lll}\text { guarded } & \mathrm{V} & 1 \\ & \text { total } & 4\end{array}$

(5) bank \begin{tabular}{lll} 
bank & $\mathrm{N}$ & 4 \\
river bank & $\mathrm{N}$ & 2 \\
banks & plur N & 1 \\
\hline & total & 7
\end{tabular}

(6) silence \begin{tabular}{lll} 
silence & N & 2 \\
silent & Adj & 2 \\
silently & Adv & 2 \\
\hline & total & 6 \\
& & \\
(7) respect & & \\
respect & N & 3 \\
\hline & total & 3
\end{tabular} (8) hang \begin{tabular}{lll} 
hanged & $\mathrm{V}$ & 5 \\
hanging & $\mathrm{N}$ & 3 \\
\hline & total & 8
\end{tabular}

(9) condemed \begin{tabular}{lll} 
conderned & Adj & 4 \\
\hline & total & 4
\end{tabular}

(10) board board $\begin{array}{ll}\mathrm{N} & 4 \\ \text { total } & 4\end{array}$ 
TABLE XLVI

ALL OCCURRENCES OF ALL FORMS OF THE TEST WORDS GROUPED BY BASE WORD WITH NUMBER OF OCCURRENCES OF FORMS IN ORDER BY INITIAL APPEARANCE IN EACH STORY (continued)

(10) voice

voice

voices

(11) bend

bend

Bend

bends

N 7

prop N 3

\begin{tabular}{lr}
$\mathrm{N}$ & 3 \\
\hline total & 13
\end{tabular}

(12) shape

shape

shapes

N 14

\begin{tabular}{lr}
$\mathrm{N}$ & 3 \\
\hline total & 17
\end{tabular}

(13) shadow

shadows

$\begin{array}{ll}\mathrm{N} & 4 \\ \text { total } & 4\end{array}$

(14) lesson

lesson $\begin{array}{ll}\mathrm{N} & 3 \\ \text { total } & 3\end{array}$

(15) engine

\begin{tabular}{lll} 
engines & $N$ & 4 \\
engine & Adj & 2 \\
\hline & total & 6
\end{tabular}

(11) crime

crime

$\begin{array}{ll}\mathrm{N} & 2 \\ \text { total } & 2\end{array}$

(12) tiger

tiger

$\begin{array}{ll}\mathrm{N} & 9 \\ \text { total } & 9\end{array}$

(13) princess

\begin{tabular}{llr} 
princess & N & 12 \\
princess's & poss N & 1 \\
prince & N & 1 \\
\hline & total & 14
\end{tabular}

(14) jealous

\begin{tabular}{lll} 
jealous & Adj & 3 \\
jealousy & $\mathrm{N}$ & 1 \\
\hline & total & 4
\end{tabular}

(15) castle

castle
(11) float

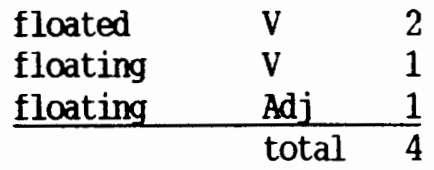

(12) escape

escape

(13) bullet

bullets $\begin{array}{ll}\text { plur N } & 3 \\ \text { total } & 3\end{array}$

(14) canscious

\begin{tabular}{lll} 
conscious & $\mathrm{Adj}$ & 4 \\
consciousness & $\mathrm{N}$ & 1 \\
\hline & total & 5
\end{tabular}

(15) current

current

Note: Each list above shows (1) all the syntactically different forms for each base word, (2) the number of occurrences of each of those different forms, and (3) the total number of occurrences of each base word, in order under each base word (in bold) as the base words occur within the story (the ordinal numbering of the base words corresponds to that used in the lists in Tables XXXIX, XL, XLIII, and XLV above). 